\title{
Membrane-bound angiotensin-I-converting enzyme : associated with cardiac contractility and vascular elasticity
}

Citation for published version (APA):

Aartsen, W. M. (2003). Membrane-bound angiotensin-I-converting enzyme : associated with cardiac contractility and vascular elasticity. [Doctoral Thesis, Maastricht University]. Universiteit Maastricht. https://doi.org/10.26481/dis.20030313wa

Document status and date:

Published: 01/01/2003

DOI:

10.26481/dis.20030313wa

Document Version:

Publisher's PDF, also known as Version of record

Please check the document version of this publication:

- A submitted manuscript is the version of the article upon submission and before peer-review. There can be important differences between the submitted version and the official published version of record.

People interested in the research are advised to contact the author for the final version of the publication, or visit the DOI to the publisher's website.

- The final author version and the galley proof are versions of the publication after peer review.

- The final published version features the final layout of the paper including the volume, issue and page numbers.

Link to publication

\footnotetext{
General rights rights.

- You may freely distribute the URL identifying the publication in the public portal. please follow below link for the End User Agreement:

www.umlib.nl/taverne-license

Take down policy

If you believe that this document breaches copyright please contact us at:

repository@maastrichtuniversity.nl

providing details and we will investigate your claim.
}

Copyright and moral rights for the publications made accessible in the public portal are retained by the authors and/or other copyright owners and it is a condition of accessing publications that users recognise and abide by the legal requirements associated with these

- Users may download and print one copy of any publication from the public portal for the purpose of private study or research.

- You may not further distribute the material or use it for any profit-making activity or commercial gain

If the publication is distributed under the terms of Article 25fa of the Dutch Copyright Act, indicated by the "Taverne" license above, 


\section{Membrane-bound \\ Angiotensin-I-converting enzyme}

associated with cardiac contractility and vascular elasticity 
Membrane-bound

\section{Anghotensîn-I-converting enzyme}

associated with cardiac contractility and vascular elasticity

Thesis, Universiteit Maastricht, Maastricht, The Netherlands.

ISBN 90-9016544-4

OW.M. Aartsen 2003

Printed by Datawyse / Universitaire pers Maastricht

Cover designed by L.M.A. Aartsen-Visser inspired by M.C. Escher

Cover produced by Aartsen \& co. 


\section{Membrane-bound \\ Angiotensin-I-converting enzyme}

associated with cardiac contractility and vascular elasticity

Proefschrift

ter verkrijging van de graad van doctor aan de Universiteit Maastricht

op gezag van de Rector Magnificus,

Prof. dr. A.C. Nieuwenhuijzen Kruseman, volgens het besluit van het College van Decanen, in het openbaar te verdedigen op donderdag 13 maart 2003 om 14.00 uur

door

Wendy Mirjam Aartsen

geboren op 25 september 1974 te Voorburg 
Promoteres:

Prof, dr. J.F.M. Smits

Prof. dr. M.J.A.P. Daemen

Beoordelingscommissie:

Prof. dr. H.J.G.M. Crijns (voorzitter)

Dr. M. van Bilsen

Dr. A.H.J. Danser

Prof. dr. P.W. de Leeuw

Dr. J.J.M Mullins

Prof. dr. M.I. Post

The research described in this thesis was supported by NWO (grant 902-16-098).

Financial support by the Netherlands Heart Foundation for the publication of this thesis is gratefully acknowledged.

Financial support by Transonic Systems Europe, Maastricht, The Netherlands is gratefully acknowledged. 
מנא מנא תקל ופ־סיג

Daniel 5: vers 25 


\section{Table of Contents}

Chapter 1 : General Introduction

General

The renin-angiotensin system

Local RAS in the cardiovascular system

Angiotensinogen

Renin production

ACE production

$A T_{1}$ and $A T_{2}$ receptor

Receptor regulation and internalisation

Possible function of local RAS

RAS and its role in growth and development of the cardiovascular system

R.AS in the developing cardiovascular system

Postnatal growth of the heart

Physiological cardiac bypertrophy

Pathological cardioc hypertrophy

Cardiac remodelling after myocardial infarction.

The role of RAS in cardiac remodelling after myocardial infarction

Local RAS activation after MI

AT receptors on myofibroblasts after MI

AT receptors on cardionyocytes after MI 
Renin inhibition $\quad 28$

Renin inhbitors $\quad 28$

Transgenic models 29

ACE inhibition $\quad 29$

ACE inhibitors $\quad 29$

Transgenic models 30

Angiotensin receptor inlibibition 31

Anglotensin receptor antagonists

Transgenic models

RAS and other neurohormone systems 34

The kallikrein-kinin system $\quad 34$

Local expression of the KKS after MI 35

RAS and KKS 35

The growth hormone/insulin-like growth factor axis 36

Local $1 G F$ and $1 G F$ receptor expression after $M I$

RAS and the GH/GF" axis

Hypotheses $\quad 40$

Outline of this thesis $\quad 40$

\section{Heart}

Chapter 2 : Cardiac perrormance in consclous mice lacking membrane-bound angiotensin $-\mathrm{I}$-converting enzyme

Chapter 3 : Cardiac performance after captopril treatment in normal mice

Chapter 4 : Heart fatty acid binding-protein and cardiac troponin $T$ plasma concentrations as markers for myocardial infarction after coronary artery ligation in mice

Chapter 5 : The role of locally expressed angiotensin-I-converting enzyme in cardiac remodelling after myocardial infarction in mice

Chapter $6:$ In mice, combined treatment with $\mathrm{AT}_{1}$ blockade and IGF-I infusion does not improve cardiac contractility after myocardial infarction 


\section{Vessels}

Chapter 7: Absence of membrane-bound angiotensin-1-converting enzyme enhances stiffness and blunts reactivity of peripheral arteries

Chapter 8 : The bradykinin type 2 receptor regulates arterial stiffness during membrane-bound angiotensin-l-converting enzyme deficiency

Chapter 9 : General Discussion

References

Summary

Nederlandse Samenvatting

Dankwoord

Curriculum vitae \& Publications 
$\triangle C E$ angiotensin-I-converting enzyme

t-ACE

membrane-bound angiotensin-I-converting enzyme

ANP

atrial natriuretic peptide

ASTA

aspartate aminotransferase

AT

angiotensin type

BK

bradykinin

BW

body weight

CI

cardiac index

$\mathrm{CK}$

creatine kinase

$\mathrm{CO}$

cardiac output

$\mathrm{cTnT/I}$

cardiac troponin $\mathrm{T} / \mathrm{I}$

GH

growth hormone

H-FABP

heart fatty acid binding protein

$H \mathbb{R}$

heart rate

HW

heart weight

IGF

insulin-like growth factor

IGFBP

insulin-like growth factor binding protein

KKS

kallikrein-kinin system

LDH

lactate dehydrogenase

MAP

mean arterial pressure

MAPK

mitogen-activated protein kinase

MHIC

myosine heavy chain

MII

myocardial infarction

$\mathrm{NO}$

nitric oxide

PDGF

platelet-derived growth factor

PKC

protein kinase $\mathrm{C}$

PRCP

prolylcarboxylpeptidase

RAS

renin-angiotensin system

SEM

standard error of the mean

SI

stroke index

SV

stroke volume

TCF

transforming growth factor

TPR

total peripheral resistance 


\title{
Chapter 1
}

\section{General Introduction}

\author{
Partly published in the Handbook of Experimental Pharmacology
}

\section{General}

Heart failure is a situation in which the heart is unable to maintain sufficient cardiac output to meet the metabolic and oxygen demands of the peripheral tissues'. This condition of the heart is associated with high morbidity and mortality. In the Netherlands, mortality due to acute coronary heart diseases decreased sharply between 1987 and 1993. However, the prevalence of deaths from stroke and congestive heart failure increased ${ }^{2}$. This trend is seen in most western countries, leading to a position of heart failure in the top three of death causes in the western society ${ }^{3}$ and more people are suffering from heart failure each year. Nowadays, occurrence of chronic cardiovascular disease is seriously boosting the demand for health care. Although most heart failure patients do have signs of pulinonary and/or systemic congestion, there is also a group of patients, which have an impaired ventricular function without symptoms. However, further decrease in cardiac function will eventually lead to congestive heart failure ${ }^{4}$. This group of patients shows us that heart failure is due to a progressive systolic and/or diastolic dysfunction. Systolic dysfunction is defined as a decrease in the ability of the left ventricle to contract normally in situations of increased resistance or afterload. Diastolic dysfunction has been described as an impaired possibility of the left ventricle to fill at normal or elevated pressure" . It is suggested that heart failure can be initiated by pathological stimuli such as hypertension, myocardial infarction, inflammation, valvular disease or genetic causes ${ }^{\circ}$. In the early phase of heart failure, a complex interplay of several neurohormonal systems is activated to maintain cardiac output and enhance contractile function of the failing heart. As long as cardiac output is 
maintained, the patient is still in the stage of compensated heart failure. Prolonged overexpression of these neurohomonal systems is accompanied by alterations in cell growth, calcum homeostasis, cross-bridge cycling and architecture in both heart and vessels. These (mal)adapations can lead the heart from compensated to a decompensated stage. One of the neurohormonal systems that might play a pivotal role in adaptations of the cardiovascular system to changed haemodynamic circumstances is the renin-angiotensin system". This system is not only involved in the regulation of the blood pressure and fluid homeostasis, but can also induce a growth response in several cell types". Better insight in the regulation of this system and the importance of its different components could help to prevent maladaptations of the cardiovascular system and to develop therapy that will slow or event revert the processes leading to congestive heart failure.

Iitstory of the renin-angintensin system

17 1898, Tigersted ${ }^{\text {th }}$ exiracted a substance from the renal cortex, which he called tenin? He infused tenin into the arculation which caused blood pressure elevation. Many Goldblat demonstrated in $1934^{1 /}$ that constriction of the renal arteries comsistenty led to hypertension, Additional experiments, meluding constriction of Whe aorta above and below the kidneys confirmed the presence of a renal pressor system. This discovery ted to the conclision that the kidney plays a central role in blood pressure regulation, ha the following years, the substance angiotensin and its substrate angiotensinogen were discovered in plasma. That angiotensin appears in two different foms, a decapeptide angiotensin I and an octapeptide called angiolensin I, was discovered by skegg's group in $1954^{12.3}$, The same group demonstrated that the netalloprotease angiotensin-1-converting enzyme (ACF) is responsible for the conversion of angiotensin 1 (Asp-Arg-Val-Tyt Ile-His-Pro-Phe(His-Led) into argiotensin 1 (Asp-Arg-Val-Tyr-lle-His-Pro-Phe), These discoveries untrvelled the backlone of today's well-known renin-angiotensin system (RAS). IXxtensive studf of the RAS has led to the discovery of at least two angiotensin II receptors, $A T$, and $A T$, These receptors are very distinet in their effects Also the enzymes of the $\mathrm{RAS}$ are extended with the so-called angiotensinases (angiotensindegenerating enzymes) 14 . The presence of angiotensinases determines the half life of angibtensin and the production of active and inactive metabolites 15.19 


\section{The renin-angiotensin system}

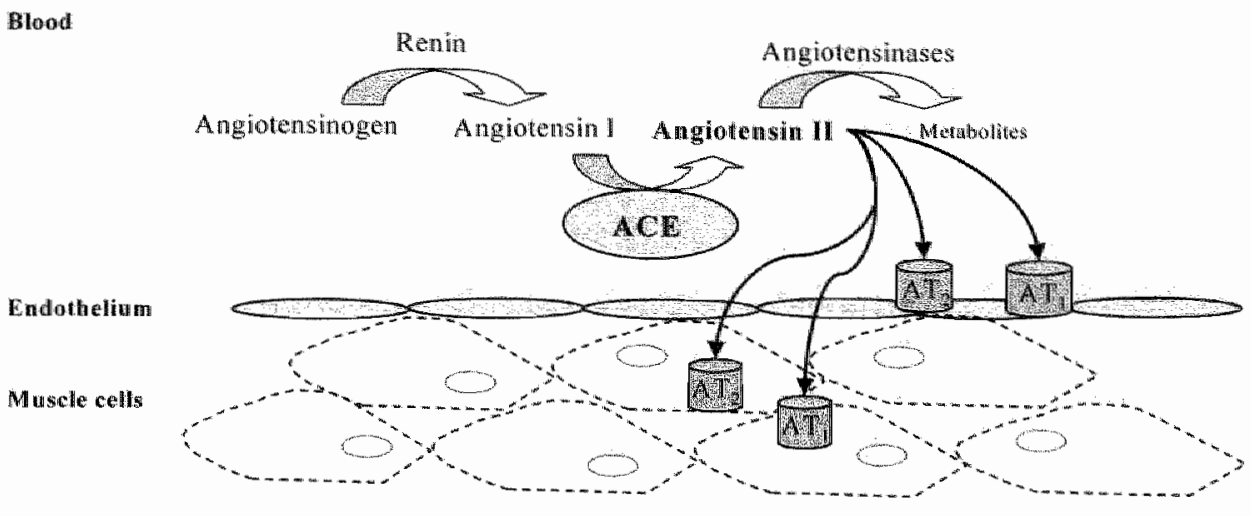

Figure 1. The circulating tenin-angiotensin system. Abbreviations: $\mathrm{ACF}$, angiotensin-1-converting enzyme, $A T_{1}$; angiotensin receptor type $1, A_{2}$; angiotensin receptor type-2

\section{Local RAS in the cardiovascular system}

The traditional concept of the renin-angiotensin system (RAS) has undergone several important changes in the last decade. The application of molecular biology and advanced biochemical techniques has led to the discovery of local angiotensin generating systems, more commonly referred to as tissue or local RAS.

Local RAS is thought to have paracrine and autocrine effects on the tissues in which it is expressed ${ }^{27}$.30 "However, several features are required before a system exhibits paracrine and autocrine characteristics. For a paracrine system, cells need to produce the hormone that affects surrounding cells of the same organ. Substrates, enzymes and receptors of the same system have to be active in one organ. For an autocrine system, substrates, enzymes and receptors have to be expressed and active in the same cell. In the case of RAS the substrate angiotensinogen, renin or renin-like enzymes (tonin, cathepsin D), ACE or ACElike enzymes (chymase, cathepsin $G$ ) and receptors $\left(A T_{1}\right.$ and $A T_{2}$ ) have to be expressed and active in one organ or even in one cell. The functional advantage of locally active RAS is especially the reaction rate, which is accelerated by a few orders of magnitude when comparing paracrine to endocrine activation. Thus, the efficiency of the system is markedly increased when renin, $\mathrm{ACE}$ and $\mathrm{AT}$, are expressed in close proximity. Yet, both paracrine and autocrine activation are less influenced by rapid changes found in the cardiovascular homeostasis. These fluctuations are mainly regulated by the endocrine system ${ }^{31}$. Much is 
know about the regulation of the endocrine system and its effects on the cardiovascular system. However, still many details about the exact function of the local RAS and the importance of its possible autocrine and paracrine effects on the cardiovascular system have to be elucidated.

\section{The brain RAS}

A nice example of a local RAS is found in the brain. 1 he brain is a unique site 10 study we effects of centrally generated angiotensin 11 because it is separated from the eireulating angiotensin II by the blood-brain barmer, veurones of the hypothalamus but aiso astrocytes and glia cells are able to produce angiotensinogen $^{20}$ it is secreted into the cerebrospinal fluid at a concentration that is 10-20\% of the plasma concentration, Furthermore, it is clear that the neurones, glia cells and astrocytes secrete a different isofom of angiotensinogen when compared to hepatic ungiotensinogen. Next to angiotensinogen, the brain also contains renin and renin-like enzymes, ACE and ACE- 1 ke enzymes and at least Iwo receptor (ypes, $A T$, and $A T$ ? 2 . Removal of the aspartic acid from the $\mathrm{N}$-teminal end of angiotensin II by angiotensinases, results in fommation of anglotensin II ( $\mathrm{des}-\mathrm{Asp}$ ) angiotensin II) This heptapeptide is not inactive; on the contrary, it is suggested to be the main effector of RAS in the brain's Angiotensin II has affinty for both the $A T_{1}$ and $A T_{2}$ receptor ${ }^{4}$ and induces vasopresssin release in the brain, which affects blood pressure. The function of the brain RAS is thought to involve central blood pressure regulation, natriures is and drinking behavioum ${ }^{2}$ 2s 26

\section{Angiotensinogen}

Although the liver is the most important organ for angiotensinogen production, low expression of angiotensinogen $M$ RNA has also been found in leukocytes ${ }^{32}$ and a variety of tissues like heart, vessels, kidney, brain, adrenal gland, lung, intestine, spleen and ovary ${ }^{22.33}$. Intracellularly, the presence of angiotensinogen protein is established in neonatal cardionyocytes and fibroblasts ${ }^{34.33}$. The total angiotensinogen protein level in the heart is approximately 10 to $25 \%$ of the circulating angiotensinogen concnetration ${ }^{36.37}$. Although local expression of angiotensinogen seems to be possible in several organs other than the liver, its contribution to local availability of angiotensinogen is still doubtful ${ }^{38}$. Under pathological circumstances, when the angiotensinogen expression is upregulated, its contribution might become more important ${ }^{39}$. 
Renin production

Originally, the active form of renin was supposed to be a component of an excituively circulatory system. However, renin has been detected intracellularly as well ${ }^{\text {to }}$. Renin mRNA expression and renin protein have been found in several extrarenal tissues such as heart, vessels, brain, adrenal gland and testis ${ }^{22,41,42}$. Active renin is also able to bind the cardiac membrame. Several cell-types including cardiomyocytes, fibroblasts and endothelial cell express the mannose-6-phosphate receptor via which prorenin and renin can be taken up from the circulation ${ }^{43}-45$. Renin can accumulate in liver, kidney, heart and blood vessels, since radioactivity was found in these organs after bolus injections with labelled renin ${ }^{464}$ ? So far, the kidney is known as the major organ able to secrete prorenin and to convert it into renin $^{48}$. If all prorenin and renin are of renal origin or that other tissues contribute to their formation as well, is still debated ${ }^{36,38,49,50}$. The contribution of local renin production might be upregulated and of more importance during pathological circumstances ${ }^{39}$.

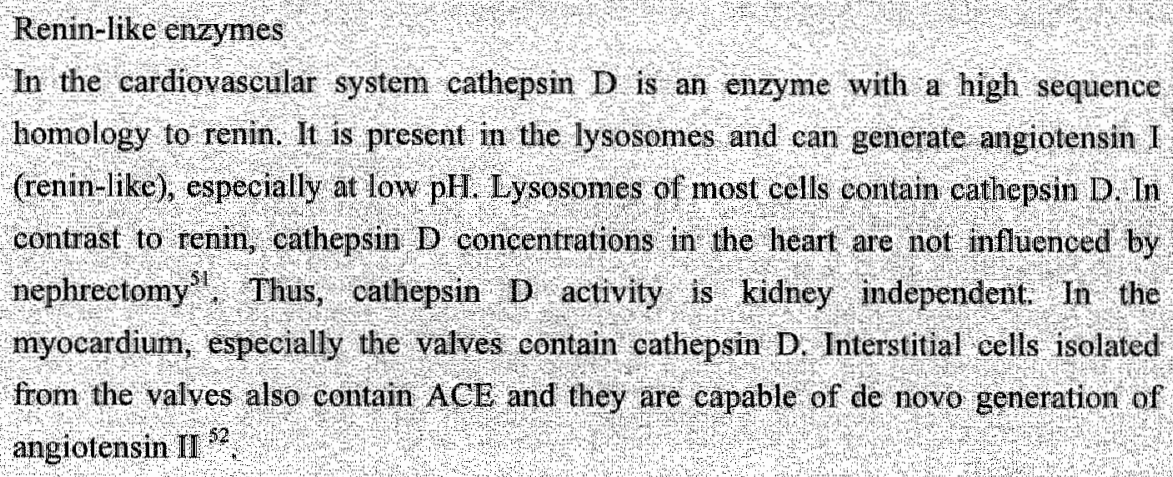

\section{ACE production}

ACE is observed intracellularly as well as membrane-bound. Several cell types including vascular smooth muscle cells, cardiomyocytes, fibroblasts, endothelial cells, neurones, monocytes and macrophages express $A C E m R N A^{2 x, 2 *}$ "In the heart high levels of $A C E$ protein are found on the valve leaflets, moderate amounts in the atria and low levells in the ventricles $^{53.54}$. That local ACE is active, was demonstrated by measuring the conversion of angiotensin $I$ into angiotensin II in isolated perfiused heart ${ }^{55}$. The coronary vascullature contains high ACE leveis in the precapillary coronary microcirculation and low concentrations in the capillaries and venes ${ }^{56}$. Apart from the coronary and pulmonary circulation, the aorta shows $\mathrm{ACE}$ activity and so does the vasculature of the hindlimb ${ }^{57,98}$. The activity of vascular ACE was demonstrated in isolated vessels. Perfusion with 
angiotensin I resulted in the generation of angiotensin II with could be blocked with ACE inhibitors $\$$

\begin{abstract}
ACE like enuynes
10 Hissues, ACI is nol the only enzyme able to generate angiotensin II from angiotensin I In the human heart, the enzyme chymase s thought to be responsible for $75 \%$ of the angiotensin 17 formation 60 . Chymase is present in granules of mast cells, endothelial cells and mesenchymal interstitial cells'. Chymase levels are approximately twofold higher in the ventricles compared to the atria. Thus, proportionally the atria exhibited high ACE aetivity, while the ventricles exhibis high chymase levels' Recenily, chymase protein and chymase activity have also been sliown in dog cardiomyocytes. 6 . The contribution of chymase to the local production of angiotensin. If and its influence on physiological and pathophysiological processes is still under investigation.
\end{abstract}

\title{
$A T_{1}$ and $\mathrm{AT}_{2}$ receptor
}

Irrespective of the question whether angiotensin II is produced locally or systemically, its effect on the cellular level is determined by its receptors: $\mathrm{AT}_{1}$ and $\mathrm{AT}_{2}$. These two receptor types are seven-transmembrane domain receptors and highly homologous (95\% identical in amino acid sequence), but they differ in their distribution. The $A T_{1}$ and $A T_{2}$ receptor mediate very distinct signalling mechanisms, although they are both supposed to be Gcoupled receptor ${ }^{63}$.

$\mathrm{AT}_{1}$ receptors are expressed in adrenal cortex and medulla, brain, lung, kidney, endothelium, vascular smooth muscle cells and heart, which are all target organs involved in the cardiovascular actions of angiotensin $\mathrm{II}^{64}$. In the heart, the highest density of $\mathrm{AT}_{\|}$ receptors is found in the conducting system ${ }^{65}$. A lower $A T_{1}$ receptor expression is found in the atria and ventricles. In rodents, two $A T_{1}$ receptor subtypes are identified as $A T_{1 a}$ and $\mathrm{AT}_{1 \mathrm{l} \%}$. These receptor subtypes share a $96 \%$ homology and can not be distinguished by pharmacological tools. In most tissues, including the heart, the $\mathrm{AT}_{1 \mathrm{a}}$ receptor is more abundantly expression than the $A T_{16}$ receptor ${ }^{66,67}$. In the vasculature, smooth muscle cells of the aorta, pulmonary and mesenteric arteries hold both $\mathrm{AT}$, receptors ${ }^{68}$. The $A T_{1}$ receptor is known to mediate most of the currently-described effects of angiotensin II like vasoconstriction, aldosteron secretion, cellular growth and differentiation.

The $\mathrm{AT}_{2}$ receptor is highly expressed in foetal tissues ${ }^{69,701}$, its expression is relatively low after birth and mainly found in kidney, adrenal medulla, uterus and ovary, vascular endothelium, heart and brain ${ }^{6 \$}$. The role of this receptor is still extensively studied. In all 
four of the rat heart chambers $A T_{2}$ receptors are found ${ }^{71.72}$. Wh the human heart, $A_{2}$ receptors are found on the fibroblasts and a relatively low degree of $\mathrm{AT}_{2}$ recentor expression is seen on myocytes of the ventricles and atria. Vessels like coronary arteriss and renal blood vessels hold $\mathrm{AT}_{2}$ receptors on their endothetium ${ }^{\text {tix }}$. Since the $\mathrm{AT}_{2}$ receptor is expressed in foetal tissues and re-expressed in pathophysiological circumstances the myocardial infarction ${ }^{67}$ and skin lesions ${ }^{73}$, it is supposed to be involved in cell growth and differentiation.

Although both the $\mathrm{AT}_{1}$ and $\mathrm{AT}_{2}$ receptor are supposed to be involved in cell growth and proliferation, their activation leads to very distinct effects. For example, AT, activation can be followed by activation of mitogen activated protein knase (MAPK). This particular pathway is thought to be responsible for protein synthesis and cell growth ${ }^{24}$ is . On the contrary, $\mathrm{AT}_{2}$ receptor activation inactivates $\mathrm{MAPK}$, which leads to the inactivation of $\mathrm{BC}$ 2 followed by the onset of apoptosis ${ }^{76}$. Moreover, $\mathrm{AT}_{2}$ receptor activation is coupled to the release of bradykinin and $\mathrm{NO}^{77}$, both known as inhibitors of cell growth. Contradictory reports demonstrated that $\mathrm{AT}_{2}$ receptor antagonism results in a decreased number of proliferating cells especially endothelial cells ${ }^{78,79}$, which leaves the exact role of the $\mathrm{AT}_{2}$ receptor unclear.

\section{Receptor regulation and internalisation}

Processes such as receptor regulation and internalisation may be crucial for the angiotensin II effects. Binding of angiotensin II to the $\mathrm{AT}_{1}$ receptor causes rapid internalisation of this ligand-receptor complex, in contrast with the $\mathrm{AT}_{2}$ receptor, which does not show internalisation ${ }^{80.81}$. Data suggest that angiotensin 11 is incorporated into the cell as a complex with its receptor ${ }^{82}$. These ligand-receptor complexes are carried intracellularly in small-coated vesicles. The low $\mathrm{pH}$ inside the lysosomes facilitates complex dissociation ${ }^{\mathrm{z},}$ and after dephosphorylation of the receptor, it is recycled to the cell membrane ${ }^{86}$ or stored in granules ${ }^{84}$. Prolonged exposure with angiotensin II evertually leads to down-regulation of the receptor population, which is a common phenomenon seen for the $A T_{1}$ receptor. Another aspect of angiotensin II internalisation is the protection of the peplide from degradation by circulating peptidases and to prolong its half-life from seconds to approximately 15 minutes $^{85}$. Once inside the cell angiotensin II can be transported, via lysosome-like vesicles, to the nucleus or the cytoplasm, or can be degraded by peptides incorporated in these lysosymes. The processes of internalisation and transport of angiotensin II are well-described in cell-types like vascular smooth muscle cells $s^{81}$ and cardiomyocytes $^{83.86}$. 
Table 1. Properties of angiotensin $\mathrm{I}$ receptors

\begin{tabular}{|c|c|c|}
\hline & $A T_{1}$ receptor & $\mathrm{AT}_{2}$ receptor \\
\hline Expression in foetus & Low & High \\
\hline \multirow[t]{9}{*}{ Distributonin adult } & Myocatdum & Myocardium \\
\hline & Endothelwm & Endothelum \\
\hline & VSMC & \\
\hline & Kidney & Kianey \\
\hline & Brain & Brain \\
\hline & Adrenal gtand & Adrenal gland \\
\hline & Liver & \\
\hline & Lungs & \\
\hline & & Uterus/Ovaries \\
\hline \multirow[t]{6}{*}{ Function } & Vasoconstriction & Vasodilation \\
\hline & Aldiosteron secretion & \\
\hline & Cellular growh & Apoptosis \\
\hline & Central osmoregulation & Behaviour \\
\hline & Central pressure & \\
\hline & regulation & \\
\hline \multirow[t]{2}{*}{ Internalisation } & Yes & No \\
\hline & 7-transmembrane & 7-transmembrane \\
\hline \multirow[t]{2}{*}{ Structure } & receptor & receptor \\
\hline & G-protein: $\mathrm{G}_{\mathrm{i}} \mathrm{G}_{\mathrm{i}}$ & G-protein: $\mathrm{G}_{\mathrm{i}}$ ? \\
\hline \multirow[t]{4}{*}{ Antagonists } & Losartan & PD 123177 \\
\hline & Valsaratan & PD 123319 \\
\hline & Irbesartan & $\mathrm{COP}_{42112}$ \\
\hline & Candesartan & \\
\hline
\end{tabular}

Abbreviations: $\mathrm{AT}$; receptor; angiotensin receptor type 1, $\mathrm{AT}_{2}$ receptor; angiotensin receptor type 2, VSMC; vascullar smooth muscle cells. Data are taken from rets. $63,68,71,75,233$.

Possible function of local RAS

Angiotensin II transport to the nucleus is initiating intracellular effects of angiotensin $\mathbb{I}$. Also the nuclear membrane holds angiotensin II receptors ${ }^{87}$. These receptors are $\mathrm{AT}_{1}$ receptors or receptors highly similar to the $A T_{1}$ receptor ${ }^{3 *}$. The effect of nuclear receptor stimulation by angiotensin II is cell proliferation. Under appropriate conditions angiotensin 
II can act as a mitogen. Activation of nuclear $A T_{\mathfrak{i}}$ receptors induces expression of $\mathrm{genes}_{\text {, }}$ including proto-oncogenes, many growth factors and growth factor receptors $\$ 9,4$

For example, in rat hepatocytes, one of the angiotensin $I$ induced growth factors is plateletderived growth factor (PDGF). The cell proliferation seen in rat hepatocytes after intracellular angiotensin II stimulation is thought to be due to increased extracellular PDGF levels. The PDGF expression was initiated by autocrine angiotensin $\mathrm{II}^{91}$. In this example, angiotensin II has most of the 'classical' growth factor features: it has dual extracellular and nuclear roles: it can be locally secreted, internalised and translocated or transferred to the nucleus. Pre-eminently, this pathway of cellular activation and regulation of cell proliferation and growth may form a substantial part of the local RAS function.

\section{Table 2. Evidence for cardiac and vascular renin-angiotensin systems}

- Renin and angiotensinogen mRNA detected in heart and vessels

- Presence of renin and angiotensinogen in heart and vessels (immunohistochemical)

- Heart and vessels can bind and incorporate (pro)renin protein

- ACE mRNA found in cardromyocytes and vascular smooth muscle cells

- Presence of ACE in heart and vessels (immunohistochemical)

- Local conversion of ang I into ang II demonstrated in heart and vessels

- Both heart and vessels exhibit angiotensin II receptors

Abbreviations: $A C E$, angiotensin-I-converting enzyme. Data are taken from refs. 20,22,28$31,33,34,36-39,42,44,46.47,50,53,54,57,58,62,63,65,139$

Although RAS expression and activity are found locally, every organ is contimuously perfused and is directly in contact with the circulating RAS. Especially when the role of local RAS in the cardiovascular function iss studied, the investigation is hampered. The two systems (local and circulating) might integrate in generating angiotensin II. At practically each step of angiotensin II generation, the process can take place intracellularly or extracellularly. For instance angiotensinogen can be taken up from the circulation and cleaved by intracellular renin or the other way around. Thus, in the interstitial space one can find angiotensin I from completely intracellular origin or completely extracellular origin or a combination of the two ${ }^{27}$. The presence of enzymes responsible for the degradation of angiotensin might play an important role in keeping these two systems separate. Peptidases are differently distributed over distinct cell compartments and cell types ${ }^{19}$. 
Aln important question is the relative contribution of tissue RAS to the local angiotensin production and the function of this local angiotensin production in the cardiovascular system. The regulation of cell proliferation and growth is thought to be a major function of local angiotensin II production, making conditions of cardiovascular growth and development of main interest to investigate the role of local angiotensin production in the cardiovascular system.

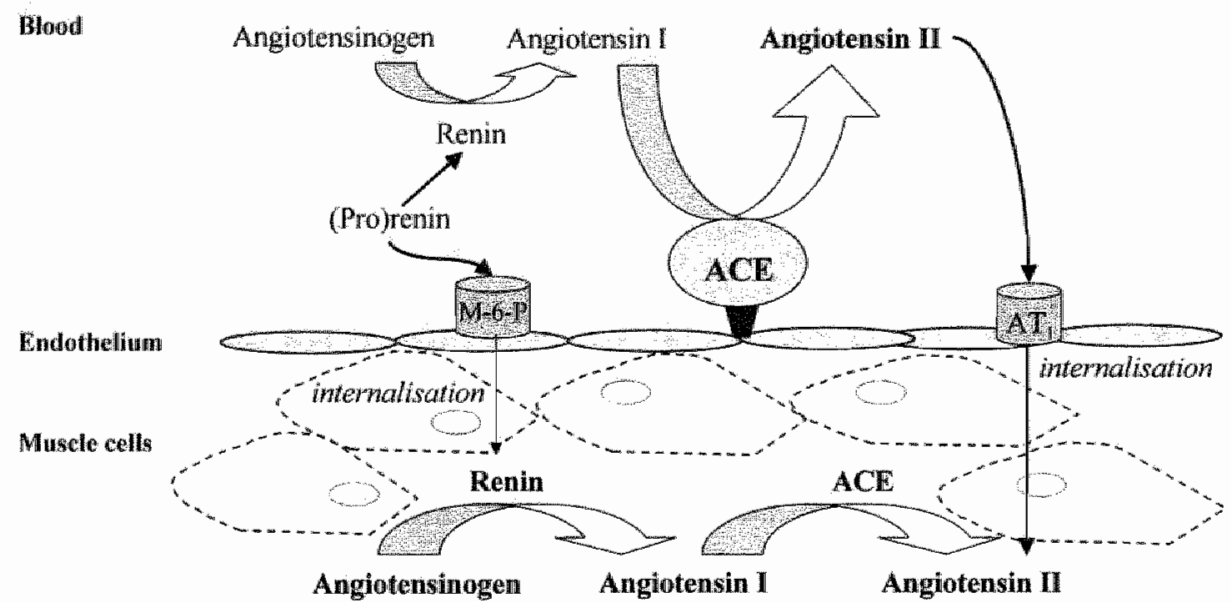

Figure 2. The local renin-angiotensin system. Abbreviations: ACE; angiotensin-f-converting enzyme, $A T_{1}$; angiotensin receptor type-1, $\mathrm{AT}_{2}$; angiotensin receptor type-2

\section{RAS and its role in growth and development of the cardiovascular system}

RAS in the developing cardiovascular system

During cardiovascular development the local RAS might be of particular importance for growth and maturation of the kidney, heart and vessels. As early as 25-27 days after conception, expression of the $\mathrm{AT}_{2}$ receptor is seen in mesenchyme surtounding the preliminary tubules and glomeruli of the human embryonic kidney. Renin mRNA can be detected at the same time in the embryonic heart. By the time of 35 days after conception all five RAS components angiotensinogen, renin, $\mathrm{ACE}, \mathrm{AT}_{1}$ and $\mathrm{AT}$, receptors are expressed in kidney, heart and vessels ${ }^{34,71.92-95}$. The exact expression pattern is changing during gestation, but RAS components remain present until birth. Although the presence of mRNA does not imply a complete self-supporting mechanism, as soon as angiotensin receptors are expressed on the foetal tissues, these tissues can be affected by angiotensin II 
whether derived from the mother or the foetus itself ${ }^{9}$. After birth, RAS mRNA levels rapidly shift to their adult expression pattern ${ }^{97}$. For example, adult lungs have the highest ACE expression. In the foetal lung ACE expression is relativaly low, as is the expression of angiotensinogen in the foetal liver ${ }^{93}$. ACE levels found in the placenta are high suggesting that the placenta might be the major site of foetal angiotensin I conversion into angiotensin .II ${ }^{\circ}$. The function of neonatal RAS is to regulate foetal blood pressure. However, the eftects of RAS on the kidneys are quite different from their effects on adult kidneys. This may be related to the unique and important function of the foetal kidney. Foetal kidneys continuously secrete fluid and electrolytes into the amniotic cavity to form the amniotic fluid. Since the salt retaining function of adult kidneys is inappropriate during intra-uterine life, the aldosterone secretion by angiotensin II is unwarranted and is therefore not developed until after birth.

The hypothesis that the RAS is involved in human foetal cardiovascular development is supported by reports of severe foetal malformations as a result of maternal treatment with ACE inhibitors during pregnancy. Kidney anomalies, patent ductus-arteriosus and hypotension are seen in newly born babies after matemal ACE inhibition. These observations together with the presence of $\mathrm{ACE}$ inhibitor, reduced ACE activity and significantly increased renin levels in umbilical venous blood suggest the relevance of $A C E$ in the cardiovascular development ${ }^{*}$. Especially in the period from middle to late gestation foetuses are sensitive to harmful effects of ACE inhibition. The exact time frame in which the role of the local RAS might be significant for cardiovascular maturation depends on the model investigated. This is especially true for the kidney. Human embryos rentain in utero until the kidneys are fully mature. However, in rodents like rats and mice, the kidneys continue to mature until 3 weeks after birth. This is exactly the period in which the ACE expression is the highest in immature rodent kidneys ${ }^{100}$. Experiments with ACE inhibition $^{101}$ and $A T$, receptor blockade ${ }^{162}$ have dernonstrated that the sensitive period to toxic effects of these compounds is from late gestation to the end of lactation. As a consequence of matenal $\mathrm{AT}_{1}$ receptor blockade, pups had reduced birth weight, decreased cardiac weight and renal histopathological changes including hypertrophy of intracortical arterioles and dilatation of the renal pelvis. ${ }^{102}$. Severe kidney malformations, next to reduced survival rate, severe hypotension, growth retardation, renal vascular wall thickening and reduced male fertility are observed in knock-out mouse models lacking

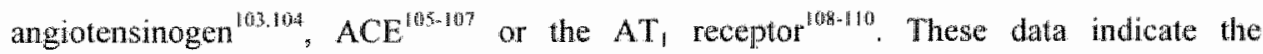
importance of RAS during kidney, heart and vessel maturation. The attention was drawn to the membrane-bound $A C E$ ( $(-A C E$ ), after the discovery that the phenotype of mice lacking membrane-bound $\mathrm{ACE}(\mathrm{t}-\mathrm{ACE}-/- \text { or } \mathrm{ACE} .2)^{107}$ is comparable to the phenotype of complete ACE knock-out mice. T-ACE -/- mice show less severe renal pathology, mainly wascular thickening, but the defect to concentrate urine is still present, as it is in complete ACE 
knock-out mice ${ }^{\text {tos. }}$. Better insight in the effects of $\mathrm{t}-\mathrm{ACE}$ deficiency on the cardiovascular system might help to elucidate the function of the local RAS during development of heart and vessels.

Postnatal growth of the heart

\section{Phystological cardiac hypertrophy}

Cardiac remodelling, or in other words structural and functional alterations of the heart, occurs in a situation of sustained excessive workload on the adult heart. Depending on the type of exercise the cardiac muscle can increase its mass with $70-80 \%$. Training-induced cardiac growth is accompanied by structural and functional changes in the coronary vasculature, which are sufficient to maintain or even to improve the blood supply to the heart, resulting in a nomal or improved cardiac index (cardiac outputbodymass). The effects of training on the cardiac function have extensively been studied and have shown to be positive for the inpaired cardiac performance found in a number of cardiopathologic states " . Unfortunately, cellular processes underlying the training-induced improvement of the cardiac contractility are mostly unclear. Striking is the fact that cardiac growth induced by training has a positive functional outcome (physiological hypertrophy or athlete's heart), while cardiac growth induced by pathological stimuli has a negative effect on the cardiac function (pathological hypertrophy). This implies that the stimulus of cardiac growth is complex interplay. One of the candidates in this complex interplay is angiotensin II. Physical training is negatively correlated with RAS activation both locally and in the circulation $^{12,13}$. However, increased levels of local and circulating RAS are observed after different patho-physiological stimuli. This distinction suggests that RAS is associated to pathological cardiac hypertrophy.

\section{Pathological cardiac hypertrophy}

Pathological cardiac hypertrophy is developed when the workload is exceeding the cardiac capacity. Loading of the heart induces hypertrophy of the myocytes. Non-myocytes like fibroblasts in the interstitial space and smooth muscle cells of the coronary vessels grow via hypertrophy and hyperplasia. Before cells start growing the mechanical alteration must be translated into a biochemical growth signal ${ }^{114}$. This biochemical signal differs according to the type of haemodymamic load. Although the exact signalling pathways are still mystic, several hypotheses have been proposed. Activation of PKC by angiotensin II. catecholamines and endothelin via their seven-transmembrane receptors might be involved as well as the binding of growth factors like, insulin-like growth factor (IGF) and 
transforming growth factor (TGF) to their tyrosine kinase receptors. Via the complex network of second messengers (e.g. MAPK, JAK/STAT) this receptor activation leads to increased DNA, mRNA and protein synthesis. DNA synthesis initiated in cardiomyocytes results in multinuclear myocardial cells ${ }^{115}$. The addition of sarcomeres in cardionyocytes leads to changes in the calcium handing. Besides growing, the cells also dedifferentiate (phenotypical changes including the re-expression of genes only expressed during foetal development) ${ }^{116.117}$. Altogether, hypertrophic myocytes are distinguishable from normal myocytes by their shape, number of nuclei, mRNA and protein levels, calcium-handling. membrane receptors and the re-expression of foetal genes.

Clinical narkers of MI

Clinically the leakage of enzymes and proteins from the heart is measurable in plasma and used to dentify the presence of nyocardial infarction ${ }^{\text {IIt }}$, Classic candidates are the enzymes aspartate animotransferase (ASAT), creatine linase (CK) and lactate dehydrogenase (LDH) 24 . These enzymes ack high specificity which has led to the discovery and use of more specilic cardiac markers like heart fatty acid binding protem (1-FABP) and eardac troponin l and $\mathrm{T}$ (cTnl/ cT TT) 126. HAFABP is a small protein involved in the cellular transpont and netaboltsm of faty acids it is abundantly present in cardiono ocyles and is rapidly released after ischaemia. Troponin 1 and $\mathrm{T}$ are part of the contraetle unit and exist in a unique cardiac isofom Allhough they are not rapidly released, thein presence in the plasmia is highly specilic for cardiac dainage ${ }^{27}$.

\section{Cardias remodelling after myocardial}

When part of the coronary circulation is suddenly occluded, the cardiac segment normally fed by the now occluded artery becomes ischaemic and prolonged oxygen deprivation leads to cell death (myocardial infarction; MI). The dying cells swell and disintegrate. Their cytoplasm seems to coagulate, their myofilaments break and finally their cell membrane bursts $^{1 / 8}$. Once the cell membrane is leaking, the cell content is able to leak into the circulation. Dead cardiomyocytes are the trigger of the wound healing response. Wound healing involves cell proliferation, differentiation and apoptosis of many different cell types. This cellular activity is initiated and regulated by growth factors and the goal is to replace the demised cells by scar tissue ${ }^{128}$. In the early inflammatory phase, macrophages, fibroblasts-like cells and endothelial cells invade the infareted area. Macrophages are responsible for the removal of dead cells and cell debris. 
A

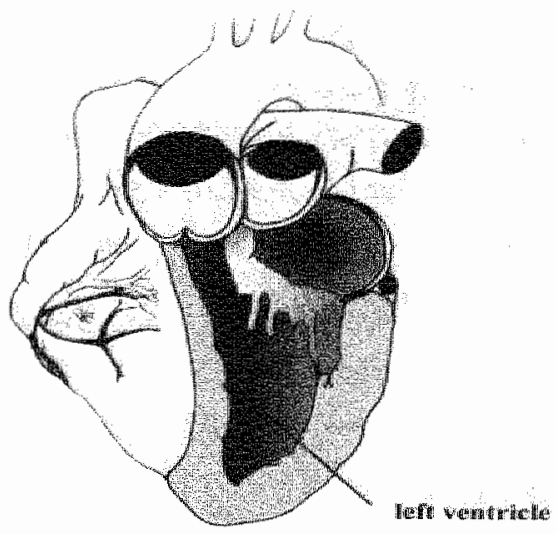

(1)

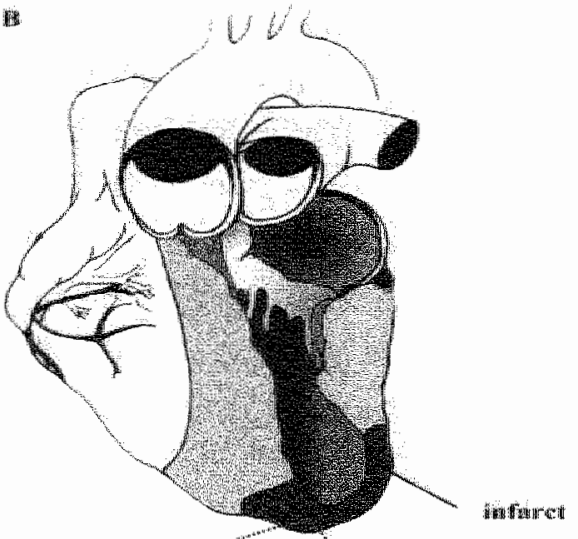

1. Cell death within hours after MI

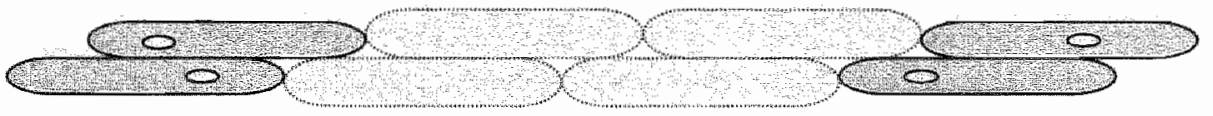

2. Inflammation 1-2 days after MI

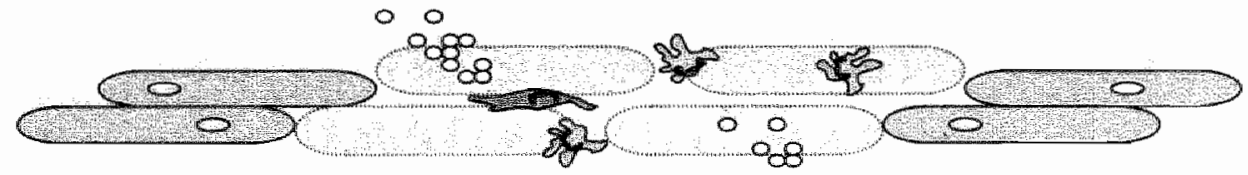

3. Granulation tissue 1-2 weeks after MI

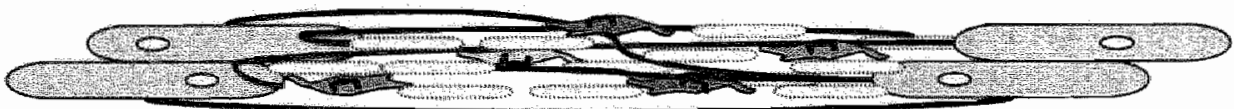

4. Scar tissue more than 3 weeks after MI

0 12. 201

Figure 3. Wound healing after myocardial infarction. A) Normal left ventricle and B) Infarcted left ventricle. 
Fibroblast-like cells and endothelial cells proliferate and create new metworks of collagen and small vessels (granulation tissue). In the following fibrogenic phase, the scar is maturating into a very collagen-rich segment form which the cells have disappeared ${ }^{129.130}$. Now the myocardium exists of two parts: the non-infarcted myocardiom and the scar, coninected to each other by the somalled borderzone.

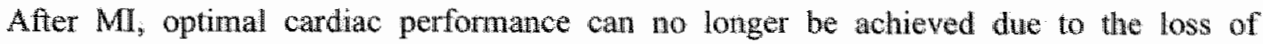
contractile units and the altered structure. Alterations in the architecture are accompanied by changes in the forces that the heart endures ${ }^{1,31}$. The heart adapts to alterations in stress (pressure load) $^{1.15,130}$ and strain (wolume load) ${ }^{18,130}$ through ventricular hypertrophy and dilation. The tension on the ventricle increases, which will lead to ventricular enlargement ${ }^{132}$. Enlargement can be found in the infarct area ("infarct expansion"13s), as well as in the surviving myocardium. The segments enlarge through cell-slippage and through the increase in cell length. To permit cell rearrangement the connective tissue matrix has to be disrupted and reorganised ${ }^{134}$. The cardiomyocytes in the non-infarcted area are triggered to increase the number of contractile units. Neovascularisation and fibrosis are found in the non-infarcted myocardium in reaction to hypertrophy and dilation". Although new vessels are created, the capillary to myocyte fiber ratio is decreased and so is the oxygen availability. The enhanced interstitial fibrosis of the myocardium causes stifiness. Therefore, myocardial infarction induces a primary alteration in the function of the infarcted region as well as time-dependent secandary changes in the non-infarcted myocardium.

\section{The role of RAS in cardiac remodelling after myocardial infarction}

Several neurohomonal systems are activated in the early phase after myocardial infarction (MI). These systems help to initiate the process of wound healing and to translate the mechanical forces into growth responses. Together they create a compensatory response, which helps to preserve cardiac performance. However, prolonged activation of these systems may lead the heart from the compensatory state into heart failure". After MI, components of both circulating RAS and local RAS are upregulated. In patients plasma angiotensin II lewels are elevated in the early days after acute $\mathrm{MI}^{\text {. }}$. Plasma renin activity measured in patients with MI was 2.7 -fold higher compared to patients without MI ${ }^{135}$. In patients with uncomplicated infarction plasma renin and angiotensin levels return to normal levels during the frist three days after infarction. This reduction is delayed when infarctions are large and sustained in situations of heart failure $\mathrm{e}^{134.138}$. The overlovded heart contains more renin, cathepsin $\mathrm{D}$, angiotensin $\mathrm{I}_{\text {, }} \mathrm{ACE}$, angiotensin $\mathrm{II}$ and angiotensin receptors than the normal heart ${ }^{62.139}$. Cardiac angiotensin II formation correlates strongly with the end 
systolic stress measured in the left ventricle ${ }^{\text {wos }}$. Moreover, cardiac enlargement subsequent to myocardial infarction car be prevented by $\mathrm{ACE}$ inhibition both in rats and patients ${ }^{14 \mathrm{I}_{1}}$. Thus, local RAS might be pivotal in the compenssatory response following MI.

\section{Local RAS actiwation after MI}

Local RAS is expressed early after MI and during heart failure. Angiotensinogen is induced as early as 5 days after expermently induced Ml. This expression is localised in the noninfarcted left wentricle. ${ }^{13.144}$. Also renin expression is induced early after $\mathrm{MI}^{30.133 .145}$. ACE is found in rat macrophages invading the necrotic area within 3 to 7 days after $\mathrm{MI}$. Within the same week, left ventricular ACE activity is approximately threefold higher and especially localised in the borderzone around the infarct area ${ }^{1472}$. At the onset of fibrosis, ACE expression on the vascular endothelial cells is elevated and myofibroblasts become ACE and renin positive $e^{56,146,14 \%}$. ACE activity continues to be elevated until at least 6 months after $\mathrm{MI}^{129}$. Remote from the infarct region, the surviving myocardium is capable to enhance its ACE mRNA and protein expression under circumstances of overloading ${ }^{150}$. Viable adult myocytes can produce angiotensin $\Pi$ and this ability is potentiated in a situation of ventricular dysfunction ${ }^{139}$." In vitro, mechanically stretched myocytes produce angiotensin II and show an autocrine hypertrophic response ${ }^{\text {s4 }}$. One of the regulating factors of ACE expression and angiotensin II production around the infarct may be local wall stress.

\section{AT receptors on myofibroblasts after MI}

In rats, the $A T_{1}$ (mainly $A T_{1: a}$ ) and $A T_{2}$ receptor populations are elevated in the infarct region $^{67,151}$. Receptor density is increased from 3 days to 8 weeks after MI and mainly in the regions of fibroblast infiltration and collagen deposition. Myofibroblasts are predominantly responsible for the elevated infarct receptor density with a majority of $\mathrm{AT}_{\|}$receptors ${ }^{152}$. Cardiac fibroblasts are also occupied by $\mathrm{AT}_{2}$ receptors ${ }^{13,154}$ and so are myofibroblasts ${ }^{155}$. In failing hearts of rats, hamsters and humans, $A T_{2}$ receptors are found on fibroblasts present at the site of interstitial fibrosis 6 \% $151,156.157$.

Stimulation of neonatal and adult rat fibroblasts with angiotensin II results in DNA synthesis, mRNA expression and protein synthesis of fibronectin and collagen IIII, via the $A T_{1}$ receptor expressed on the cell-surface ${ }^{158,159}$. Human adult fibroblasts express $\mathrm{AT}_{\mathrm{i}}$

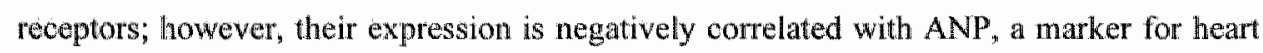
failure ${ }^{157.160}$. Stimulation of human fibroblasts with angiotensin II results in laminin and fibronectin mRNA expression, but collagen mRNA expression is not upregulated 161.16 " Stimulation of the $\mathrm{AT}_{2}$ receptor with angiotensin II results in the down-regulation of fibronectin and collagen synthesis as well as inhibition of the mitogenic response induced by stimulation of the $A T_{1}$ receptor ${ }^{156.15 \%}$. 


\section{AT receptors on cardiomyocytes after $\mathrm{MI}$}

Expression of angiotensin receptors after MI is less abundant on cardiomyocytes compared to fibroblasts ${ }^{151}$. Viable cardiomyocytes elevate their angiotensin receptor population within 2-3 days after $\mathrm{MI}^{163}$. Prolonged overload of the myocardium demonstrated that hypertrophic hearts exhibit more angiotensin receptors than normal hearts ${ }^{164,165}$. The predominant receptor subtype expressed by myocytes is $\mathrm{AT}_{1}^{130,166} . \mathrm{AT}_{2}$ receptor mRNA is observed in cardiomyocytes, but its expression seems not enhanced within $24 \mathrm{~h}$ after $\mathrm{MI}^{16 \%}$ In contrast, mechanical stretch applied to neonatal rat myocytes in vitro resulted in the upregulation of both receptor subtypes ${ }^{84.16 \%}$.

\section{Table 3. Activation of RAS after MI}

\begin{tabular}{|c|c|c|c|}
\hline & $\begin{array}{l}\text { Expression } \\
\text { (mRNA) }\end{array}$ & Time-point & Cell-type \\
\hline Angiotensinogen & + & 5 days & fibroblasts, myocytes \\
\hline Renin & + & 2-7 days & fibroblasts, myocytes (borderzone) \\
\hline $\mathrm{ACE}$ & + & 3-7 days & $\begin{array}{l}\text { macrophages, fibroblasts, } \\
\text { myocytes, endothelial and smooth } \\
\text { muscle cells }\end{array}$ \\
\hline$A T_{1}$ receptor & + & 3 days & fibroblasts (infarct), myocytes \\
\hline $\mathrm{AT}_{2}$ receptor & + & 7 days & fibroblasts (infarct), myocytes (?) \\
\hline
\end{tabular}

Data are taken from refs $56,67,94,143-153,157,162,166,167$

Stimulation of $\mathrm{AT}_{1}$ receptor on neonatal rat myocytes with angiotensin II leads to activation of growth-related genes followed by cell growth ${ }^{90,16 \%}$, which can be counter-acted via stimulation of the $\mathrm{AT}_{2}$ receptor. Not only myocyte size can be affected by angiotensin II but also its function. In these cells contractility is closely related to ion currents ${ }^{170}$. Recently it has been described that cardiomyocyes isolated from hypertrophied heart had depressed contractile reserve ${ }^{171}$. Angiotensin $I I$ can alter ion currents via both the $A T_{1}$ and $A T_{2}$ receptors ${ }^{134}$. Contractility is supposed to be increased via stimulation of the $A T_{1}$ receptor due to increase of cellular calcium. Furthermore, the calcium sensitivity of the myofilaments is enhanced in the presence of angiotensin $\mathbb{I I}^{17 \% \cdot 1 \% 6}$. The exact effects of changes in ion currents after stimulation of the $\mathrm{AT}_{2}$ receptors have not been elucidated yet. 
It appears that the cardiac expression pattem of angiotensin II receptors after MI depends on: 1) species;

2) celll-typer,

3) time-point (early after MI, fibrogenic phase or heart failure) and

4) localisation within the heart (non-infarcted zone, border or infarct zone) ${ }^{177}$.

However, it is clear that the total angiotensin binding capacity is increased after Ml, together with the increased possibility to generate angiotensin $\mathbb{1}^{16 \%}$. In vitro stimulation of cardiomyocytes and fibroblasts showed that angiotensin II via the $A T_{1}$ receptor induced hypertrophy and hyperplasia respectively ${ }^{89.178 .17 \%}$. Angiotensin II might have autocrine effects on the myofibroblasts and on cariomyocytes, affecting the fibrogenic response of wound healing, myocyte growth and contractile function after myocardial infarction ${ }^{180}$. These actions are not solitary. The cardiomyocyte growth response to angiotensin II is transformed in the presence of fibroblasts $169.18 \mathrm{i}$. Medium of angiotensin II-stimulated fibroblasts contained trophic components for myocytes ${ }^{169}$ and induced mRNA expression of angiotensinogen in these myocytes ${ }^{181.182}$. After MI, when many fibroblasts are activated and invade the myocardium, local RAS might influence cardiac remodelling in an autocrine and paracrine way.

\section{Inbibition of the RAS}

Renin inhibition

\section{Renin inhibitors}

Angiotensinogen and renin form a unique couple. Angiotensinogen is the only known substrate for renin. Since the structure of angiotensinogen is not conserved actoss all species, renin is only able to cleave angiotensinogen from closely related species ${ }^{183}$. These characteristics combined with the fact renin is the rate-limiting enzyme of the RAS, make renin an attractive target for development of inhibitors (e.g. enalkiren) ${ }^{\text {s.4 }}$. Inhibition of renin activity results in decreased arterial presstre, decreased angiotensin I and II levels, but elevated angiotensinogen levels and higher rellease of renin ${ }^{18 .}$. Stinulation of both angiotensin receptors is impaired during renin inhibition ${ }^{186}$. Hypertension is a condition in which renin inhibitors could be very effective. Notwithstanding the efforts put into the development, so far renin inhibitors exhibited a very low bioavailability, which made them inappropriate for clinical use ${ }^{187}$. Just recently the tirst orally active renin inhibitor has been described $^{188}$. Nevertheless, experimental renin inhibitors used in vivo or in vitro and transgenic models, have provided insight in the importance of renin regulation. One conclusion that can be drawn from these experiments is that renin release is mainly 
regulated by systemic fluctuations in blood pressure and salt levels rather than looal angiotensin 11 availibility ${ }^{189}$.

\section{Transgenic models}

Mice with a genetic deletion of angiotensinogen ${ }^{103}$ or renin ${ }^{100}$ have been generated. Newly born angiotensinogen and renin knockout mice die within a week after birth due to renal failure $^{191}$. As to be expected, angiotensinogen knockout mice exhibit hypotension and so do renin knockout mice. A causal relationship is found (in mice) between blood pressure and incremental functional angiotensinogen genes ${ }^{192-194}$, which proofs the indispensable role of angiotensiogen and renin for blood pressure regulation. Additional phenotypical features are observed in the kidney and brain ${ }^{104,190,195}$. Other technically sophisticated models were created to study the relevance of locally available renin ${ }^{196}$. Species specificity of the reninangiotensinogen action afforded the opportunity to create mice with organ specific expression of human renin and/or human angiotensinogen. These models demonstrated that expression of human renin and angiotensinogen completely corrected lack of mouse angiotensimogen ${ }^{19.3}$. Overexpression of human angiotenisogen and renin in the normal mouse kidney induced hypertension in the absence of circulating human angiotensinogen and with normal circulating angiotensin II levels ${ }^{197}$, demonstrating the importance of renal renin and angiotensinogen in blood pressure regulation.

\section{ACE inhibition}

\section{$A C E$ inhibitors}

ACE inhibitors were first discovered as natural peptides found in the venom of the South American snake Bothrops jararaca ${ }^{198}$. Pharmacological development of ACE inhibitors resulted in orally available RAS inhibitors ${ }^{200,201}$. In contrast to renin is $\mathrm{ACE}$ an enzyme with many substrates. It consists of two catalytic sites, each with its own kinetics and substrates ${ }^{202}$. ACE irihibitors can differ in their lipophilicity and affinity for the N-catalytic or C-catalytic site 2003.204 . Directly after inhibition of the ACE activity, plasma angiotensin II levels are lowered and angiotensin I levels are increased. In contrast, bradykinin, which is normally degraded by $A C E$, is now accumulating in the circulation.

ACE inhibitors have become established therapeutic agents in the treatment of hypertension and congestive heart failure ${ }^{200 w_{2} 20 s}$. Blood pressure is significantly reduced during treatment with ACE inhibitors. The antihypertensive effect of ACE-inhibitors is associated with vasodilation, improved endothelial function and alterations in remodelling of blood vessels including improvement of arterial compliance $e^{206,20 \%}$. During $\mathrm{ACE}$ inhibition the vascular inward remodelling found in hypertensive subjects is reduced or prevented ${ }^{208,209}$. Positive 
influences of $\mathrm{ACE}$ inlibition on the surviwal rate and ventricular remodelling after myocardial infarction have been extensively studied in humans ${ }^{210-212}$ and animal models ${ }^{205.213 .214}$ and the najor ACE inhibitor clinical trails have been summarised ${ }^{213.216}$. The main conclusions are 1) a substantial mortality and morbidity benefit to post-MI patients and 2) a reduction of the post-MI left ventricular dysfunction and heart failure. Animal studies on this subject are very helpful to elucidate the exact mechanisms underlying the beneficial effects of ACE inhibition after MI. Prolonged captopril treatment of rats with MI demonstrated that increased survival rate was accompanied by smaller infarcts and smaller end-diastolic volumes ${ }^{14}$. Lower internal load of the heart might be one explanation for the prevention of ventricular enlargement. This hypothesis was supported by the results obtained in studies with pressure-induced cardiac thypertrophy. ACE inhibition prevented or reduced the cardiac hypertrophy caused by experimental hypertension ${ }^{142.267 .217}$ or aorta stenosis $^{218}$. This would suggest that any type of effective antihypertensive treatment should result in a regression of hypertrophy that is proportional to the degree of blood pressure reduction. However, this correlation is not supported by experimental evidence. Classical vasodilators are very effective in reducing blood pressure but the reduction of cardiac hypertrophy was not in all cases related to the reduction in pressure ${ }^{219220}$. Another explanation for the beneficial effects of: ACE inhibition might be that the coronary flow is enhanced during ACE inhibition, most likely via reduction of coronary resistance ${ }^{221}$. This enhanced coronary flow was also seen in the absence of changes in the gystemic vascular resistance or plasma renin activity ${ }^{222}$. These data point in the direction of cardiac RAS and its involvement in cardiac remodelling after MI. This hypothesis is supported by the observation that beneficial effects on cardiac contractility have even been found with lowdose ACE inhibition without reduction of blood pressure ${ }^{223}$. In vitro, angiotensin II administration is capable of inducing hypertrophy in cardiomyocytes without additional loading or contractile activity. This trophic effect of angiotensin II was even enhanced in myocytes isolated from infarcted hearts ${ }^{224}$. The discovery of cardiac RAS expression after MII and trophic effects of angiotensin II on different cell-types present after MI has led to the hypothesis that effectiveness of ACE inhibition after MI is partly due to inhibition of especially locally produced angiotensin $\mathrm{I}^{222}$.

\section{Transgentic models}

ACE knockout mice models have been generated in three different forms so far. The first (ACE.1) is the complete ACE knockout mouse ${ }^{105}$, the ACE.2 or tissue ACE deficient mouse $^{107}$ exhibits only the $A C E N$-domain without the ability to bind the celli membrane. In the ACE. 3 model, ACE is only produced within hepatocytes ${ }^{225}$. Both the ACE.1 and ACE.2 mice suffer from hypotension and abnormal renal function whereas the ACE.3 mice exhibit a normal blood pressure and normal renal function ${ }^{199,225}$. Anemia and reduced male fertility 
have been observed in both ACE 1 and ACE $2^{2112 z 6}$ but were not adressed in the ACE. model. Striking is the fact that neithei anemia nor male infertility have been described in the angiotensmogen or renin knockout models ${ }^{227}$. These distinct phenotypical abnomalities point in the direction of the additional functions of the $\mathrm{ACE}$ enzyme in other neurohormone systems like the kallikrein-kinin system.

\begin{abstract}
Local ACE and male fertiliny
The testis is an organ in which all RAS components are locally expressed. The testis contains high levels of $\mathrm{ACl}$, both the testicular $\mathrm{ACT}$, consisting of only one catalytie site and somatic ACE, consisting of two catalytic sites. Testicular ACE is localised in the cytoplasma of sperm and somatie ACE in semiral plasmats Several studies demonstrated that testicular ACE comcentrations are related to male fertility $^{\text {low? }}$ ACE levels comelate with the quality of semen (spematozonl density

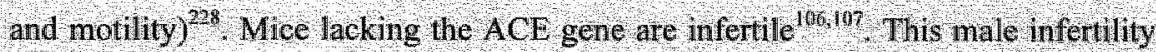
can be restored through specific re-expression of testicular ACE, without restoring the kidney malfomations 29 , suggesting that testicular ACF is not exchanged with the circulation. Iurthemore nice lacking the angiotensinogen gene are fedtle ${ }^{230}$ which suggests that angiotensin I derived from angiotensinogen is not an essential subsirate for testreular ACE. Other substrates such as bradykinin might be essential for male fertlity. Al kallikrein kinin system elements are present in the rat testis ${ }^{23}$. Moreover, bradykinin is able to stimulate germ cell proliferation in vitio ${ }^{232}$. This example shows that local ACE can be of major importance alliough its main activity might not nvolve the production of angiotensin 1 .
\end{abstract}

\title{
Angiotensin receptor inhibition
}

\section{Anghotensin receptor antagonists}

Several potent and selective angiotensin receptor antagonists have been created ${ }^{23}$. From clinical trials it has become clear that antagonism of the $\mathrm{AT}_{\mathbb{1}}$ receptor has been very effective in blood pressure lowering ${ }^{234}$. Also vascular hyperthrophy and endothelial dysfunction caused by hypertension were corrected after treatment with the $\mathrm{AT}_{1}$ antagonist; $\operatorname{losartan}^{335}$. Hypertrophy of the myocardium induced by prolonged hypertiension could also be corrected by $\mathrm{AT}$, receptor antagonism. Since the effects of $\mathrm{AT}_{1}$ receptor antagonists are distinct form those of ACE inhibitors, they may lhave potential advantages over ACE inhibitors $^{236}$. ACE inhibitors reduce the total angiotensin II amount and thereby the total 
receptor activation. By blocking only the $A T_{1}$ receptor more argiotensin $I I$ is released due to the negative feedback regulation of renin release and becomes avallable to bind the $A T_{2}$ receptor. Additionally certain side effects of ACE inkibition like cough and adverse skin reactions may be absent during $A T$, antagonism ${ }^{23}$. The exact benefit of these distinct actions is still under investigation in situations of hypertension, heart failure and after $\mathrm{MI}^{236.23}$. AT, receptor blockade after $\mathrm{MI}$ prevents or attenuates cardiac loading, left ventricular expansion and hypertrophy ${ }^{23-246}$. Moreover, fibrosis of the non-infarcted myocardium is reduced and capillary density slightly increases compared to non-treated infarcted animals ${ }^{240-242}$. Thus, beneficial effects of $A C E$ inhibition and $A T_{1}$ receptor blockade are highly comparable. Yet, after MI, no concensus has been reached on the exact mechanisms involved in the beneficial effects. It is still questioned whether the reduced $A T$, activation is crucial for the beneficial effects of $\mathrm{ACE}$ inhibition or the activation of the bradykinin receptor type 2 activation $\left(\mathrm{BK}_{2} \text { receptor }\right)^{243}$. It is not exactly clear what the role of $\mathrm{AT}_{2}$ receptor activation is during $\mathrm{AT}_{1}$ receptor antagonism. This receptor might be involved in both structural and functional remodelling early after $M I$. $A T_{2}$ receptor antagonism reduced DNA synthesis, endothellial cell proliferation and stroke volume in infarcted rat hearts at 14 days after $\mathrm{MI}^{78}$.

Remarkable observations have been made in the comparison between ACE inhibition and $A T_{1}$ receptor blockade. Surprising is the fact that cardiac $A C E$ activity is inpaired during $A C E$ inhibition, but allso during $A T_{1}$ receptor blockade. Antagonism of the $B K_{2}$ receptor attenuated positive effects on hypertrophy of both $\mathrm{ACE}$ inhibition and $A T_{1}$ receptor blockade ${ }^{77,244}$. ACE inhibitor treatment and $A T_{1}$ antagonism are not only compared but they are also combined. By combining these two, synergistic effects are found. Results show less inflammatory cellular infiltration and less collagen deposition after $\mathrm{MI}$ in rats treated with both fosinopril and valsartan ${ }^{245,246}$. More information about the local interactions and pathophysiological role of RAS is needed to elucidate the therapeutical potential of interference with this system.

\section{Transgenic models}

An alternative method to inactivate the $A T_{1}$ receptor is obtained in the $A T_{1 \text { and }}$ and $T_{i b}$ double knockout mouse ${ }^{108 \%}$. Phenotypically this model is similar to the angiotensinogen knockout mouse ${ }^{103}$ except for its cardiac vetricular septum defect. These results confirm that most angiotensin II action are mediated by the $\mathrm{AT}_{1}$ receptor. Especially the $\mathrm{AT}_{1 \mathrm{a}}$ receptor is responsible for the blood pressure and renal function, since animals knockout for $A T_{6 a}$ showed many similarities to the angiotensinogen knockout and $\mathrm{AT}_{\mathrm{ta}}$ and $\mathrm{AT} \mathrm{T}_{\mathrm{b}}$ double knockout ${ }^{109247}$. A very elegant study in single $\mathrm{AT}_{\mathrm{lal}}$ knockout mice showed that after MI, wild-type animals exhibited more LV enlargement, fibrosis, ventricular dysfunction and mortality ${ }^{248}$. 


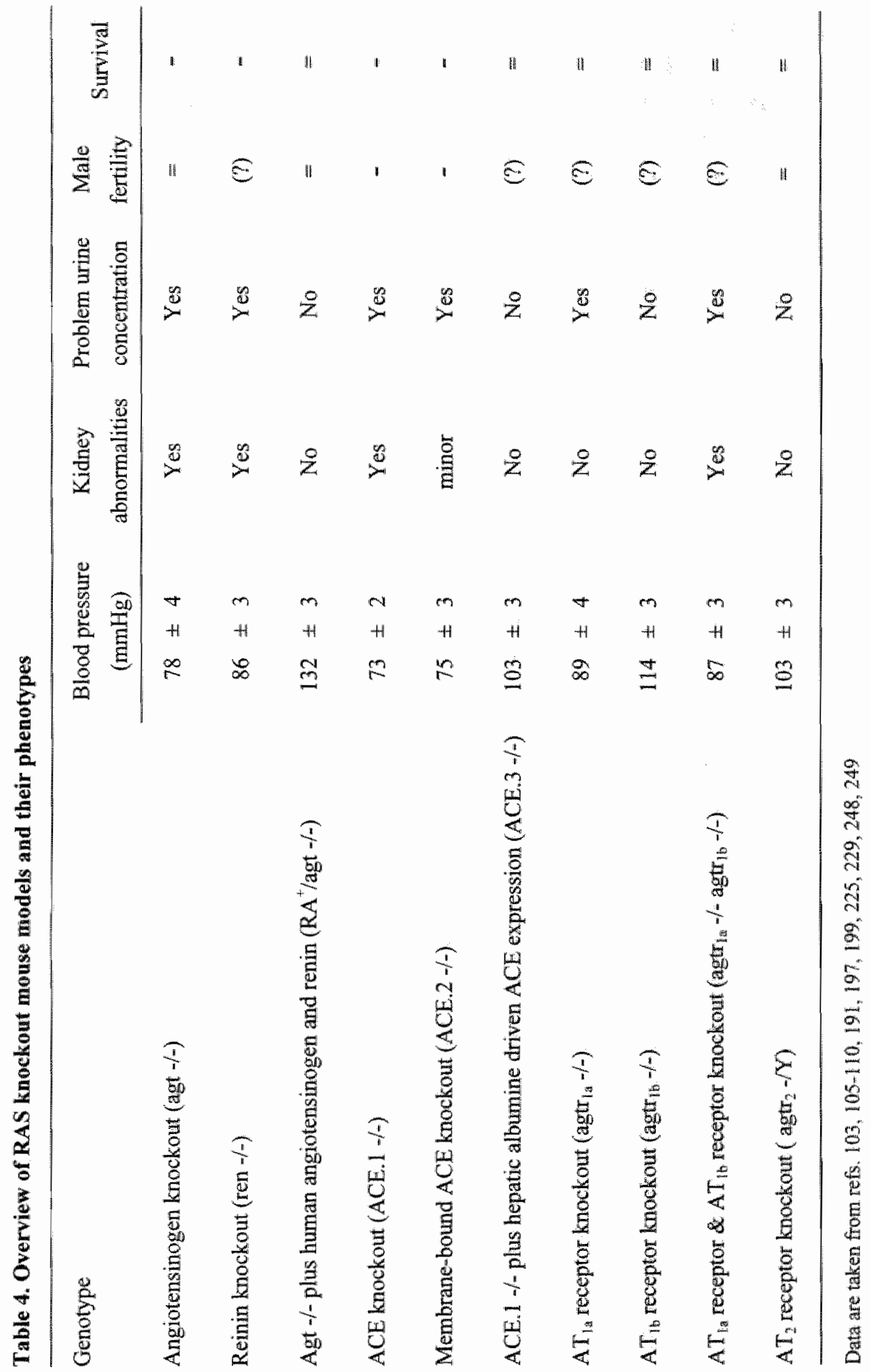


This beneficial outcome of $\mathrm{AT}_{\mathrm{fa}}$ knockout mice was accompanied by attenuation of TGF- $\beta$, collagen, ANP and $\beta M H C$ expression. These genes are involved in growth response, fibrosis, ventricular dysfunction and foetal programming. To elucidate the function of the $\mathrm{AT}_{2}$ receptor, its knockout model ${ }^{249}$ can be very helpful. Despite the high $\mathrm{AT}_{2}$ receptor expression in foetal tissues, $\mathrm{AT}_{2}$ knockout mice developed normally ${ }^{249}$. However, detailed examination revealed that they exhibited higher circulating $\mathrm{ACE}$ activity ${ }^{250}$ and more fibrosis of the kidney induced by ureteral stenosis than their wild-type littermates ${ }^{251}$.

\section{R.AS and other neurohormone systems}

The kallikrein-kinin system

One of the neurohormone system that is closely connected to RAS is the kallikrein-kinin system (KKS). This system has been discovered 40 years ago and has been associated with blood coagulation ${ }^{252}$. The system consists of many different components that can be divided into five categories; $\quad$ 1) kallikreins or kinin-forming enzymes,

2) kininogens or kallikrein substrates,

3) kinins or active kallikrein products

4) kinin degrading enzymes and

5) kinin receptors ${ }^{6}$.

A generally known pathway starts with prokallikrein, which is converted into kallikrein by prolylcarboxylpeptidase (PRCP). Kallikrein is the active enzyme responsible for the conversion of kininogen into the vasoactive peptide bradykinin. The effects of kinins are mediated by the bradykinin receptors $B K_{1}$ and $B K_{2}$. Bradykinin acts as a vasodilator through the stimulation of the $\mathrm{BK}_{2}$ receptor, which is followed by the release of endothelium-derived factors including nitric oxide $(\mathrm{NO})^{77,253}$. Moreover, bradykinin is able to activate the production of prostaglandins, such as $\mathrm{PGI}_{2}$. In contrast to the mitogenic actions of angiotensin II, bradykinin is known to exhibit antigrowth effects on the tissues in which it is expressed ${ }^{254-256}$. Bradykinin has a very short half-life in plasma $(10-50$ s). The most efficient inactivator of bradykinin is kininase II, also known as $\mathrm{ACE}^{5.257}$. Several metabolites derive from the degeneration of kinins. One of these is des- $\mathrm{Arg}^{9} \mathrm{Kinin}$, an activator of the $\mathrm{BK}_{1}$ receptor. In contrast to the constitutive expression of the $\mathrm{BK}_{2}$ receptor, is the $B K_{1}$ receptor only expressed under certain circumstances, like inflammation and sepsis $^{258}$. Except for being observed and active in plasma, are components of KKS also locally expressed in tissues, including heart and vessels ${ }^{6,259}$. 
Local expression of the $K K S$ after $M I$

The isolated heart possesses the ability to generate bradykinin and this ability is increased after ischaemia ${ }^{260262}$. Directly $(1-6$ days) after occlusion of the coronary circulation the expression pattern of $B K_{2}$ receptors is enhanced, mainly in the left ventricle, but also remote from the infarct site in septum and right ventricle ${ }^{263}$. Recent work suggested that kinins have both short-term and long-term cardioprotective effects after MI. Short-term protection is due to reduction of the ischaemia-reperfusion injury ${ }^{264}$. Long-term effects inwolve reduced ventricular hypertrophy ${ }^{26.5}$, fibrosis ${ }^{266}$ and progression to heart failure 255.

\section{RAS and KKS}

RAS and KKS share at least three enzymes for the activation or inactivation of then components: PRCP, kallikrein and ACE. Additionally to these interactions it has been described that activation of the $\mathrm{AT}_{2}$ receptor leads to increased bradykinin production ${ }^{77}$. In vitro stimulation of cardiomyocytes with angiotensin II leads to the enhanced expression of $\mathrm{BK}_{2}$ receptors, while similar stimulation of vascular smooth muscle cells laads to the elevated expression of both bradykinin recepiors ${ }^{267}$.

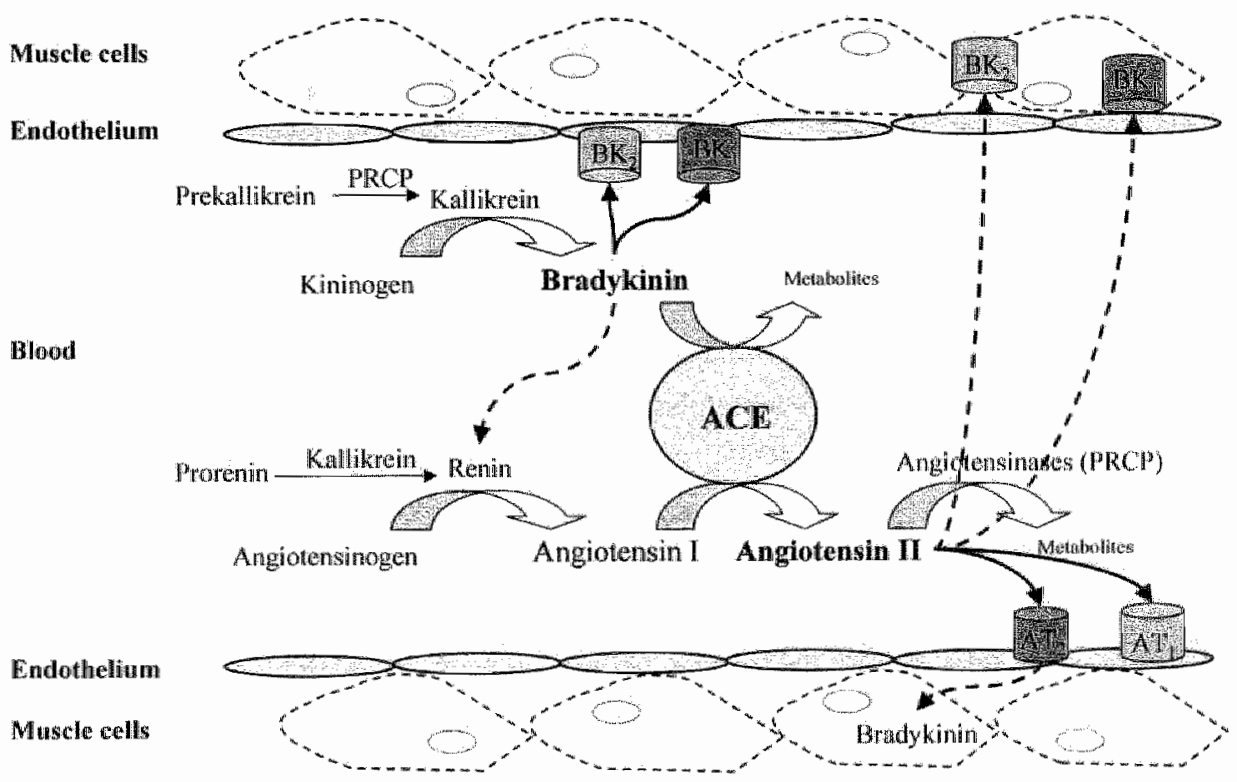

Figure 4. Interactions between kallikrein-kinin system (KKS and renin-angiotensin system (RAS).

$---=$ stimulation, Abbreviations: $A C E$; angiotensin-l-converting enzyme, $A T_{i}$, angiotensin receptor type-1, $\mathrm{AT}_{\mathrm{t}}$; angiotensin receptor type-2, M-6-P; mannose-6-phosphate receptor, $\mathrm{PRCP}$; prolylcarboxylpeptidase. 
Considering the established roles of angiotensin II and bradykinin it appears that KKS serves as a physiological counterbalance to the tension elevating and prothrombotic RAS. In perspective of the beneficial effects of $A C E$ inhibitors obtained after $M I$ and during heart failure, these beneficial effects may be partly due to changes in KKS. Disturbance of the balance between RAS and KKS was evident in $\mathrm{BK}_{2}$ knockout nice ${ }^{26 \%}$. These mice exhibited decreased renin expression ${ }^{269}$, hypertension and cardiac remodelling accompanied by impaired cardiac performance and by blocking the $\mathrm{AT}_{1}$ receptor cardiac remodelling could be prevented ${ }^{770}$. These studies nicely show the close connection between the two systems in cardiac growth regulation. The exact proportion of the influence of angiotensin II and bradykinin during cardiac remodelling after MI needs to be further elucidated.

The growth hormone/insulin-like growth factor axis

In the growth hormone/insulin-like growth factor axis, each factor has its own specific role in supporting growth and development. Growth hormone $(\mathrm{GH})$ is a single polypeptide $(22 \mathrm{kDa})$ and its secretion from the pituitary acidophilic cells is regulated by the neuropeptides somatostatin (SS) and growth hormone-releasing hormone (GHRH). GHRH stimulates, while SS inhibits the release of $\mathrm{GH}^{2 n}$. These two hormones are influenced by numerous other neuropeptides and factors involved in conditions of stress and malnutrition. GH is essential for postnatal growth and normal carbohydrate, lipid, nitrogen and mineral metabolism. After the secretion of $\mathrm{GH}$ into the circulation, $\mathrm{GH}$ binds the GH receptor, which causes a release of insulin-lilke growth factors (1GFs) into the circulation. Many tissues are able to produce IGFs, but the liver is its main source. IGFs are single-chain polypeptides $(7,5 \mathrm{kDa})$ that are structurally related to proinsulin and relaxin. They exist in two major forms, IGF-I and IGF-II. IGF-I mediates many of the effects of growth hormone on postnatal growth by stimulating cellalar proliferation and differentiation ${ }^{272}$. The cellular effects are mediated by the IGF-I and IGF-II/mannose-6-phosphate receptor. The differences between IGF-I and IGF-II are reflected in their expression patterns. IGF-I is expressed at a low level in the developing embryo. Postmatally the IGF-I production by the liver is induced as a result of GH production by the pituitary. In contrast, [GF-II's high expression is started in the developing embryo directly post implantation. IGF-II is suggested to be a foetal growth factor since mice carrying only one functional IGF-II gene are severely growth deficient. Additionally, mice lacking the expression of IGF-I and IGF-I receptor have a high neonatal mortility and marked growth retardation ${ }^{273,274}$. IGF effects are determined by difference in IGFs and IGF-receptor expression. IGF actions are additionally modulated by a family of specific high affinity binding proteins (IGFBPs). To date, six different IGFBPs have been purified, cloned and characterised, and they all show a high 
degree of structural similarity ${ }^{275}$. Overall these binding proteins have been proposed to modulate IGF actions through a variety of mechanisms, including an increase of their halflife, transport of IGFs in the circulation and across the capillary membranes, localisation of IGFs to specific tissues and modulating IGF binding to cell receptors. The expression pattern of the IGFBP family is complex. The two best characterised IGFBPs are IGFBPI and IGFBP3.

\section{IGFBPI and IGFBP3}

In the rat, IGFBPI expression is high in foetal liver and declines to a low level after birth. On the contrary, IGFBP3 has a very low expression during embryogenesis and its expression is induced after birth due to the influence of the GH secretion by the pituitary $^{276}$. IGFBPI is negatively regulated by insulin and positively by cyclic adenosine monophosphate (CAMP). IGFBPI is not restricted to the circulation and is considered to function as a transport protein, taking IGF-I fitom the intravascular space through the endothelial wall to its target cells? IGFBPI can both inhibit and enhance the IGF-I actions at different sites, depending on its stage of phosphorylation and the local proteolysis. IGEBP3 expression is GI dependent. Its expression is highly correlated to IGFI and positively influenced by insulin. IGFBP3 forms a ternary complex together with IGF-I or IGF-II and a liver-detived glycoprotein 7". This complex is believed to carry most of the circulating IGFs in healthy adults, A possible role for IGFBP3 is prolonging the half-life of $1 G \mathrm{H} 1$ and IGF-H. The release of IGFs from the complexes is regulated by $\mathrm{pH}$ and IGFBP3 proteolysis $^{27}$

\section{Local IGF and IGF receptor expression after $M I$}

One of the important mediators of cardiac remodelling, angiotensin II, has been discussed in the prewious paragraphes. Another mediator might be IGF. IGFs and their receptor are expressed in the normal heart and vessels ${ }^{272}$. In vitro, IGF production can be induced by cellular stretch ${ }^{278}$. Just like angiotensin II and its receptors, are IGFs, IGFBPs and IGF receptors expressed at higher level after myocardial infarction ${ }^{279}$. This expression is mainly found in myocytes of the border zone. IGF-I and IGF-I receptors are upregulated within 1 day and were still detectable at 7 days after $\mathrm{MI}^{280.281}$. Several in vitro studies have demonstrated that IGF-I and IGF-II in physiological concentrations are able to induce protein and DNA synthesis in meonatal ${ }^{282}$ and adult cardiac myocytes ${ }^{243}$. In vivo experiments showed that exogenous administration of IGF-I and IGF-II might enhance 


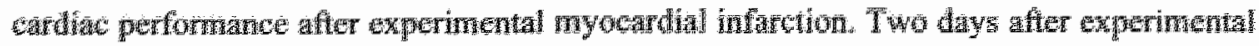
Mits reated with lot-I exhibited higher left wentricular end diatolic pressure and stroke

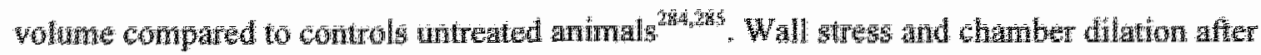

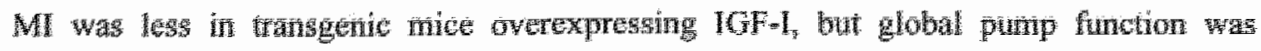
similarly impaired. Lnereased $\mathrm{Ca}^{3+}$ sensitivity and velocity of shorting are observed in myocytes isolated from these nice $e^{285}$. Protective effects of IGF-II infusion are observed

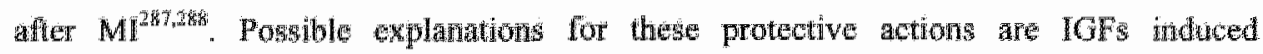
physiological hypertroplyy of remaining myocytes resulting in entanced cardiac performance.

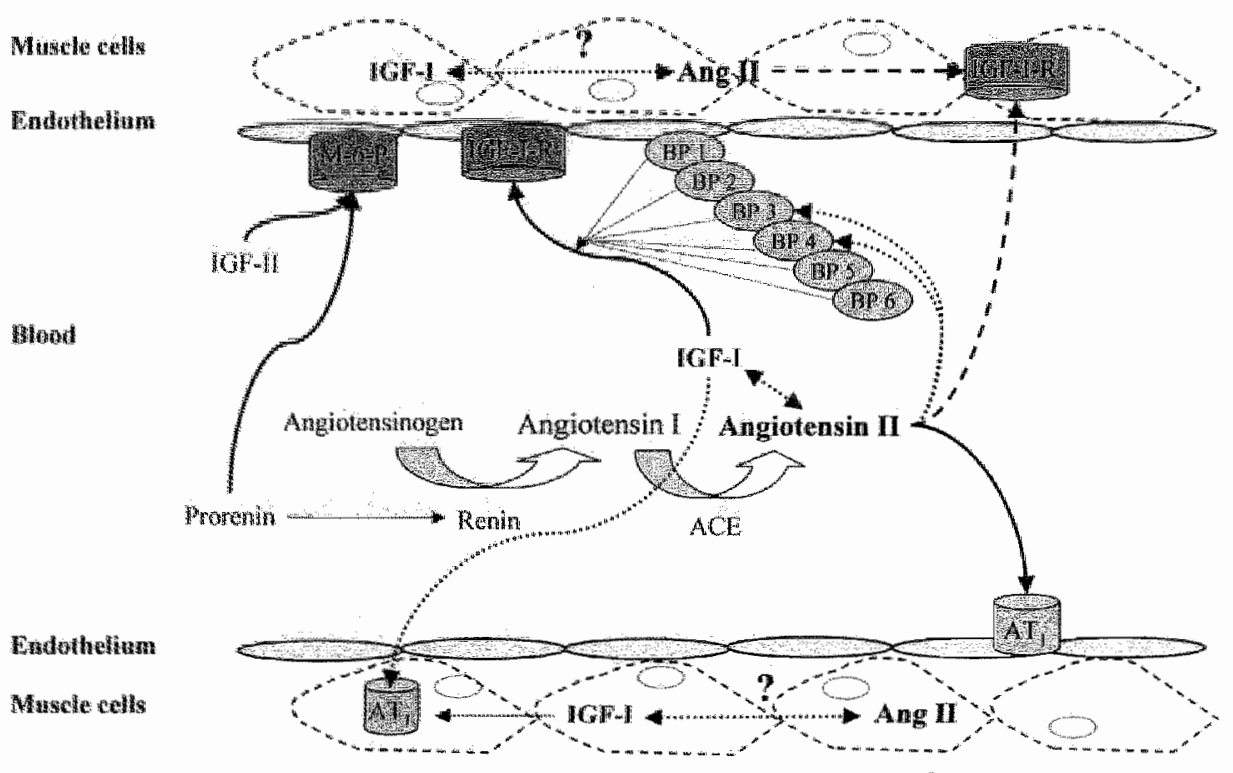

Figure 5. Interactions between the growth homone/insulin-like growth factor axis (GH/GF-1) and the renin-angiotensin system (R.AS) $-{ }_{-}-$= stimulation, .......... = inhibition, $A C E$; angiotensin I-converting enzyme $\mathrm{AT}_{1}$; angiotensin receptor type-1, $\mathrm{AT}_{2}$; angiotensin receptor type-2, $\mathrm{M}-6-\mathrm{P}$; mannose-6mphosphate receptor, BP; binding protein.

\section{RAS and the GH/GF axis}

Interactions between RAS and the GH/IGF axis are multiple. While the mannose-6phosphate receptor is involved in the cellular uptake of prorenin, this receptor is also known as the IGF-II receptor and responsible for growth induced by IGF-II. Regulation of the IGF actions by angiotensin II can be multiple. Infusion of angiotensin II causes downregulation of circulating IGF-I and IGFBP3. However, in the heart, IGF-I receptor expression is 
elevated together with the level of IGF-I, whle the inhibitory IGFBP4 is downregulated ${ }^{25}$. ${ }^{292}$. On the other hand, infusion of growth hormone (GH) promotes the renin activity ${ }^{293}$. The interaction between angiotensin II and $\mathbb{I G F}-\mathrm{I}$ can take place at different levels, via interference on each others expression, via interference on the expression of each others receptors and wia cross-talk between the second messenger systems ${ }^{294}$ "In cardiae fibroblasts stimulation with angiotensin II leads to activation of IGF-I and vice versa ${ }^{265}$. In vitro; stretch on cardiomyocytes leads to the expression of angiotensin II receptors and an increased production of angiotensin $\mathbb{L}$. In certain cells angiotensin II initiates apoptosis which is prevented in th epresence of IGF-I $^{296}$. IGF-I was able to reduce the amount of apoptosis initiated by angiotensin II, through decreasing the angiotensin II production and through cross-talk between second messenger pathways, shifting the balance from apoptotic signals to anti-apoptotic signals ${ }^{296}$. Both growth factors, angiotensin II and IGF-I, seem to have much in common. However it is still mystic which delicate differences can explain the association of angiotensin II with pathological cardiac hypertrophy, while ICF-I is associated with pysiological cardiac hypertrophy ${ }^{297}$.

Table 5. Effects of angiotensin II compared to IGF-I

\begin{tabular}{|c|c|c|}
\hline & Angiotensin II & $\mathbb{I G F}-\mathbb{I}$ \\
\hline Upregulated after MI & + & + \\
\hline Expression induced by mechanical stretch & + & + \\
\hline $\begin{array}{l}\text { Induces DNA replication and protein } \\
\text { synthesis }\end{array}$ & $f$ & + \\
\hline $\begin{array}{l}\text { Induces hypertrophy and hyperplasia } \\
\text { (cardiomycytes an fibroblasts) }\end{array}$ & + & + \\
\hline Enhances $\mathrm{CA}^{2+}$ sensitivity & + & + \\
\hline Enhances cardiac function after MI & - & + \\
\hline
\end{tabular}

Data are taken from refs. $74,84,89,90,140,155,158,161-164,169,174-176,278-288,296-$ 298. 


\section{Hypothestes:}

As highlighted in the previous sections, the RAS exists as a circulating and a local system. However the function of this local RAS is still unclear. During growth responses many RAS components are present at the site of cellular enlargement and proliferation. Whether the local presence of these components is crucial for the growth of surrounding tissues is not clear. The effects of ACF inhibition on growth are striking. Both in situations of normal foetal growth and in situations of pathologic cardiac or vasicular growth, $\mathrm{ACE}$ inhibition attenuates growth. During foetal development $\mathrm{RAS}$ components are expressed in the kidney, heart and vessels. So far, only the negative effects of $\mathrm{ACE}$ inhibition on the maturation of the kidney have been described extensively. Studies investigating the effects of ACE inhibition on the maturation of the heart or vasculature are scarce. We hypothesised that membrane-bound $A C E$ (t-ACE) might influence the functional and structural maturation of heart and vessels.

Although activation of the local RAS is not directly under the influence of sharp systemic haemodynamic fluctuations, the presence of $\mathrm{ACE}$ near the site of the $\mathrm{AT}$, receptor is known to accelerate the reaction velocity, which makes it very efficient in its response to sustained haemodynamic alterations. Prolonged haemodynamic changes have been found in a situation of myocardial infarction. The infarcted area is replaced by scar tissue while the impaired cardiac performance is compensated by hypertrophy of the cardionyocytes. We hypothesised that ACE bound to the membrane ( $\mathrm{A}-\mathrm{ACE}$ ) is an important mediator of functional and structural cardiac remodelling after myocardial infarction.

After myocardial infarction, prolonged activation of compensatory systems can result in maladaptations leading to heart failure. Interventions in the compensatory systems can possibly result in a more positive balance between systems in favour of the cardiac function, as is observed during ACE inhibition. Two candidate systems which activation can be beneficial for cardiac remodelling after MI are the kallikrein-kinin system (KKS) and the growth hormone/insulin-like growth factor (GH/TGF-I) axis. The third hypothesis of this thesis is that shifting the balance between $\mathbb{R A S}$ and KKS towards KKS will result in a better cardiovascular homeostasis after myocardial infarction and this positive effect will even be enlinanced through stimulation of the GH/IGF axis.

\section{Outline of this thesis}

The aim of this thesis is to study the role of membrane-bound angiotensin-I-converting enzyme (t-ACE) in cardiovascular homeostasis. The model used in this thesis is the $\mathrm{t}-\mathrm{ACE}$ (or ACE.2) deficient mouse $\mathrm{e}^{107}$. This mouse model is created through targeted homologous recombination. The DNA construct used contained the somatic ACE exons (13-25) and was placed directly behind the somatic exon 12 , covering the site of the testis promoter, in order 
to create a complete ACE only driven by the somatic promoter. However, due to a cryptic splice site, mice carrying two copies of this construct express a truncated ACE driven by the sonatic promotor. This ACE consists of only the N-teminal enzymatic site without the membrane-anchor.

\section{Membrane-bound ACE deficiency}

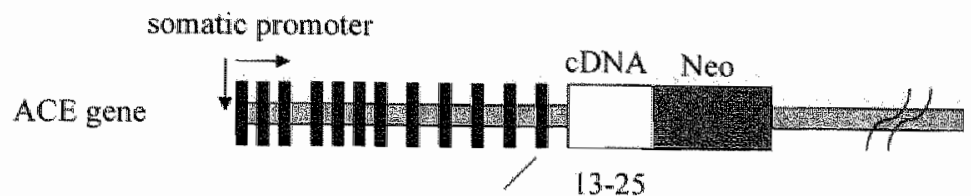

12

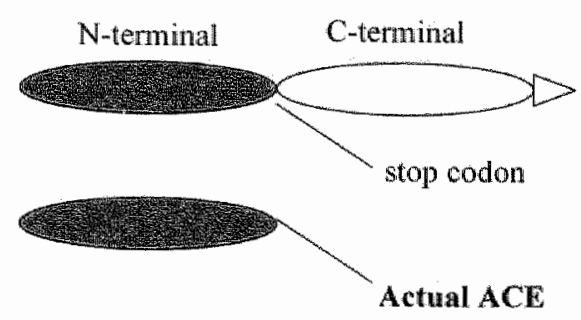

Figure 6. Targeted homologous recombination of the somatic ACE gene creating the membrane-bound deficient mouse model.

The effects of membrane-bound ACE deficiency on the cardiac function under normal circumstances are described in chapter 1. Cardiac function was studied after prolonged captopril treatment to investigate if the functional alterations observed in membrane-bound ACE deficiency mice are the consequence of prolonged $\mathrm{ACE}$ inhibition or derived from membrane-bound ACE deficiency during foetal development (chapter 2). In chapter 3, HFABP and cTnT were tested as early markers for myocardial infarction in mice, in order to group the animals before further treatment. The role of membrane-bound $\mathrm{ACE}$ during the functional and structural alterations of the heart after myocardial infarction was investigated in chapter 4 . The hypothesis that cardiac contractility after myocardial infarction improves by treating the animals with a combined therapy of $\mathrm{AT}$, receptor antagonism and IGF-I infusion was tested in chapter 5 . During these experiments, interest in the vascular effects of membrane-bound ACE deficiency grew. The hypothesis that membrane-bound ACE deficiency is not only affecting the heart but also the vasculature was investigated in chapter 6 , these results are described together with the effect of prolonged ACE inhibition by captopril. The final chapter (7) entails the experiments performed to study the role the $\mathrm{BK}_{2}$ receptor in vascular elasticity. 


\section{Abstract}

Angiotensin-l-converting enzyme (ACE) is a component of the systemic and the local renin-angiotensin system (RAS). ACE is locally expressed in the heart, but the importance of locally cxpressed ACE for the cardiac function is still unclear. By comparing cardiac function of adult mice lacking membrane-bound ACE (I-ACE) and their wild-type litternates, we tested the hypothesis that $\mathrm{t}-\mathrm{ACE}$ is involved in regulation of cardiac function. Cardiac output (CO) was measured under conscious conditions after implantation of a transi-lime flow probe around the ascending aorta. $\mathrm{CO}$ was determined under resting conditions as well as after stimulation with dobutamine or volume-loading. Although tACE $\%$ hearts were subjected to a lower afterload compared to will-type hearts, no differences were found in cardiac performance. Mean arterial pressure (MAP) was $80 \pm 3$ $(t-\mathrm{ACE}-/-)$ ws. $110 \pm 4 \mathrm{mmHg}(\mathrm{t}-\mathrm{ACE}+/+)$, and cardiac index (CI) at rest was $0.42 \pm 0.05$ $(\mathrm{t}-\mathrm{ACE}+1+\mathrm{n}=8)$ vs. $0.49 \pm 0.05 \mathrm{ml} / \mathrm{kg} / \mathrm{min}(\mathrm{t}-\mathrm{ACE}-1-, \mathrm{n}=7)$. After stimulation with dobutamine $(16 \mu \mathrm{g} / \mathrm{min}$ ), Cl increased to $0.54 \pm 0.05$ and $0.59 \pm 0.08 \mathrm{ml} / \mathrm{kg} / \mathrm{min}$ (t-ACE $+1+$ vs. $t-\mathrm{ACE}-1-$ ). Volume-loading was able to increase $\mathrm{CI}$ to $0.63 \pm 0.07$ vs. $0.65 \pm 0.08$. Since $\mathrm{t}-\mathrm{ACE}$-/- hearts failed to reach a higher maximil stroke volume in spite of reduced afterload, a change in the relationship between pressure and stroke volume is suggested, which might be due to a reduced cardiac contractility. Lack of membrane-bound ACE was not compensated by increased cardiac catecholamines. Three conclusions can be drawn form this study 1) the significantly lower blood pressure observed in $\mathrm{t}-\mathrm{ACE}-1$ - mice is due to decreased peripheral resistance $(7.2 \pm 0.8 \mathrm{vs} .9 .0 \pm 0.9 \mathrm{mmHg} \cdot \mathrm{min} / \mathrm{ml}) ; 2)$ absence of tACE changes the relationship between aortic pressure and stroke volume which might implicate a reduced cardiac contractility; 3) lack of membrane-bound ACE is not compensated by increased cardiac catecholamine content. 


\section{Chapter 2}

\section{Cardiac performance in conscious mice}

\section{lacking membrane-bound angiotensin-I-}

\section{converting enzyme}

Wendy M. Aartsen, J.J.M. Debets, B.J.A.Janssen, M.J.A.P. Daemen and J.J*.M. Smits

\section{Introduction}

The enzyme ACE is present in the circulation in a soluble form and bound to the cellsurface of endothelial cells. ACE is involved in the endocrine effects of the circulating renin-angiotensin system (RAS). However, as a membrane-bound enzyme, ACE can also participate in the local production of angiotensin II and act as a component of the local RAS. Although RAS components are widely expressed in several organs ${ }^{26,41}$, including the heart $^{38}$, the function of this local RAS expression and activity is still unclear.

Mice genetically deficient for tissue $\mathrm{ACE}$ (t-ACE $/ /$ or $\mathrm{ACE} 2)^{107}$ have been created. In these mice, only the $\mathrm{N}$-terminal end of ACE is expressed and released into the circulation. This ACE is unable to bind the cell membrane. Mice homozyous for this genetic alteration exhibit low blood pressure, renal vascular thickening and functional kidney problems ${ }^{107}$. The persistent low blood pressure observed in $\mathrm{t}-\mathrm{ACE}-1 /$ mice indicates that the haemodynamics are altered. Since angiotensin $I I$ is known to exhibit positive inotropic effects on the heart ${ }^{298}$, the significantly lower blood pressure found in this model might originate from a changed cardiac function. To test the thypothesis that $1-A C E$ is involved in regulation of cardiac performance, cardiac function of conscious $\mathrm{t}-\mathrm{ACE} / \mathrm{H}$ mice was investigated under resting conditions and after stimulation with either dobutamine or volume-load ${ }^{299}$. 
Since anglotensin II is able to increase the release of norepinephrine for sympathetic nerve endings $^{3 i v}$, a second objective of this study was to investigate the effects of $\mathrm{t}-\mathrm{ACE}$ deficiency on sympathetic activation. Prolonged treatment with $\mathrm{ACE}$ inhibitor or $\mathrm{AT}$, antagonists has been reported to result in an increased cardiac catecholamine content ${ }^{302.303}$. By increasing the sympathetic stimulation of the heart the lack of local angiotensin II production might be compensated. To unmask this potential compensatory response the cardiac cateholamine content was determined in mice lacking $1-\mathrm{ACE}$ and compared to cardiac catecholamine content determined in wild-type mice.

\section{Materials and Methods}

\section{Animals}

The generation of mice with a C57BL6/129/SV genetic background and lacking membranebound angiotensin-I-converting enzyme (t-ACE-/-) has been described by Esther et al ${ }^{10 \%}$. Mice heterozygous for the mutated ACE allele ( $\mathrm{t}-\mathrm{ACE}+/-$ ) were bred to obtain mice homozygous for the mutated ACE allele (t-ACE-/-) and their will-type littermates (t-ACE $+/+$ ). All animals were housed in groups of 4 to 6 and had free access to standard food (SRMA-1210; Hope Farms, Woerden, The Netherlands) and tap water. Adult male mice were used and all experiments were conducted according to institutional guidelines and conformed to the guide for the care and use of laboratory animals, published by the US National Institutes of Health (NIH Publication No 85m-23, revised 1996).

\section{Genotyping}

To genotype the newly bred pup, a small part of the tail was cut off and genomic DNA was isolated. DNA was extracted according to the manufacturer of the Qiagen DNA isolation kit (Qiagen GmbH, Hilden, Germany). PCR analyses were performed on the genomic DNA. $1.5 \mu 1$ of genomic DNA was added to the ready-to-go PCR beads (Amersham Pharmacia Biotech) diluted in $23.5 \mu \mathrm{l}$ water containing $1.5 \mathrm{U}$ Taq DNA polymerase, $10 \mathrm{mMTris}-\mathrm{HCl}$, $50 \mathrm{mM} \mathrm{Kel}, 1.5 \mathrm{mM} \mathrm{MgCl}, 200 \mu \mathrm{M}$ of each dNTP and $200 \mathrm{nM}$ of each primer. For $\mathrm{t}-\mathrm{ACE}$ mice we used the three primers as described by Esther et al. ${ }^{10 \%}$.

Flow probe implantation

Probe implantation was performed according to a method described elsewhere ${ }^{299}$ "Briefly, implantation was performed under halothane $\left(2 \%\right.$ in a $1: 1$ mixture of $\mathrm{NO}_{2}-\mathrm{O}_{2}$ at 1,000 $\mathrm{ml} / \mathrm{min})$ or isoflurane anaesthesia $(1.5-2 \%$ in normal air at $150 \mathrm{~mL} / \mathrm{min})$. After quick intubation mice were artificially ventilated and their body temperature was maintained at $37^{\circ} \mathrm{C}$ by a heating pad. The second left intercostal space was carefully opened about $2 \mathrm{~mm}$ 
from the stemum. The ascending aorta was dissected from surrounding tissues and the transit-time flow probe (type 1.5 SL, Transonic) was placed around the aorta. The position of the flow probe was optimised through observation of the flow signals. Gel (Surgilube) was inserted between the probe and the aorta to optimise the flow signal. The wound was closed in layers. The connector of the probe was then tunmeled subcutaneously to the neck and fixed. The animals were allowed to breath spontaneously and to recover at $30^{\circ} \mathrm{C}$. For analgesia , buprenorphine $(0.5 \mathrm{mg} / \mathrm{kg})$ was injected subcutaneously directly after surgery and on the following day.

Implantation of the catheters

Five days after implantation of the flow probe, catheters were implanted as described previously $^{304}$. Briefly, mice were anaesthetised with ketamine (100 mg/kg i.m.) and xylazine ( $5 \mathrm{mg} / \mathrm{kg} \mathrm{s.c.)}$. For blood pressure recordings a heparinised saline filled catheter artery (PE-25 heat stretched at its tip) was placed into the abdominal aorta via the femoral artery. In the jugular vein a second catheter (PE 10) was placed for infusions. Both catheters were subcutaneously tumneled to the neck and fixed. $1 \mathrm{ml}$ Ringer"s solution was given i.p. to help the animals to recover. Buprenorphine $(0.5 \mathrm{mg} / \mathrm{kg})$ was given for analgesia.

\section{Measurements of cardiac function}

Two days after catheter implantation flow probes were connected to the recording equipment (type T206, Transonic Systems) ${ }^{29 \%}$. The arterial catheter was connected to a pressure transducer (micro-switch, model 156PC $156 \mathrm{WL}$, Honeywell Inc., Amsterdam, the Netherlands, Amsterdam, The Netherlands). Mean arterial pressure (MAP), stroke volume (SV) and heart rate (HR) were determined from which cardiac output and total peripheral resistance were calculated. SV index (SI) and CO index (CI) were obtained by dividing SV and $\mathrm{CO}$ by body weilght in $\mathrm{g}$.

\section{Dobutamine infusion}

Before starting dobutamine infusion, steady-state resting walues of cardiac function were recorded for at least 10 minutes. The catheter in the jugular vein was then connected to an unfusion pump filled with dobutamine $(1 \mathrm{mg} / \mathrm{ml})$. The infusion was started at a rate of 16 $\mu \mathrm{l} / \mathrm{min}$ and was continued until functional parameters had reached new steady-state levels.

\section{Volume-loading}

When the functional parameters had normalised after the infusion of dobutamine (minimally 30 minutes), resting values were recorded again for at least 10 minutes. The syringe of the infusion pump was replaced by a new syringe filled with warm $\left(37^{\circ} \mathrm{C}\right)$ 
Ringer"s solution. The Ringer's solution was infused via the jugular vein at a rate of 2.5 $\mathrm{ml} / \mathrm{min}$ for 60 seconds, which approximately doubled the blood volume of the mouse (2 ml). During both dobutamine infusion and volume-loading, when maximal $\mathrm{CO}$ was reached, values were recorded over a period of at least 10 seconds, their average was calculated and reported as walues for stimulated cardiac function.

At the end of the experiment, mice were anaesthetised with pentobarbital $(100 \mathrm{mg} / \mathrm{kg}$, i.p.) and the position of the fow probe was determined to ensure that it did not cause any mechanicall limitation on the function of the heart.

\section{Ventricular catecholamine content}

After sacrifice with an overdoses of pentobarbital, hearts were dissected and atria were removed. The ventricles were weighed and stored in $0.5 \mathrm{M}$ acetic acid at $-20^{\circ} \mathrm{C}$. The next day, hearts were homogenised in $0.5 \mathrm{M}$ acetic acid. The homogenate was kept at $100^{\circ} \mathrm{C}$ for 15 minutes to extract catecholamines from the tissue. The content of noradrenaline, adrenaline and dopamine was determined by high-performance liquid-chromatography and fluorescence detection. Levels are expressed relative to ventricular weight.

\section{Statistics}

All data are presented as means \pm SEM. The haemodynamic data were compared using paired (effect of stimulation) or Wilcoxon Signed Rank test when normality test failed and unpaired Student's $r$-tests (between $t-A C E+/ 4$ and $t-A C E-/-$ ) or Mann-Whitney $U$ test when normality test failed. Statistical significance was accepted if $\mathrm{p}<0.05$.

\section{Results}

\section{Gieneral}

Wild-type animals weighed significantly more than mice deficient for membrane-bound $\mathrm{ACE}(\mathrm{t}-\mathrm{ACE}-/-)$. Ventricular weight of $\mathrm{t}-\mathrm{ACE}-/-$ mice was comparable to ventricular weight of $\mathrm{t}-\mathrm{ACE} \alpha /$ mice, as shown in table 1 . In table 2 , baseline haemodynamics of $\mathrm{t}$ $\mathrm{ACE}+1+$ and $\mathrm{t}-\mathrm{ACE} /$ - mice are summarised. Because of the differences in body weight both $\mathrm{SV}$ and $\mathrm{CO}$ were corrected for body weight resulting in comparable values for $\mathrm{SI}$ and CI for $\mathrm{t}-\mathrm{ACE}+1+$ and $\mathrm{t}-\mathrm{ACE}-/$ mice. Resting haemodynamic values were comparable between the two mouse groups, except for the mean arterial pressure (MAP). T-ACE mice exhibited a significantly lower blood pressure compared to wild-type mice. Under resting conditions the calculated total peripheral resistance (TPR) tended to be lower in $t$ ACE $/$ mice compared to $\mathrm{t}-\mathrm{ACE}+1+$ mice $(7.2 \pm 0.8 \mathrm{vs} .9 .0 \pm 0.9 \mathrm{mmHg} \mathrm{min} / \mathrm{ml})$, however this difference did not reach statistical significance $(p=0.2)$. 
Table 1. Body weight, ventricular weight and catecholamine content

\begin{tabular}{lcc}
\hline & $\mathrm{t}-\mathrm{ACE}+1+$ & $1-\mathrm{ACE}-1-$ \\
\cline { 2 - 3 } $\mathrm{N}$ & 7 & 7 \\
$\mathrm{BW}(\mathrm{g})$ & $31 \pm 1$ & $26 \pm 2 *$ \\
$\mathrm{VW}(\mathrm{g})$ & $0.14 \pm 0.01$ & $0.14 \pm 0.01$ \\
Noradrenaline $(\mathrm{pg} / \mathrm{g})$ & $7.7 \pm 4.2$ & $4.4 \pm 1.3$ \\
Adrenaline $(\mathrm{pg} / \mathrm{g})$ & $0.26 \pm 0.07$ & $0.26 \pm 0.07$ \\
Dopamine $(\mathrm{pg} / \mathrm{g})$ & $4.1 \pm 0.9$ & $5.3 \pm 1.6$
\end{tabular}

Data are presented as mean \pm SEM. Catecholamine content is relatively expressed to ventricular weight. Abbreviations: $N$; number, $B W$; body weight, VW; ventricular weight. * Significantly different from $t-\mathrm{ACE}+/+(\mathrm{p}<0.05)$.

Table 2. Haemodynamic parameters at rest

\begin{tabular}{lcc}
\hline & i-ACE $+1+$ & t-ACE $-/-$ \\
\cline { 2 - 3 } $\mathrm{N}$ & 8 & 7 \\
$\mathrm{SV}(\mu \mathrm{l})$ & $18.6 \pm 2.0$ & $18.4 \pm 1.3$ \\
$\mathrm{SI}(\mu \mathrm{l} / \mathrm{g})$ & $0.63 \pm 0.06$ & $0.73 \pm 0.08$ \\
$\mathrm{CO}(\mathrm{ml} / \mathrm{min})$ & $12.4 \pm 1.4$ & $12.2 \pm 0.9$ \\
$\mathrm{CI}(\mathrm{ml} / \mathrm{min}, \mathrm{g})$ & $0.42 \pm 0.05$ & $0.49 \pm 0.05$ \\
$\mathrm{HR}(\mathrm{bpm})$ & $662 \pm 14$ & $657 \pm 19$ \\
$\mathrm{MAP}(\mathrm{mmHg})$ & $110 \pm 4$ & $80 \pm 3 *$ \\
\hline
\end{tabular}

Data are presented as mean $\pm \mathrm{SEM}$. Abbreviations: $\mathrm{SV}$; stroke volume, $\mathrm{SI}_{\text {; stroke index }} \mathrm{CO}$; cardiac output, $\mathrm{CI}$; cardiac index, HR; heart rate MAP, mean arterial pressure. * Significantly different from $t-A C E+4(p<0.05)$.

Dobutamine infusion

When cardiac function was stimulated with dobutamine a significant increase in $\mathrm{SV}$ (18.6. 2.0 vs. $21.4 \pm 1.9 \mu 1), \mathrm{CO}(12.4 \pm 1.4 \mathrm{vs} .15 .9 \pm 1.4 \mathrm{ml} / \mathrm{min})$ and HR $(662 \pm 14 \mathrm{vs} .744 \pm 9$ 
bpm) was found in $\mathrm{t}-\mathrm{ACE}+1+(\mathrm{n}=8)$, while MAP was significantly reduced $(111 \pm 4$ vs. 78 $\pm 3 \mathrm{mmHg})$. Similar results were obtained in $\mathrm{t}-\mathrm{ACE}-1-(\mathrm{n}=7)$ mice as shown in table 3 . Dobutamine infusion lowered the MAP in both $t-A C E+1+$ and $t-A C E-/-$ in comparable proportions $(-32 \pm 2$ vs. $-26 \pm 4 \mathrm{mmHg})$.

Table 3. Haemodynamic parameters after dobutamine stimulation

\begin{tabular}{|c|c|c|c|c|}
\hline \multirow[b]{2}{*}{$\mathrm{N}$} & \multicolumn{2}{|c|}{$\mathrm{t}-\mathrm{ACE}+\mathrm{H}$} & \multicolumn{2}{|c|}{$1-\mathrm{ACE}-1-$} \\
\hline & 7 & & 7 & \\
\hline $\operatorname{SV}(\mu l)$ & 21.4 & $\pm 1.9+$ & 20.1 & $\pm 1.4 \dagger$ \\
\hline $\mathrm{SI}(\mu \mathrm{L} / \mathrm{g})$ & 0.72 & $\pm 0.06 t$ & 0.80 & $\pm 0.09 \dagger$ \\
\hline $\mathrm{CO}(\mathrm{ml} / \mathrm{min})$ & 15.9 & $\pm 1.4 \dagger$ & 14.5 & $\pm 1.3 \dagger$ \\
\hline $\mathrm{Cl}(\mathrm{ml} / \mathrm{min} . \mathrm{g})$ & 0.54 & $\pm 0.05+$ & 0.59 & $\pm 0.08 \dagger$ \\
\hline HR (bpm) & 745 & $\pm 9 \uparrow$ & 719 & $\pm 23 \dagger$ \\
\hline MAP (mmHg) & 78 & $\pm 3 \uparrow$ & 53 & $\pm 5^{*} \dagger$ \\
\hline
\end{tabular}

Data are presented as mean $\pm \mathrm{SEM}$. Abbrewiations: $\mathrm{SV}$; stroke volume, SI; stroke index, $\mathrm{CO}$; candiac output, $\mathrm{Cl}$; cardiac index, $\mathrm{HR}$; heart rate MAP, mean arterial pressure. * Significantly different from $1-A C E+/ 4(p<0.05)$. * Significantly different from walues at rest $(p<0.05)$.

Table 4. Haemodynamic parameters after volume loading

\begin{tabular}{lcc}
\hline & $\mathrm{t}-\mathrm{ACE}+\mathrm{H}$ & $\mathrm{t}-\mathrm{ACE}-\mathrm{-}$ \\
\cline { 2 - 3 } $\mathrm{N}$ & 7 & 7 \\
$\mathrm{SV}(\mathrm{\mu l})$ & $28.6 \pm 2.8 \dagger$ & $25.8 \pm 1.8 \dagger$ \\
$\mathrm{SI}(\mu \mathrm{l} / \mathrm{g})$ & $0.94 \pm 0.10 \dagger$ & $1.01 \pm 0.10 \dagger$ \\
$\mathrm{CO}(\mathrm{ml} / \mathrm{min})$ & $18.9 \pm 1.9 \dagger$ & $16.1 \pm 1.4 \dagger$ \\
$\mathrm{CI}(\mathrm{ml} / \mathrm{min} \mathrm{g})$ & $0.63 \pm 0.07 \dagger$ & $0.65 \pm 0.08 \dagger$ \\
$\mathrm{HR}(\mathrm{bpm})$ & $663 \pm 20$ & $630 \pm 24$ \\
$\mathrm{MAP}(\mathrm{mmHg})$ & $99 \pm 4$ & $68 \pm 2 *$ \\
\hline
\end{tabular}

Data are presented as mean \pm SEM. Abbreviations: SV; stroke volume, SI; stroke index, CO; cardiac output, $\mathrm{Cl}$; cardiac index, $\mathrm{HR}$; heart rate MAP, mean arterial pressure. * Significantly different from $t-A C E+/+(p<0.05)$. + Significantly different from values at rest $(p<0.05)$. 


\section{Volume-loading}

After dobutamine infusion one $\mathrm{t}-\mathrm{ACE}+1+$ mouse died, so $7 \mathrm{t}-\mathrm{ACE}+1+$ and $7 \mathrm{t}-\mathrm{ACE}-$ mice were subjected to volume-loading. After loading the $t-\mathrm{ACE}+/ 4$ circulation with 2.5 ml Ringer's solution in 60 seconds both SV $(21.2 \pm 2.1$ vs. $28.6 \pm 2.8 \mu \mathrm{l})$ and $\mathrm{CO}(13.2 \pm$ $1.2 \mathrm{vs} .18 .9 \pm 1.9 \mathrm{ml} / \mathrm{min})$ were significantly increased. HR $(628 \pm 12 \mathrm{vs} .663 \pm 20 \mathrm{bpm})$ and MAP (100 \pm 5 ws. $99 \pm 4 \mathrm{mmHg}$ ) were not affected by volume loading. Results obtained after loading the $t-A C E-1$-circulation were comparable (table 4). Volume-loading decreased MAP in t-ACE $/-$ slightly ( $75 \pm 4$ vs. $68 \pm 2 \mathrm{mmHg}, \mathrm{p}=0.2$ ), but not significantly. Maximal $\mathrm{CO}$ after loading tended to be lower in $\mathrm{t}-\mathrm{ACE}-\mathrm{t}-$, but calculation of $\mathrm{CI}$ showed that these values were comparable $(\mathrm{t}-\mathrm{ACE}+1+\mathrm{t}: 0.63 \pm 0.07$ vs. $0.65 \pm 0.08$ $\mathrm{ml} / \mathrm{min} / \mathrm{kg})$.

\section{Discussion}

In the present study the cardiac performance of conscious mice was investigated througll chronic implantation of a transit-time flow probe around the ascending aorta. Cardiac performance of wild-type mice was compared to cardiac performance of mice lacking the membrane-bound $\mathrm{ACE}$ ( $\mathrm{t}-\mathrm{ACE}$ ), to investigate the role of membrane-bound $\mathrm{ACE}$ in cardiac performance. At rest, the cardiac haemodynamic parameters measured in $\mathrm{t}-\mathrm{ACE}-1-$ mice were comparable to $\mathrm{t}-\mathrm{ACE}+1+$ mice. Confirming previous findings, mean arterial pressure (MAP) in $1-A C E ~-/$ - was significantly reduced ${ }^{107}$. These data suggest that hypotension observed in $\mathrm{t}$-ACE $-/$ mice is due to a reduced total peripheral resistance (TPR; $7.2 \pm 0.8$ vs. $9.0 \pm 0.9 \mathrm{mmHg} . \mathrm{min} / \mathrm{ml}$ ) rather than a decreased cardiac perlormance. The lower TPR can be explained by the reduced $\mathrm{ACE}$ activity in $\mathrm{t}-\mathrm{ACE}-/$-mice. Reduced production of the potent vasoconstrictor angiotensin II can lead to a decreased peripheral resistance. It has also been described that $\mathrm{t}-\mathrm{ACE}$ /- mice have a lower haematocrit compared to their wildtype littermates, which also contributes to lowering resistance ${ }^{226}$.

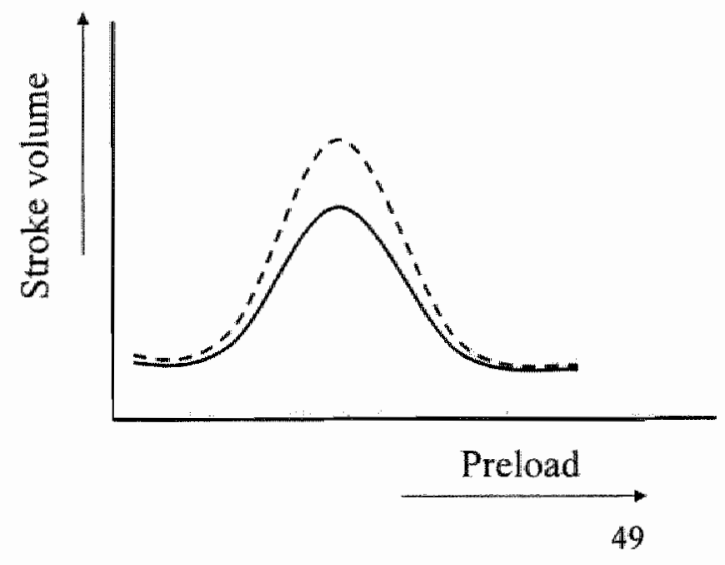

Pigure 1. Frank-Staring relationslip between preload and groke volume.

and normal afterlload.

- - Charve in calse of reduced afterload. Figure iss modified from Spicgel et al ${ }^{\text {mos }}$. 
As described by the Frank-Starling relationship (figure 1) related to the end-diastolic wall tension induced by preload. This relationship follows a bell-shaped curve. The preload is positively related to stroke volume up to a certain optimum; after which the relationship between preload and stroke volume becomes negative. Alterations in contractility and afterload will change the optimum and the slope of this relationship. As depicted in figure 1, a decrease in afterload will Jead to an upward shift in maximal stroke volume and an increase in the slope of the curve.

The cardiac afterload is reduced in a situation of hypotension as is observed in $\mathrm{t}-\mathrm{ACE}-\mathrm{f}$ mice. To determine maximal stroke volume the circulation was loaded with $2.5 \mathrm{ml}$ Ringer's solution in 60 seconds. Maximal stroke volume was reached in both $t-A C E+/+$ and $\mathrm{t}-\mathrm{ACE}$ / - mice within 60 seconds, peaking at values of $28.6 \pm 2.8$ and $25.3 \pm 1.8 \mu \mathrm{l}$ respectively. No significant difference was found between $t-A C E ~ t /+$ and $t-A C E-/$ - in their maximal stroke volume, which is remarkable since the mean arterial pressure (MAP) or afterload in the $\mathrm{t}-\mathrm{ACE}=/ \mathrm{r}$ remains significantly lower (Tables 1 and 4 ). The upward slope of the relationship between preload and stroke volume was also calculated (data not shown) but revealed no differences between $\mathrm{t}-\mathrm{ACE}-/-$ and $\mathrm{t}-\mathrm{ACE}+1+$.

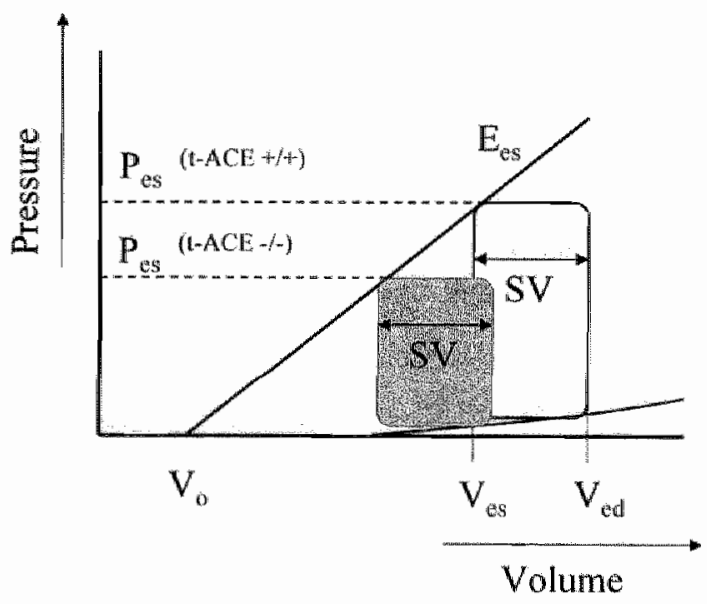

Figure 2. Linear relationship between: volume and pressure (UnterstitzungsZuckungs-Kurve). $\mathrm{SV}$ is equal in both groups while $P_{e s}$ is reduced in $1-A C E-/-$ compared to $\mathrm{t}-\mathrm{ACE}+1+$ If $\mathrm{E}_{\mathrm{sis}}$ and $\mathrm{SV}$ are equal, a reduced $P_{\text {es leads to a }}$ reduced $V_{i d}$ and increased ejection fraction $\left(S W / V_{*}-V_{w}\right)$. Figure is modified from splegel et ans

As described by Spiegel et al ${ }^{305}$, the relationship between end-systolic pressure $\left(P_{e s}\right)$ or peak aortic pressure and stroke volume is linear $\left(\mathrm{P}_{\mathrm{ks}}=\mathrm{E}_{\mathrm{ss}}\left(\mathrm{V}_{\mathrm{cs}}-\mathrm{Vo}\right)\right.$; figure 2). The slope of this relationship is called the end - systolic ventricular elastance $\left(E_{w s}\right)$. $E_{\mathrm{es}}$ is considered an index of left ventricular contractility, which is independent of preload and afterload. $V_{\text {ed }}$ is enddiastollic volume, $V_{\text {es }}$ is end-systolic volume and $V_{0}$ is the volume axis intercept of the endsystolic pressure-volume relationship. If $P_{\mathrm{a}}$ is reduced (lower afterload in $\mathrm{t}$-ACE $-/$ ) and $\mathrm{SV}$ is equal, either $V_{\text {ed }}$ or the $E_{\mathrm{es}}$ (contractility) is reduced, according to this relationship. In case of a reduced $V_{\text {id }}$ the ejection fraction $\left(S V / V_{0 \cdot}-V_{0}\right.$ ) should be increased in $t-A C E-/-$ 
compared to $\mathrm{t}-\mathrm{ACE}+1+$ (figure 2). No differences were found in ventricular weight between t-ACE -7 and $\mathrm{t}-\mathrm{ACE}+\%$. It has been described that chronic captopril treatment in rats increases the stiffness of the left ventricle with and without infarction. An increased stiffiness is inversely related to ventricular volume ${ }^{30 \%}$. More information is needed to conclude if $V_{\text {ed }}$ in $\mathrm{t}-\mathrm{ACE}-/$ mice is different from $\mathrm{V}_{\mathrm{ed}}$ in $\mathrm{t}-\mathrm{ACE}+/+$ mice. If $\mathrm{V}_{\mathrm{w} d}$ is considered equal, the ventricular elastance ( $E_{\mathrm{ss}}$ ) or contractility in $\mathrm{t}-\mathrm{ACE} / \mathrm{-}$ heart is impaired compared to $\mathrm{t}-\mathrm{ACE}+1+$ hearts (figune 3 ).

Figure 3 . Linear relationship between wolume and pressure (UnterstatzungsZuckungs-Kurve). $\mathrm{SV}$ is oqual in both groups while $\mathrm{P}_{\text {ess }}$ is reduced in $\mathrm{ACE}$ $/$ - compared to $t-A C E$ w. $/ 4$, If $V_{e d}$ and SV atre equal, a reduced Pes leads to a reduced $\mathrm{E}_{4: 8}$ (contractility). Figure is modified from Spiegel et at ${ }^{\text {to }}$

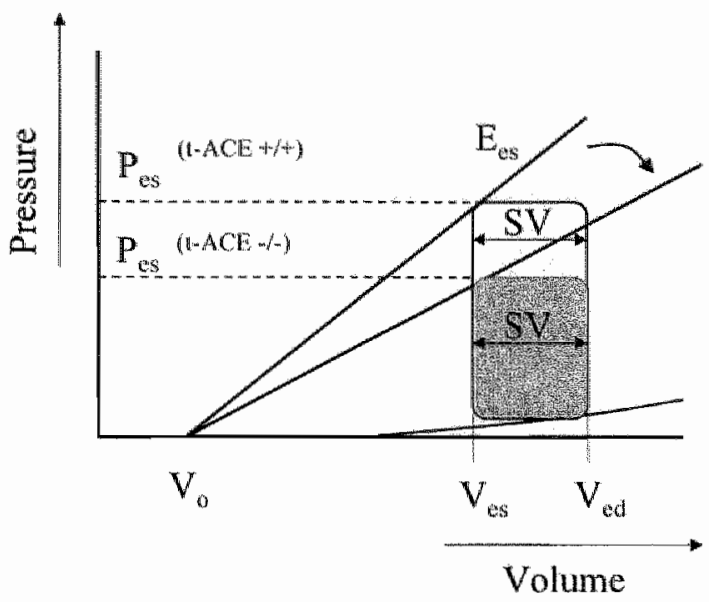

The local availability of angiotensin II might be important for cardiac contraction. Cardiac contractility might be affected by the lack of membrane-bound $\mathrm{ACE}$ since angiotensin II is known to change the intracellular calcium concentrations and calcium handling ${ }^{298}$. Further investigation is needed to confirm the hypothesis that cardiac contractility in $\mathrm{A}-\mathrm{ACE}-/-$ mice is reduced and which mechanism is involved in this reduced cardiac contractility.

Angiotensin II and sympathetic activity are known to be closely linked. Angiotensin II is able to facilitate noradrenaline release from the nerve endings through activation of the presynaptic $A T_{1}$ receptor ${ }^{300,30 \%}$. The lack of local angiotensin II production due to the absence of membrane-bound ACE might affect the sympathetic stimulation of the heart. After chronic treatment with both $\mathrm{ACE}$ inhibitors and $\mathrm{AT}$, receptor antagonists the cardiac catecholamine content is increased ${ }^{3(2,303}$. However, in $\mathrm{t}-\mathrm{ACE} / /$ mice no changes were found in the cardiac catecholamine content.

The haemodynamic reaction to dobutamine was distinct from the cardiac stimulation with volume-loading, which is to be expected from the nature of the two stimuli. In the case of volume-loading the preload is increased to its maximum and causes an increase in stroke volume as described by the Frank-Starling mechanism. Dobutamine is a asellective 
$\beta_{1}-$-receptor agonist and receptor activation leads to increase in both cardiac inotropy and chronotropy. Our results show that dobutamme increased both SV and HR. The decrease in $\mathrm{MAP}$ is induced via stimulation of the vascular $\beta_{2}$-receptor by dobutamine, which results in vasodilation. T-ACE $-/-$ mice showed similar reaction to the dobutamine infusion as $\mathrm{I}-\mathrm{ACE}$ $+1+$ mice (a reduction in MAP of approximately $25 \mathrm{mmHg}$ ). Thus, also at functional level no indication was found that the lack of membrane-bound ACE affects the cardiac $\beta_{1}-$ receptor density.

In summary thembrane-bound $\mathrm{ACE}$ deficiency does not alter cardiac output at rest. Thus, the significantly reduced $\mathrm{MAP}$ is due to the reduced peripheral resistance. The response of the heart to dobutamine or volume loading is not altered in the absence of $\mathrm{A}-\mathrm{ACE}$. However, the lower afterload is not accompanied by an increased maximal stroke volume, which suggests that the ventricular contractility is reduced. No indications were found that the lack of membrane-bound $\mathrm{ACE}$ is compensated by changes in the sympathetic nervous system or cardiac $\beta_{1}$-receptors.

\section{Ackinowledgements}

The authors thank Dr. K.E. Bernstein for the gift of the 1-ACE knockout mice. P.J.A. Leenders, N.J.E. Bitsch and G.M.J. Janssen are gratefully acknowledged for their technical assistance. 
. 


\begin{abstract}
Angiotensin-l-converting enzyme (ACE) exists in two forms; one is circulating and the other one is bound to the cell-membrane. Both forms are active generators of angiotensin II. The membrane-bound ACE (t-ACE) might be associated with cardiac contractility, since in mice lacking $\mathrm{t}-\mathrm{ACE}$ a reduced cardiac contractility compared to their wild-type littermates was suggested. This impaired cardiac contractility could originate from a disturbed cardiovascular maturation caused by the lack of $-\mathrm{ACE}$. $\mathrm{T}-\mathrm{ACE}+1+$ mice were treated with captopril $(80 \mathrm{mg} / \mathrm{kg} / \mathrm{day})$ form 3 until 12 weeks of age to investigate the effects of prolonged ACE inhibition after the critical period of organogenesis. Cardiac performance was investigated at 12 weeks by measuring the cardiac output $(\mathrm{CO})$ via an electromagnetic flow probe placed around the ascending aorta. Mean arterial pressure (MAP) was measured through a cannula in the abdominal aorta. Both parameters were determined at rest and after a volume loading of $2.5 \mathrm{ml}$ warm $\left(37^{\circ} \mathrm{C}\right)$ Ringer's solution in 60 seconds. Captopril treatment effectively inhibited the ACE activity and reduced MAP from $111 \pm 2(n=7)$ to 80 $\pm 7 \mathrm{mmHg}(\mathrm{n}=5)$. Both cardiac index at rest (Cl, $0.12 \pm 0.02 \mathrm{vs} .0 .20 \pm 0.02 \mathrm{ml} / \mathrm{min} / \mathrm{g})$ and maximal Cl $(0.34 \pm 0.15$ vs. $0.59 \pm 0.07 \mathrm{ml} / \mathrm{min} / \mathrm{g})$ were significantly reduced in captopril treated mice compared to untreated mice. Together, with the hypothesised reduced cardiac contractility observed in $\mathrm{t}-\mathrm{ACE}$ - $/$ - mice, these data suggest that cardiac contractility in mice is related to total ACE activity, independent of its source, and that the impaired cardiac contractility in $\mathrm{A}-\mathrm{ACE}-/$ - mice is not due to an impaired foetal development.
\end{abstract}




\section{Cardiac performance after captopril treatment in normal mice}

Wendy M. Aartsen, B.J.A. Janssen, M.J.A.P. Daemen and J.F.M. Smits

\section{Introduction}

Angiotensin-1-converting enzyme (ACE) is a component of the renin-angiotensin system (RAS), which is both systemically and locally active ${ }^{28.41}$. Both plasma and membranebound $\mathrm{ACE}$ contribute to the generation of the vasoactive peptide angiotensin $\mathrm{II}^{27,28}$. In the previous chapter, the mouse model lacking membrane-bound $\mathrm{ACE}$ ( $\mathrm{t}-\mathrm{ACE}-1-$ or $\mathrm{ACE} .2$ ) was used to unravel the role of locally produced angiotensin II in cardiovascular homeostasis. Data derived from this study suggest that $\mathrm{t}-\mathrm{ACE}$ deficiency in mice reduces cardiac contractility.

17here are strong indications that RAS is involved in cardiac maturation. During foetal development RAS components are expressed in kidney, heart and vessels ${ }^{34,71.92,45}$ "ACE inhibition in the mother during late pregnancy or lactation causes severe malformation of the offspring ${ }^{92,93,101}$. In the present study we investigated the hypothesis that the lack of $t-$ ACE during foetal development might affect the cardiac maturation and result in a depressed cardiac function in adulthood. Therefore, $t-A C E+1+$ mice were treated with captopril from 3 weeks to 12 weeks of age. At the end of the treatment their cardiac function was investigated and compared to untreated $t-A C E+f+$ mice. 


\section{Materials and Methods}

\section{Animals}

Wild-type animals (t-ACE $+1+$ ) with a C57BL6/129/SV genetic background were crossed and their male offspring had access to either tap water or captoprij dissolved in tap water $(80 \mathrm{mg} / \mathrm{kg} / \mathrm{day})$ from the age of three weeks until 12 weeks after birth. All animals were housed in groups of 4 to 6 and had free access to standard food (SRMA-1210; Hope Farms, Woerden, The Netherlands). All experiments were conducted according to institutional guidelines and conformed to the guide for the care and use of laboratory amimals, published by the US National Institutes of Health (NIH Publication No 85-23, revised 1996).

\section{Implantation of the catheters}

Catheters were implanted as described previously ${ }^{304}$. Briefly, mice at 12 weeks of age were anaesthetised with ketamine $(100 \mathrm{mg} / \mathrm{kg}$ i.m.) and xylazine $(5 \mathrm{mg} / \mathrm{kg} \mathrm{s.c.}$ ). For blood pressure recordings a heparinised saline filled catheter (PE-25 heat stretched at its tip) was placed in the abdominal aorta via the femoral artery. In the jugular wein a second catheter (PE 10) was placed for infusions. Both catheters were tunneled subcutaneously to the neck and fixed.

\section{Blood pressure measurement}

At day 5 after implantation of the catheters, the arterial catheter was connected to a pressure transducer (Micro-Switch, model 156PC 156 WL, Honeywell Inc., Amsterdam, the Netherlands). Blood pressure signals were recorded and 10 minutes of stable recordings were used to calculate the mean arterial pressure (MAP) at rest. Dose-response curves for angiotensin I and II were constructed, in a cumulative way from 0 until $35 \mathrm{ng}(0-1.5 \mathrm{ng} / \mathrm{kg})$. Each dose was injected (i.v.) at the time of maximal MAP to avoid tachyphylaxis. At each step, the maximal increase in MAP was calculated.

\section{Measurements of cardiac function}

Directly after blood pressure measurements, mice were anaesthetised for hamodynamic measurements. The animals were anaesthetised with pentobarbital sodium $(110 \mathrm{mg} / \mathrm{kg} \mathrm{i.p.}$ ), followed by intubation of the trachea ( $1.1 \mathrm{~mm}$ stainless steel) to allow positive pressure respiration with room air $(1.5-2 \mathrm{ml}, 70 / \mathrm{min})$. Their body temperature was kept at $37^{\circ} \mathrm{C}$ via a heating-pad. The saline filled catheter (PE 25) placed into the abdominal aorta was connected to a pressure transducer (micro-switch, model $156 \mathrm{PC} 156 \mathrm{WL}$, Honeywell Inc., Amsterdam, the Netherlands). The catheter (PE 10) placed in the jugular vein was used for injections. The third right intercostal space was then opened and the ascending aorta was 
dissected free from the surrounding tissue. An electromagnetic flow probe (1.0mm, Skalat, Delf, The Netherlands) was placed around the aorta just above the heart, to measure stroke volume (SW) and heart rate (HR) from which cardiac output (CO) was calculated. MAP and CO were determined at rest for at least 10 minutes. The circulation was then loaded by infusion of $2.5 \mathrm{ml}$ wam $\left(37^{\circ} \mathrm{C}\right)$ Ringer's solution in 1 minute and maximal values for $\mathrm{SV}$ and $\mathrm{CO}$ were recorded. Stroke index (SI) was calculated as stroke volume divided by body weight and cardiac index (CI) was calculated as cardiac output divided by body weight in $g$.

\section{Statistics}

Haemodynamic data are shown as mean \pm SEM. The impact of the captopril treatment was tested with a two-way ANOVA for repeated measurements in case of the angiotensin I and II curves. The impact of captopril treatment on cardiac function was tested with urpaired Student's $t$-test or Mann-Whitney $U$ test when normality test failed. The effect of wolume loading was tested with a paired Student's $t$-test or Wilcoxon Signed Rank test when normality test failed. Statistical significance was accepted if $\mathrm{p}<0.05$.

\section{Results}

Table 1. Body weight, heart weight, blood pressure and heart rate of untreated $\mathrm{t}-\mathrm{ACE}+/+$ and captopril treated $\mathrm{t}-\mathrm{ACE}+/+$ mice

\begin{tabular}{lcc}
\hline & $\begin{array}{c}\text { t-ACE }+1+ \\
\text { untreated }\end{array}$ & $\begin{array}{c}\text { t-ACE }+1+ \\
\text { captopril }\end{array}$ \\
\cline { 2 - 3 } $\mathrm{N}$ & 9 & 6 \\
$\mathrm{BW}(\mathrm{g})$ & $24 \pm 0.4$ & $23 \pm 0.7$ \\
$\mathrm{HW}(\mathrm{g})$ & $0.13 \pm 0.01$ & $0.09 \pm 0.01 *$ \\
$\mathrm{HW} / \mathrm{BW}(\%)$ & $0.57 \pm 0.03$ & $0.39 \pm 0.03$ \\
$\mathrm{MAP}(\mathrm{mmHg})$ & $111 \pm 2(7)$ & $80 \pm 7 *(5)$ \\
$\mathrm{HR}(\mathrm{bpm})$ & $550 \pm 36(7)$ & $600 \pm 48(5)$ \\
\hline
\end{tabular}

Data are presented as mean \pm SEM. Abbreviations: BW; body weight, HW; heart weight $\mathrm{BW} / \mathrm{HW}$; bodly weight heart weight ratio. Captopril; $\mathrm{t}-\mathrm{ACE}+\mathrm{H}+$ mice treated with captopril $(80$ $\mathrm{mg} / \mathrm{kg})$ from $3-12$ weeks of age. * Significantly different from $\mathrm{t}-\mathrm{ACE}+/+(\mathrm{p}<0.05)$.

Body weight, heart weight, blood pressure and heart rate of untreated $(n-9)$ and captopril treated mice $(\mathrm{n}=6)$ determined at the age of 12 weeks are shown in Table 1. Captopril 
treated mice had significantly lighter hearts compared to the untreated mice. Also the calculated heart weightbody weight ratio was significantly lower in captopril treated mice. Blood pressture meastured under conscious conditions was significantly reduced during the prolonged treatment with captopril. A separate group of control (4) and captopril treated animals (4) were used to construct a curve for growth and water consumption (Figure 1). No differences were observed in drinking behaviour of untreated and captopril treated animals. Growth of untreated and captopril treated animals was comparable up to the age of 12 weeks, thereafter growth of captopril treated animals was reduced and untreated animals became significantly theavier.

\section{Growth curve}

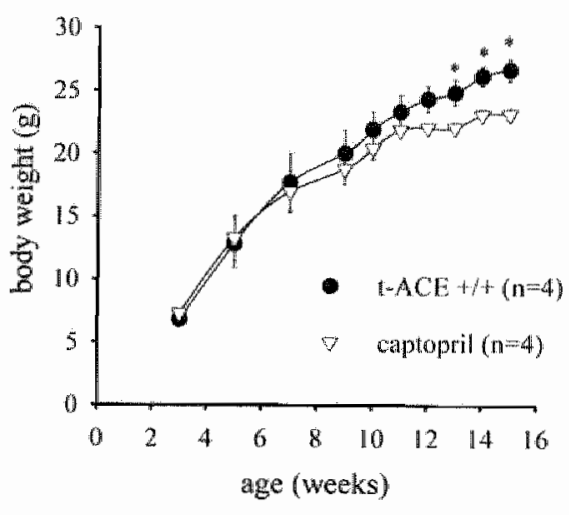

\section{Water consumption}

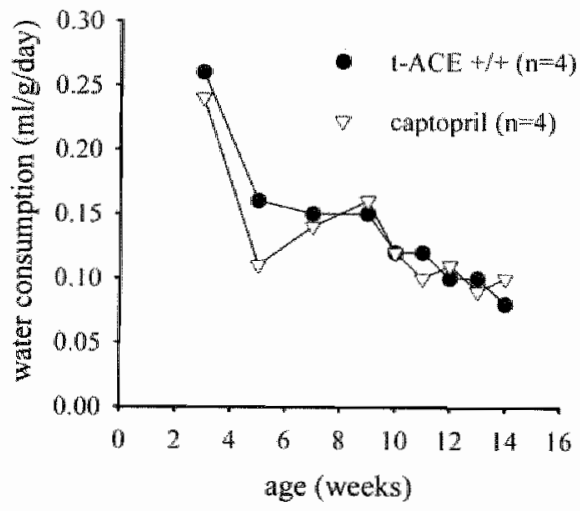

Figure 1. Left panel: Growth curve (from 3 until 15 weeks of age) of untreated and captopril ( 80 $\mathrm{mg} / \mathrm{kg} / \mathrm{day}$ ) treated $\mathrm{t}-\mathrm{ACE}+1+$ mice. Right panel: Water consumption (from 3 untill 15 weeks of age) determined in untreated and captopril $(80 \mathrm{mg} / \mathrm{kg} / \mathrm{day})$ treated $\mathrm{t}-\mathrm{ACE}+1+$ mice.

\section{Angiotensin I and II dose-response curves}

The blood pressure response to angiotensin I and II infusion is shown in figure 2. The blood pressure increase during angiotensin I infusion was significantly reduced after captopril treatment. Blood pressure in captopril treated t-ACE $+1+$ mice remained constantly lower than blood pressure of control $\mathrm{t}-\mathrm{ACE}+1+$ mice during both angiotensin $I$ and angiotensin II infusion. The dose-response curve of angiotensin I was shifted to the right in captopril treated mice compared to the control mice, while the dose-response curve of angiotensin II was comparable, but started at a lower pressure in captopril treated mice compared to control mice. 


\section{Dose-response Angiotensin I \& II}
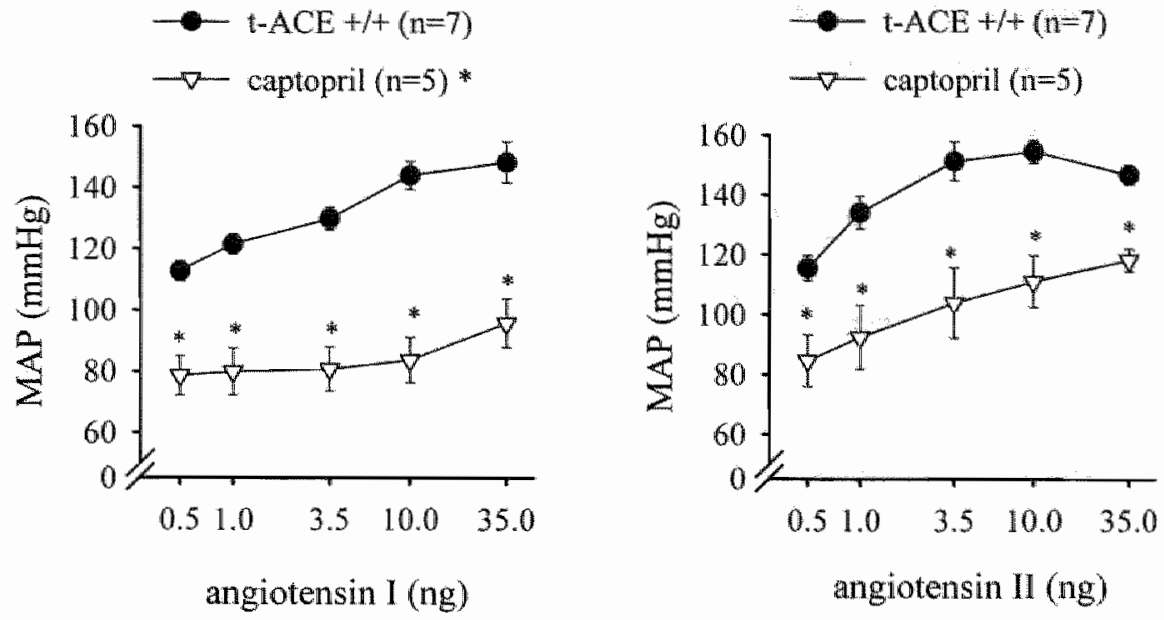

Figure 2. Dose-response curves of angiotensin I (left) and II (right) in untreated and captopril (80 $\mathrm{mg} / \mathrm{kg} /$ day) treated $\mathrm{t}-\mathrm{ACE}+1+$ mice. * Significantly different from wntreated $\mathrm{t}-\mathrm{ACE}+1+(\mathrm{p}<0.05)$.

* (in legends) Significant interaction between MAP and captopril treatment $(p<0.05)$.

Measurements of cardiac performance

Figure 3 shows the parameters of cardiac function under pentobarbital anaesthesia. At rest, stroke index and cardiac index of captopril ( $80 \mathrm{mg} / \mathrm{kg} / \mathrm{day}$ ) treated $\mathrm{t}-\mathrm{ACE}+1+$ were significantly lower compared to stroke and cardiac indices of untreated $t-\mathrm{ACE}+/+$ mice. After volume loading the maximal stroke and cardiac index determined in captopril treated t-ACE $+/+$ mice was significantly lower than in control mice. To correct for the significantly lower heart weight/body weight found in captopril treated $t-A C E+/ t$, maximal stroke work (stroke volume times mean arterial pressure) per heart weight was callculated. Values are $2.6 \pm 0.3 \mathrm{mmHg} . \mathrm{ml} / \mathrm{g}$ for untreated $\mathrm{t}-\mathrm{ACE}+\mathrm{t}+$ versus $1.4 \pm 0.2$ $\mathrm{mmHg} \cdot \mathrm{ml} / \mathrm{g}$ for captopril treated $\mathrm{t}-\mathrm{ACE}+1+$, which is significantly different $(\mathrm{p}=0.02)$. 

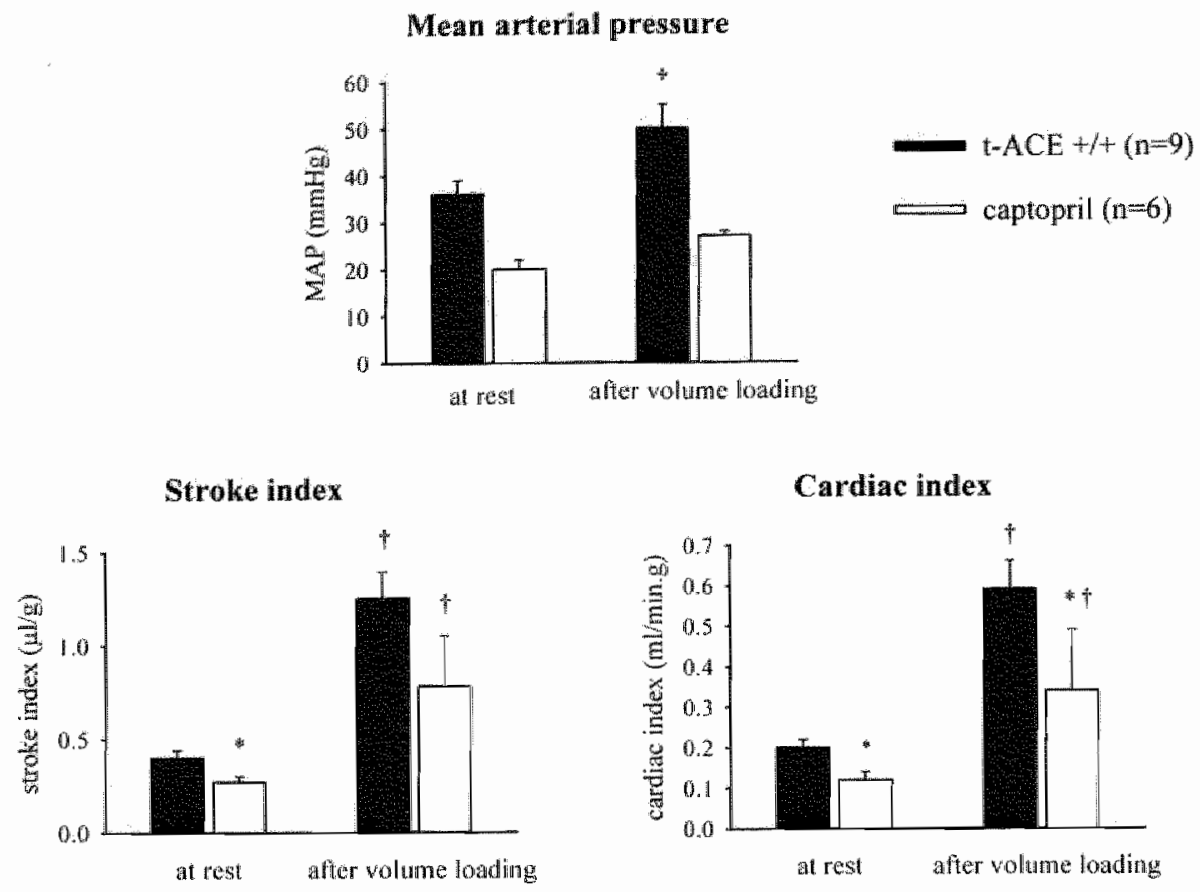

Figure 3. Cardiac performance measured in untreated $\mathrm{t}-\mathrm{ACE}+1+$ and captopril treated (80 $m \mathrm{mg} / \mathrm{kg} / \mathrm{day}) \mathrm{t}-\mathrm{ACE}+\mathrm{t}$. Upper panel: mean arterial pressure determined at rest and after volume loading. Left panel: Stroke index determined at rest and after wolume loading. Right panel: Cardiac index determined at rest and after volume loading. * Significantly different from untreated $t-A C E$ $+1+(p<0.05)$. + Significantly different from values determined at rest $(p<0.05)$.

\section{Discussion}

Angiovensin-I-converting enzyme (ACE) is active as a circulating enzyme and as a membrane-bound enzyme and both enzyme forms contribute to the angiotensin II generation $^{27,23}$. In the previous chapter, cardiac performances of mice lacking membranebound $\mathrm{ACE}$ ( $(-\mathrm{ACE}-/-)$ was investigated under normall conditions and the results suggest that cardiac contractility is reduced in the absence of $\mathrm{t}-\mathrm{ACE}$. Since ACE expression is found in kidney, heart and vessels during gestation ${ }^{92.93}$ and $\mathrm{ACE}$ inhibition is proven to be toxic for foetal development ${ }^{100,10 !}$, we hypothesised that the reduced cardiac contractility found in $\mathrm{t}-\mathrm{ACE}-/$ mice might be due to an impaired foetal development. 
Captopril treatment ( $80 \mathrm{mg} / \mathrm{kg} / \mathrm{day}$ ) started at the age of 3 weeks in $\mathrm{t}-\mathrm{ACE}+1 / 4$ mice did not affect their growth nor did it change their water consumption. However, it signifieantly lowered their heart weight and heart weight/body weight ratio. Although in a previous study heart weight of $t-A C E-/$ mice was lower compared to $\mathrm{t}-\mathrm{ACE}+/+$ hearts, $\mathrm{t}-\mathrm{ACE} /-$ mice exhibited no reduced heart weight/body weight ratio. These cardiac "atrophic" effects of ACE inhibitors have previously been described in rats ${ }^{30 \%}$. Moreover, angiotensin 11 is known to be trophic for cardiomyocytes in witro ${ }^{90.169}$ and in vivo ${ }^{309}$. Angiotensin I administration showed that $A C E$ inhibition in the captopril treated $t-A C E+/ 4$ mice was very effective. In contrast to this effective pharmacologic inhibition, $1-\mathrm{ACE} \%$ mice express a truncated form of ACE, which is still able to produce angiotensin II. Indeed, angiotensin II plasma levels in $\mathrm{t}-\mathrm{ACE}-/$ mice are reduced to approximately $20 \%$ of the $\mathrm{t}-\mathrm{ACE}+1+$ plasma levels ${ }^{226}$, which might be enough to prevent a reduced heart weight/body weight ratio, as observed after prolonged pharmalogic ACE inhibition.

Prolonged treatment with captopril $(80 \mathrm{mg} / \mathrm{kg} / \mathrm{day})$ significantly reduced mean arterial pressure to a comparable level as observed in $\mathrm{t}-\mathrm{ACE} /-$ mice. Cardiac performance was determined under anaesthesia in captopril $(80 \mathrm{mg} / \mathrm{kg} /$ day $)$ treated and untreated $\mathrm{t}-\mathrm{ACE}+\mathrm{H}$ mice. Already at rest, stroke index and cardiac index were lower in captopril treated mice compared to untreated mice. After volume loading, SI and $\mathrm{Cl}$ remained lower in captopril treated compared to untreated $\mathrm{t}-\mathrm{ACE}+1+$ mice. A similar trend was found in $\mathrm{t}-\mathrm{ACE}-1-$ mice, but this reduction in SI and $\mathrm{Cl}$ did not reach statistical significance. Reduced SI and CI found in captopril treated mice might be due to their reduced heart weight. However, stroke work corrected for heart weight was still significantly lower in captopril treated ( 2.6 $\pm 0.3 \mathrm{mmHg} . \mathrm{ml} / \mathrm{g})$ than in untreated $\mathrm{t}-\mathrm{ACE}+/+$ mice $(1.4 \pm 0.2 \mathrm{mmHg} \cdot \mathrm{ml} / \mathrm{g})$. Thus, the impaired cardiac contractility observed in $\mathrm{t}-\mathrm{ACE}-/-$ mice is not due to an altered cardiovascular maturation, since prolonged pharmacological ACE inhibition started at 3 weeks of age induces a simillar impaired contractility. Stringent ACE inhibition reduces cardiac contractility even more than the lack of membrane-bound $\mathrm{ACE}$, which suggests that low levels of circulating angiotensin II in t-ACE - / mice ${ }^{22 t}$ are able to partly compensate for the reduced cardiac contractility. Angiotensin II has been shown to influence niyocyte contractility via several mechanisms. Angiotensin II is involved in $\mathrm{Ca}^{2+}$ handling of the myocyte either via activation of the $\mathrm{AT}_{1}$ receptor followed by the release of intracellular $\mathrm{Ca}^{24}$ or by increasing the myofilament affinity towards $\mathrm{Ca}^{2+298}$. Indirectly, angiotensin II may have a positive inotropic effect via the induction of other neurohormones such as noradrenaline ${ }^{360.301}$ and 1 GF- ${ }^{291}$, which are both known to stimulate the cardiac contractility ${ }^{310.31 !}$. In contrast, $\mathrm{NO}$ is known to reduce noradrenaline release. During $\mathrm{ACE}$ inhibition the bradykinin degeneration is impaired, leaving more bradykinin available to activate the bradykinin type 2 receptor and induce NO release ${ }^{3 / 2}$. Whether the lack of angiotensin II or the surplus of bradykinin is responsible for the reduction in cardiac 
contractility found in mice during pharmacological $A C E$ inhibition requires further investigation.

In conclusion, the reduced cardiac contractility observed in $1-A C E-1-$ mice is not due to the lack of $t-A C E$ during foetall development since prolonged $\mathrm{ACE}$ inhibition induced by captopril administration after the critical period of organogenesis reduced cardiac contractility in a similar way.

\section{Acknowledgements}

P.J.A. Leenders, N.J.J.E. Bitsch and A. Strzelecka are gratefully acknowledged for their technical assistance. 



\begin{abstract}
Ligation of the main left coronary artery is used in mice as a model for myocardial infarction (MT). We tested whether plasma concentrations of heart-lype fatty acid binding protein (H-FABP) and/or cardiac troponin $\mathrm{T}(\mathrm{CTnT})$ discriminate between infarcted and sham-operated mice and allow estimation of infarct size. Mice were subjected to coronary artery ligation or sham surgery and release-curves of H-FABP and $\mathrm{CTnT}$ were determined. At 4 h after surgery the mean $( \pm$ S.D) H-FABP plasma concentration was $46 \| 134 \mu \mathrm{g} /$ $(\mathrm{n}=10)$ in $\mathrm{MI}$ and 185 w $51 \mu \mathrm{g} / 1(\mathrm{n}=6 ; \mathrm{p}<0.001)$ in sham-operated mice. By $24 \mathrm{~h}$ after surgery H-FABP levels had returned to normal in both groups. cTnT plasma concentrations increase up to $48 \mathrm{~h}$ after $\mathrm{MI}$ to $13.5 \pm 6.2 \mu \mathrm{g} / \mathrm{l}(\mathrm{n}=6 ; \mathrm{p}<0.001)$ compared with $0.031 \pm 0.063$ $\mu \mathrm{g} / \mathrm{l}(\mathrm{n}=7)$ in sham-operated mice. Linear regression analysis revealed a significant correlation between plasma H-FABP at $4 \mathrm{~h}$ and infarct size assessed 7 days after surgery. In conclusion, plasma cTnT at $48 \mathrm{~h}$ after infarction can be used to distinguish MI from sham mice, whereas H-FABP concentration at $4 \mathrm{~h}$ can be used for stratification of animals according to infarcl size.
\end{abstract}




\title{
Heart fatty acid binding-protein and cardiac
}

\section{troponin $T$ plasma concentrations as markers}

for myocardial infarction after coronary

\section{artery ligation in mice}

\author{
Wendy M. Aartsen, M.M.A.S.L. Pelsers, W.T. Hermens, J.F.C. Glatz, M.J.A.P. Daemen \\ and J.F.M. Smits.
}

Pflugers Archives- European Journal of Physiology $2000439: 416-422$

\section{Introduction}

Permanent occlusion of the main left coronary artery in mice results in antero-apical infarcts with features such as ventricular dilation, wall thinning and septum hypertrophy which are highly comparable to those in rats ${ }^{313,314}$. In most experiments animals are stratified into groups with different interventions. To distinguish between sham-operated and infarcted animals and to construct groups with comparable infarct sizes at the start of each study, a method is needed that not only confirms the presence of myocardial infarction, but also quantifies infarct size. Ideally, both parameters should be available at an early time point. In patients, several criteria have been defined by the World Health Organisation $^{30}$ to diagnose acute myocardial infarction including electrocardiograph changes and increases in plasma concentrations of cardiac proteins. 
Clinically, the enzymes aspartate aminotransferase (ASAT), creatine kinase (CK) and lactate dehydrogenase (LDH) are being used as plasma markers for the detection of cardiac iniury. Although isoforms of $\mathrm{CK}$ and $\mathrm{LDH}$, like $\mathrm{CK}-\mathrm{MB}, \mathrm{LDH}_{1}$ and $\mathrm{LDH} \mathrm{H}_{2}$ are highly expressed in myocardium, these markers are not cardiac specific. Increased levels of these enzymes are also observed in clinical settings without myocardial injury (a.g. trauma and various inllammatory myopathies) ${ }^{120.121}$. Experimental MI after coronary artery ligation is complicated by skeletal muscle injury, which makes it necessary to use a more cardiac specific marker. Recently, plasma markers such as myoglobin, heart-type fatty acid-binding protein (H-F ABP) and cardiac troponin $\mathrm{T}$ and troponin $\mathrm{I}$ (c $\mathrm{Tm} \mathrm{T} / \mathrm{c} \mathrm{T} I$ ) have been introduced, allowing a faster and better diagnosis ${ }^{122-126,315}$. H-FABP and myoglobin are detectable in the circulation at th after the onset of anginal compliant, which makes them useful as early markers $^{316}$. Although $\mathrm{CTnT}$ and $\mathrm{CTnI}$ are slowly released into the circulation these markers are more specific for myocardial injury than $\mathrm{CK}$ and $\mathrm{LDH}^{322-325}$. Thus, both H-FABP (as an early marker) and cTnT/cTnI (as a specific marker) are potential candidates for biochemical determination of myocardial damage after experimental coronary artery ligation in mice.

FABPs are present in the cytoplasm of fatty acid utilising cells in liver, skeletal muscle and heart $^{32}$. They constitute a family of small proteins (14-16 kDa) involved in the cellular transport and metabolism of fatty acids ${ }^{329}$. Heart-type FABP is abundant in cytoplasm of myocardial cells ${ }^{327}$. Following cell damage due to acute myocardial ischaemia, H-FABP is rapidly released into the circulation, from which it is cleared unchanged by the kidneys. This makes it possible to determine H-FABP levels both in plasma and urine ${ }^{316,317,336}$. In humans, elevated plasma levels were found within $3 \mathrm{~h}$ after the onset of anginal complain. Moreover, in these patients a significant correlation was found between the amount of released H-FABP and the infarct size ${ }^{316}$. Similar results have been demonstrated after experimental MI in rats: significantly more H-FABP is found in 24 h urine from rats with Mil compared to sham-operated rais ${ }^{318}$.

Troponins are part of the contractile unit in muscle cells. The troponin complex contains three different troponin polypeptides: troponins $\mathrm{T}(37 \mathrm{kDa}), 1(24 \mathrm{kDa})$ and $\mathrm{C}(18 \mathrm{kDa})^{332}$. Troponin $T$ and troponin $\mathbb{I}$ can be used as cardiac specific markers, since the heart muscle expresses a unique troponin $\mathrm{T}$ and $\mathrm{I}$ isoform $(\mathrm{cTnT} / \mathrm{cTnI})^{333.332}$. CTn T and $\mathrm{Tn}$ Thave been evaluated for the diagnosis of myocardial injury. Increased cTnT and cTnI levels are found after $\mathrm{MI}^{319}$ and in nyocarditis ${ }^{320}$. In humans, rats and swine release kinetics of cTnT and CTnI have been compared to those of CK, LDH and myoglobin ${ }^{327}$. Data indicated that both markers are specilic tor cardiac injury and are superior to CK, LDH and myoglobin ${ }^{321-32.5}$. More recently O'Brien et al ${ }^{326}$ demonstrated that $c T n T$ is a useful marker to confirm doxorubicin induced myocardial damage in mice.

In the present study we investigated the possibility to estimate the infaret size by analysis of a single blood sample. To determine a suitable time point and to perform linear regression 
analysis between H-FABP or CTnT concentrations and the percentage of the lef ventricle infarcted, a short-term and long-term study were designed. In the short-term-study, Swiss mice were subjected to experimental coronary artery ligation followed by blood sampling and the measurement of H-FABP and CTnT plasma concentrations at 1, 2, 4 and $6 \mathrm{~h}$ after surgery. In the long-term study, Swiss mice were subjected to experimental coronary artery ligation and blood was sampled at 4,24 and $48 \mathrm{~h}$ after surgery. Hearts were fixed at 7 days after surgery and infarct sizes were determined histologically. Linear regression analysis was performed with biochemically determined marker levels. The data show that CTnT is a highly sensitive and specific marker for the detection of myocardial injury in mice. However, we found no correlation between cTnT plasma concentrations ( $48 \mathrm{~h}$ ) and infaret size. H-FABP plasma concentrations at $4 \mathrm{~h}$ correlated well with infarct size determined histologically at 7 days after surgery.

\section{Materials and methods}

\section{Animals}

Adult (10-week-o॥d) male, Swiss mice (Iffa Credo, The Netherlands) weighing between 35 $45 \mathrm{~g}$ at the time of surgery were used. Animals were housed in groups of 4 to 8 and had free access to standard food (SRMA-1210; Hope Farms, Woerden, The Netherlands) and tap water. All experiments were conducted according to institutional guidelines and conformed to the guide for the care and use of laboratory animals, published by the US National Institutes of Health (NIH Publication No 85-23, revised 1996).

\section{Experimental design}

Two types of experiments were conducted. The short-term study was designed to estimate the time-rellease curve of H-FABP and cTnT. For this, the aorta was cannulated and blood was sampled at $1,2,4$ and $6 \mathrm{~h}$ after surgery. The long-term study was designed to analyse the correlation between a single blood sample and the eventual infarct size at 7 days after surgery. In the long-term study animals were subjected to surgery followed by blood sampling via puncture of the orbital plexus at 4,24 and $48 \mathrm{~h}$ after surgery. The hearts were fixed at 7 days after surgery and infarct size was determined.

\section{Coronary artery ligation}

The method to establish $\mathrm{MI}$ in mice has been described elsewhere ${ }^{3 / 3 / 4}$ "Briefly, the animal was anaesthetised with pentobarbitone sodium (110 $\mathrm{mg} / \mathrm{kg}$ i.p.), the trachea was intubated and connected to a pressure-cycled ventilator $(1.5-2 \mathrm{ml}, 70 / \mathrm{min})$. After opening the skin, the left 4 th intercostal space and the pericardial sac, a ligature (6-0 prolene) was tied around 
the main left coronary artery. Then chest and skin were closed with 5-0 silk sutures under application of gentle pressure on both sides of the thorax to remove air, after which the animal was allowed to recover. Sham surgery was performed identically except for the ligature around the left coronary artery.

\section{Blood sampling}

During the same surgical session, a catheter (PE 25 tubing) was implanted into abdominal aorta via the femoral artery. The saline-filled catheter was exteriorised in the neck and elosed with a metal plug. Blood samples $(200 \mu 1)$ were collected in heparinised tubes at 1 , 2, 4 and $6 \mathrm{~h}$ after ligation; samples were replaced by equal volumes of saline. In the longterm study, blood was obtained by puncture of the orbital plexus under ether anaesthesia at 4,24 and $48 \mathrm{~h}$ after surgery. After centrifugation of the blood for 10 minutes at $10000 \mathrm{xg}$, plasma was stored at $-20^{\circ} \mathrm{C}$ until assayed for $\mathrm{H}-\mathrm{FABP}$ and $\mathrm{cTnT}$ concentration.

\section{Immunoassay for H-FABP}

A sandwich enzyme linked immunosorbent assay (ELISA) for rodent H-FABP was provided by Hycult Biotechnology, Uden, The Netherlends ${ }^{315}$. In short, $50 \mu$ of the second monoclonal antibody against H-FABP (conjugated with horseradish peroxidase, HRP) and $50 \mu \mathrm{l}$ of either the diluted plasma or the H-FABP standards $(0-25 \mu \mathrm{g} / 1)$ were added first to the pre-coated plate. After incubation for $3 \mathrm{~h}$ at room temperature, the wells were washed 4 times with $200 \mu \mathrm{l}$ buffer followed by the addition of $100 \mu \mathrm{l}$ substrate solution. After $15 \mathrm{~min}$ the reaction was stopped by adding $100 \mu 1$ stop solution and the absorbance at $450 \mathrm{~nm}$ was measured using a Titertek Multiscan MKII microplate reader. The detection limit of the assay was $0.1 \mu \mathrm{g} / \mathrm{H}-\mathrm{FABP}$ and the inter-and intra-assay analytical imprecision were below $10 \%$.

Immunoassay for cardiac troponin $T$

Plasma cTnT concentrations were determined using the second-generation cTnT enzymlinked immunoassay (Enzymun-test Troponin-T; Boehringer Mannheim Corp., Indianapolis, Ind) ${ }^{122}$. Undiluted plasma $(50 \mu 1)$ and standards $(0-18.8 \mu \mathrm{g} / 1)$ were added to the wells of polyvinyl microtitre plates precoated with streptavidin. Then $200 \mu l$ phosphate buffer (40mM; pH7.0) containing both biotinylated anti-troponin-T antibodies M7 (1.5 ming/) and HRP labelled anti-troponin-T antibody M11.7 (>100 U/L) were added, followed by an incubation of 1 hour at room temperature. According to the manufacturer's instructions, the wells were washed 3 times with sodium perborate $(3.2 \mathrm{mM}, 2,2$-azino-bis 3-ethylbenzothiazoline-6-sulfonate substrate ( $1.9 \mathrm{mM}$ in $0.1 \mathrm{mM}$ phosphate buffer) was added and after 15 minutes of incubation, the absorbance was measured at $405 \mathrm{~nm}$ using a Titertek Multiscan MKII microplate reader. 


\section{Measurement of infarct size}

One week after surgery all animals were killed by an overdose of pentobarbitone sodium. Hearts were weighed and fixed in $10 \%$ phosphate buffered formalin for $24 \mathrm{~h}$. After fixation the hearts were cut longitudinally through the left and right ventricles, dehydrated and paraffin embedded. Sections of $4 \mu \mathrm{m}$ were cut from both heart halwes and stained with the AZAN technique. These sections were analysed by computerised morphometry system (Quantimet 570, Leica, The Netherlands). MI size was measured as percentage of the left ventricle circumference, taking the average of both heart halves ${ }^{313}$.

\section{Statistics}

Data are presented as mean \pm S.D. Sensitivity and specificity are calculated from the longterm study. Sensitivity was defined as the percentage of correctly diagnosed infaretions. Specificity was defined as the percentage of correctly diagnosed non-infarctions. The positive predictive value is defined as the percentage of correct positive tests and the negative predictive vallue as the percentage of correct negative tests. Statistical analysis was performed using unpaired Student's $t$-tests or Mann-Whitney $U$ test when normality test failed and linear regression analysis. Statistical significance was accepted if $p<0.05$.

\section{Heart Fatty Acid-Binding Protein}

\section{Cardiac Troponin $\mathbf{T}$}
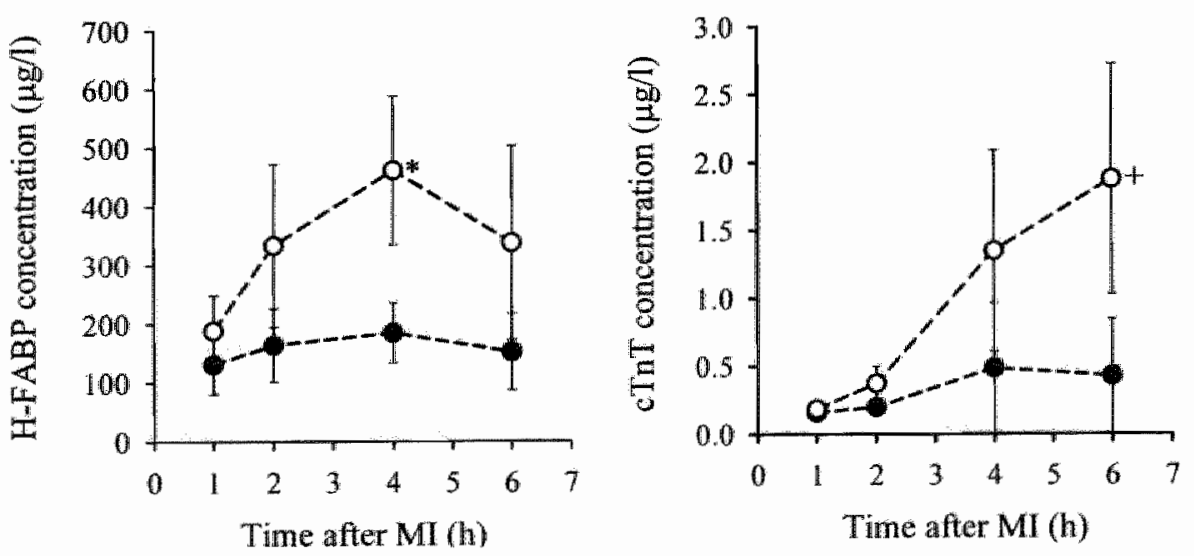

Figure 1. Short-term study: plasma heart-type farty acid-binding protein (H-FABP, left panell) and cardiac troponin T (cTnT, right panel) concentrations measured at $1,2,4$ and $6 \mathrm{~h}$ after coronary artery ligation causing myocarclial infarction (MD) in mice. Mean \pm SD sham-operated (solid circles; $n=6$ ); Me (open circles; $n=10$ ) mice, $+p<0.05, * 0.0001$ 


\section{Resilts}

\section{General}

A total of 53 animals were subjected to surgery. For the short-term study 9 animals were sham-operated of which $8(89 \%)$ survived; 15 animals were subjected to coronary artery ligation of which $11(73 \%)$ survived. These animals were cannulated for blood sampling at $1,2,4$, and $6 \mathrm{~h}$ after surgery. Animals were under anaesthesia until approximately $3 \mathrm{~h}$ after surgery. Animals that had not regained consciousness at $4 \mathrm{~h}$ after surgery (two shamoperated and one MI) were exclude and died within $24 \mathrm{~h}$, leaving six sham-operated and ten infarcted mice included in the short-term study.

For the long-term study 9 of the 10 sham-operated animals survived (90\%) and 10 of the 19 animals subjected to coronary artery ligation survived $(53 \%)$. One infarcted mouse failed to regain consciousness after $4 \mathrm{~h}$ and was excluded. Thus for the later time-points nine shamoperated animals and nine animals with MI were re-anaesthetised with ether to perform puncture of the orbital plexus at 4,24 and 48 h after surgery.

\section{Heart Fatty Acid-Binding Protein}

\section{Cardiac Troponin T}
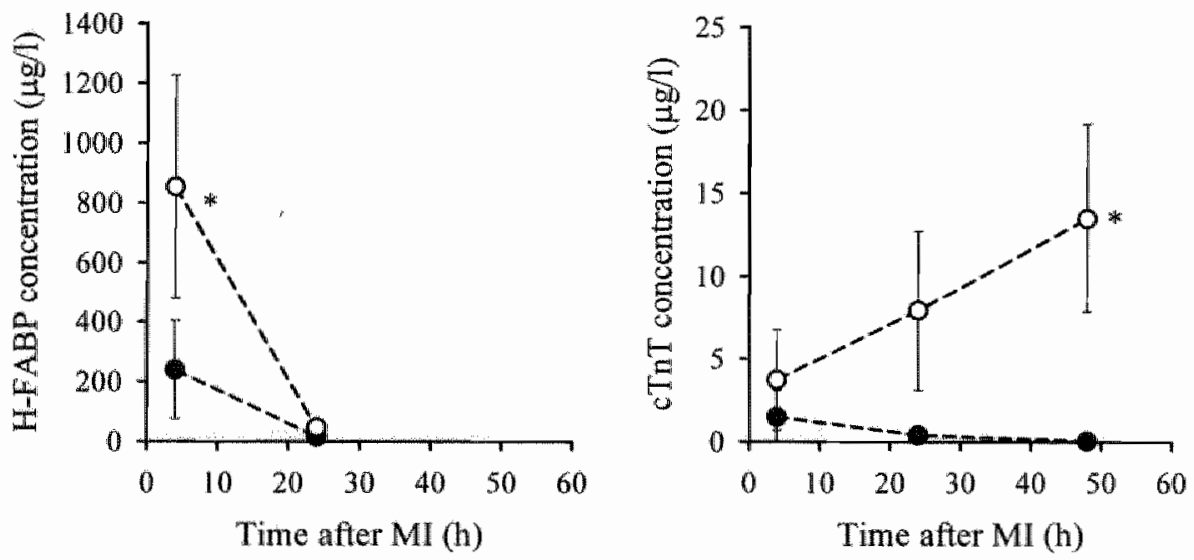

Figure 2. Long-term study: plasma heart fatty acid-binding protein (H-FABP, left panel) and cardiac troponin T (cTnT, right panel) concentrations measured at 4,24 and $48 \mathrm{~h}$ after coronary artery ligation causing myocardial infarction (MI) in mice. Mear \pm SD sham-operated (solid circles; $n=9$ ); MI (open circles; $n=9$ ) mice, $+p<0.05, * 0<0.001$. 


\section{H-FABP plasma concentrations}

The time-course of plasma H-FABP after MI is shown in figure 1 . Within 2 h after surgery H-FABP plasma concentration was above control $(33 \pm 28 \mu g /)$ and peak levels of HFABP were measured at $4 \mathrm{~h}$. At that time significantly higher concentrations were measured in animals with MI compared than in sham-operated animals ( $461 \pm 134 \mu \mathrm{g} / \mathrm{l}$ and $185 \pm 51 \mu \mathrm{g} / \mathrm{l}$ respectively, $\mathrm{p}<0.05$ ). In the long-term experiment (figure 2), plasma $\mathrm{H}$ FABP raised in both sham and MI animals. Again significant difference was observed between H-FABP concentrations of sham-operated and MI animals at 4 h. H-FABP plasma concentrations of both groups returned to baseline level at $24 \mathrm{~h}$ after surgery. In hearts from animals included in the second experiment, infarcted areas were measured as percentages of the left ventricle. The infarct sizes were between $29.9 \%$ and $59.5 \%$ of the left circumference and the infarct size correlated significantly $(\mathrm{p}=0.02)$ with plasma H-FABP concentrations measured at $4 \mathrm{~h}$ (figure 3). Using H-FABP as a marker for $\mathrm{MI}$ in mice, a sensitivity of $78 \%$ and a specificity of $89 \%$ was reached. The positive predictive value of this test was $88 \%$ and the negative predictive value $80 \%$.

\section{Heart Fatty Acid-Binding Protein}

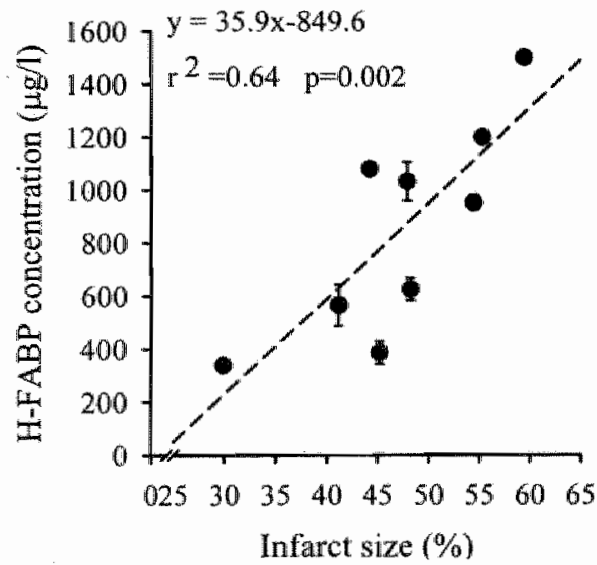

Cardiac Troponin T

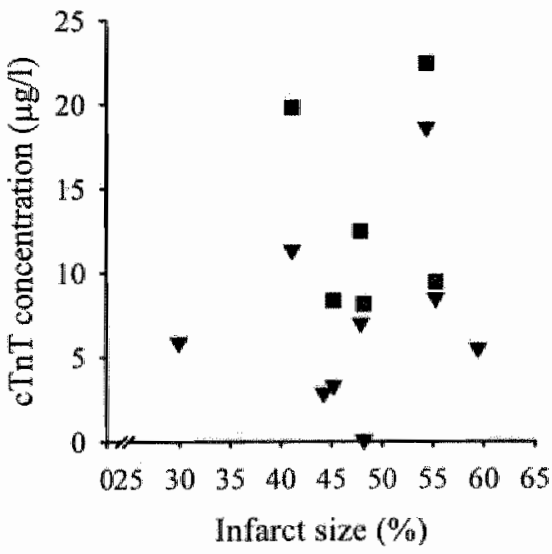

Figure 3. Relationship between infarct size and plasma concentration of H-FABP (left panel) and cTnT (right panel). Left panel: linear regression anallysis of the plasma H-FABP concentration at 4 $h$ after MI, derived from two separate ELISA measurements (mean $\pm \mathrm{SD}$; solid circles) and the percentage of the left ventricle infarcted. Right panel: lack of correlation between the plasma cTht concentration at 24 (solid triangles) and 48 (solid squares) h after $M I$ and the percentage of the left ventricle infarcted, measured at 7 days after $M$ I. 


\section{Cardiac TnT plasma concentrations}

cTnT plasma concentrations were increased in both groups whithin $6 \mathrm{~h}$ after surgery and at 6 h a significant differences were found between mice with $M I(n=10)$ and sham operated animals ( $n=4$, figure 1). In the long-term experiment, plasma cTnT concentration in sham operated nice $(\mathrm{n}=9)$ returned to baseline level $(0.031 \pm 0.063 \mathrm{ng} / \mathrm{ml})$ after $24 \mathrm{~h}$ while mean CTnT plasma concentration of infarcted animals $(n=9)$ continued to increase up to $48 \mathrm{~h}$ after MI $(13.46 \pm 6.21 \mathrm{ng} / \mathrm{ml} ; \mathrm{n}=9$, figure 2). Plasma cTnT did not correlate with the infarct size at either time point. Nevertheless, cTnT measured at $48 \mathrm{~h}$ after $\mathrm{MI}$ in mice is a highly sensitive $(100 \%)$ and specific $(100 \%)$ marker for the presence of myocardial injury. As test for myocardial injury, eTnT concentration at $48 \mathrm{~h}$ after MI had both positive and negative predictive values of $100 \%$

\section{Discussion}

Previous results indicated that ligation of the main left coronary artery in mice results in remodelling of the heart comparable to that observed in rats ${ }^{3 / 3,3 / 4}$. The early recognition of successfully infareted animals and the non-invasive estimation of infarct size is a major problem in studies on the effects of interventions on cardiac function and remodelling. Therefore, we sought a method to allow assessment of cardiac necrosis in mice early after coronary artery ligation. The results indicate that cTnT plasma concentration at $48 \mathrm{~h}$ after surgery is a highly specific and sensitive indicator for the presence of cardiac necrosis. In addition, plasma H-FABP concentration at $4 \mathrm{~h}$, although less sensitive and specific, correlates with infarct size.

In humans, elevated plasma H-FABP levels are found within $3 \mathrm{~h}$ after the onset of anginal compliant. Moreover, in these patients a significant correlation is found between the amount of released H-FABP and the infarct size "Similar results were obtained in the present study. At $4 \mathrm{~h}$ after surgery, H-FABP plasma concentrations were significantly increased in mice with histologically verified infarcts compared to sham-operated animals. Within $24 \mathrm{~h}$, H-FABP plasma levels had returned to baseline level. The increased H-FABP concentrations in sham-operated animals are most likely explained by H-FABP expression in the skeletal muscle ${ }^{30,3,1}$. Since H-FABP concentrations measured at 4 h after surgery correlate with the extent of infarction established histologically at 7 days after surgery, it is possible to estimate infarct size within a few hours after surgery.

In patients suffering myocardial infarction, $c T n T$ and cTnll serum levels are increasing within $6 \mathrm{~h}$ after the onset of chest pain and remain elevated for at least 4 days ${ }^{120,127,334}$. In the present study we measured plasma cTnT concentrations until $48 \mathrm{~h}$ after surgery and mice with MI exhibited steadily increasing cTnT plasma levells up to $48 \mathrm{~h}$. The slightly 
elevated levels in sham-operated animals may have been caused by cross-reactivity of the antibody with skeletal muscle $\operatorname{TnT}$. Due to its prolonged elevated plasma levels, eTnT is a late (48 h after MI) but very sensitive (100\%) and specific (100\%) plasma marker. Despite this, no correlation was found between the infarct size and $\mathrm{c} T \mathrm{nT}$ concentrations measured at 4,24 or $48 \mathrm{~h}$ after surgery.

Higher concentrations for both H-FABP and $\mathrm{CTnT}$ were consistently found in the long-term study compared to the short-term study. The reason for this discrepancy is not clear, but could derive from the different methods used to collect the blood samples. Due to these difference the results should be interpreted separately. Only the H-FABP and cTnT concentrations obtained from the long-term study, in which blood was obtained by puncture of the orbital plexus were related to infarct size.

There are several possible explanations for the apparent lack of correlation between infarct size and the plasma concentration of cTnT. The applicability of measurements of cardiac proteins in plasma as indicators for cardiac injury depends upon several assumptions. Firsily, the protein studied must be of (preferential) cardiomyocyte origin. Secondly, it must be contained within the cell under normal conditions and leak out upon cell death. This is the case for both H-FABP and cTnT. Independent of the rate of leakage, the plasma concentration-time integral of a protein that originates exclusively from cardiomyocytes will depend on the number of myocytes that expel their cytoplasm and the concentration of the particular protein therein. Assuming that the latter is constant, the integral should reflect the extent cell death. However, the small blood volume in mice prohibits frequent sampling which is required to determine the integral. Alternatively, if the protein studied is excreted via the kidneys, quantitative collection of urine over a prolonged period would allow measurement of the total amount of protein expelled. Again, the small amount of concentrated urine secreted by mice makes this approach impractical. Measurement of a plasma concentration at a single time point is practical, but the predictive value of such measurements depends upon the kinetics of release into, and excretion from plasma. The former depends upon diffusion and thus the rate of leakage is negatively correlated with the size of the molecule. Since cTnT is about 2.5 times larger than H-FABP it may be expected to enter the circulation more slowly than the latter. Leakage of $\mathrm{cTnT}$ is further slowed by the fact that only approximately $5 \%$ is present in a free form; most $\mathrm{cTnT}$ is complexed within the cardiomyocytes ${ }^{35.336}$. As demonstrated in this study H-FABP plasma concentrations are more rapidly normalised compared to $\mathrm{cTnT}$ suggesting that the clearance rate of H-FABP is much higher. Katus et al ${ }^{335,337}$, on the other hand, have suggested that the serum half-life of cTnT in humans is only $2 \mathrm{~h}$. Together with the fact that mice with myocardial infarction had increasing $\mathrm{cTnT}$ plasma concentrations until $48 \mathrm{~h}$ after surgery and sham-operated animals returned to baseline levels within $24 \mathrm{~h}$ suggests ongoing release of $\mathrm{cTnT}$ rather than very slow clearance kinetics. Hence, a single determination of the $\mathrm{cTn} T$ 
plasma concenstration should be less sensitive to differences in the extent of the infarct than the rapidly released and cleared H-F ABP. Aitematively, it has been suggested that cTnT is not only released into the circulation in its free form, but may circulate as a complex with cTnI and/or $\mathrm{eTnC}^{3.4}$. To detect all cTnT released from the heart after MI, antibodies employed should be capable to recognize both free and complexed $c \operatorname{Tn} \mathbb{T}$. Whether this is the case for the antibodies used in this study is unknown.

The present study describes a method for estimating the experimentally induced infarct size in mice with a single blood sample. Before stratification of the animals into different groups it is often usseful to know if the induced coronary artery ligation has been succesful. Both $\mathrm{H}$ FABP and CTnT can be used as plasma markers of myocardial damage in mice after experimentally induced MII. H-FABP plasma concentration at $4 \mathrm{~h}$ after surgery correlates with the infarct size measured hilstologically at 7 days after MI. cT T plasma concentration at $48 \mathrm{~h}$ after surgery does not relate to infarct size, but may serve as a very reliable qualitative marker.

\section{Acknowledgements}

The authors wish to thank J.J.M Debets, P.J.A. Leenders, N.I.J.E. Bitsch and M.L.L.. Mullers-Boumans for their technical assistance. We wish to thank Hycult Biotechnology, Uden, for providing reagents. This study was supported in part by the Ministry of Economic Affairs; grant BTS 97.188 
" 


\section{Abstract}

Angiotensin II, generated from angiotensin I by angiotensin-I-converting enzyme (ACE), induces multiple effects including vasoconstriction, positive cardiac inotropy, hypertrophy of cardiomyocytes and proliferation of filbroblasts. ACE exists both in a membrane-bound $(\mathrm{t}-\mathrm{ACE})$ and a soluble form. The functional importance of locally produced angiotensin II is still unclear. In the present study, mice lacking membrane-bound angiotensin-I-converting enzyme (t-ACE - /) were used to investigate the importance of $\mathrm{t}-\mathrm{ACE}$ during cardiac remodelling after myocardial infarction. Mice were subjected to coronary artery occlusion or sham surgery. At 14 days after MI, stroke volume (SV) was determined with an electromagnetic flow probe around the ascending aorta. Mean arterial pressure (MAP) was measured through a cannula in the abdominal aorta. Both parameters were determined at rest and after a volume loading of $2.5 \mathrm{ml}$ warm $\left(37^{\circ} \mathrm{C}\right)$ Ringer's solution in 60 seconds. Hearts were dissected and formalin-fixed to measure infarct size, cardiac dimensions and collagen concentration. Tissue levels of angiotensin I and II were determined in hearts and kidneys. At rest, under pentobarbital anaesthesia $\mathrm{t}-\mathrm{ACE}$ - - mice $(\mathrm{n}=12)$ exhibited a significantly lower MAP $(26 \pm 3$ vs. $45 \pm 3 \mathrm{mmHg})$ than $\mathrm{t}-\mathrm{ACE}+1+(\mathrm{n}=11)$. SV was similar in both strains. Maximal SV was significantly reduced after MI. Furthermore, infarcted tACE $-1-(n=6)$ exhibited a significantly lower maximal SVcompared to infarcted $t-A C E+1+$ mice $(n=5 ; 20.4 \pm 1.5$ vs. $29.6 \pm 2.3 \mu \mathrm{l})$. Structural cardiac parameters as well as cardiac and renal angiotensin $\mathrm{II}$ levels in $\mathrm{t}-\mathrm{ACE}-/-$ and $\mathrm{t}-\mathrm{ACE}+/+$ were comparable. These results suggest that the structural adaptations of the heart that follow MI are independent of $\mathrm{t}-\mathrm{ACE}$. However, the presence of $\mathrm{t}-\mathrm{ACE}$ is necessary for maintenance of cardiac function. 


\section{The role of locally expressed angiotensin-I-}

\section{converting enzyme in cardiac remodelling after myocardial infarction in mice}

Wendy M. Aartsen, M.P. Schuijt, A.H.J. Danser, M.J.A.P. Daemen and J.F.M. Smits.

Cardiovascular research 2002 56: 205-213

Introduction

Treatment with angiotensin-I-converting enzyme (ACE) inhibitors is a comerstone of therapy following myocardial infarction $(\mathrm{MI})^{33 s}$. However, the exact mechanism through which quality of life and survival are improved is still debated. Beneficial effects on cardiac contractility have even been found with low-dose ACE inhibition without reduction of blood pressure ${ }^{223}$, which suggests the involvement of tissue ACE.

After MI, the myocyte loss is followed by invasion of inflammatory cells and fibroblasts. Collagen deposition by these fibroblasts and hypertrophy of the remaining myocytes firstly compensate for the myocyte loss but may eventually lead to heart failure ${ }^{133}$. During these processes both the cardiac and circulating renin-angiotensin system (RAS) activities are enthanced. ${ }^{144,147,150,166,330}$. Elevated ACE levels have been shown at the site of wound healing in diverse tissues ${ }^{3 \neq 0}$. Also early after MI, ACE expression is found on endothelival cells, fibroblasts and macrophages ${ }^{149}$. Here, ACE can contribute to the local angiotensin II generation and bradykinin degeneration. Both peptides can participate in the processes of 
inflammation and wound healing. Angiotensin II can act, independently of blood pressure, as a growth factor for cardiomyocytes and fibroblast ${ }^{341}$. Bradykinin is a proinflamuatory puptide ${ }^{342}$. Since both the $A T_{1}$ receptor and the $B K_{2}$ receptor are expressed at the infarction site, and blockade of either of these receptors leads to changes in cardiac wound healing ${ }^{34} \cdot 3: 344$, the local ACE availability may be involved in cardiac remodelling after MI: Recently, by using the membrane-bound ACE knockout mouse $(t-A C E ~ \%)^{107}$, we demonstrated a reduction in pulmonary artery remodelling after chronic alveolar hypoxia ${ }^{345}$. This $\mathrm{t}$-ACE - - mouse model is used in the present study to investigate to what extent local $\mathrm{ACE}$ activation contributes to the structural and functional adaptations that occur after MII.

ACE is an enzyme bound to the cell membrane, that can be enzymatically cleaved producing the soluble form of $\mathrm{ACE}^{345}$. To investigate the role of membrane-bound $\mathrm{ACE}$ on cardiac function and structure after MI we used 1 -ACE knockout mice generated by Esther et al ${ }^{107}$. This transgenic mouse model has a genetically modified ACE gene, that leads to the formation of ACE lacking the C-terminal part of the enzyme, leaving only the N-terminal active site. Thus, only soluble ACE is expressed in mice carrying two alleles for the mutation (t-ACE - - - ) T-ACE $-/$ - mice and their wild-type littermates $(\mathrm{t}-\mathrm{ACE}+/ \mathrm{t})$ were subjected to chronic coronary artery ligation or sham surgery. Structural and functional measurements were performed at 14 days and 3 months after $\mathrm{MI}^{1 / 1,34}$. No significant structural differences were found in infarcted mice lacking $\mathrm{t}-\mathrm{ACE}$ when compared to their wild-type littermates. However, they exhibited a remarkable functional adaptation to MI.

\section{Materials and Methods.}

Animals

The generation of mice with a $\mathrm{C} 57 \mathrm{BL} 6 / 129 / \mathrm{SV}$ genetic background and lacking membranebound angiotensin-1-converting enzyme ( $\mathrm{t}-\mathrm{ACE}-/-)$ has been described by Esther et al ${ }^{107}$. Mice that were heterozygous for the mutated $A C E$ allele $(1-\mathrm{ACE}+H-)$ were bred to obtain mice that were homozygous for the mutated ACE allele ( $\mathrm{t}-\mathrm{ACE}-\mathrm{f}-)$ and their wild-type littermates $(\mathrm{t}-\mathrm{ACE}+1+$ ). All animals were housed in groups of 4 to 6 and had free access to standard food (SRMA-1210; Hope Farms, Woerden, The Netherlands) and tap water. The study was started when the mice were between 12 and 16 weeks old, at that time the animals weighed $26 \pm 2$ grams. All experiments were conducted according to institutional guidelines and conformed to the guide for the care and use of laboratory amimals, published by the US National Institutes of Health (NIH Publication No 85-23, revised 1996). 


\section{Genotyping}

To genotype the newly bred pups, a small part of the tail was cut off and genomic DNA was isolated. DNA was extracted according to the manufacturer of the Qiagen DNA isolation kit (Qiagen GmbH, Hilden, Germany). PCR analyses of the genomic DNA were performed using the primers sets described by Esther et al. ${ }^{107}$. $1.5 \mu$ of genomic DNA was added to the ready-to-go PCR beads (Amersham Pharmacia Biotech) diluted in $23.5 \mu \mathrm{l}$ water containing $1.5 \mathrm{U}$ Taq DNA polymerase, $10 \mathrm{mM}$ Tris-HCl, $50 \mathrm{mM} \mathrm{Kcl}, 1.5 \mathrm{mM}$ $\mathrm{MgCl}_{2}, 200 \mu \mathrm{M}$ of each dNTP and $200 \mathrm{nM}$ of each primer.

\section{Experimental myocardial infarction}

Experimental myocardial infarction was induced according to a method described previously ${ }^{333}$. Briefly, the mouse was anaesthetised with xylazine $(5 \mathrm{mg} / \mathrm{kg}$ s.c.) and ketamine (100mg/kg i.m.). While the mouse was fixed on its back, the trachea was intubated (1.1 $\mathrm{mm}$ stainless steel) to allow positive pressure respiration with room air (1.5$2 \mathrm{ml}, 70 / \mathrm{min})$. A ligature (6-0 prolene) was tied around the main left coronary artery after opening the skin, the left 4 th intercostal space and the pericardial sac. Then chest and skin were closed with 5-0 silk sutures under application of gentle pressure on both sides of the thorax to remove air, after which the animal was allowed to recover at $30^{\circ} \mathrm{C}$. Sham surgery was performed identically, except that the ligature around the left coronary artery was not tied.

\section{Tissue processing}

At 14 days or 3 months after surgery animals were sacrificed after cardiac functional measurements by injecting cadmium chloride $\left(\mathrm{CdCl}_{2} ; 0.1 \mathrm{M}\right)$. Hearts of the t-ACE mice were dissected at 14 days and 3 months after surgery. At a pressure of $100 \mathrm{mmHg}$, the animals were perfused with phosphate buffer (PBS; pH 7.4) containing $0.1 \mathrm{mg} / \mathrm{ml}$ sodium nitroprusside through a meedle in the left ventricle. After 3 minutes, the perfusion solution was replaced by $5 \%$ formalin in PBS, which was infused for another 3 minutes. Heart, lung and liver were dissected and weighed, followed by formalin ( $10 \%$ in PBS) fixation for $24 \mathrm{~h}$. The heart was then cut longitudinally through the left and right ventricles and both halves were paraffin embedded following routine histological procedures, after which $4 \mu \mathrm{m}$ sections were prepared for morphometry.

\section{Morphometry}

Infarct size, left ventricle diameter, septum and infarct thickness were all determined using a computerised morphometry system (Quantimet 570, Leica, the Netherlands). Sections from both heart halves were stained with the AZAN technique to distinguish between collagen and heart muscle. In a section from the centre of the infarct, infarct size was 
measured as the percemtage of the left ventricular circumference. On the same section, left ventricular circumference, septal and infarct areas were measured. Left ventricular diameter was calculated by dividing the inner circumference by $\pi$ assuming a circular shape for the left ventricular lumen. Septal and infarct thickness were estimated dividing the areas by their average length ${ }^{33.344}$.

\section{Collagen content}

Sections from both heart halves were deparaffinised and incubated in phosphomolybdic acid $(0.2 \%)^{34 \%}$ for 5 minutes, followed by incubation with a Sirius red $(0.1 \%)$ in saturated picric acid solution for 90 minutes. After washing with $0.01 \mathrm{M} \mathrm{HCl}$ for 2 minutes, the sections were dehydrated and protected with coverslips. Under the microscope (magnification $400 \mathrm{x}$ ) the collagen content was measured in the middle of the right ventricular, left ventricular and septum walls. For each area, six optical fields from both heart halves were analysed for the relative collagen content using a computerised morphometry system (Quantimet 570, Leica). Collagen present around vessels and endocardium was excluded from the total amount of Sirius red positive tissue, so only interstitial collagen was determined.

\section{Measurements of cardiac function}

Haemodynamic measurements were performed at 14 days and 3 months after MI. The animal was anaesthetised with pentobarbital sodium $(110 \mathrm{mg} / \mathrm{kg}$ i.p.), followed by intubation of the trachea $(1.1 \mathrm{~mm}$ stainless steel) to allow positive pressure respiration with roon air $(1.5-2 \mathrm{ml}, 70 / \mathrm{min})$. While the mouse was lying on a heating-pad, its body temperature was kept at $37^{\circ} \mathrm{C}$. To measure mean arterial blood pressure (MAP) a saline filled catheter (PE 25) was placed in the abdominal aorta via the femoral artery and connected to a pressure transducer (micro-switch, model 156PC $156 \mathrm{WL}$, Honeywell Inc., Amsterdam, the Netherlands Amsterdam, the Netherlands). Another catheter (PE 10) was placed the jugular vein for injections. The third right intercostal space was then opened and the ascending aorta was dissected firee from the surrounding tissue. An electromagnetic flow probe (1.0mm, Skalar, Delft, The Netherlands) was placed around the arorta just above the heart to measure stroke volume (SV) and heart rate (HR) from which cardiac output (CO) was calculated. MAP and CO were determined at rest for at least 10 minutes. The circulation was then loaded by infusion of $2.5 \mathrm{ml}$ warm $\left(37^{\circ} \mathrm{C}\right)$ Ringer's solution in $\mathbb{1}$ minute and maximal values for $\mathrm{SV}$ and $\mathrm{CO}$ were recorded. Thereafter, the heart was arrested in diastole through infusion of $0.5 \mathrm{ml}$ cadmium chloride $\left(\mathrm{CdCl}_{2} ; 0.1 \mathrm{M}\right)$ 
Tissue angiotensin concentrations

Adult $t-A C E$ mice were sacrificed with an overdose of pentobarbital. Hearts and kidneys were isolated and snap-frozen in liquid nitrogen. Angiotensin (Ang) $Y$ and II were measured in cardiac and renal tissue as described previously, using SepPak extraction and highperformance liquid chromatography separation ${ }^{349}$. For each measurement, hearts or kidneys of 3-4 animals were pooled. ${ }^{125} \mathrm{I}$-Ang I was added prior to the extraction procedure, to correct for llosses during extraction and separation. The concentration of ${ }^{125} \mathrm{~L}$-Ang I and the concentrations of tissue Ang I and II in the HPLC eluate fractions were measured by gamma counting and radioimmunoassay respectively. The lowest concentration that could be measured was 2 fmol/g for Ang I and 1 fmol/g for Ang II.

\section{Statistics}

Angiotensin I and II levels are shown in a box plot. Haemodynamic and histological data are shown as means \pm SEM. The impact of the genetic modification and the surgery were tested in a two-way analysis of variance, followed by Fisher's LSD test to correct for unequal group sizes. Statistical significance was accepted if $p<0.05$.

\section{Results}

\section{General}

For the study at 14 days after MI, $35 \mathrm{t}-\mathrm{ACE}-/$ and $24 \mathrm{t}-\mathrm{ACE}+/+$ mice were subjected to surgery. Seven of twenty-five $t-A C E-/-$ mice $(28 \%)$ survived occlusion of the main left coronary artery whereas seven of ten $\mathrm{t}-\mathrm{ACE}-/-$ mice $(70 \%)$ survived the sham operation. The wild-type littermates $(t-\mathrm{ACE}+1+$ ) were less susceptible to the surgery. A total of 24 animals was subjected to surgery of which $64 \%$ (nine out of fourteen) survived coronary artery occlusion and $90 \%$ (nine out of ten) survived the sham surgery. All $t-A C E$ mice that had survived surgery were used to determine cardiac perfornance. One infarcted $\mathrm{t}-\mathrm{ACE}-/$ and one sham-operated $\mathrm{t}-\mathrm{ACE}-/$ - died during preparation for these measurements, while four infarcted and three sham-operated wild-type littermates did not complete this procedure. HW/BW ratios from animals used in the haemodynamic measurements are summarised in Table 1 and 3 . Although the $H W / B W$ ratio was increased at 14 days after myocardial infarction in both $\mathrm{t}-\mathrm{ACE}+/+$ and $\mathrm{t}-\mathrm{ACE}-\%$, these increases were not significantly different from the ratios measured in sham-operated mice. During the 3 months, HW/BW ratios increased further and became significantly different from the sham ratios in $t-A C E H+$ mice, while $t-A C E-/$ - mice showed a trend to increased $H W / B W$ ratio. (Table 1). 


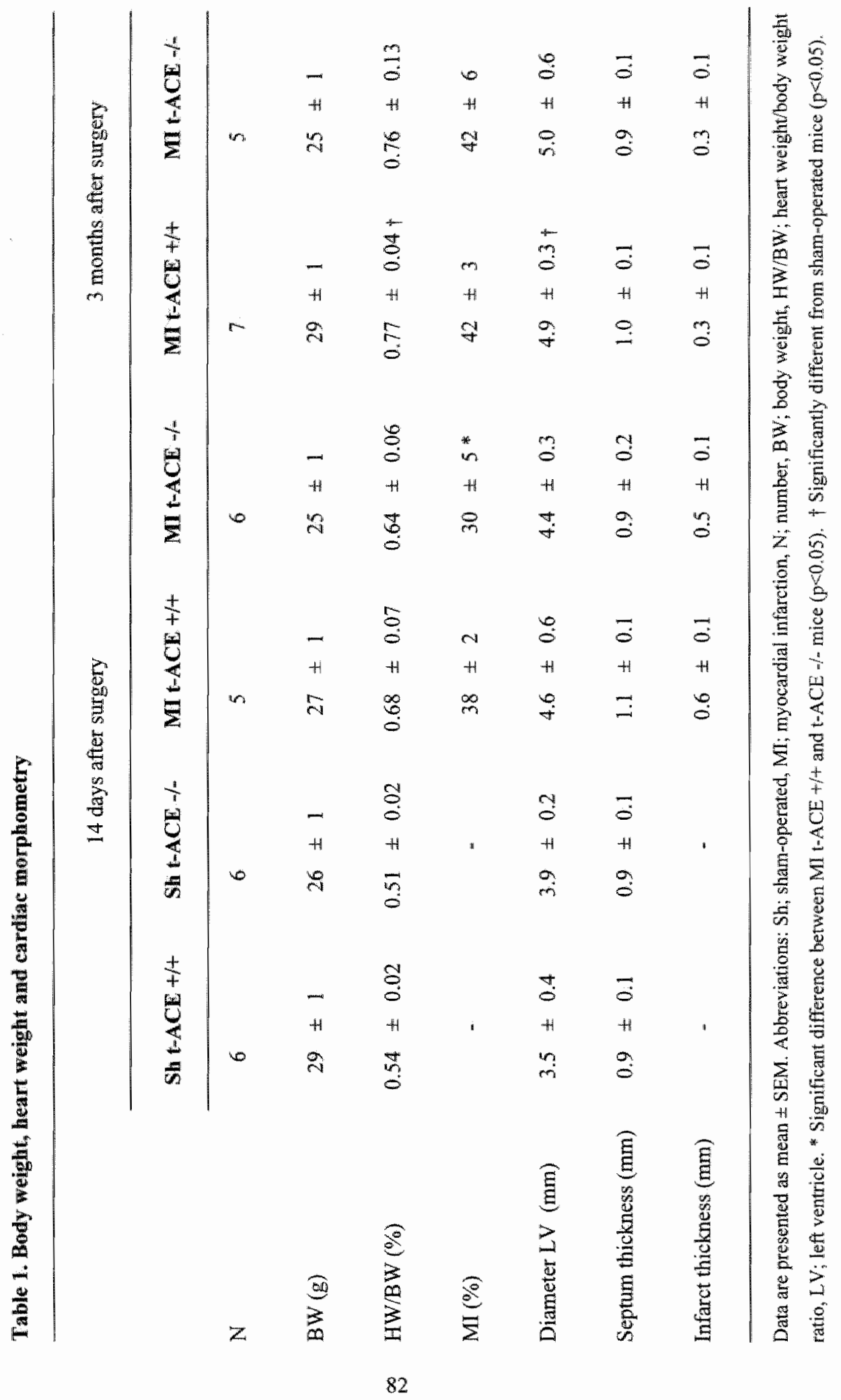




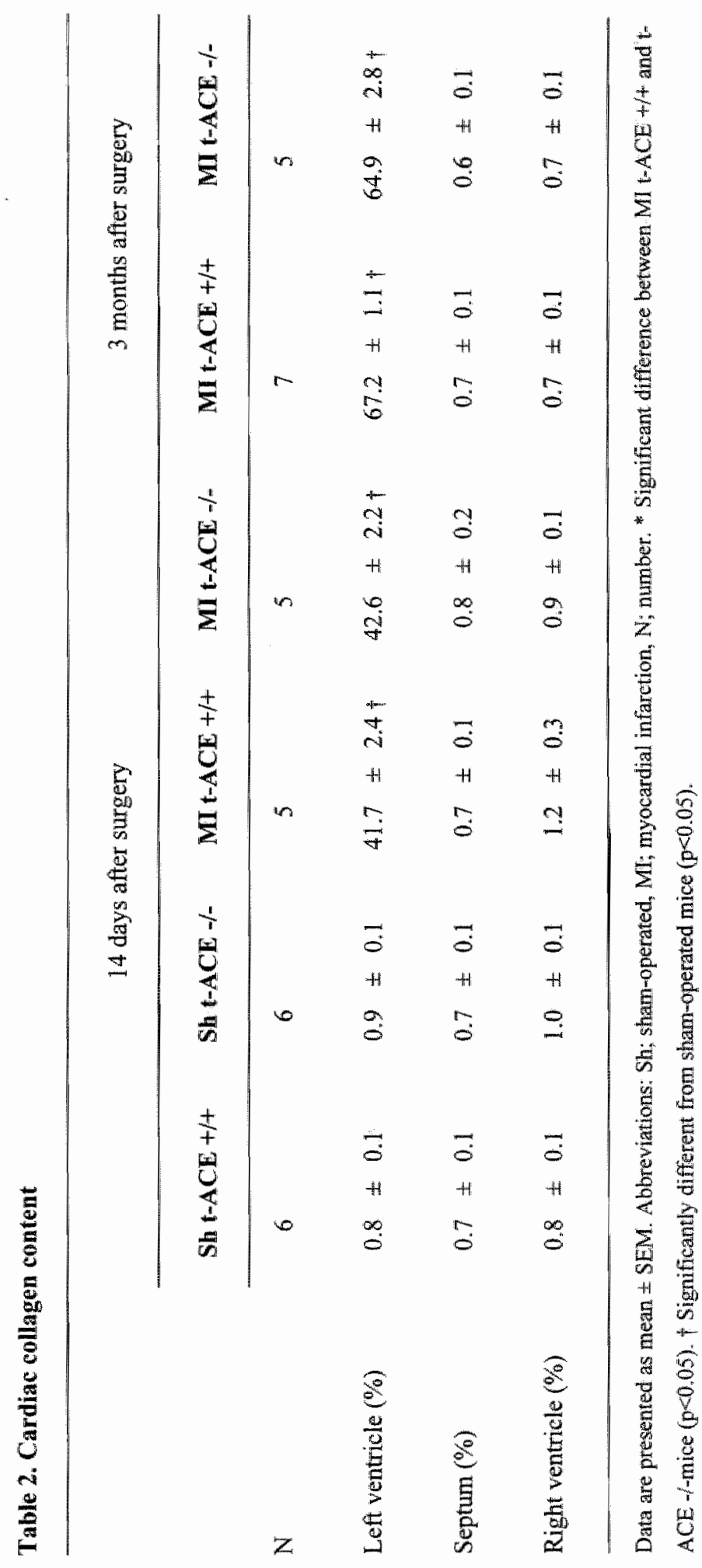




\section{Morphometry}

At 14 days, in $\mathrm{t}-\mathrm{ACE}+1+$ mice about $38 \%$ of the left ventricullar circumference had been replaced by collagen, while the infarct size in $\mathrm{t}-\mathrm{ACE}-\mathrm{-}$ - mice was only $30 \%$. Although the 1-ACE $\%$ mice had significantly smaller infarcts, no differences were found in left ventricular diameter, septum or infarct thickness between $1-\mathrm{ACE}+1$ th and $\mathrm{t}-\mathrm{ACE}-1-$ mice at 14 days after MI or at 3 months after MI (Table 1). At 3 months after MI, the left ventricle of infarcted mice was enlarged compared to the left ventricle of sham-operated mice, but thiss enlargement was only significantly different in $t-\mathrm{ACE}+1+$ mice.

\section{Collagen content}

After $M$, the left ventricular collagen content in $t-A C E+1+$ mice increased from $0.9 \pm 0.1 \%$ to $42 \pm 2 \%$ within 14 days and further to $66 \pm 1 \%$ after 3 months (Table 2 ). This increase was similar in $\mathrm{t}-\mathrm{ACE}-\mathrm{m}$ - mice. No increased collagen content was found in the right ventricle or in the non-infarcted septum. At 14 days after MI, a significant difference was found in infarct size between $t-A C E-/-$ and $t-A C E+/+$ mice. No significant differences were found in infarct size after 3 months.

\section{Measurements of cardiac function}

Haemodynamic parameters measured at rest and after volume load with $2.5 \mathrm{ml}$ Ringer's solution in 1 minute at 14 days after MI are shown in Figure 2. T-ACE $-/-$ mice exhibited a significantly lower mean arterial pressure (MAP) than wild-type mice (Table 3). At rest, no significant differences were found in heart rate (HR), stroke volume (SV) or cardiac output (CO) between the four groups. In animals with MI maximal SV after volume load was reduced. Moreover, maximal SV was significantly lower in both sham operated and infarcted $\mathrm{t}$-ACE $-/$ mice compared to their wild-lype littermates. Similar results were obtained for maximal $\mathrm{CO}$ (Fig 2). Thus, MI resulted in an impaired left ventricular function which was more pronounced in $1-\mathrm{ACE}-/=$ than in $t-\mathrm{ACE}+/+$. At 3 months after MI the condition of both $\mathrm{t}-\mathrm{ACE}+4$ and $1-\mathrm{ACE}-/$ mice was too much impaired to cope with either the anaesthesia or the $2.5 \mathrm{ml}$ volume-load. All animals died during the haemodynamic measurements. 
Stroke volume at rest

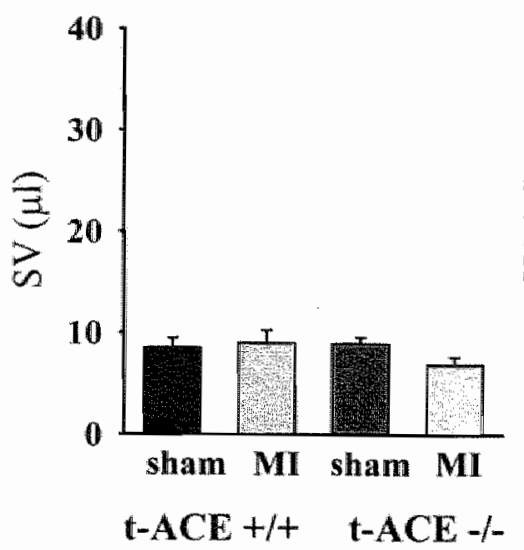

Cardiac output at rest

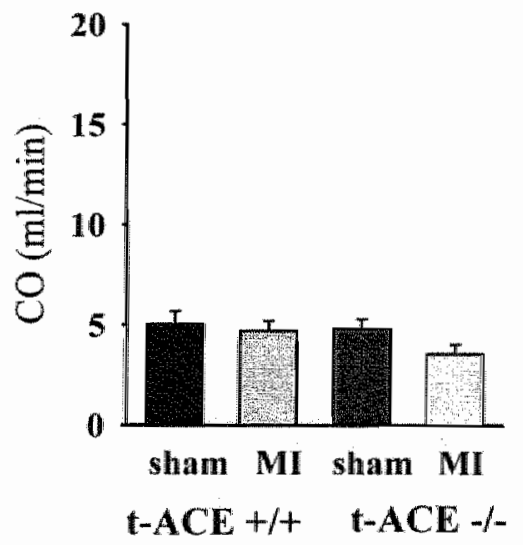

Maximal Stroke volume

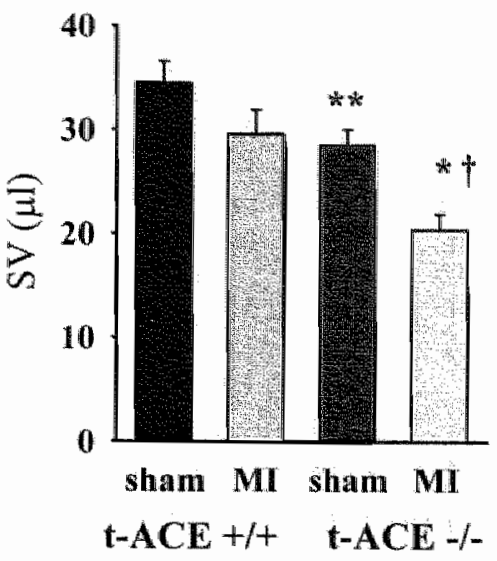

\section{Maximal \\ Cardiac output}

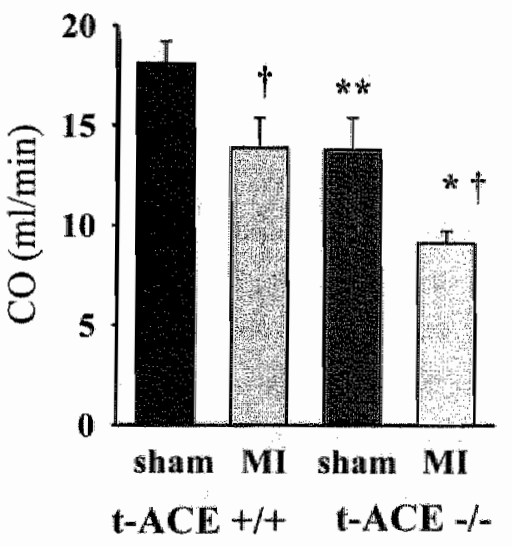

Figure 1. Haemodynamic measurements. CO; cardiac output and SV; stroke volume are determined at rest and after a volume-load of $2.5 \mathrm{ml}$ Ringer's solution $\left(37^{\circ} \mathrm{C}\right)$ in 1 minute. (Dark bars) sham-operated animals, (light bars) infarcted animals, $t-A C E+1+$, sham $(n=6)$ and MI $(n=5), t-A C E$ - - sham $(n=6)$ and MI $(n=6)+$ + Significant different from shamoperated mice $(\mathrm{p}<0.05)$ * Significant difference between $\mathrm{Ml} \mathrm{t}-\mathrm{ACE}+\mathrm{H}+$ and $\mathrm{t}-\mathrm{ACE}-\mathrm{-mice}$ $(p<0.05)$. * Significant difference between sham-operated $\mathrm{t}-\mathrm{ACE}+1+$ and $\mathrm{t}-\mathrm{ACE}-\mathrm{H}-\mathrm{mice}$ $(p<0.05)$. 
Table 3. Haemodyanic parameters at rest

14 days after surgery

\begin{tabular}{|c|c|c|}
\hline Sh $-A C E+/ t$ & Sh $1-\mathrm{ACE}-\%$ & MI t-ACE $+1+$ \\
\hline
\end{tabular}

$\mathbb{N}$

6

5

6

6

$\begin{array}{lccccc}\text { BW (g) } & 29 \pm 1 & 27 \pm 1 & 29 \pm 3 & 26 \pm 1 \\ \text { MAP (mmHg) } & 48 \pm 4 & 25 \pm 4 * * & 42 \pm 5 & 28 \pm 5 \text { * } \\ \text { HR (bpm) } & 603 \pm 27 & 558 \pm 42 & 557 \pm 39 & 533 \pm 49 \\ \mathrm{SV}(\mu \mathrm{l}) & 8.5 \pm 1.1 & 9.0 \pm 0.7 & 9.0 \pm 1.4 & 7.0 \pm 0.8 \\ \mathrm{CO}(\mathrm{mL} / \mathrm{min}) & 5.0 \pm 0.7 & 4.8 \pm 0.5 & 4.7 \pm 0.5 & 3.6 \pm 0.5\end{array}$

Data are presented as mean \pm SEM. Abbreviations: $\mathrm{BW}$; body weight, Sh; sham-operated, MI; myocardial infarction, $\mathrm{HR}$; heart rate, MAP; mean arterial pressure, SV; stroke volume, CO; cardiac output. Significant difference between MI $\mathrm{t}-\mathrm{ACE}+1+$ and $\mathrm{t}-\mathrm{ACE} / \mathrm{-mice}(\mathrm{p}<0.05)$.** Significant difference between sham-operated $t-A C E+/+$ and t-ACE $/-$ mice $(p<0.05)$.

Tissue angiotensin concentrations

Angiotensin I and angiotensin II concentrations measured in pooled samples (3-4 animals per sample) of $t-A C E+1+(n=13)$ and $t-A C E-/-(n=10)$ hearts and kidneys are shown in Figure 1. No differences for either angiotensin I or angiotensin II levels were found in the kidneys of both strains: Ratios for angiotensin II/ angiotensin I (AngI//AngI) of $\mathrm{t}-\mathrm{ACE}+1+$ and $\mathrm{t}-\mathrm{ACE}+/$ mice were comparable $(1.0 \pm 0.4$ vs. $2.1 \pm 0.8$ respectively). Cardiac angiotensin I and II levels were not significantly different comparing $\mathrm{t}-\mathrm{ACE}-/-$ and $\mathrm{t}-\mathrm{ACE}$ H/4 mice. Hearts of t-ACE knockout mice tended to exhibit a lower Ang II/ Ang I ratio (0.4 $\pm 1.7)$ than their wild-type littermates $(5.9 \pm 2.8)$, although the difference did not reach statictical significance.

\section{Discussion}

In the present study, the role of membrane-bound ACE during the remodelling after $\mathrm{MI}$ was investigated using the membrane-bound $A C E$ knockout mouse (t-ACE - $/-$ ) as originaly described by Esther et al. ${ }^{107}$. The absence of locally available ACE nesulted in reduced maximal stroke volume and cardiac output, which was not associated with differences in the structural adaptations. 
Cardiac

[Angiotensin I]

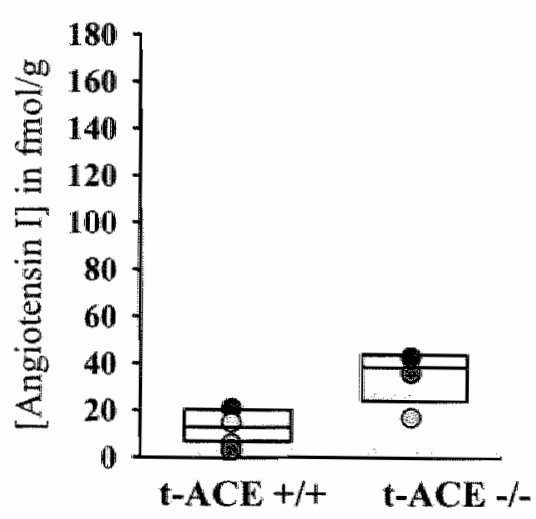

Cardiac

[Angiotensin II]

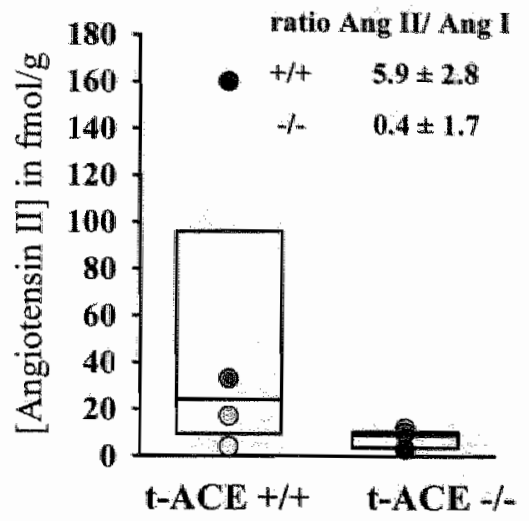

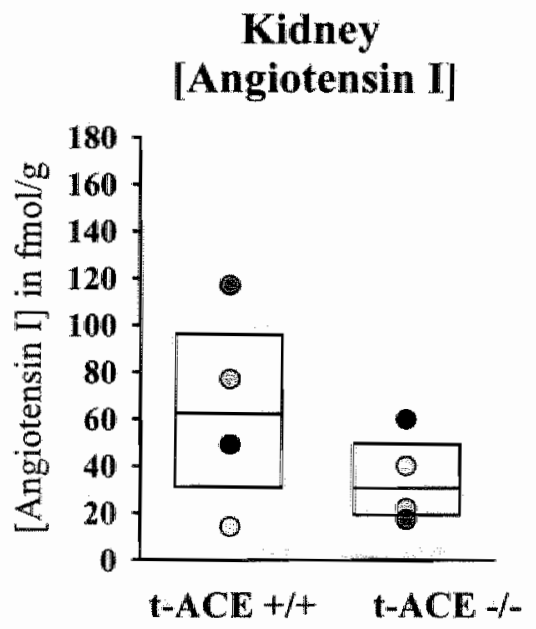

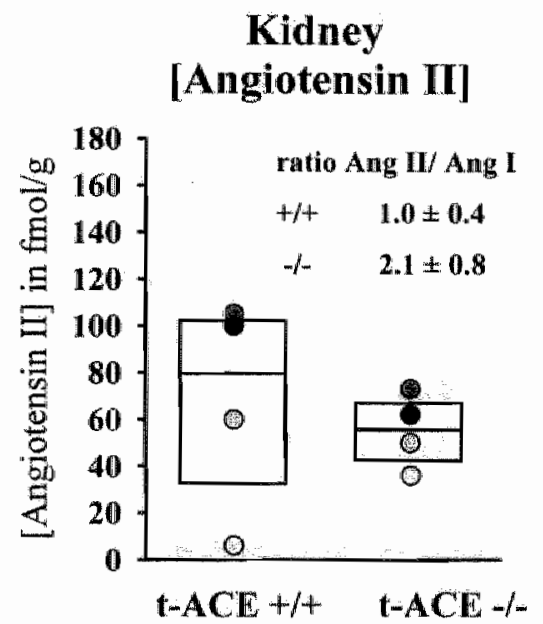

Figure 2. Tissue angiotensin concentrations. Each data point represents a pool of $3-4$ animals. Data are presented as median and $90^{\text {th }}$ percent confidence interval.

At 14 days after MI, a significant difference was found in infarct size between $\mathrm{t}-\mathrm{ACE}-\mathrm{-}$ and $\mathrm{t}-\mathrm{ACE}+/+$ mice. No significant difference in infarct size was found at 3 months after MI. However, the infarct collagen percentage increased between 14 days and 3 months. This increase in collagen percentage might be due to early collagen synthesis followed by infarct dilation in combination with loss of cells (necrotic cell, inflammatory cells and 
fibroblasts), as depicted by the increase of left ventricular diameter and decreased wall thickness. The process of wound healing involves many factors including mechanical stress, transforming growth factor- $\beta$, endothelin- 1 , tumor necrosis factor- $\alpha$ and angiotensin $I^{\text {I. }}$. Besides influencing wound healing these regulators also influence each other's expression $^{35 i}$. It might be that the lack of locally produced angiotensin II is abolished by one or seweral other regulators, resulting in a normal wound healing. The lack of differences in the struetural remodelling (morphometry and collagen content) after MI between $\mathrm{t}-\mathrm{ACE}$ $-1-$ and $t-A C E+H+$ mice may derive from the relative normal tissue angiotensin II levels. Only recently a reliable method to measure the exact tissue angiotensin I and II levels has been developed ${ }^{3}$. Samples from three or four mice had to be pooled due to the very low angiotensin levels in tissues and the small amounts of tissue that can be obtained from these mice. No significant differences were found in the tissue angiotensin I and II levels. The comparable angiotensin $I 1$ levels found in absence of membrane-bound ACE may depend upon the uptake of angiotensin II from the circulation ${ }^{37}$ or upon alternative pathways to produce angiotensin $\mathrm{IC}$, such as cathepsins ${ }^{351}$ chymase ${ }^{32,353}$. Chymase is present in mast cells, which are especially found in hypertrophied and failing hearts ${ }^{353}$, which suggests compensation. However, t-ACE -/. mice exhibited significantly lower plasma levels for angiotensin $\mathrm{II}^{226}$ and a significant lower blood pressure. Although the structural adaptations were not different, $\mathrm{t}-\mathrm{ACE}-/-$ mice showed reduced maximal stroke volume. This occurred in the sham operated group and became even more pronounced after MI and persisted after correction for body weight (data not shown). This observation is even more remarkable given the fact that $\mathrm{t}-\mathrm{ACE}-/-$ mice had significant smaller infarcts compared to their wildtype littermates.

The reduced maximal stroke volume in $\mathrm{t}$-ACE $-/$ - mice without differences in structural adaptation suggests that the absence of $\mathrm{t}$-ACE has an effect on compliance of the ventricle or the contractility of the myocytes. An increased cardiac collagen content impairs ventricular compliance. However, no differences were found in the collagen content of the nomal or infareted $1-\mathrm{ACE}-/$ - compared to $\mathrm{t}-\mathrm{ACE}+/ \mathrm{t}$ heart. Obviously, collagen is only one factor involved in cardiac compliance. Other cell-matrix structures (like fibronectin, virtonectin and intergrins) can be changed in the absence of $t-A C E$, leading to an altered cardiac compliance ${ }^{114}$. Angiotensin 11 has been shown to influence the myocyte contractility via several mechanisms. Angiotensin II is involved in the $\mathrm{Ca}^{2 *}$ handling of the myocyte either via activation of the $\mathrm{AT}_{1}$ receptor followed by the release of intracellular $\mathrm{Ca}^{2+}$ or by increasing the myofilament affinity towards $\mathrm{Ca}^{2+298}$. Indirectly angiotensin II can have a positive inotropic effect via the induction of other neurohormones such as noradrenaline ${ }^{300.301}$ and $I G F-I^{291}$. Both hormones are known to stimulate the cardiac contractility ${ }^{30,311}$. In contrast, noradrenaline release is reduced by NO. T-ACE $-/$ - mice might exhibit an overstimulated bradykinin-NO pathway due to the absence of $\mathrm{t}-\mathrm{ACE}{ }^{312}$. 
Therefore the final inotropic action of angiotensin II is an end product of complex interactions, which can dramatically be altered after myocardial infarction. Litwin et al ${ }^{3.44}$ demonstrated in rats that the intracellular $\mathrm{Ca}^{2+4}$ transients changed after $\mathrm{MI}$ and those changes could be prevented when chronic treatment with captopril was started at 1 week after the operation. To investigate a possible time dependent effect of the absence of t-ACE after MI, we tried to determine the cardiac output at 3 month after MI. However, at 3 month after MI both $\mathrm{t}-\mathrm{ACE}+/+$ and $\mathrm{t}-\mathrm{ACE}-/$ - mice were too weak to determine the cardiac performance, suggesting that a long-term beneficial effect of $\mathrm{t}-\mathrm{ACE}$ absence does not exist. With respect to the structural adaptations of the heart at 3 months after MI, again no differences were found between $\mathrm{t}-\mathrm{ACE}+/ \mathrm{t}$ and $\mathrm{t}-\mathrm{ACE}-/ \mathrm{-}$ mice.

Part of the clinical beneficial effects of ACE inhibition might not be mediated through deactivation of $\mathrm{AT}_{1}$ receptors, but mediated through inhibition of bradykinin breakdown. Nolly et $\mathrm{al}^{239}$ demonstrated that the heart expresses a functional local kallikrein-kinin system. Enhanced activation of the bradykinin-NO pathway has several beneficial effects under ischemic conditions such as an enhanced coronary blood flow, improved cardiac metabolism and reduction of the incidence of ventricular fibrillation ${ }^{355}$. Furthermore, the induced production of $\mathrm{NO}$ is believed to have negative influence on cell growth ${ }^{254}$. The fact that $\mathrm{t}-\mathrm{ACE}-/$ mice in the present study exhibited no significant difference in the hypertrophic response compared to their wild-type littermates, suggests that the bradykininNO pathway does not contribute to the cardiac structural remodelling after MI. Another indication for this comes from observations in mice lacking the $\mathrm{AT}_{2}$ receptor. Recent studies have shown that activation of the $\mathrm{AT}_{2}$ receptor leads to the production of $\mathrm{NO}^{77}$. Since the $\mathrm{AT}_{2}$ receptor is upregulated after $\mathrm{MI}$ and is strongly related to fibrosis ${ }^{251}$, we investigated the role of this receptor in the early changes in cardiac dimensions and collagen content at 7 days after MI, using the same experimental procedures as described above for the $\mathrm{t}-\mathrm{ACE}-1-$ mice. No differences were found in the structural parameters between mice lacking the $\mathrm{AT}_{2}$ receptor and their wild-type littermates (unpublished results). Genetic manipulation of the ACE gene resulted in a mouse model with a specific absence of membrane-bound $\mathrm{ACE}$. Esther et al ${ }^{107}$ demonstrated that the ACE activity in the lung, kidney and testis of $\mathrm{t}-\mathrm{ACE}-/-$ mice was undetectable. However, this model is not without limitations. The absence of $\mathrm{t}-\mathrm{ACE}$ affects the blood pressure, $\mathrm{t}-\mathrm{ACE}+\%$ mice have significantly lower blood pressures compared to their wild-type littermates. Also t-ACE -/ kidney function is impaired which is observed by a urinary concentrating defect. These differences in basal haemodynamics could be an explanation for the increased susceptibility of the $\mathrm{t}-\mathrm{ACE}-/$ - mice towards surgery. Cardiac haemodynamics are directly related to the blood pressure. Lower blood pressure may lead to a lower coronary perfusion, while it reduces the cardiac workload due to the decreased afterload. A reduction of the afterload is thought to be in favour of adequate cardiac remodelling after MI. However, despite the 
significantly lower blood pressure in $\mathrm{t}-\mathrm{ACE}-/$ mice, cardiac structural remodelling was similar and cardiac function was impaired, as compared to $\mathrm{t}-\mathrm{ACE}+1+$ mice. The fact that lack of 1 ACE is associated with reduced blood pressure, however, makes it impossible to conclude if the hamodynamic results found in this study are directly or indirectly caused by the absence of tissue $\mathrm{ACE}$.

\section{Conclusions}

The data derived from the present study suggest that, after MI, locally available ACE does not contribute to the early structural changes in the myocardium. However, $\mathrm{ACE}$ is involved in regulation of cardiac performance. T-ACE $/$ - mice do have reduced maximal stroke volume compared to their wild-types littermates, which suggests that locally available $\mathrm{ACE}$ contributes to the maintenance of cardiac function and is required for full compensation after MI.

\section{Acknowlledgements}

The authors thank Dr. K.E. Bernstein for the gift of the t-ACE knockout mice. J.J.M. Debets, P.J.A. Leenders, N.J.J.E. Bitsch, M.J.A. Verluyten, R. Jaspers, R. Ceulen and J.G.L.M. Luemans are gratefully acknowledged for their technical assistance. 



\begin{abstract}
Cardiac angiotensin and IGF-I receptors are both upregulated shortly after myocardial infarction (MI). Beneficial effects on cardiac function have been observed during antagonism of the $A T$, receptor as well as during stimulation of the IGF-I receptor. In the present study, combined treatment with losartan and IGF-I is hypothesised to be more beneficial for cardiac performance after MI than losartan treatment alone. To test this hypothesis, infarcted mice were either untreated, treated with losartan or losartan $+\mathbb{I G F}-1$. At 14 days after MI, left ventricular pressure, $+\mathrm{dp} / \mathrm{dt}$ and $-\mathrm{dp} / \mathrm{dt}$ were measured via a catheter-tip pressure transducer. Cardiac dimensions and collagen content were determined but no effects of $\mathrm{AT}$, inhibition or IGF-I administration were observed. At rest, losartan treatment ( $\mathrm{n}=7$ ) reduced cardiac loading, cardiac contractility ( $+\mathrm{dp} / \mathrm{dt} ; 2262 \pm 129 \mathrm{mmHg} / \mathrm{s}$ ) and relaxation ( $-\mathrm{dp} / \mathrm{dt} ; 1961 \pm 140 \mathrm{mmHg} / \mathrm{s})$ compared to untreated mice $(\mathrm{n}=4,4452 \pm 526$ and $3979 \pm 548 \mathrm{mmHg} / \mathrm{s}$ ). By adding IGF-I to losartan cardiac contractility and relaxation were enhanced ( $3390 \pm 396$ and $3010 \pm 323 \mathrm{mmHg} / \mathrm{s}, \mathrm{n}=7$ ). After dobutamine stimulation, maximal cardiac contractility and relaxation remained lower in both treated groups compared to the untreated $\mathrm{MI}$ group. The difference in cardiac contractility between losartan and losartan + IGF-I observed at rest, was no longer present after dobutamine stimulation. This might be explained by the significantly greater response to dobutamine in the losartan group compared to losartan $+I^{-F}-I$ group ( $58 \pm 1 \%$ vs. $41 \pm 5 \%$ ). Thus, early $A T$, receptor antagonism after $\mathrm{MI}$ reduces cardiac contractility, which can partly be restored by the addition of $I G E-I$.
\end{abstract}




\title{
Chapter 6
}

\section{In mice, combined treatment with $\mathrm{AT}_{1}$}

\author{
blockade and IGF-1 infusion does not
}

improve cardiac contractility after

\section{myocardial infarction}

\author{
Wendy M. Aartsen, K.F.J. de Brouwer, W.A. Buuman, M. van Bilsen, M.J.A.P. Daemen \\ and J.F.M. Smits
}

\section{Introduction}

Two neurohormonal systems that are activated after MI are the renin-angiotensin system (RAS) and the growth homone/insulin-like growth factor axis (GH/IGF axis). Within one week after M1, all components of the RAS are expressed in the infarcted area and noninfarcted surviving myocardium ${ }^{39,67.143-145.147 .148,151}$. IGFs and IGF receptors are also expressed at higher level after myocardial infarction. This expression is mainly located in myocytes of the border zone. IGF-I and IGF-I receptors expression are upregulated within 1 day and are still detectable at 7 days after $\mathrm{MI}^{279-28 !}$.

Both the angiotensin II and IGF-I signaling pathways are thought to be involved in the early process of cardiac remodelling. Angiotensin II influences fibroblast proliferation and the production of extracellular matrix proteins ${ }^{356}$. Stimulation of neonatal and adult rat fibroblasts with angiotensin II results in DNA synthesis, mRNA expression and protein synthesis of fibronectin and collagen I/II, via the AT, receptor expressed on the cell- 
surface ${ }^{158 / 5 \%}$ Stmulation of $\mathrm{AT}$, receptors on neonatal rat myocytes leads to activation of growth-related genes, followed by cell growth ${ }^{\text {90.7ng }}$. Several in vitro studies have demonstrated that physiological concentrations of IGF-I and IGF-II are able to induce protein and DNA synthesis in neonatal ${ }^{282}$ and adult cardiac myocytes ${ }^{2 B 3}$, leading to cellular growth. Since increased $\mathrm{Ca}^{2+}$ sensitivity and velocity of shortening is observed in myocytes isolated from IOF-I overexpressing mice ${ }^{2 B(}$, it is hypothesised that IGF-I is able to improve myocyte contractility.

Prolonged activation of these neurohormonal systems is accompanied by cellular changes like cell growth and altered calcium homeostasis, changes in cross-bridge cycling and architecture in both heart and vessels. These (mal)adapations can lead the heart from its compensated stage into the stage of heart failure ${ }^{6}$. High angiotensin II levels are associated with pathological hypertrophy ${ }^{35}$ and cardiac maladaptations, while IGF-I elevation is associated with adaptive and physiological cardiac hypertrophy ${ }^{297}$. Inthibition of the RAS after MI." either through administration of $\mathrm{ACE}$ inhibitors ${ }^{200,210,338}$ or $A T_{\sharp}$ receptor antagonisus $^{358-360}$ has been reported to be positive for the patient's quality of life and survival ${ }^{236}$. Progressive cardiac dilatation and hypertrophy are delayed by RAS inhibition and cardiac function after $\mathrm{MI}$ is enhanced ${ }^{141,213214}$. In vivo experiments showed that administration of exogenous IGF-I and growth hormone (GH) enhance cardiac performance after experimental $\mathrm{MI}$ in rats. "Two days after experimental MI, rats treated with IGF-I exhibited increased stroke volume compared to untreated control $\mathrm{Mll}$ animals ${ }^{28,285}$. Also growth hormone administration, which elevates serum $\mathbb{I G F}$-I concentrations attenuates left ventricular adaptations and improves cardiac function? ${ }^{361.362}$.

In the present study, we hypothesised that cardiac contractility after MI improves by combining RAS inhibition with IGF- administration. Experimental. MI was induced in mice, which were then divided into three groups receiving either no treatment, losartan, or losarten plus IGF-I for the first 14 days after MI. After 14 days of treatment, left ventricular contractility and relaxation were determined. No effects of losartan or losartan + IGF-I administration on ventricular dilatation or hypertrophy nor on collagen deposition were observed at 14 days after MI. However, losartan reduced cardiac contractility and this effect was partly abolished by the addition of IGF-I.

\section{Materials and Methods}

Animals

Adult male Swiss mice (Iffa Credo) of approximately 30 grams were used. All animals were housed in groups of 4 to 6 and had free access to tap water and standard food (SRMA. 1210; Hope Farms, Woerden, The Netherlands). All experiments were conducted according 
to institutional guidelines and conformed to the gwide for whe care and use of laboratory ammals, published by the US National Institutes of Health (NTH Publication No 85-23, revised 1996).

\section{Experimental myocardial infarction}

Experimental myocardial infarction was induced according to a method described previously $^{313}$. Briefly, the mouse was anaesthetised with xylazine (5mg/kg s.c.) and ketamine $(100 \mathrm{mg} / \mathrm{kg}$ i.m.). While the mouse was fixed on its back, the trachea was intubated ( $1.1 \mathrm{~mm}$ stainless steel) to allow positive pressure respiration with room air (1.5$2 \mathrm{ml}, 70 / \mathrm{min})$. A ligature $(6-0$ prolene $)$ was tied around the main left coronary artery after opening the skin, the left 4 th intercostal space and the pericardial sac. Then chest and skin were closed with 5-0 silk sutures under application of gentle pressure on both sides of the thorax to remove air, after which the animal was allowed to recover at $30^{\circ} \mathrm{C}$.

\section{Implantation of osmotic mini-pumps}

Within $24 \mathrm{~h}$ after surgery, mice were briefly re-anaethetised with ketamine $(50 \mathrm{mg} / \mathrm{kg}$ i.m.) and xylazine ( $5 \mathrm{mg} / \mathrm{kg} \mathrm{sc}$.) to implant the osmotic mini-pumps. Osmotic mini-pumps (Alzet, 2002; Alza corp., Palo Alto, CA) were filled with losartan (10 mg/kg/day, Merck) $)^{363}$ or losartan (10mg/kg/day) + recombinant human IGF-I $(6 \mathrm{mg} / \mathrm{kg} / \mathrm{day}$, Chiron cooperations, $C A)^{364}$ in saline to infuse the animals for 14 days.

\section{Plasma glucose levels and IGF-I concentration}

At day 13 after surgery animals were deprived from food. The next day, mice were reanaethetised with pentobarbital $(110 \mathrm{mg} / \mathrm{kg}$ i.p.). Blood $(0.3 \mathrm{ml})$ was sampled via orbitapuncture to determine plasma glucose level and plasma IGF-I concentration. Plasma glucose levels were determined directly using the Glucometer Elite (Bayer B.V. Mijdrecht, The Netherlands). EDTA was added to the rest of the blood sample. Blood samples were centrifuged for 10 minutes at $10000 \mathrm{xg}$, followed by the removal of the plasma which was stored at $-80^{\circ} \mathrm{C}$ until further analysis. Plasma endogenous $1 \mathrm{GF}-\mathrm{I}$ concentration was

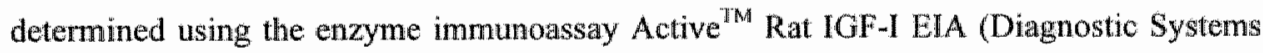
Laboratories, Webster). According to the manufacturer this enzyme ummunoassay allows the dettection of rat IGF-I without cross-reaction with human IGF-I. Cross-reactivity with mouse IGF-I made it possible to detect endogenous mouse IGF-I without measuring the exogenous human $\llbracket \mathrm{GF}-\llbracket$.

\section{Left ventricular pressure}

The mouse was fixed on its back and the trachea was intubated (1.1 $\mathrm{mm}$ stainless steel) to allow positive pressure respiration with room air (1.5-2 $\mathrm{ml}, 70 / \mathrm{min})$. Body temperature was 
continuously monitored wia a rectal thermocouple and kept at $37^{\circ} \mathrm{C}$. The skin in the neck was opened and the right carotid artery was dissected free from surrounding tissues. Via the carotid artery a catheter tip pressure transducer (Miko tip 1.4F; Millar Instruments, Houston, TX) was inserted into the left wentricle. The shape of the pressure signal confirmed the correct position of the pressure transducer. Another catheter (PE 10 ) was placed in the jugular vein for injections. Left ventricular pressure was monitored for at least 10 minutes at rest. Thereafter, a dobutamine infusion was started. Pressure values were used to determine left ventricular peaks systolic pressure, maximal positive $(+\mathrm{dp} / \mathrm{dt})$ and negative (-dp/dt) pressure development.

\section{Dobutamine infusion}

The venous catheter was connected to a syringe-pump containing dobutamine (SigmaAldrich, Steinheim, Germany) dissolved in saline $(4.5 \mu \mathrm{g} / \mathrm{ml})$. A dose-response curve from 0 to $15 \mathrm{ng} / \mathrm{g} / \mathrm{min}$ dobutamine was constructed. Left ventricular pressure was monitored continuously. Left ventricular peak systolic pressure, maximal positive $(+\mathrm{dp} / \mathrm{dt})$ and negative $(-\mathrm{dp} / \mathrm{dt})$ pressure development were determined at each dobutamine dose.

\section{Tissue processing}

At 14 days after surgery animals were sacrificed after haemodynamic measurements by injecting cadmium chloride $\left(\mathrm{CdCl}_{2} ; 0.1 \mathrm{M}\right)$ directly into the heart. At a pressure of 100 mmHg, the animals were perfused with phosphate buffer (PBS; $\mathrm{pH} 7.4$ ) containing 0.1 $\mathrm{mg} / \mathrm{ml}$ sodium nitroprusside (Sigma-Aldrich) through a needle in the left ventricle. After 3 minutes, the perfusion solution was replaced by $5 \%$ formalin in PBS, which was infused for another 3 minutes. Heart, lung and liver were dissected and weighed, followed by formalin (10\% in PBS) fixation for $24 \mathrm{~h}$. The heart was then cut longitudinally through the left and right ventricles and both halves were paraffin-embedded following routine histological procedures, after which $4 \mu \mathrm{m}$ sections were prepared for morphometry.

\section{Morphometry}

Infarct size, left ventricle diameter, septum and infarct thickness were all determined using a computerised morphometry system (Quantimet 570 , Leica, the Netherlands). Sections from both heart halves were stained with the AZAN technique to distinguish between collagen and heart muscle. In a section from the centre of the infarct, infarct size was measured as the percentage of the left ventricular circumference ${ }^{344}$. From the same section values for ventricle diameter, septum and infarct thickness were obtained. Left ventricle diameter was calculated by dividing the inner circumference by $\pi$ assuming the left ventricular lumen as a circular shape. Septum and infarct thickness were estimated by taking the defined septum or infarct area which was then divided by its average length ${ }^{313}$. 


\section{Collagen content}

Sections from both heart halves were deparaffinised and incubated in phosphomolybdic acid $(0.2 \%)^{3.48}$ for 5 mimutes, followed by incubation with a Sirius red $(0.1 \%)$ in saturated picric acid solution for 90 minutes. After washing with $0.01 \mathrm{M} \mathrm{HCl}$ for 2 mimutes, the sections were dehydrated and protected with coverslips. Under the microscope (magnification $400 \mathrm{x}$ ) the collagen content was measured in the middle of the right ventricular, left ventricular and septum walls. For each area, six fields from both heart halves were analysed for the relative collagen content using a computerised morphometry system (Quantimet 570, Leica). Collagen present around vessels and endocardium was excluded from the total amount of Sirius red positive tissue, so only interstitial collagen was determined.

\section{Statistics}

All data are presented as means \pm SEM. The haemodynamic and histological values were compared using a one-way ANOVA. A Two-way ANOVA for trepeated measurements, followed by Bonferroni's t-test was used to test the effect of dobutamine infusion within one group. Statisticall significance was accepted if $\mathrm{p}<0.05$.

\section{Results}

At the start of the experiments mice weighed $32 \pm 0.5$ gram. Mice were divided into three groups; untreated, treated with losartan $(10 \mathrm{mg} / \mathrm{kg} /$ day) and treated with losartan (10 $\mathrm{mg} / \mathrm{kg} /$ day) plus rhIGF-I ( $6 \mathrm{mg} / \mathrm{kg} /$ day). At 14 days after MI, heart, lung, liver and body weights were determined. These data as well as the plasma glucose and IGF-I levels are shown in Table 1. Losartan treatment after MI did not affect heart, lung, liver or body weight. Also the plasma glucose and endogenous IGF-I concentrations did not change during losartan administration. However, addition of rhIGF-I to losartan treatment resulted in increased body weight, heart weight increased slightly, while lung and liver weights were not affected. This resulted in significantly decreased lung or liver weight/body weight ratios and an unaltered heart weight/body weight ratio. rhIGF-I addition to losartan treatment after MI reduced both plasma glucose and endogenous IGF-I concentrations. 
Table 1. Body, heart and lung weights, and plasma glucose and IGF-I levels

\begin{tabular}{|c|c|c|c|c|c|c|}
\hline & \multicolumn{6}{|c|}{14 days after surgery } \\
\hline & \multicolumn{2}{|c|}{$\begin{array}{c}\text { MI } \\
\text { untreated }\end{array}$} & \multicolumn{2}{|c|}{$\begin{array}{c}\text { MI } \\
\text { losartan }\end{array}$} & \multicolumn{2}{|c|}{$\begin{array}{c}\text { MI } \\
\text { losartan + IGF-I }\end{array}$} \\
\hline $\mathbb{N}$ & \multicolumn{2}{|l|}{8} & \multicolumn{2}{|l|}{7} & \multicolumn{2}{|l|}{8} \\
\hline $\mathrm{BW}(g)$ & 35 & \pm 0.8 & 36 & \pm 0.4 & 43 & $\pm 1.2 *$ \\
\hline $\mathrm{HW}(\mathrm{g})$ & 0.25 & \pm 0.01 & 0.23 & \pm 0.02 & 0.27 & \pm 0.01 \\
\hline HW/BW $(\%)$ & 0.70 & \pm 0.04 & 0.63 & \pm 0.04 & 0.63 & \pm 0.03 \\
\hline $\mathrm{LW}(\mathrm{g})$ & 0.34 & \pm 0.04 & 0.29 & \pm 0.02 & 0.28 & \pm 0.01 \\
\hline $\mathrm{LW} / \mathbb{B W}(\%)$ & 0.99 & \pm 0.13 & 0.79 & \pm 0.06 & 0.65 & $\pm 0.02 *$ \\
\hline $\operatorname{LifW}(\mathrm{g})$ & 2.5 & \pm 0.1 & 2.5 & \pm 0.1 & 2.3 & \pm 0.1 \\
\hline $\operatorname{LiW} / \mathrm{BW}(\%)$ & 7.0 & \pm 0.5 & 6.8 & \pm 0.2 & 5.4 & $\pm 0.1 *+$ \\
\hline Glucose level $(\mathrm{mM})$ & 6.4 & \pm 0.8 & 8.0 & \pm 0.3 & 4.7 & \pm 0.4 \\
\hline \multicolumn{7}{|l|}{ Endogenous } \\
\hline IGF-I level $(\mathrm{mg} / \mathrm{ml})$ & 0.80 & \pm 0.02 & 0.82 & \pm 0.04 & 0.38 & $\pm 0.11 *$ \\
\hline \multicolumn{7}{|c|}{$\begin{array}{l}\text { Data are presented as mean } \pm \text { SEM. Abbreviations: MI; myocardial infarction, BW; body weight, } \\
\text { HW; heart weight, HW/BW; heart weight/body weight ratio, LW; lung weight, LW/BW; lung } \\
\text { weight/body weight ratio, LiW; liver weight, LiW/BW; liver weight/body weight ratio. Losartan } \\
\text { truatment for } 14 \text { days after MI at } 10 \mathrm{mg} / \mathrm{kg} / \mathrm{day} \text {. Losartan }(10 \mathrm{mg} / \mathrm{kg} / \mathrm{day}) \text { to } 1 \mathrm{GF}-1(6 \mathrm{mg} / \mathrm{kg} / \mathrm{day}) \\
\text { treatment for } 14 \text { dlays after MI. Significantly different from untreated MI (p<0.05). t? }\end{array}$} \\
\hline
\end{tabular}

Morphology and collagen content

Parameters for cardiac morphology at 14 days after MI in untreated, losartan treated and losartan + IGF-I treated mice are shown in table 2. Infarct size, left ventricular diameter, infarct and septum thickness were not affected by losartan, nor by the combined treatment with losartan and IGF-I. Collagen content in the infarct area, border zone and non-infarcted septum was comparable in all three groups. 


\section{Table 2. Cardiac morphometry and collagen content}

\begin{tabular}{|c|c|c|c|c|c|c|}
\hline \multirow[b]{2}{*}{$\cdot$} & \multicolumn{6}{|c|}{14 days after surgery } \\
\hline & & $\begin{array}{l}\text { MI } \\
\text { treated }\end{array}$ & & $\begin{array}{l}\text { MI } \\
\text { artan }\end{array}$ & losart & $\begin{array}{l}\text { MI } \\
\text { an + IGF-I }\end{array}$ \\
\hline $\mathrm{N}$ & 3 & & 4 & & 3 & \\
\hline Infarct $(\%)$ & 51 & \pm 4 & 48 & \pm 3 & 53 & \pm 2 \\
\hline LV diameter $(\mathrm{mm})$ & 4.9 & \pm 0.4 & 4.8 & \pm 0.4 & 4.4 & \pm 0.6 \\
\hline Infarct thickness (mm) & 0.4 & \pm 0.03 & 0.4 & \pm 0.04 & 0.4 & \pm 0.07 \\
\hline Septum thichness (mm) & 0.7 & \pm 0.1 & 1.0 & \pm 0.1 & 0.8 & \pm 0.1 \\
\hline Collagen infarct $(\%)$ & 69 & \pm 2 & 71 & \pm 4 & 69 & \pm 5 \\
\hline Collagen septum (\%) & 0.7 & \pm 0.1 & 0.9 & \pm 0.2 & 0.9 & \pm 0.1 \\
\hline Collagen borderzone $(\%)$ & 47 & \pm 2 & $5 \|$ & \pm 2 & 47 & \pm 5 \\
\hline
\end{tabular}

Data are presented as mean \pm SEM. Abbreviations: $L V$; left ventricle, $M I$; myocardial infarction. Losartan treatment for 14 days after MI at $10 \mathrm{mg} / \mathrm{kg} /$ day. Losartan $(10 \mathrm{mg} / \mathrm{kg} / \mathrm{day})+1 \mathrm{GF}-\mathrm{I}$ (6mg/kg/day) treatment for 14 days after MI. * Significant different from untreated MI $(p<0.05)$. Significant different from losartan treated MI $(\mathrm{p}<0.05)$.

\section{Left ventricular pressure measurements}

Pressure values at rest are shown in figure 1. At rest, losartan treatment during the first 14 days after MI significantly decreased ventricular systolic pressure (panel $\mathrm{C}$ ), maximal ventricular contraction ( $+\mathrm{dp} / \mathrm{dt}$, panel B) and relaxation (-dp/dt, Panel D). No significant difference was observed in heart rate (panel A) and end-diastolic pressure (panel E). The addition of IGF-I to losartan treatment significantly increased ventricular systolic pressure, maximal ventricular contraction and relaxation compared to losartan treatment allone. The effects of cardiac stimulation with dobutamine are also shown in figure 1. Dobutamine administration increased heart rate, ventricular systolic pressure, cardiac contractility and relaxation in all three groups. The effect of dobutamine was significantly greater in the losartan groups compared to the untreated group (panel F). By adding IGF-I to losartan the enhanced effect of dobutamine was abolished. The differences in ventricular systolic pressure, ventricular contraction and relaxation between losartan and losartan + IGF-I observed at rest were no longer observed after dobutamine stimulation. 


\section{Discussilon}

After myocardial infarction (MI), both the renin-angiotensin system (RAS) and growth hormone/insulin-like growth factor axis (GH/IGF-1 axis) are activated and they may be involved in ventricular remodelling and cardiac performance. Improvement of cardiac function and attenuation of left ventricular remodelling have been demonstrated during RAS inhibition, but also during stimulation of the GH/IGF-I axis through administration of either exogenous GH or exogenous IGF-I I $^{14,213,214,284,285,361,365}$. Moreover, high angiotensin II levels are associated with pathological cardiac hypertrophy ${ }^{397}$, while high IGF-1 levels are observed in a situation of physiological hypertrophy ${ }^{297}$. Accordingly we hypothesised that a combination therapy based on RAS inhibition and stimuation of the GH/IGF axis should be superior to RAS antagonism alone. In the present study, the effects of $\mathrm{AT}_{1}$ antagonism combined with IGF-I administration on cardiac remodelling and cardiac contractility were investigated at 14 days after $\mathrm{MI}$ and compared to $\mathrm{AT}_{1}$ antagonism alone.

\section{A Heart rate}

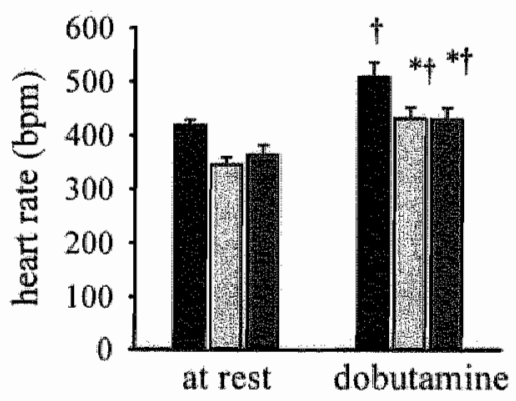

C Systolic pressure

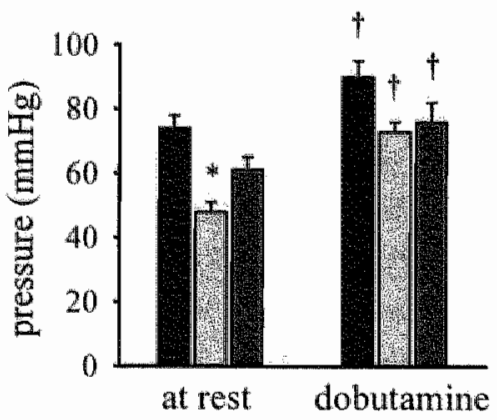

\section{B Ventricular contraction}

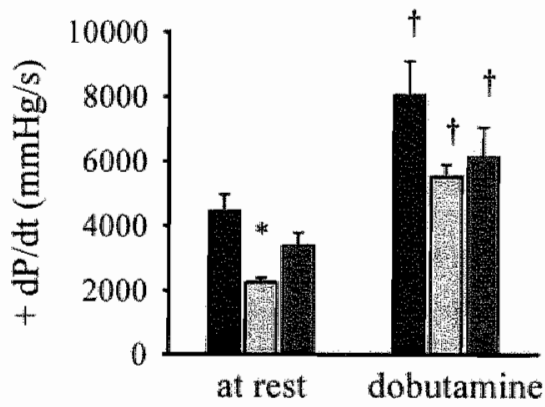

D Ventricular relaxation

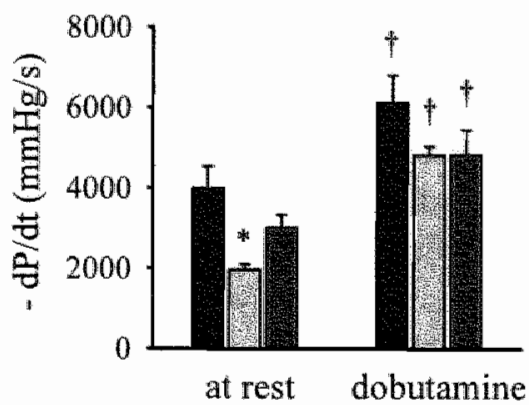




\section{E End-diastolic pressure}

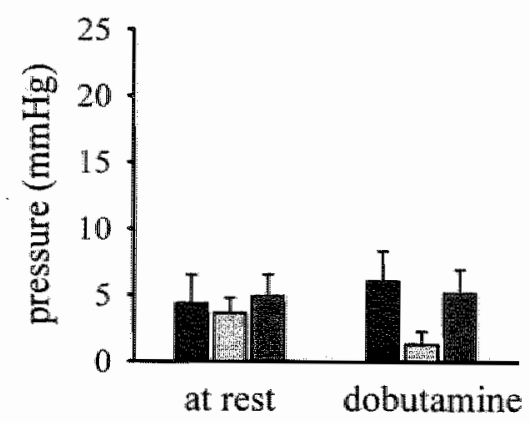

MI untreated $(n=4)$

\section{F Relative increase}

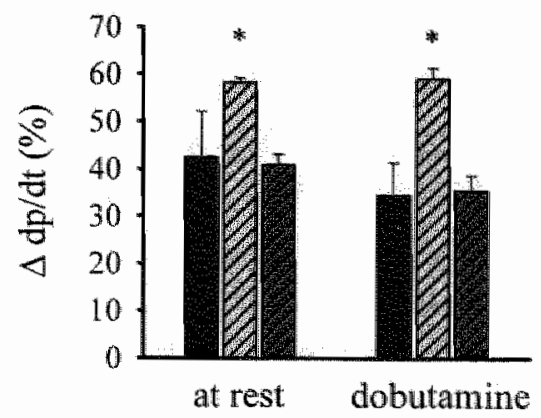

MI losartan $+1 \mathrm{GF}-\mathrm{I}(\mathrm{n}=7)$

Figure 1. Pressure values determined at $\$ 4$ days after MI in untreated, losartan treated and losartan + IGF-I treated mice. Panel A) heart rate, at rest and after dobutamine stimulation, Panel $B$ and D) maximal ventricular contraction and relaxation at rest and after dobutamine stinulation, Panel C) ventricular systolic pressure, at rest and after dobutamine stimulation, Panel ventricular diastolic pressure at rest and after dobutamine stimulation, Panel F) relative effect of dobutamine on contraction and relaxation. * significantly different from untreated. $\$$ significantly different from values measured at rest.

Body, heart and lung weights were not affected by losartan treatment. Plasma glucose and IGF-I levels were determined, since angiotensin II has been shown to modulate the IGF-I plasma levels under normal circumstances ${ }^{289,291}$ and during chronic heart failure ${ }^{366}$. Moreover, IGF-I is strongly related to the glucose metabolism because of its insulin-like activities $^{367}$. Plasma glucose and endogenous IGF-I concentrations were comparable in untreated and losartan treated mice, indicating that losartan treatment in mice does not affect endogenous IGF-I plasma levels.

The glucose levels were determined after one night of food-deprivation. Results show that IGF-I administration lowered the plasma glucose concentration. By using the Active ${ }^{\text {IM }}$ Rat IGF-I EIA (Diagnostic Systems Laboratories, Webster) only IGF-I of mouse origin was determined, which was downregulated during the infusion with (rh)IGF-I. By adding IGF-I to the losartan treatment, body weight increased without changes in heart weight/body weight ratio. Lung and liver weight remained stable, resulting in a reduced lung and liver weight/body weight ratio. The effects of IGF-I and GH on body weight have been studied previously ${ }^{364}$. In mice, 14 days treatment with IGF-1 slightly increases body, heart and lung 
weight without changing their ratios ${ }^{364}$. In the present study, IGF-I administration combined with $\mathrm{AT}$, receptor antagonism after $\mathrm{MI}$ results in a disproportional growth.

Structural parameters determined in histological sections of the heart were not altered after 14 days of losatan treatment. Also the addition of IGF-I to losartan treatment did not affect cardiac structural changes after MI: infarct size, cardiac dimensions and collagen content remained comprarable in all groups. Two studies with a comparable experimental outline investigated the effects of IGF-I or GH on cardiac dimensions, collagen content and cardiac contractlity in rats shortly after MI. Administration of $1 G F-1$ for 14 days after MI did not affect infaret size or collagen content, but significantly enhanced stroke volume Similarly, GH infusion for 1 week after MI did not change septum or left ventricle wall. thickness nor ventricular diameter. However, ejection fraction and cardiac output ware increased significantly ${ }^{362}$. Prolonged GH treatment also alters cardiac geometry ${ }^{365.368}$. It is conceivable that at 14 days of losartan + IGF-I treatment after MI the functional effects. precede the structural effects.

After MI in mice, ventricular systolic pressure, maximal ventriculat contraction and relaxation are depressed ${ }^{313,369}$. Ventricular systolic pressure at rest was even lower in losartan treated hearts. Unloading of the heart reduced both contractility $(+\mathrm{dp} / \mathrm{dt}$ ) and relaxation $(-\mathrm{dp} / \mathrm{dt})$. These results are controversial, since several studies on chronic RAS inhibition after Ml demonstrate unloading of the heart combined with an improved cardiac contractility $^{214.376}$. However, different animal models were used and in most of these studies inhibition of RAS activity was started at a later time point compared to the present study. Previous studies on $\mathrm{MI}$ in mice, demonstrate that both chronic ACE imhibition started immediately after $\mathrm{MI}$ and the genetic lack of membrane-bound $\mathrm{ACE}$ result in a reduced contractility of the heart. In rats, similar results on cardiac contractility were observed when $A T$, receptor blockade was started at one day after MI. Left ventricular dp/dt was reduced after MI and even further reduced when the heart was unloaded by prolonged losartan or captopril treatment ${ }^{143,3547 !}$. Since ventricular" systolic pressure was significantly lower in losartan treated animals compared to untreated animals, the decrease in maximal ventricular contraction and relaxation might be secondary to a reduction in cardiac loading. After correcting maximal ventricular contraction and relaxation for the afterload (systolic pressure), nomalised dp/dt values were still significantly lower in losartan group compared to the untreated group $\left(48 \pm 4 \mathrm{vs} .64 \pm 3(\mathrm{p}=0.02)\right.$ and $\left.41 \pm 3 \mathrm{vs} .57 \pm 4 \mathrm{~s}^{-1}(\mathrm{p}=0.046)\right)$. These values are inversely related to maximal contraction and relaxation time. Thus, losartan administrated imnediately after MI reduces cardiac contractility independently of its pressure effect.

By combining losartan with IGF-I the ventricular systolic pressure, maximal ventricular contraction and relaxation significantly increased compared to losartan alone. In mice without myocardial infarction, IGF-I infusion did not affect left ventricular pressure nor left 
wentricular $\mathrm{dp} / \mathrm{dt}^{365}$. GH/IGF-I administration combined with captopril did not affeet pressure but increased $\mathrm{dp} / \mathrm{dt}$ in rats ${ }^{370}$. The increased maximal ventricular contraction and relaxation observed after IGF-I addition to the losartan treatment might be secondary to its increasing effect on ventricular systolic pressure. After correcting maximal ventricular contraction and relaxation for the afterload, values were not significantly higher in the losartan + IGF-I group compared to the losartan group ( $54 \pm 3$ vs. $48 \pm 4$ and $48 \pm 3$ vs. 41 $\pm 3 \mathrm{~s}^{-1}$ ). These results suggest that IGF-I is able to elevate cardiac contractility and relaxation during $\mathrm{AT}_{1}$ antagonism and that this effect is related to the altered systolic pressure.

Maximal contractility and relaxation were increased in all three groups through cumulative infusion of dobutamine. Maximal contractility and relaxation remained lower in the losartan and losartan + IGF-I treated groups compared to the untreated group. Moreover, the difference between losartan and losartan + IGF-I observed at rest disappeared after dobutamine infusion. This might be explained by the significantly enhanced response to dobutamine in the losartan treated animals. Prolonged treatment with ACE inhibitors or $\mathrm{AT}_{1}$ antagonists have been reported to result in an increased cardiac catecholamine content $^{302,303}$. Furthermore, prolonged captopril treatment increases the $\beta$-receptor density ${ }^{372.373}$. A recent study demonstrated that $\mathrm{GH}$ administration started at 3 days postinfarction downregulated cardiac catecholamine content without changing the $\beta$-receptor density ${ }^{365}$. The opposite was observed in IGF-1 deficient mice exhibiting an enhanced $\beta$ adrenergic response due to an increased adenylyl cyclase activity without changes in $\beta$ receptor density ${ }^{374}$. Although the exact mechanism needs to be elucidated, these data suggest a relationship between the GH/GG-I axis and the sympathetic nervous system. Adding IGF-I to losartan seems to restore the enhanced $\beta$-adrenergic response observed during losartan administration.

In conclusion, $\mathrm{AT}_{1}$ receptor antagonism in mice started at an early time point after $\mathrm{MI}$ reduces cardiac contractility and relaxation, without changing the structural remodelling after MI. Addition of IGF-I to losartan treatment after MI is able to increase cardiac contractility and relaxation at rest but not after maximal stimulation with dobutamine. This suggests a role of the sympathetic nervous system in the effect of IGF-I on cardiac contractility.

\section{Acknowledgements}

J.J.M. Debets, P.J.A. Leenders and N.J.J.E. Bitsch are gratefully acknowledged for their technical assistance. 


\begin{abstract}
Angiotensin-l-converting enzyme (ACE) inhibition during hypertension affects arterial structure and reactivity. ACE exists as a circulating and as a membrane-bound enzyme (i$A C E$ ). In this study, the effects of $t-A C E$ deficiency on the peripheral arterial system were investigated and compared to the effects of pharmacological $A C E$ inhibition with captopril. In the aorta, carotid artery and mesenteric artery isolated from $-\mathrm{ACE}-1-$ and $t-\mathrm{ACE}+/+$ mice (1) the relationship between transmural pressure $(20-140 \mathrm{mmHg})$ and diameter and (2) the responsiveness to vasoactive agents like potassium; $K$, phenylephrine; Phe, and acetylcholine; Ach, were determined. This procedure was repeated in $\mathrm{t}-\mathrm{ACE}+1+$ mice treated with captoprill ( $80 \mathrm{mg} / \mathrm{kg} /$ day, from $3-12$ weeks of age). In all tested vessels, $\mathrm{t}-\mathrm{ACE}$ deficiency and $A C E$ inhibition resulted in a reduced vascular elasticity. Vascular reactivity changes were observed in the $1-\mathrm{ACE}-/$ aorta, of which the maximal relaxing response to Ach ( $4 \pm 2$ vs. $24 \pm 2 \%$ was reduced. Contractile responses to $K^{+}(0.7 \pm 0.1$ ws. $1.6 \pm 0.1$ $\mathrm{N} / \mathrm{m})$ and Phe $(0.4 \pm 0.1 \mathrm{ws} .1 .0 \pm 0.1 \mathrm{~N} / \mathrm{m})$ were reduced in $\mathrm{t}-\mathrm{ACE}-\mathrm{m}$ and in $\mathrm{t}-\mathrm{ACE}+1+$ captopril compared to $\mathrm{ACE}+\mathrm{H}+$ carotid arteries. Lack of $\mathrm{t}-\mathrm{ACE}$ blunts vessel reactivity and increases arterial stiffness, which is not due to ACE deficiency during foetal development, since similar vascular alterations can be found in captopril treated $t-A C E+/ 4$ mice.
\end{abstract}




\section{Absence of membrane-bound angiotensin-I-} converting enzyme enhances stiffness and

\section{blunts reactivity of peripheral arteries}

Wendy M. Aartsen, R.H. Hilgers, P.M.H. Schiffers, MI.J.A.P. Daemen, J.G.R. De Mey and J.F.M. Smits

Submitted to Journal of Vascular Research

\section{Introduction}

Many vascular alterations have been described during inhibition of the renin-angiotensin system (RAS) in cardiovascular diseases. Angiotensin-1-convering enzyme (ACE) inhibition reduces or prevents the vascular inward remodelling found in hypertensive subjects $^{208,209}$. Artenial stiffness observed in essential hypertension is reduced after angiotensin receptor type 1 antagonism ${ }^{375}$. Also intima-formation after arterial injury or during atherosclerosis ${ }^{376,377}$ is significantly reduced by $\mathrm{ACE}$ inhibition. Additionally, $\mathrm{ACE}$ inhibition results in functional improvement of the arterial endothelium-dependent relaxation in spontaneously hypertensive rats ${ }^{378}$ and in patients with coronary artery disease $^{379}$. These data strongly suggest the involvement of the RAS in vasculat structure and function.

ACE is a component of the RAS, it is active in the circulation, but also expressed and active in various organs including the vessel wall ${ }^{57,380}$. Both plasma and membrane-bound $\mathrm{ACE}$ 
contribute to the generation of the vasoactive peptide angiotensin $\mathrm{II}^{28.27}$ and angiotensin II is known to be an important regulator of vascular tone. It acts directly by stimulation of vascular AT receptors and indirectly via, for instance, the stimulation of noradrenalinerelease from nerve endings ${ }^{360}$. Sewerall studies demonstrated that angiotensin II induces a growth response in cultured vascular smooth muscle cells ${ }^{381}$ and arterial thickening, even when infused at a non-pressor dose $\mathrm{e}^{332}$. Recently we proved the involvement of membranebound $\mathrm{ACE}$ ( $\mathrm{t}-\mathrm{ACE}$ ) in pulmonary vascular remodelling induced by hypoxia, which is independent of blood pressure ${ }^{345}$.

Here we hypothesised that membrane-bound $\mathrm{ACE}$ is also involved in the structural and functional maturation of the peripheral vasculature. To tests this hypothesis we used the genetically modified mouse lacking membrane-bound $\mathrm{ACE}(\mathrm{t}-\mathrm{ACE}-/ /-)^{107}$ which produces a truncated form of $\mathrm{ACE}$ consisting of only the $\mathrm{N}$-terminal enzymatic site without the ability to bind the cell-membrane. Phenotypically these mice exhibit a significantly lower systemic blood pressure compared to their wild-type littermates ${ }^{107}$. In the present study, changes in the peripheral arterial system due to the absence of $\mathrm{t}-\mathrm{ACE}$ were investigated. The thoracic aortas, common carotid and mesenteric arteries from $\mathrm{t}-\mathrm{ACE}+/+$ and $\mathrm{t}-\mathrm{ACE}-/-$ mice were studied in vitro. Elastic characteristics and responses to vasoactive agents were examined. Morphological parameters were measured to relate the mechanical vessel properties to the vessel structure. In the second part of the study, the vascular effects of t-ACE deficiency were compared with vascular effects of pharmacological ACE inhibition. Elastic characteristics and responses to vasoactive agents of the carotid and mesenteric artery were examined at 12 weeks of age in untreated and captopril treated t-ACE $+/+$ mice.

\section{Materials and Methods}

Animals

The generation of mice with a C57BL6/129/SV genetic background and lacking membranebound angiotensin-l-converting enzyme (t-ACE- - ) has been described by Esther et al ${ }^{107}$. Mice heterozygous for the mutated $\mathrm{ACE}$ allele $(\mathrm{t}-\mathrm{ACE}+/)$ were bred to obtain mice homozygous for the mutated ACE allele (t-ACE-/-) and their wild-type littermates (t-ACE $+/ 4)$. Adult female mice $(\mathrm{t}-\mathrm{ACE}+/ \mathrm{t}$ and $\mathrm{t}$-ACE $-/$ - $)$ were used to investigate the effects of $\mathrm{t}$ $\mathrm{ACE}$ deficiency. The age of these mice varied between 6 and 12 months, but mice were age-matched between the two genotypes. Additionally, wild-type animals $(\mathrm{t}-\mathrm{ACE}+/ \mathrm{t})$ were crossed and their female offspring had access to either tap water or captopril dissolved in tap water $(80 \mathrm{mg} / \mathrm{kg} /$ day) from the age of 3 weeks until 12 weeks after birth. All animals were housed in groups of 4 to 6 and had free access to standard food (SRMA-1210; Hope Farms, Woerden, The Netherlands) and tap water. All experiments were conducted 
according to institutional guidelines and conformed to the gute for the care and use of laboratory animals, published by the US National Institutes of Healih (NMI Publication No $85-23$, revised 1996 ).

\section{Genotyping}

To genotype pups genomic DNA was isolated form the tail using the Quagen DNA isolation. kit (Qiagen GmbH, Hilden, Germany). Ready-to-go PCR beads (Amersham Phammacia Biotech) were used for $\mathrm{PCR}$ analyses on genomic DNA. The three primers used are described by Esther et al ${ }^{107}$.

\section{Blood pressure}

Mice were anaesthetised with pentobarbital (110 mg/kg i.p.) and placed on a heating-pad to maintain body temperature at $37^{\circ} \mathrm{C}$. To measure mean arterial blood pressure (MAP) a saline filled catheter (PE 25) was inserted into the abdominal norta via the femoral artery and connected to a pressure transducer (Micro-Switch, model 156PC $156 \mathrm{WL}$, Honeywell Inc., Amsterdam, the Netherlands Amsterdam, the Netherlands). Blood pressure signals were recorded and 10 minutes of stable recordings were used to calculate the MAP.

\section{Pressure-Diameter curves}

After blood pressure measurements, 3-4 mm segments of a first-order mesenteric artery were isolated. Arteries were transferred to a dual-chamber arteriograph (Living systems Instrumentation). One end of the vessel was mounted onto the proximal microcannula. After flushing the artery with HEPES buffer the other end was tied around the distal microcannula ${ }^{383}$. The cannulas were connected to a feedback controlled pressure pump (Living systems Instrumentation) and the internal diameter was visualised by an inverted microscope (Nikon TMS) with video camera (Stemmer). The $10 \mathrm{ml}$ organ bath was filled with calcium free HEPES buffer at $37^{\circ} \mathrm{C} ; 10 \mu \mathrm{M}$ sodium nitroprusside (SNP) was added to assure maximal vasodilatation. Inner diameter was determined as function of imposed pressure $(20-140 \mathrm{mmHg})$ in case of the mesenteric artery. The same procedure was followed for the thoracic anta and common carotid artery, however these arteries were only cannulated at one end while the other end was closed (blind sac). The aorta and carotid artery outer diameters were related to imposed pressure (20-190 $\mathrm{mmHg}$ ). For $1-\mathrm{ACE}-1$ mice and their wild-type littermates the aorta, carotid and mesenteric artery were used, while only the carotid and mesenteric artery were used from untreated $\mathrm{t}-\mathrm{ACE} H+t$ and $t$ ACE $+1+$ mice treated with captopril. 


\section{Arterial Reactivity}

$2 \mathrm{~mm}$ arterial segments of thoracic aorta, common carotid and first-order mesenteric antery from $\mathrm{t}-\mathrm{ACE}-/$ and $\mathrm{ACE}+\mathrm{A}+$ mice were mounted in a wire-myograph setup (model 610 , Danish Myothechnology, Denmark). Organ baths were filled with Krebs-Ringer's solution and aterated with $95 \% \mathrm{O}_{2}$ and $5 \% \mathrm{CO}_{2}$ while maintaining temperature at $37^{\circ} \mathrm{C}$. Arterial segments were stretched to their optimal diameter. The optimal diameter was defined as the diameter at which the contractile response to $40 \mathrm{mM}$ potassium solution was maximal. After incubation with capsaticin ( $1 \mu \mathrm{M}$ ) for 30 minutes to desensitise the sensory nerve fibres, a stable contraction to $40 \mathrm{mM}$ potassium was established. Relaxation-response curves to calcitonin gene-related peptide (CGRP, $10^{-30}$ to $10^{-3} \mathrm{M}$ ) were constructed. Thereafter contraction-response curves for norepinephrine $\left(\mathrm{NE}, 10^{-18}\right.$ to $\left.10^{-5} \mathrm{M}\right)$ and phenylephrine (Phe, $10^{-85}$ to $10^{-5} \mathrm{M}$ ) were constructed. Relaxation-response curves to acetylcholine (Ach $10^{-8}$ to $10^{-5} \mathrm{M}$ ) and sodium nitroprusside (SNP, $10^{-8}$ to $10^{-5} \mathrm{M}$ ) were constructed after precontraction with $40 \mathrm{mM}$ potassium, in the absence or presence of indomethacine ( $3 \mu \mathrm{M})$ and L-NAME (0.1 $\mathrm{mM})$. The same procedure was repeated in the carotid artery from untreated t-ACE $+1+$ and $t-\mathrm{ACE}+/+$ mice treated with captopril.

\section{Morphometry}

Vessels were formalin-fixed at $80 \mathrm{mmHg}$ in the arteriograph. $4 \mu \mathrm{m}$ cross sections were prepared and elastin was stained with Lawson solution (Boom bv., Meppel, The Netherlands) followed by visualisation through a Zeiss Axioscope equipped with standard CCD camera (Sony). Video images were analysed with commercially available software (JAVA 1.21, Jandel Scientific) to measure media cross-sectional area, media thickness, radius and wall-to-lumen ratio. To obtain the elastin/collagen ratio, cross sections $(4 \mu \mathrm{m})$ were deparaffinised and incubated in phosphomolybdic acid $(0.2 \%)^{348}$ for 5 minutes, followed by incubation with Sirius red $(0.1 \%)$ in saturated picric acid solution for 90 minutes. After washing with $0.01 \mathrm{M} \mathrm{HCl}$ for 2 minutes, the sections were dehydrated and protected with coverslips. Collagen content was measured at $400 \mathrm{x}$ magnification in the wortic media (JAVA 1.21, Jandel Scientific).

\section{Calculation of parameters}

Arterial distensibility, or the relative change in volume induced by a given increase in pressure was estimated by: $\mathrm{DC}=\Delta \mathrm{A} / \mathrm{A}_{\mathrm{n}-1}, \Delta \mathrm{P} \quad(\mathrm{DC}=\text { distensibility, } \mathrm{A}=\text { area, } \mathrm{P}=\text { pressure })^{38 *}$. For the mesenteric artery also circumferential wall stress and incremental elastic modulus were calculated $^{325 .}$. Circumferential wall stress $(\sigma)$ is related to wall thickness $(W t)$ and wall tension (T): $\sigma=T / W t$. According to Laplace's Law, wall tension depends upon transmural pressure $(\mathrm{Pt})$ and radius $(\mathrm{r})$ : $\mathrm{T}=\mathrm{Pt}$.r. Incremental elastic modulus $\left(\mathrm{E}_{\mathrm{inc}}\right.$ ) was calculated 
according to Bergel $^{336}: E_{\text {inc }}=1.5 r_{0}{ }^{2} \cdot r_{i} \cdot \Delta P /\left(r_{0}{ }^{2}-r_{i}{ }^{2}\right) \cdot \Delta r_{i}$ which derives from $0.75 d / W D C$, where $r_{0}=$ outer radius, $r_{i}=$ inner radius and $d=$ outer diameter.

\section{Statistics}

Data are shown as means $\$$ SEM. The impact of the genetic modification or captopril treatment was tested with a two-way ANOVA for repeated measurements in case of the pressure-diameter curves. A unpaired Student's $t$-test or Mann-Whitney $U$ test when normality test failed, was used to test the impact of the genetic modification or captopril treatment on vascular reactivity. Statistical significance was accepted if $\mathrm{p}<0.05$.

\section{Results}

\section{General}

Age-matched female t-ACE - mice had significantly lower body weights than female t$\mathrm{ACE}+/+$ mice. $\mathrm{T}-\mathrm{ACE}-/-$ mice exhibited significantly lower blood pressures than $\mathrm{ACE}$ $+1+$ mice, while heart rate was elevated (Table 1). At 12 weeks, body weight, blood pressure and heart rate of untreated and captopril treated $t-A C E+1+$ mice was determined (Table 1 ). Body weight of captopril treated $t-A C E+1+$ mice was significantly lower than body weight of untreated mice. Captopril treatment resulted in a blood pressure decrease, which was similar to the blood pressure measured in $\mathrm{t}-\mathrm{ACE} \%$ mice. No differences in the heart rate were found between captopril treated animals and control animals.

Table 1. Body weight, heart rate and blood pressure

\begin{tabular}{|c|c|c|c|c|}
\hline & $\mathrm{t}-\mathrm{ACE}+1+$ & $t-\mathbf{A C E}-1$ & $\begin{array}{l}\text { t-ACE }+/+ \\
\text { untreated }\end{array}$ & $\begin{array}{l}\text { t-ACE -/ } \\
\text { captopril }\end{array}$ \\
\hline $\mathbb{N}$ & 10 & 10 & 5 & 5 \\
\hline $\mathrm{BW}(\mathrm{g})$ & $28 \pm 1$ & $23 \pm 1 *$ & $22 \pm 1$ & $19 \pm 1 * *$ \\
\hline $\mathrm{MAP}(\mathrm{mmLg})$ & $38 \pm 2$ & $26 \pm 2 *$ & $38 \pm 8$ & $22 \pm 3 *$ \\
\hline HR (bpm) & $400 \pm 24$ & $517 \pm 25 *$ & $451 \pm 13$ & $429 \pm 26$ \\
\hline
\end{tabular}

Data are presented as mean \pm SEM. Abbreviations: BW; body weight, MAP; mean arterial pressure, HR; heart rate. Captopril; t-ACE $+/+$ mice treated with captopril ( $80 \mathrm{mg} / \mathrm{kg} /$ day) from $3-$ 12. weeks after birth. * Significant difference between $\mathrm{t}-\mathrm{ACE}+\%+$ and $\mathrm{t}-\mathrm{ACE}+/$-mice $(\mathrm{p}<0.05)$. * Significantly different from untreated t-ACE + +4 mice $(p<0.05)$. 


\section{Pressure-diameter curves}

Pressure-diameter curves for the thoracic aortaly, common carotid artery and first-order mesenteric artery of $\mathrm{t}-\mathrm{ACE}-$ and $\mathrm{t}-\mathrm{ACE}+1+$ mice are shown in figure 1 , together with calculated distensibility. Figure 2 shows the pressure diameter curves and calculated distensibility obtained from the carotid artery and first-order mesenteric artery of $1-\mathrm{ACE}+1 /$ mice untreated and treated with captopril. The pressure-diameter curves shown for the carotid artery and aorta are comparable to the curve Bergel ${ }^{386}$ obtained from the thoracic aorta (blind sac). The pressure-diameter curves of the mesenteric artery were constructed in a situation of fixed length and show a typical progressive decrease of distensibility ${ }^{386}$. In al] t-ACE - $/$ vessels tested, the distensibility was reduced compared to $t-A C E+/+$ vessels. Vascular distensibility of captopril treated vessels was significantly lower compared to untreated vessels.

Figure 3 shows the incremental elastic modulus $\left(E_{\text {inc }}\right)$ of the mesenteric artery as a function of circumferential wall stress of both the $t-\mathrm{ACE}-\%$ and age-matched $t-\mathrm{ACE}+\%+$, together with untreated $\mathrm{t}-\mathrm{ACE}+/+$ and captopril treated $\mathrm{t}-\mathrm{ACE}+/+\mathrm{E}_{\mathrm{inc}}$ was only calculated for the mesenteric artery because wall thickness of the aorta and carotid artery could not be visualised. Results indicate that $E_{\text {inc }}$ is increased in $\mathrm{t}-\mathrm{ACE}-/$-mesenteric arteries, which means a reduced elasticity when compared to the $\mathrm{t}-\mathrm{ACE}+/ 4$ vessels. In captopril treated mesenteric arteries $\mathrm{E}_{\mathrm{inc}}$ was also increased compared to the untreated mesenteric arteries.

\section{Pressure-diameter curves}

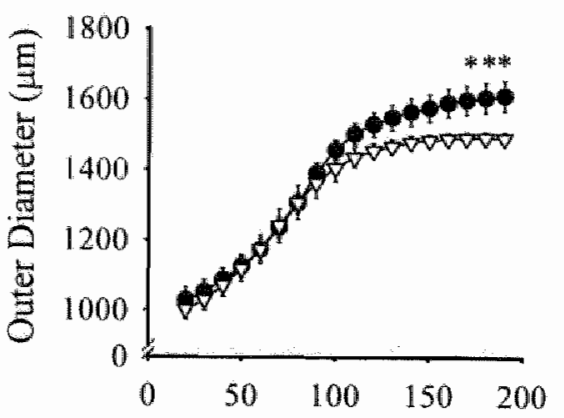

Arterial Distensibility

Aorta

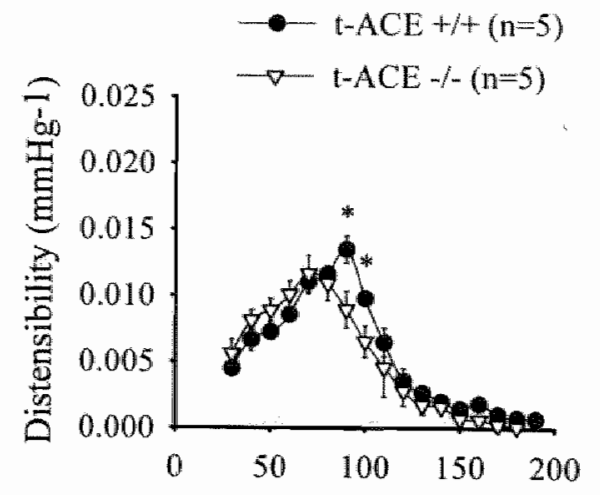




\section{Pressure-diameter curves}

\section{Arterial Distensibility}

\section{Carotid artery}
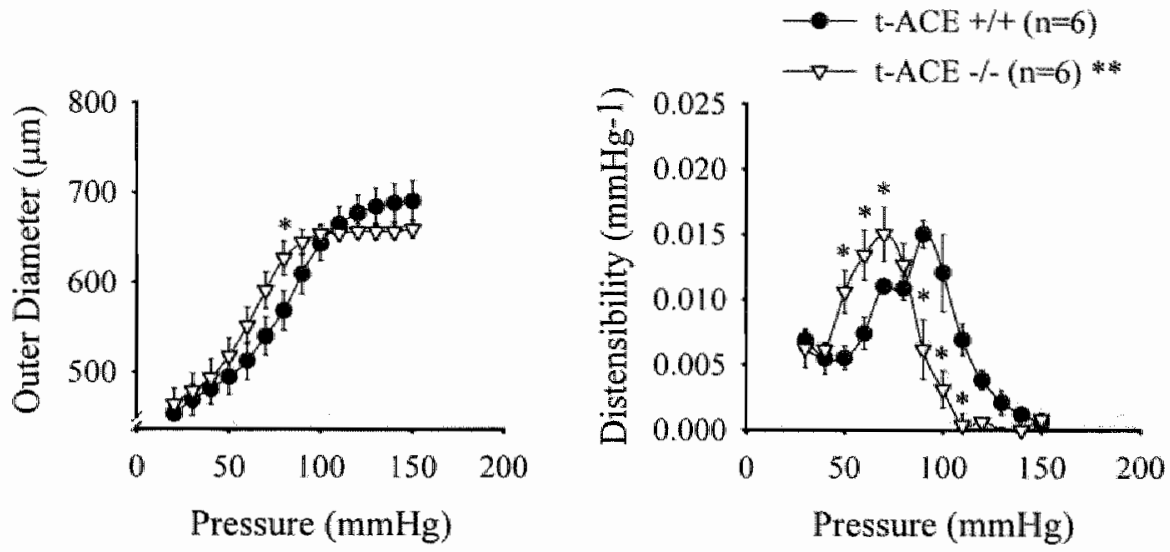

Mesenteric artery
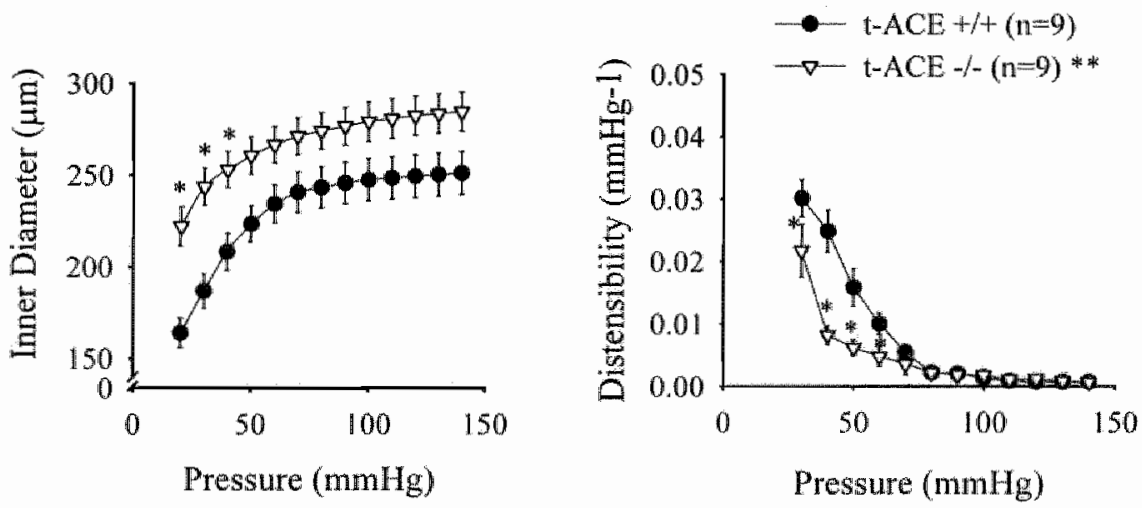

Figure 1. Left panel: Relationship between imposed pressure and diameter in isolated aorta (top panel), carotid artery (middle panel) and mesenteric artery (bottom panel) from $t-\mathrm{ACE}+1 \mathrm{t}$ and $\mathrm{t}-$ ACE -/- mice. Right panel: Calculated distensibilty for the aoria, carotid artery and mesenteric artery. Significant difference between wild-type $($ t- $\mathrm{ACE}+/+)$ and knockout mice $(\mathrm{t}-\mathrm{ACE}-1-$; $p<0.05) . *$ (in legends) Significant interaction between pressure and genotype ( $p<0.05$ ). 
Pressure-diameter curves

Arterial Distensibility

Carotid artery

$\rightarrow \mathrm{t}-\mathrm{ACE}+\mathrm{t}+(\mathrm{n}=7)$

$\rightarrow$ captopril $(n=7) * *$
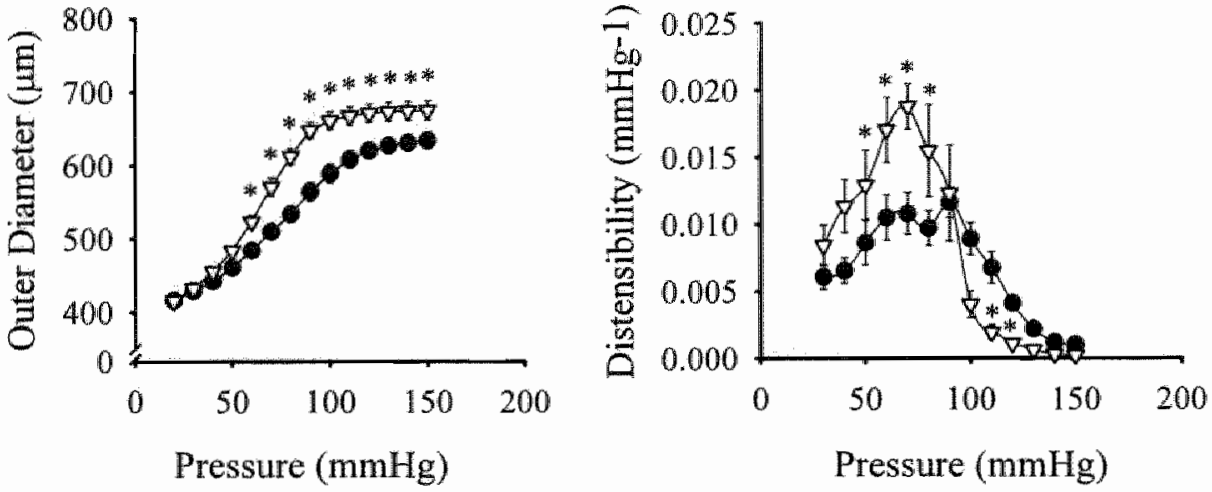

Mesenteric artery
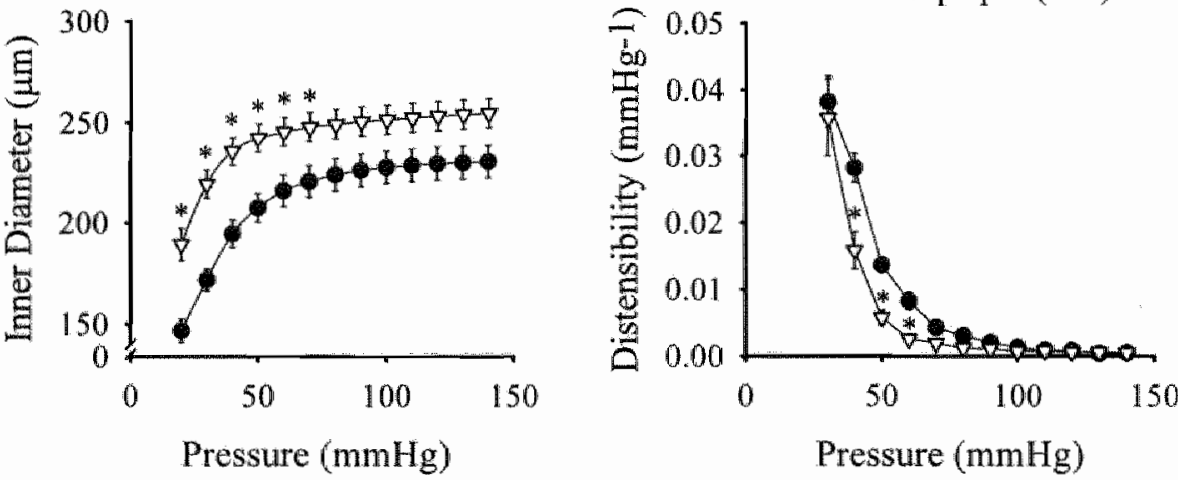

Figure 2. Left panel: Relationship between inposed pressure and diameter in isolated carotid artery (top panel) and mesenteric artery (bottom panel) from $\mathrm{t}-\mathrm{ACE}+\%+$ and captopril-treated $\mathrm{t}-$ ACE $+1+$ mice. Right panel: Calculated distensibilty for carotid artery and mesenteric artery. * Significant difference between captopril treated and untreated $t-A C E+H+(p<0,05)$. ** (in legends) Significant interaction between pressure and treatment $(p<0.05)$. 


\section{Incremental elastic modulus}

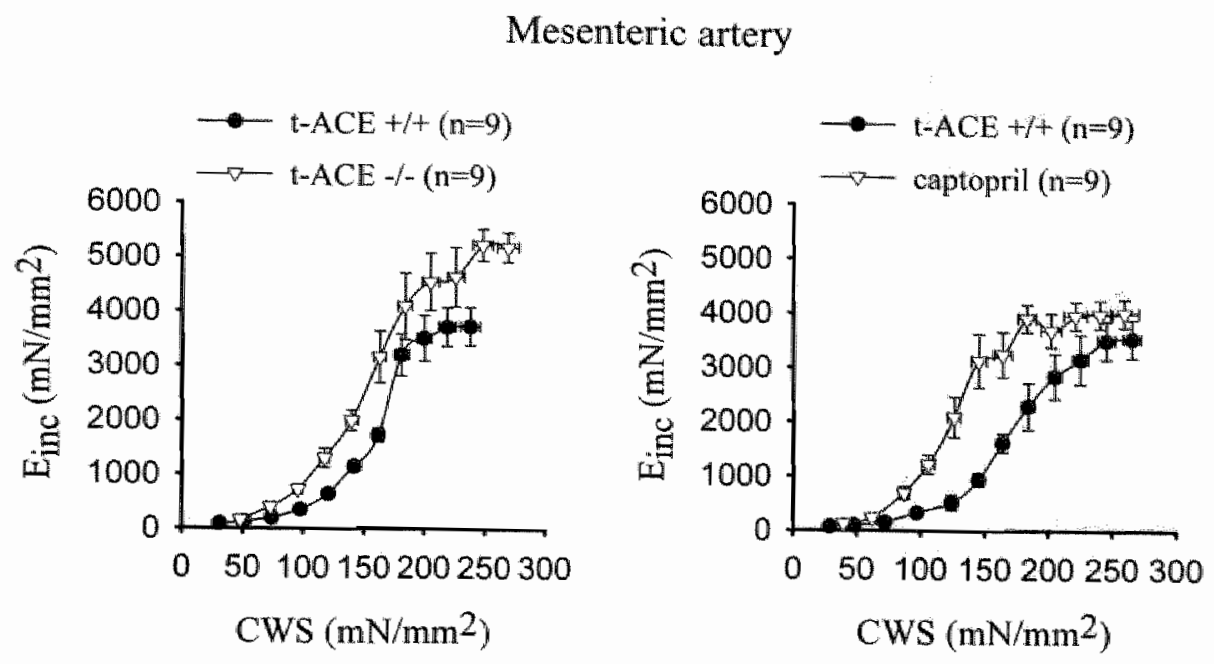

Figure 3. Left pane: Calculated incremental elastic modulus of the mesenteric artery ( $\mathbb{E}_{\text {inc }}$ ) plotted against the circumferential wall stress (CWS) determined in $1-\mathrm{ACE}-1-$ and $\mathrm{ACE}+4$ mice. Right panel: Calculated incremental elastic modulus of the mesenteric artery (Einc) plotted against the circumferential wall stress (CWS) determined in captopril treated and untreated t$A C E+f+$ mice.

\section{Morphometry}

Four parameters of arterial structure were determined and are presented in Table 2 . No significant differences in the carotid and mesenteric artery structure were found between 1 $\mathrm{ACE}-1-$ and $\mathrm{t}-\mathrm{ACE}+1+$ mice. Aortic media cross sectional area (CSA) and media thickness (Mt), were significantly reduced in $\mathrm{t}-\mathrm{ACE}$ - / aortas. The cross sectional area and wall thickness of captopril treated carotid arteries were significantly reduced compared to untreated carotid arteries, resulting in a reduced wall-to-lumen ratio. In the mestenteric arteries, captopril treatment resulted in an increased radius compared to the untreated mesenteric arteries, which resulted in a significant reduction of the wall-to-lumen ratio in captopril-treated vessels compared to control vessels. Because of the small vessel size, reliable values for collagen and elastin percentages could only be obtained from aortic sections (Table 2). The percentages of collagen and elastin were similar in both groups. 


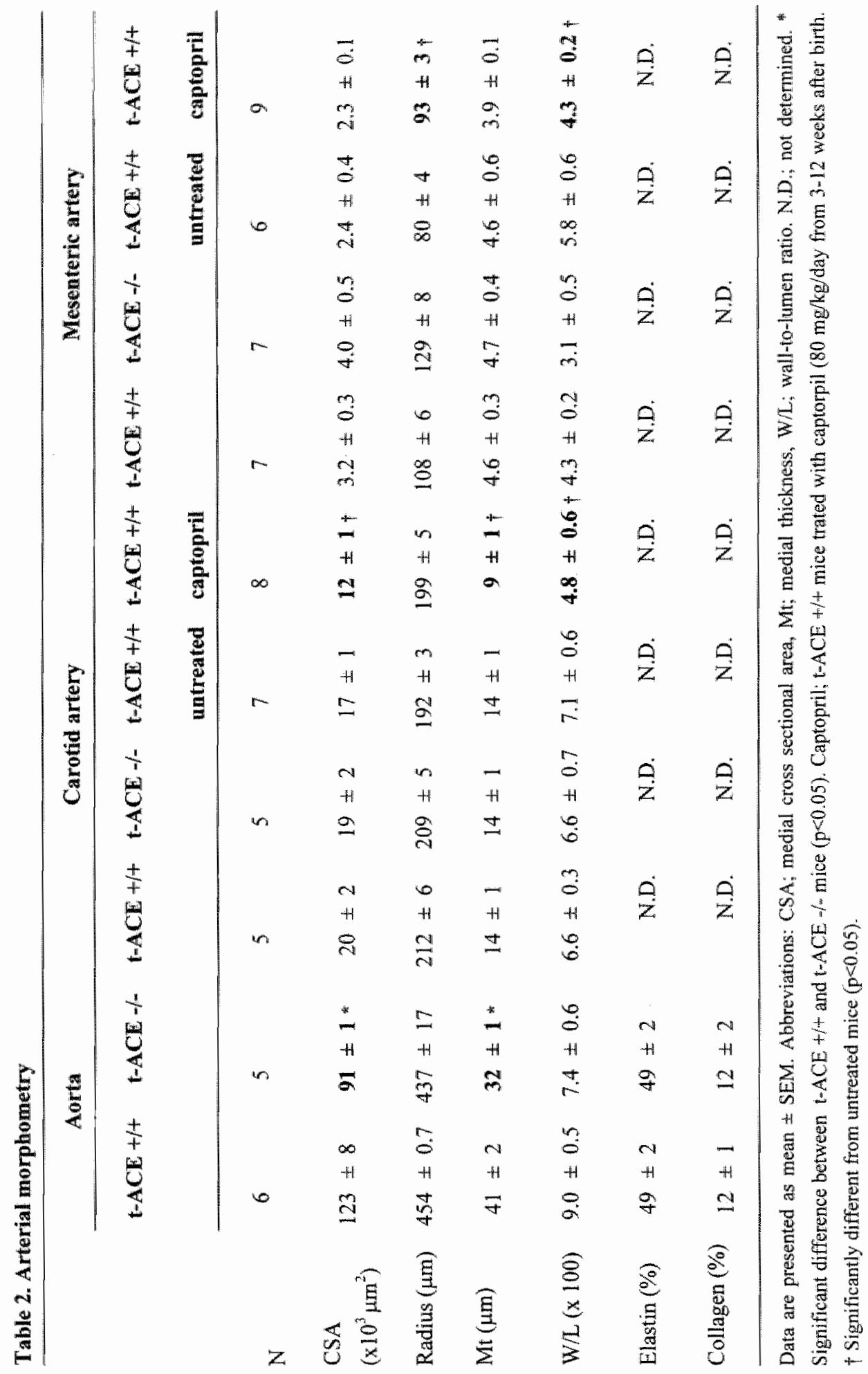




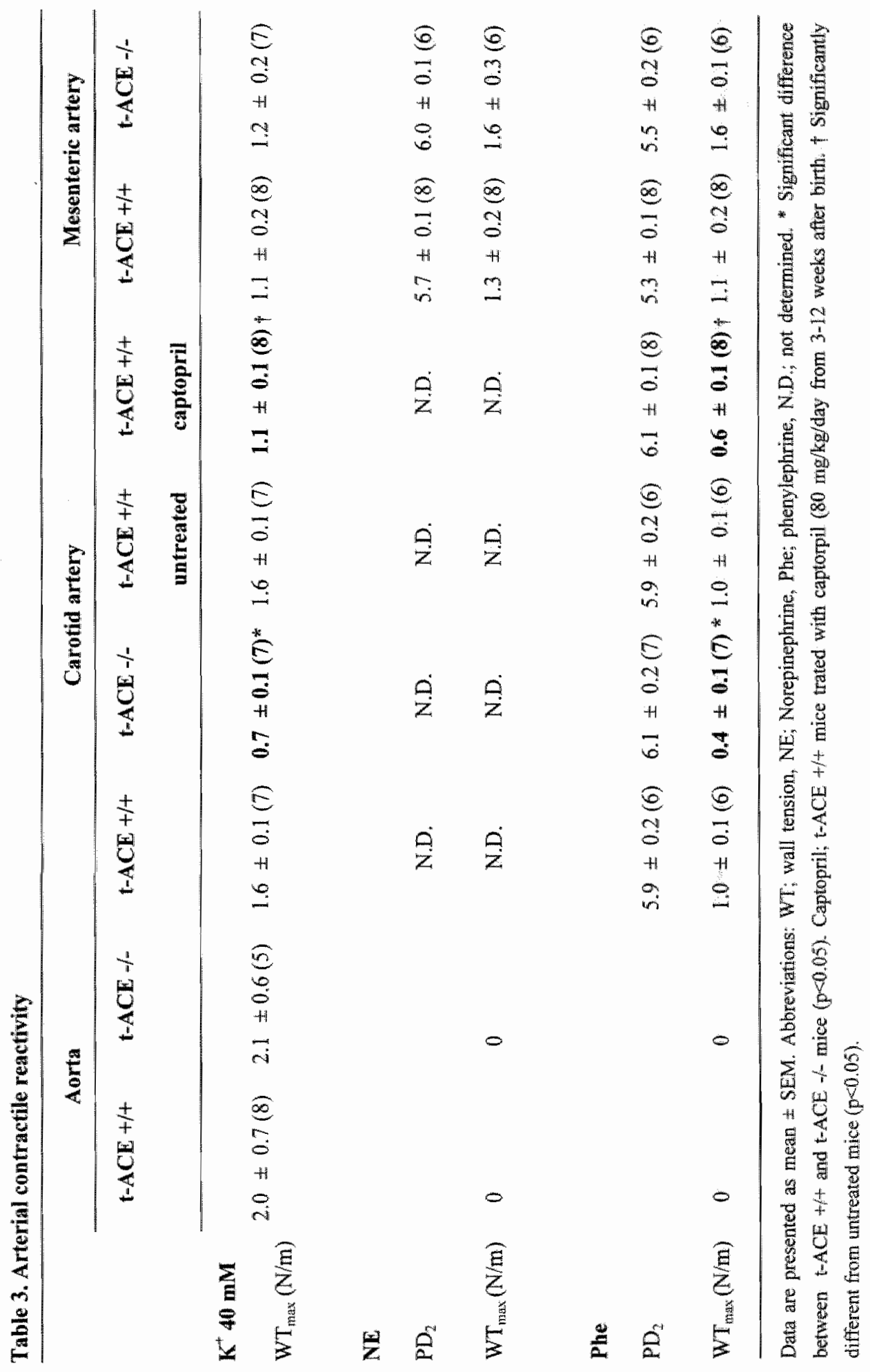




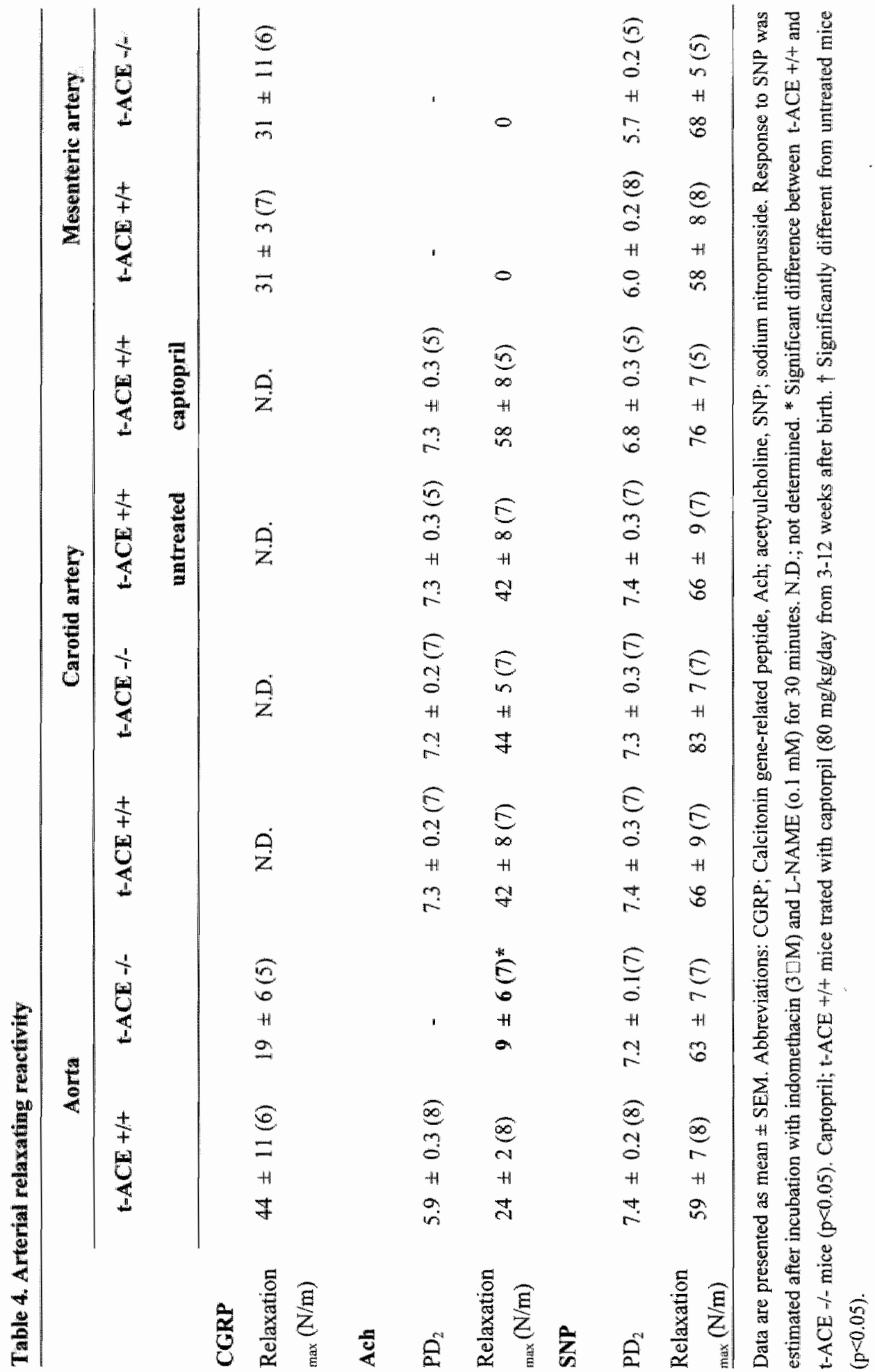




\section{Arterial Reactivity}

$\mathrm{PD}_{2}$ values and maximal wall tension, calculated from the isometric tension developed in response to vasoconstrictor stimuli in thoracic aorta, common carotid artery and mesenteric artery of $\mathrm{t}-\mathrm{ACE}-/-$ and $\mathrm{t}-\mathrm{ACE}+/+$ mice, are shown in Table 3. These results are shown together with the response to vasoconstrictor stimuli observed in the common carotid artery of untreated and captopril treated $\mathrm{t}-\mathrm{ACE}+1+$ mice. With all tested vasoconstrictors no differences were found in the reactivity of the mesenteric artery or aorta between $\mathrm{t}-\mathrm{ACE}-\mathrm{H}$ and $\mathrm{t}-\mathrm{ACE}+/+$. In $\mathrm{t}-\mathrm{ACE}-/-$ carotid artery the response to both potassium and phenylephrine was significantly lower than in $\mathrm{t}-\mathrm{ACE}+\mathrm{t}+\mathrm{t}$ vessels. Similar results were observed in the carotid arteries of captopril treated mice when compared to untreated controls.

Arterial responses to vasodilators are shown in Table 4. While the percentage of arortic dilation induced by CGRP and sodium nitroprusside was similar in vessels from $\mathrm{t}-\mathrm{ACE}-\mathrm{-}$ and $\mathrm{t}-\mathrm{ACE}+/+$ mice, a significant difference between $\mathrm{t}-\mathrm{ACE}-/-$ and $\mathrm{t}-\mathrm{ACE}+/+$ mice was found in the maximal relaxation of the aorta to acetylcholine. Relaxation of the mesenteric and carotid artery was similar in $\mathrm{t}-\mathrm{ACE}-/-$ and $\mathrm{t}-\mathrm{ACE}+/ \mathrm{t}$ mice. Captopril treatment had no effect on the relaxation of the carotid artery. No response to acetylcholine was detectable in the mesenteric artery. Yet, structural integrity of the endothelium of these mesenteric arteries was demonstrated on $4 \mu \mathrm{m}$ cross sections.

\section{Discussion}

\section{General}

In the present study the effect of membrane-bound $\mathrm{ACE}$ (t-ACE) deficiency ${ }^{107}$ on systemic arteries was investigated. The mechanical characteristics, structure and reactivity of the thoracic aorta, common carotid artery and first-order mesenteric artery were studied. The absence of $t-A C E$ reduced the distensibility of all vessels tested. The reactivity-changes due to the $\mathrm{t}-\mathrm{ACE}$ deficiency were regionally heterogeneous. Similar results were obtained in vessels isolated from captopril treated animals. Since these animals were treated after lactation until early maturity, these data suggest that the vascular alterations found in t-ACE $-/$ mice are not due to $\mathrm{t}-\mathrm{ACE}$ deficiency during foetal development.

\section{Pressure-diameter relationship}

Both the aorta and the carotid artery showed a sigmoid pressure-diameter relationship. The sigmoid shape of the curve is directly related to the composition of the wall ${ }^{387,388}$. The pressure-diameter curves of the mesenteric arteries show a steady increase, which developed faster in $\mathrm{t}-\mathrm{ACE}-/$ mesenteric arteries than in $\mathrm{t}-\mathrm{ACE}+1+$ arteries, indicating a 
reduced distensibility in the absence of $1-A C E$. The distensibility of the large $\mathrm{t}-\mathrm{ACE}-\mathrm{H}$ arteries shows an optimum at a lower pressure when compared to wild-type arteries, indicating that $1-A C E-1-$ vessels are less elastic than $t-A C E+1+$ vessels. In carotid arteries from captopril treated animals, the pressure-diameter relationship was shifted to the left compared to control $\mathrm{t}-\mathrm{ACE}+/ t$ wessels. Distensibility between 80 and $120 \mathrm{mmHg}$ was. reduced in the captopril group. Similar results were obtained for the captopril-treated. mesenteric artery as in the $\mathrm{t}-\mathrm{ACE}-\%$ mesenteric artery. The pressure-relationship of the mesenteric artery showed a steady increase, which reached its maximal diameter at a lower pressure in the captopril treated vessels than in the control vessels. Captopril treated vessels showed a decreased distensibility along the whole curve. Since the elastic characteristics are tested in vitro without flow or vascular tone the decreased distensibility is directly related to the vessel wall composition ${ }^{338}$.

The elastic properties of maximally dilated arteries depend on vessel wall components and on vessel geometry. Morphometric analysis showed that the aortic media-cross sectional area, radius, media thickness and wall-to-lumen ratio were all reduced in $\mathrm{t}-\mathrm{ACE}-/$ - mice compared to $\mathrm{t}-\mathrm{ACE}+1+$ mice, whille the carotid and mesenteric arteries showed no structural differences. In captopril treated animals, media cross-sectional area, wall thickness and wall-to-lumen ratio of the carotid artery were significantly reduced, while the radius of the mesenteric artery was significantly increased after captopril treatment resulting in a reduced wall-to-lumen ratio.

By calculating the incremental elastic modulus $\left(\mathbb{E}_{\text {inc }}=\mathrm{d} / \mathrm{Wt} . \mathrm{DC}\right)$, the relationship between strain and stress, changes in vessel wall morphometry, which affect elasticity, are taken into account. Although the wall thickness (Wt) of the carotid arteries and aortas could not be visualised, it was determined after fixation at $80 \mathrm{mmHg}$. The morphometry of the carotid artery was similar in both $\mathrm{t}-\mathrm{ACE}-/-$ and $\mathrm{ACE}+1+$; a reduced distensibility was found at pressures between 80 and 120 mmltg, which suggests an increased $E_{\text {ine }}$ in the carotid artery as well. The distensibility (DC) of the aorta was only slightly reduced at pressures between 80 and $120 \mathrm{mml} / \mathrm{g}$; however, wall thickness at $80 \mathrm{mmHg}$ was significantly reduced while the outer diameter was not significantly different. When DC is decreased and wall thickness is either equal or reduced, $\mathrm{E}_{\text {int }}$ is increased. This implies that $\mathrm{E}_{\text {inc }}$ is increased in both the carotid artery and aorta of $\mathrm{t}-\mathrm{ACE}-\%$. Thus, elasticity of all vessels investigated in the present study was reduced in the absence of $t$-ACE when compared to wild-type animals. Similar results were obtained for the captopril treated vessels. Both mesenteric and carotid artery of treated animals showed a reduced distensibility. The reduced wall thickness of the carotid artery results in an even higher $\mathrm{E}_{\text {ine }}$ or reduced elasticity.

It has been demonstrated that angiotensin II is involved in the regulation of the collagen concentration of the arterial wall ${ }^{389}$. Thus, the reduced elasticity found in the present study might be the result of an altered elastin/collagen ratio. Because of its size, only the aorta 
could be used to determine the elastin/collagen ratio. The data indicate that the percentages of both elastin and collagen were similar in $1-\mathrm{ACE}-/$ - and $\mathrm{t}-\mathrm{ACE}+/ 4$ aortas. An explanation for the reduced vascular elasticity without alterations in the elastin/collagen ratio might be found in the cell-matrix cross-bridges. For instance cell-matrix cross-bridges between fibronectin and the $\alpha 5 \beta 1$-integrin receptor are responsible for the formation of a network between all wall components. Cyclic stretch stimulates vascular firbonectin gene expression via the angiotensin type 1 receptor ${ }^{390}$. Changes in the density of these cross-bridges may be reflected in an altered passive stiffness of the arterial wall. In the present study, fibronectin concentration determined in formalin-fixed vessel was too low to quantify or detect differences in fibromectin concentration berween the groups.

The blood pressure reduction found in $\mathrm{A}-\mathrm{ACE}-/$ - mice is similar to the reduction found in captopril treated $t-A C E H /+$, which subscribes the importance of membrane-bound $A C E$ in the regulation of blood pressure ${ }^{107}$. Thus, angiotensin II shortage might directly result in the increased vascular stiffness found in the present study, or indirectly via blood pressure reduction. A second candidate, which can be involved, is bradykinin. Permanent ACE inhibition either induced by captopril or due to the lack of membrane-bound. ACE could result in persistent high bradykinin levels. Bradykinin induced by estrogen treatment of ovariectomised rats has been associated with an increased arterial stiffness ${ }^{34}$. Further investigation is needed to conclude if either the angiotensin II shortage or the bradykinim surplus is responsible for the captopril induced vascular stiffness.

\section{Vessel reactivity}

Studies on angiotensin II administration ${ }^{392}$ and $\mathrm{ACE}$ inhibition during hypertension ${ }^{379}$ have demonstrated alterations in vascular reactivity. The mesenteric artery reactivity in $\mathrm{A}-\mathrm{ACE}-\mathrm{A}-$ mice did not differ from that in $\mathrm{t}-\mathrm{ACE}+/+$. However, contraction of the carotid artery induced by potassium or phenylephrine was significantly reduced. Similar results were abtained in captopril treated carotid arteries as in $\mathrm{t}-\mathrm{ACE}-1$ - carotid arteries. Contraction induced by potassium and phenylephrine was significantly reduced, while vasodilatation induced by acetylcholine or SNP was unchanged. The heterogeneous vascular reactivity changes might be due to a differential expression pattern of $\mathrm{ACE}$ along the normal vascular ree $^{393}$.

$\mathrm{T}-\mathrm{ACE}-1$ - aortas exhibited a reduced relaxation to acetylcholine. However, the response to exogenous NO (sodium nitroprusside) was unaltered. Vessels were precontracted with potassium. This excludes the influence of the endothelium-dependent hyperpolarising factor $(\mathrm{EDHF})^{394}$, suggesting that the reduced relaxation induced by actetylcholine is either due to an impaired $\mathrm{NO}$ generation or a changed prostaglandin generation ${ }^{395}$. Incubation of the vessels with L-NAME $\left(10^{-4} \mu \mathrm{M}\right)$ after precontraction with potassium (40mM) induced a contraction that was similar in both $\mathrm{t}-\mathrm{ACE}-/$ and $\mathrm{t}-\mathrm{ACE}+1 /$ aortas. Also the contraction 
following incubation with indomethacin was not altered, indicating that the basal NO and prositaglandin production were comparable (data not shown). Reduced endotheliumdependert relaxation of the aorta in the absence of $t-A C E$ is a remarkable observation compared to studies with $A C E$ inhibitors. Hypertension and coronary artery disease are characterised by an impaired endothelium-dependent relaxation, which can be restored by inhibition of $\mathrm{ACE}^{399,396}$, suggesting a relationship between $\mathrm{ACE}$ and endotheliumdependent relaxation of the aorta. Strong suggestions have been made for the involvement of bradykinin and the $\mathrm{BK}_{2}$ receptor in the response of the aorta to chronic $\mathrm{ACE}$ inhibition. $^{397,396}$. In $\mathrm{ACE}-1-$ mice, alterations in the kallikrein system can not be excluded due to the permanent absence of membrane-bound $\mathrm{ACE}$. Interestingly, the $\mathrm{BK}$, receptor is mainly expressed in the aortic endothelium, while its expression in mesenteric arteries is confined to smooth muscle cells ${ }^{398}$. Thus, alterations in endothelium-dependent relaxation to bradykinin may be more pronounced in the aorta than in carotid or mesenteric artery. Together, these results show that absence of $\mathrm{t}-\mathrm{ACE}$ initiated a reduced endotheliumdependent relaxation of the arta and reduced contraction in the carotid artery. Comparable results are found in rats chronically treated with $\mathrm{L}-\mathrm{NAME}{ }^{399}$. Counteracting the continuously high bradykinin levels may underlay this phenomenon. However, further investigation is needed to confirm this hypothesis.

The effects of $\mathrm{t}-\mathrm{ACE}$ deficiency on the peripheral arterial system could be due to $\mathrm{t}-\mathrm{ACE}$ deficiency during foetal development. However, captopril treatment of the $\mathrm{t}-\mathrm{ACE}+1+$ animals in the present study was started at the age of 3 weeks after birth and induced arterial stiffiness or changes vascular reactivity comparable to $\mathrm{t}-\mathrm{ACE}$ deficiency. The fact that captopril treatment, when started at 3 weeks postnatally, induces the same vascular changes as those found in $\mathrm{t}-\mathrm{ACE}$-/- mice suggests that these vascular alterations are not due to $1-A C E$ deficiency during foetal development. Moreover, these results show that mainly membrane-bound $\mathrm{ACE}$ is involved in the vascular effects of $\mathrm{ACE}$ imhibition.

\section{Acknowledgenent}

The authors thank Dr. K.E. Bernstein for the gift of the t-ACE knockout mice. $K$. Ruijtenbeek, M.W. Sanders, G.E. Fazzi, J.J.M. Debets, N.J.J.E. Bitsch, R. Jasper and J.G.L.M. Luermans are gratefully acknowledged for their technical assistance. 
3 


\section{Abstract}

Arterial stiffness is modified in situations of cardiovascular diseases and during therapy with angiotensin-I-converting enzyme ( $A C E$ ) inhibitors. We observed that mice lacking the membrane-bound ACE (t-ACE -/-) exhibit a reduced arterial elasticity compared to their wild-type littermates. Increased arterial stiffness was also observed after prolonged $\mathrm{ACE}$ inhibition in $\mathrm{t}-\mathrm{ACE}+1+$ mice. During $\mathrm{ACE}$ inhibition, both angiotensin II production and degeneration of bradykinin are reduced. We hypothesised that bradykinin type 2 receptor $\left(\mathrm{BK}_{2}\right)$ stimulation might be involved in the increased arterial stiffness. T-ACE $-/-$ and $\mathrm{t}-$ $\mathrm{ACE}+1+$ mice were treated with the $\mathrm{BK}_{2}$ antagonist Hoe $140(1 \mathrm{mg} / \mathrm{kg} / \mathrm{day})$ for 14 days. After 14 days blood pressure was measured through a cannula in the abdominal aorta. Segments of the common carotid artery were placed in an arteriograph to determine the passive pressure-diameter relationship. Maximal distensibility was reached at $75 \mathrm{mmHg}$ in t-ACE -1 - carotid arteries, while maximal distensibility in $\mathrm{t}-\mathrm{ACE}+1+$ arteries was reached at $90 \mathrm{mmHg}$. After Hoe 140 treatment, the distensibility curve of the $\mathrm{t}-\mathrm{ACE}-\%$-carotid arteries was significantly shifted towards the distensibility curve of the $t-A C E+/ t$ carotid arteries ( $\mathrm{p}<0.001$ ). Hoe 140 administration increased blood pressure in both groups by approximately $10 \mathrm{mmHg}$ without changing the pressure difference between the two groups. Thus, arterial stiffness induced during $\mathrm{ACE}$ inhibition depends upon stimulation of the $\mathrm{BK}_{2}$ receptor. 


\title{
The bradykinin type 2 receptor regulates arterial stiffness during membrane-bound angiotensin-I-converting enzyme deficiency
}

\author{
Wendy M. Aartsen, M.I.A.P. Daemen, J.G.R. De Mey and J.F.M. Smits
}

Submitted to Journal of Cardiovascular Pharmacology

\section{Introduction}

Vascular remodelling and vascular dysfunction occur under several pathological circumstances. Changes in the vascular dimensions, composition and tone may all contribute to an altered vascular elasticity. Pharmacological inhibition of the angiotensin-1converting enzyme (ACE) has been described to reduce and prevent vascular remodelling and vascular dysfunction in hypertension ${ }^{208,209,400}$, myocardial infarction ${ }^{401}$, heart fallure $^{378.402}$ and atherosclerosis ${ }^{379,403,404} . \mathrm{ACE}$ inhibition not only impairs the production of angiotensin II but also the degeneration of bradykinin. Since angiotensin II is able to induce collagen production ${ }^{38 \%}$ and bradykinin is associated with a reduction in the collagen expression, these compounds might be directly involved in the regulation of the composition of the arterial wall ${ }^{266}$. Moreover, both compounds are vasoactive and may affect the vascular elasticity via their influence on vascular tone ${ }^{405}$.

Previous experiments using the membrane-bound ACE knockout mouse model $(\mathrm{t}-\mathrm{ACE}-/-)$, demonstrated that $t-A C E$ is involved in vascular remodelling ${ }^{345}$, vascular reactivity and vascular elasticity. Mice lacking membrane-bound ACE express a truncated form of ACE 
consisting of only the N-terminal end. The activity of this circulating trancated ACE to generate angiotensin II is reduced to $20 \%$ of the normal ACE activity ${ }^{107}$. Vessels from $t-$ ACE $/$ exhibit a reduced elasticity compared to vessels of $t-A C E+1+$ mice. Similar effects were obtained after prolonged captopril treatment in $1-A C E+1+$ mice. Yet, it is not clear whether these effects are due to a decrease in the angiotensin II or an increase in the bradykinin concentration. In the present study we tested the hypothesis that bradykinin type 2 receptor $\left(\mathrm{BK}_{2}\right)$ stimulation contributes to the reduced arterial elasticity observed in mice lacking membrane-bound $\mathrm{ACE}$. We determined the static arterial elasticity of mice wildtype $(\mathrm{t}-\mathrm{ACE}+/ \mathrm{H})$ or knockout $(\mathrm{t}-\mathrm{ACE}-/-)$, that were untreated or treated with the $\mathrm{BK}_{2}$ receptor antagonist Hoe 140 for 14 days.

\section{Materials and Methods}

\section{Animals}

The generation of mice with a C57BL6/129/SV genetic background and lacking membranebound angiotensin- $\mathbb{I}$-converting enzyme (t-ACE-/-) has been described by Esther et allo7. Mice heterozygous for the mutated ACE allele (t-ACE +/-) were bred to obtain mice homozygous for the mutated ACE allele (t-ACE-/-) and their wild-type littermates ( $\mathrm{t}-\mathrm{ACE}$ $+/+$ ). All animals were housed in groups of 4 to 6 and had free access to tap water and standard food (SRMA-1210; Hope Farms, Woerden, The Netherlands). All experiments were conducted according to institutional guidelines and conformed to the guide for the care and use of laboratory animals, published by the US National Institutes of Health (NIH Publication No 85-23, revised 1996).

\section{Genotyping}

To genotype pups genomic DNA was isolated form the tail using the Qiagen DNA isolation kit (Qiagen GmbH Hilden, Germany). Ready-to-go PCR beads (Amersham Pharmacia Biotech) were used for PCR analyses on genomic DNA. The three primers used are described by Esther et al ${ }^{10}$.

\section{Implantation of osmotic mini-pumps}

Age-matched (12-16 weeks old) male $\mathrm{t}-\mathrm{ACE}+/ \mathrm{t}$ and $\mathrm{t}-\mathrm{ACE}-/$ - mice were anaethetised with ketamine $(50 \mathrm{mg} / \mathrm{kg}$ i.m.) and xylazine $(5 \mathrm{mg} / \mathrm{kg} \mathrm{sc}$.). Osmotic mini-pumps (Alzet, 2002; Alza corp., Palo Alto, Ca, U.S.A.) were filled with Hoe 140 (Sigma-Aldrich, Steinheim, Germany) dissolved in saline (1. mg/kg/day) $)^{243406}$ and were subcutaneously implanted at the back of the neck. 
Implantation of the catheters

At 10 days after mini-pump implantation, catheters were implanted as described previously 304 . Briefly, mice were anaesthetised with ketamine $(100 \mathrm{mg} / \mathrm{kg} \mathrm{i.m}$ ) and $\mathrm{xylazine}$ (5mg/kg s.c.). For blood pressure recordings a heparinised saline filled catheter (PE-25 heat stretched at its tip) was placed in the abdominal aorta via the fenoral artery. A second catheter (PE-10) was placed in the jugular vein for infusions. Both catheters were subcutaneously tunneled to the neck and fixed.

\section{Bload pressure measurement}

At 14 days after the start of Hoe 140 infusion, the arterial catheter was connected to a pressure transducer (Micro-Switch, modell 156PC 156 WL, Honeywell Inc., Amsterdam, the Netherlands Amsterdam, the Netherlands). Blood pressure signals were recorded and 10 minutes of stable recordings were used to calculate the mean arterial pressure (MAP) at rest. Dose-response curves for angiotensin I and II were constructed in a cumulative way from 0 until $35 \mathrm{ng}(0-1.5 \mu \mathrm{g} / \mathrm{kg})$. Each next dose was injected (i.v.) at the time of maximal MAP to avoid tachyphylaxis. At each step, the maximal increase in MAP was calcullated. To establish the $\mathrm{BK}_{2}$ receptor inhibition, a bolus injection of bradykinin ( $25 \mathrm{ng}$ ) dissolved in $10 \mu t$ of sterile water was injected and blood pressure changes were recorded.

\section{Pressure-Diameter curves}

After blood pressure measurements animals were killed by pentobarbital overdose and 3$4 \mathrm{~mm}$ segments of the common carotid artery were isolated. Arteries were transferred to a dual-chamber arteriograph (Living systems Instrumentation, Burlington, USA). One end of the vessel was mounted onto a microcannula. After flushing the artery with HEPES buffer the other end of the artery was closed (blind sac). The cannula was connected to a feedback controlled pressure pump (Living systems Instrumentation, Burlington, USA) and the outer diameter was visualised by an inverted microscope (Nikon TMS) with video camera (Stemmer). The $10 \mathrm{ml}$ organ bath was filled with calcium free $\mathrm{HEPES}$ buffer at $37^{\circ} \mathrm{C}$ and sodium nitroprusside (SNP; $10 \mu \mathrm{M}$ ) was added to assure maximal vasodilatation. Outer diameter was determined as a function of imposed pressure. Arterial distensibility, or the relative change in volume induced by a given increase in pressure was estimated by: $\mathrm{DC}=\Delta \mathrm{A} / \mathrm{A}_{\mathrm{n} \mathrm{n}: \mathrm{i}} . \Delta \mathrm{P}$ (DC; distensibility, $\mathrm{A}$; area and $\mathrm{P}$; pressure) ${ }^{384}$.

\section{Morpliometry}

Vessels were formalin-fixed at $80 \mathrm{mmHg}$ in the arteriograph. $4 \mu \mathrm{m}$ cross sections were prepared and elastin was stained with Lawson solution (Boom bv.) followed by visualisation through a Zeiss Axioscope equipped with standard CCD camera (Sony). Video images were analysed with commercially available software (JAVA I.21, Jandel 
Scientific) to measure media cross-sectional area, media thickness, radius and wall-tolumen ratio.

\section{Statistics}

Data are shown as means \pm SEM. The effects of the Hoe 140 treatment were tested by a two-way ANOVA for repeated measurements in case of the angiotensin I and II curves and the pressure-diameter curves. Two-Way ANOVA followed by a Bonferroni t-test, was used to test the effect of Hoe 140 treatment on general and histological parameters. Statistical significance was accepted if $\mathrm{p}<0.05$.

\section{Results}

Table 1. Body weight, heart rate and blood pressure

\begin{tabular}{|c|c|c|c|c|}
\hline & $\mathrm{t}-\mathrm{ACE}+\mu$ & $t-\mathbf{A C E}-/-$ & $\begin{array}{c}\text { t-ACE }+/ t \\
\text { Hoe } 140\end{array}$ & $\begin{array}{l}\text { t-ACE - }- \\
\text { Hoe } 140\end{array}$ \\
\hline$N$ & 7 & 6 & 6 & 5 \\
\hline $\mathrm{BW}(\mathrm{g})$ & $28 \pm 1$ & $23 \pm 1 *$ & $26 \pm 1$ & $26 \pm 1$ \\
\hline $\mathrm{MAP}(\mathrm{mmHg})$ & $\begin{array}{r}\text { N.D. } \\
(100 \pm 5)\end{array}$ & $\begin{array}{c}\text { N.D. } \\
\left(75 \pm 4^{*}\right)\end{array}$ & $120 \pm 5$ & $87 \pm 8 *$ \\
\hline HR (bpm) & 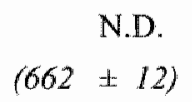 & $\begin{array}{c}\text { N.D. } \\
(627 \pm 21)\end{array}$ & $673 \pm 32$ & $612 \pm 50$ \\
\hline
\end{tabular}

Data are presented as mean \# SEM. Abbreviations: BW; body weight; MAP; mean arterial pressure, HR; heart rate. N.D.; not determined. Significant difference between $\mathrm{t}-\mathrm{ACE} H t+$ and $\mathrm{t}$ ACE - $/$ - mice $(p<0.05)$. Data in itatics are taken from previous experiments with $t-A C E+1+$ and tACE - mice (Chapter 2).

\section{General}

Age-matched Hoe 140 treated $t-A C E+/ 4$ and $t-A C E-/-$ mice were comparable in body weight, while untreated $t-A C E-$ - were significantly lighter than untreated $t-A C E+/ 5$ mice (Table 1). Blood pressure was only determined in Hoe 140 treated $\mathrm{t}-\mathrm{ACE}+1+$ and $\mathrm{t}-\mathrm{ACE}-/$ as previous experiments repeatedly confirmed the reduced blood pressure in $\mathrm{t}-\mathrm{ACE}-\mathrm{m}-\mathrm{mice}$

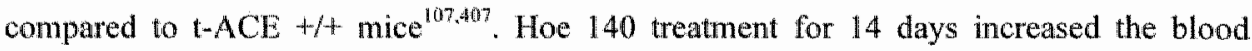
pressure by $10 \mathrm{mmHg}$ in $\mathrm{t}-\mathrm{ACE}+1+$ and $\mathrm{t}-\mathrm{ACE}-1-$ mice compared to blood pressure of untreated $t-A C E+/ t$ and $t-A C E-t-$ as measured in previous experiments. Heart rate was not 
influenced by the administration of Hoe 140 when compared to heart rate values for $\mathrm{t}-\mathrm{ACE}$ $+1+$ and $1-\mathrm{ACE}-/ \sim$ obtained in previous experiments.

Angiotensin I and II dose-response curves

The blood pressure response to angiotensin I and II infusion is sllown in figure 1. Pressure responses to angiotensin I in treated $\mathrm{t}-\mathrm{ACE}-/$ were impaired compared to the response to angiotensin I observed in treated $\mathrm{t}-\mathrm{ACE}+/+$ mice. Angiotensin II induced similar tesponses in both groups, but the blood pressure in $\mathrm{t}-\mathrm{ACE}-/-$ mice remained significantly lower along the entire curve. A bolus injection of bradykinin $(25 \mathrm{ng})^{406}$, which reduces blood pressure by approximately $30 \mathrm{mmHg}$ in untreated animals (data not shown), did not affect the blood pressure in Hoe 140 treated $1-\mathrm{ACE}-/$ and $\mathrm{H}-\mathrm{ACE}+/+$ mice, which indicates that the $\mathrm{BK}_{2}$ receptors were effectively blocked.

\section{Dose-response Angiotensin I \& II}
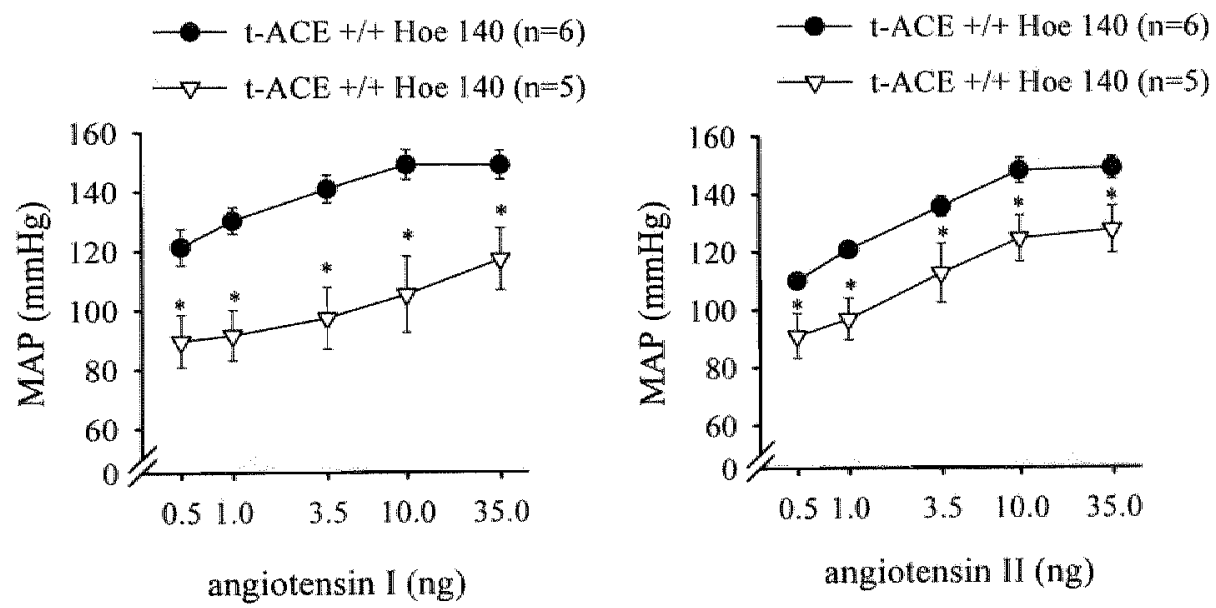

Figure 1. Dose-response curves for the pressure effects of angiotensin I (left) and 11 (right) Hoe 140 ( $1 \mathrm{mg} / \mathrm{kg} /$ day) treated $\mathrm{t}-\mathrm{ACE}+1 /$ mice. * Significantly different from Hoe 140 treated $\mathrm{t}-\mathrm{ACE}$ $+1 / 4+(p<0.05)$. 


\section{Pressure-diameter curves}

\section{Carotid artery}

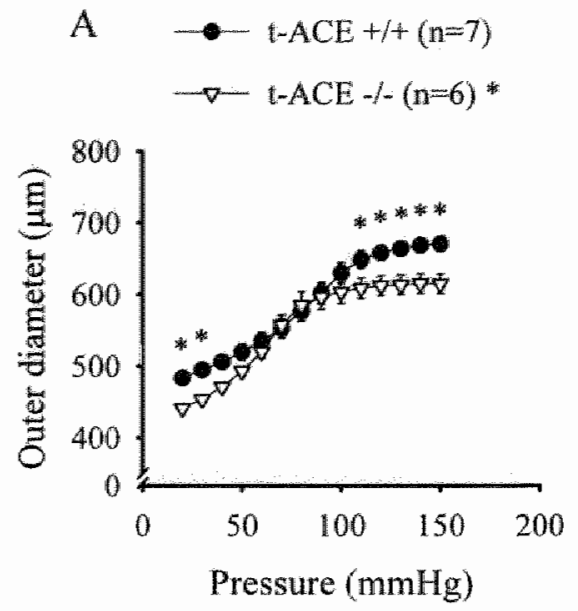

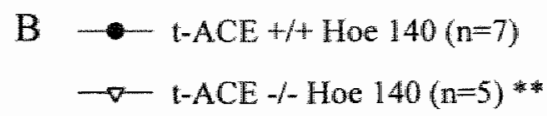

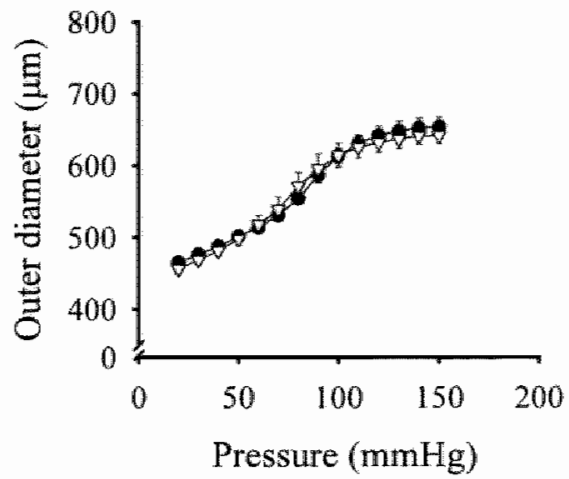

\section{Arterial Distensibility}

C
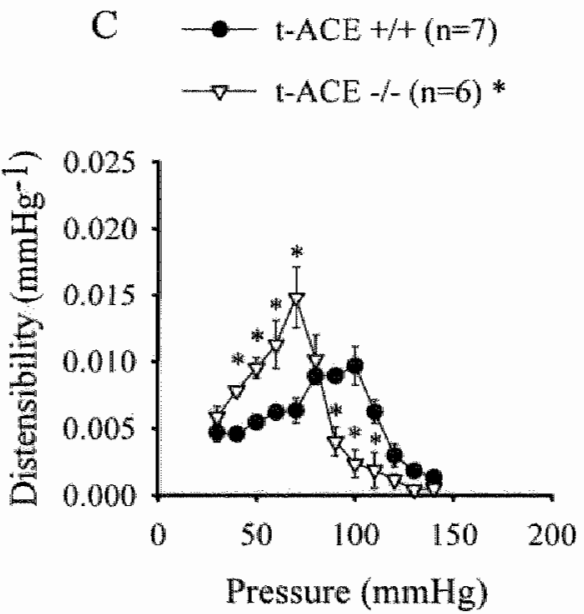
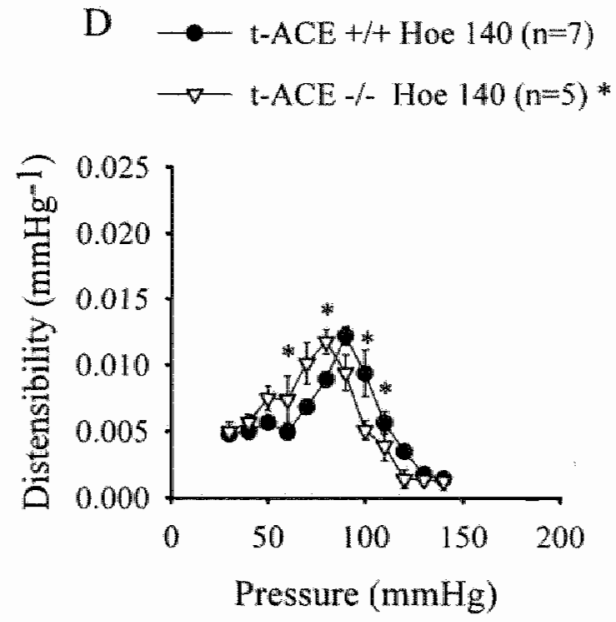

Figure 2. Left panel: Relationship between imposed pressure and diameter (A) and calculated distensibility in isolated carotid artery from $\mathrm{t}-\mathrm{ACE}+/+$ and $\mathrm{t}-\mathrm{ACE}-1-$ mice (C). Right panel: Relationship between imposed pressure and diameter (B) and calculated distensibilty in isolated carotid artery from $\mathrm{t}-\mathrm{ACE}+/+$ and $\mathrm{t}-\mathrm{ACE}-/$ mice treated with Hoe 140 for 14 days (D). *Significant difference between wild-type $(\mathrm{t}-\mathrm{ACE}+/+)$ and knockout mice (t-ACE $-/-; \mathrm{p}<0.05)$. ** Significantly different from untreated mice ( $p<0.05$ ) * (in legends) Significant interaction between pressure and genotype $(\mathrm{p}<0.05)$.** (in legends) Interaction between pressure and genotype is significantly different after treatment $(p<0.05)$. 
Pressure-diameter curves

Pressure-diameter curves obtained in the isolated carotid arteries and the calculated distensibility are shown in figure 2. The pressure-dianeter curves showed a typical S-shape in both $\mathrm{t}-\mathrm{ACE}+/+$ and $\mathrm{t}-\mathrm{ACE}-/$ - arteries ${ }^{386}$. At $20 \mathrm{mmHg}$, the dianeter of the untreated $\mathrm{t}-$ ACE $-/$ - carotid artery was significantly smaller than the diameter of the antreated $1-\mathrm{ACE}$ $+/+$ carotid artery. In untreated $t-A C E-/$ - carotid arteries the maximal dianueter was reached at a lower pressure compared to the untreated $1-\mathrm{ACE}+1+$ carotid artery. Maximal distensibility was reached at $75 \mathrm{mmHg}$ in $\mathrm{t}-\mathrm{ACE} /$ carotid arteries, while maximal distensibility in $t-A C E+/ 4$ arteries was reached at $90 \mathrm{mmHg}$. Moreover, the carotid distensibility between $80 \mathrm{mmHg}$ and $120 \mathrm{mmHg}$ was significantly lower in $\mathrm{t}-\mathrm{ACE}-/$ compared to t-ACE $+/ t$ mice. After 14 days of Hoe 140 treatment ( $1 \mathrm{mg} / \mathrm{kg} / \mathrm{day})$ no differences in the pressure-diameter curves could be observed between $\mathrm{t}-\mathrm{ACE}-/ \mathrm{m}$ and $\mathrm{t}$ $\mathrm{ACE}+1+$ mice. In $\mathrm{t}-\mathrm{ACE}-/-$ mice, both the carotid diameter-pressure $(p=0.02)$ and distensibility curves $(\mathrm{p}<0.01)$ were changed and shifted towards the $t-A C E+1+$ curves. The Hoe 140 treatment had no effect on the pressure-diameter and distensibility curve of the t$\mathrm{ACE}+1+$ mice.

Table 2. Arterial morphometry

\begin{tabular}{|c|c|c|c|c|}
\hline & \multicolumn{4}{|c|}{ Carotid artery } \\
\hline & $t-\mathbf{A C E}+1+$ & $t-A C E-1-$ & $\begin{array}{c}\text { t-ACE }+/ t \\
\text { Hoe } 140\end{array}$ & $\begin{array}{c}\text { t-ACE - }- \\
\text { Hoe } 140 \\
\end{array}$ \\
\hline$N$ & 6 & 6 & 7 & 5 \\
\hline $\begin{array}{l}\text { CSA } \\
\left(\times 10^{*} 4 \mathrm{~m}^{2}\right)\end{array}$ & $20 \pm 1$ & $14 \pm 1^{*}$ & $20 \pm 3$ & $17=1$ \\
\hline Radius ( $\mu \mathrm{m})$ & $202 \pm 5$ & $196 \pm 1$ & $208 \pm 115$ & $191 \pm 4$ \\
\hline$M t(\mu \mathrm{m})$ & $15 \pm 1$ & $11 \pm 1^{*}$ & $15 \pm 1$ & $14 \pm 1$ \\
\hline$W / L(x 100)$ & $7.6 \pm 0.1$ & $5.6 \pm 0.3$ & $7.6 \pm 0.1$ & $7.2 \pm 0.7+$ \\
\hline
\end{tabular}

Data are presented as mean \pm SEM. Abbreviations: CSA; medial cross sectional area, Mt: medial thickness, W/L wall-to-lumen ratio, Hoe $140 ; \mathrm{t}-\mathrm{ACE}+/+$ and $1-\mathrm{ACE}+/$ mice treated with Hoe 140 ( $1 \mathrm{mg} / \mathrm{kg} / \mathrm{day}$ ) for 14 days. * Significant difference between $\mathrm{t}-\mathrm{ACE}+\%+$ and $\mathrm{t}-\mathrm{ACE}+\%$ mice $(\mathrm{p}<0.05)$. + Significantly different from untreated mice $(p<0.05)$. 


\section{Morphometry}

Four parameters of arterial structure were detemined and are presented in Table 2 . A significantly smaller media cross-sectional area was observed in the $1-\mathrm{ACE}$ - / carotid arteries compared to $\mathrm{t}-\mathrm{ACE}+1+$ carotid arteries. The arterial lumen diameter after fixation at $80 \mathrm{mmHg}$ was comparable in both strains, however the media thickness measured in tACE - - - carotid arteries was significantly smaller than the media thickness of $t-A C E+H+$ carotid arteries. A reduced media thickness without a change in diameter results in a decreased wall-to-lumen ratio in $\mathrm{t}-\mathrm{ACE}-/$ arteries. After 14 days of treatment with Hoe $140(\mathrm{mg} / \mathrm{kg} / \mathrm{day})$ the four structural parameters were similar for treated $\mathrm{t}-\mathrm{ACE}+\mathrm{t}+$ and $\mathrm{t}-$ ACE - mice.

\section{Díscussion}

Under several pathological circumstances such as hypertension ${ }^{400408}$, myocardial infarction $^{408}$ and atherosclerosis ${ }^{404}$, angiotensin-I-converting enzyme (ACE) inhibition enhances vascular elasticity. Paradoxically, we demonstrated that mice lacking membranebound $\mathrm{ACE}$ (t-ACE -/-) exhibit reduced arterial elasticity. During $\mathrm{ACE}$ inhibition angiotensin II levels are decreased and bradykinin levels are increased. In the present study, we investigated the hypothes is that bradykinin type 2 receptors ( $B K_{2}$ receptor) are involved in reduction of arterial elasticity observed in $\mathrm{t}-\mathrm{ACE}-/ \mu$ mice. By infusion of $\mathrm{BK}_{2}$ receptor antagonist Hoe 140 for 14 days, the decreased arterial elasticity in $\mathrm{H}-\mathrm{ACE}-\mathrm{f}$ - was normalised without affecting the blood pressure difference between $\mathrm{t}-\mathrm{ACE}-\mathrm{t}$ and $\mathrm{t}-\mathrm{ACE}+\mathrm{t}+\mathrm{mice}$, indicating that the reduced vascular elasticity observed in $\mathrm{t}-\mathrm{ACE}-1 /$ mice results from stimulation of the $\mathrm{BK}_{2}$ receptor.

The diameter-pressure relationship in untreated $\mathrm{t}-\mathrm{ACE}$-/- was significantly different from the dimeter-pressure relationship in untreated $1-\mathrm{ACE}+1+$ mice. The distensibility of the carotid $\mathrm{t}-\mathrm{ACE}$ - - arteries shows an optimum at a lower pressure when companed to wildtype arteries, indicating that $t-A C E-f$-vessels are less elastic than $t-A C E+/ t$ vessels. After 14 days of Hoe 140 treatment the cliameter-pressure relationships in $\mathrm{t}-\mathrm{ACE} / \mathrm{-}$ and $\mathrm{t}-\mathrm{ACE}$ $+/+$ were indistinguishable. The distensibility curve of the $1-\mathrm{ACE}-/$ - carotid arteries was significantly shifted towards the distensibility curve of the $\mathrm{t}-\mathrm{ACE}+/ \mathrm{t}$ carotid arteries ( $p<0.001$ ). These results suggest that the bradykinin type 2 receptor is involved in the increased arterial stiffness observed in mice lacking membrane-bound $A C E$.

Since the elastic characteristics were tested in vitro without flow or vascular tone, the alterations in distensibility are directly related to the vessel wall composition ${ }^{33 s}$. The elastic properties of maximally dilated arteries depend on vessel wall components and on vessel geometry. In our previous study, collagen and elastin densities were similar in aorta's from 
$1-A C E-1-$ and $t-A C E+1+$ mice, which suggests that the reduced elasticity found in mice deficient for $\mathrm{t}-\mathrm{ACE}$ is not due to a change in elastim/collagen ratio. An alternative explanation for the reduced vascular elasticity might be found in the cell-inatrix crossbridges. For instance cell-matrix cross-bridges between fibronectin and the $\alpha 5$ pl-integrin receptor are responsible for the formation of a network between all wall components ${ }^{409}$.

Morphometric analysis showed that the carotid media cross-sectional area, media thickness and wall-to-lumen ratio were all reduced in $1-\mathrm{ACE}-/$ mice compared to $1-\mathrm{ACE}+1+$, this was not observed in our previous study, this discrepancy might be due to the difference in age of mice used in these studies. No differences in the vessel geometry were observed between Hoe 140 treated $\mathrm{t}-\mathrm{ACE}+/ \mathrm{t}$ and $\mathrm{t}-\mathrm{ACE}-/$ arteries. Normalisation of the vascular geometry could be related to the normalisation in body weight after Hoe 140 treatment: Alterations in body weight and glucose metabolism during ACE inhibition have been described previously and the effects on insulin and glucose metabolism are subscripted to the elevated bradykinin levels ${ }^{\text {4it).41! }}$.

By calculating the incremental elastic modulus $\left(\mathrm{E}_{\mathrm{ine}}=\mathrm{d} / \mathrm{Wt} \mathrm{DC}\right)$, or relationship between strain and stress, changes in vessel wall morphometry, which affect elasticity, are taken into account. Although the wall thickness (Wt) of the carotid arteries could not be visualised, it was determined after fixation at $80 \mathrm{mmHg}$. The distensibility (DC) of the $1-\mathrm{ACE}-/$ - carotid antery was reduced at pressures between 80 and $120 \mathrm{mmHg}$ and wall thickness at $80 \mathrm{mmHg}$ was significantly reduced whille the outer diameter (d) was unaltered. When DC is decreased and wall thickness is reduced, $E_{\text {inc }}$ is increased. This contirms the earlier observation that arterial elasticity in $\mathrm{A}-\mathrm{ACE} /-$ mice is reduced. The geometry of the carotid artery was similar in both Hoe 140 treated $\mathrm{t}-\mathrm{ACE}-/$ and $\mathrm{t}-\mathrm{ACE}+/ t$. The difference in distensibility between Hoe 140 treated $\mathrm{t}-\mathrm{ACE}+/ 4$ and $\mathrm{t}-\mathrm{ACE}-1-$ carotid arteries was much smaller compared to untreated vessels. Furthermore, the wall-to-lumen ratio significantly uncreased after Hoe 140 infusion was catised by an increase in wall thickness. Both the reduction of distensibility and wall thickness were restored. Thus, the increase in $E_{\text {int }}$ observed in $\mathrm{t}-\mathrm{ACE}-/$ arteries can be abolished by 14 days of Hoe 140 treatment. In the present study, the vascular elasticity was measured in vitro without flow or vascular tone. Therefore, alterations in the elasticity are directly related to the vessel wall composition ${ }^{3 *}$. Alterations in, for instance, the fibrinolytic balance will lead to changes in the composition of the vascular extra cellular components. Both angiotensin II and bradykinin are able to influence the vascular fibrinolytic balance $403,412,413$.

These results suggest that the bradykinin type $2\left(\mathrm{BK}_{2}\right)$ receptor is involved in the increased. arterial stiffness observed in $t-A C E$ - mice. Enhanced vasodilatation by bradykinin together with an increased arterial stiffness has been demonstrated in ovariectomised rats treated with estrogen ${ }^{3 \%}$. However, the exact mechanism behind the $\mathrm{BK}_{2}$ receptor stimulation and arterial elasticity is still unclear. Bradykinin acts as a vasoditator via the 
$\mathrm{BK}_{2}$ receptor by releasing endothelium-derived factors including nitric oxide (NO) ${ }^{7.53}$. The blood pressure is affected by Hoe 140 treatment resulting in an increase of approximately $10 \mathrm{mmHg}$ compared to the blood pressure values for $\mathrm{ACE}-\mathrm{AC}$ and $\mathrm{A}-\mathrm{ACE}$ $+1+$ mice measured in a previous study. A similar effect on the blood pressure has been demonstrated in young rats treated for several weeks with Hoe $140^{\text {th }}$. The blood pressure difference of approximately $30 \mathrm{mmHg}$ between untreated $\mathrm{t}-\mathrm{ACE}-1-$ and $\mathrm{t}-\mathrm{ACE}+\mathrm{t}$ remained unaffected by 14 days of Hoe 140 treatment. Despite maintenance of this pressure difference, arterial elasticity was restored by Hoe 140 , which suggests that the increased arterial stiftiness observed in $\mathrm{t}-\mathrm{ACE}$-/ mice is not related to the blood pressure.

Stimulation of the $\mathrm{BK}_{2}$ receptor leads to the release of prostaglandins and $\mathrm{NO}^{415}$. NO has been related to an enhanced arterial elasticity ${ }^{46,49}$. Moreover, acute infusion of bradykinin increases atterial compliance in vivo ${ }^{418}$. High prostaglandin llevels might be involved in an increased vascular elasticity. However, prostacyclin production during indapanide treatment improves arterial compliance in hypertensive patients ${ }^{49}$. So far, studies report an enhanced arterial elasticity in response to increased bradykinin concentrations. However, the majority of these studies were performed in a situation of cardiovascular diseases, such as hypertension ${ }^{400408}$, myocardial infarction ${ }^{404}$ and atherosclerosis ${ }^{404}$. In the $\mathrm{t}-\mathrm{ACE}-/-$ mice bradykinin is supposed to be upregulated without obvious signs of cardiovascular disease.

Hoe 140 administration only affected the $1-A C E-/$ - carotid artery elasticity and not the elasticity of the $\mathrm{t}-\mathrm{ACE}+/ \mathrm{H}$ carotid artery, suggesting that $\mathrm{BK}_{2}$ antagonism does not affect arterial elasticity in general but only during $\mathrm{t}-\mathrm{ACE}$ deficiency. Dose-response curves obtained for angiotensin I and II in Hoe 140 treated $t-A C E+1+$ mice did not differ from the angiotensin $\mathrm{J}\left(\mathrm{pD}_{2} 8.7 \pm 0.2\right.$ vs. $\left.8.5 \pm 0.2\right)$ and angiotensin II curves $\left(\mathrm{pD}_{2} 8.7 \pm 0.1\right.$ vs. $8.9 \pm$ $0.1)$ obtained in a previous study with $\mathrm{t}-\mathrm{ACE}+/+$ mice. After Hoe 140 treatment the effect of angiotensin I on blood pressure in $\mathrm{t}-\mathrm{ACE}-/-$ mice remained significantly reduced compared to $\mathrm{t}-\mathrm{ACE}+/ 4$ mice, while the reaction to angiotensin II was comparable between the nwo groups. These data suggest that the Hoe 140 infusion did not affect the ACE activity or the $A T_{1}$ receptor response. The exact mechanism behind the reduction of vascular elasticity by $\mathrm{BK}_{2}$ receptor (over)stimulation during 1 -ACE deficiency remains to be established.

In conclusion, the arterial stiffiness observed in mice lacking membrane-bound ACE originates from (over)stimulation of the bradykinin type 2 receptor and is independent of the blood pressure. Further investigation is necessary to elucidate the exact role of the $\mathrm{BK}_{2}$ receptor in regulation of arterial elasticity during prolonged $A C E$ inhibition. 


\section{Acknowledgements}

The authors thank Dr. K.E. Bernstein for the gift of the t-ACE knockout mice. P.J.A. Leenders, G.E. Fazzi, P.M.H. Schiffers and G.P.J. Bost are gratefully acknowledged for their technical assistance. 
78

- 


\section{General Discussion}

Angiotensin-I-converting enzyme (ACE) takes a central place in this thesis. This multifunctional enzyme is present in the cardiovascular system as a circulating enzyme and as an ectoenzyme comected to the cell membrane ( $t-A C E)$. At the cell membrane, $t-A C E$ is part of the local renin-angiotensin system (RAS). Local RAS expression is often enhanced in conditions of growth. However, its exact function remains to be established. In this thesis, we hypothesised that $\mathrm{t}-\mathrm{ACE}$ is involved in structural and functional cardiovascular maturation. Furthermore, we thypothesised that $\mathrm{t}-\mathrm{ACE}$ plays an important role in structural and functional repair of the heart after myocardial infarction (MI). Both hypotheses were tested in mice lacking membrane-bound ACE. The experimental data showed that the lack of $\mathrm{t}-\mathrm{ACE}$ affected the functional maturation of the heart, resulting in a reduced cardiac contractility. In the vessels, $\mathrm{t}-\mathrm{ACE}$ deficiency affected both artetial function and structure, which led to a reduced arterial reactivity and arterial elasticity. After MI, $-A C E$ is involved in the functional recovery, while structural remodelling after myocardial infarction is independent of t-ACE. Additional data suggest that an important part of the effects of i$\mathrm{ACE}$ deficiency on cardiovascular function might be due to cross-talk between the RAS and the kallikrein-kinin system (KKS). Our final hypothesis entails that combined therapy with IGF-I and an AT, antagonist would be more beneficial for the cardiac performance after $\mathrm{MI}$ than the conventional single treatment with $\mathrm{AT}_{1}$ antagonism. However, this hypothesis was not supported by experimental data.

\section{The role of $t-A C E$ in cardiovascular maturation}

The existence of a mouse model that expresses $A C E$ without a membrane anchor ${ }^{\text {in? }}$ (ACE.2) creates the opportunity to investigate whether ACE positioned at the cell membrane is important for maturation of the cardiac structure and function. Without ACE 
connected to the cell membrane the maximal cardiac contractility in adult mice is impaired (Chapter 1). The importance of membrane-bound ACE for the maturation of arterial structure and function has been demonstrated in chapter 6 , which describes that $H$-ACE deficiency results in arterial stiffness and blunts arterial reactivity. Similar results were obtained after long-term treatment with captopril, started at 3 weeks after birth (chapters 2 \& 6). This excludes the possibility that $\mathrm{t}-\mathrm{ACE}$ deficiency during foetal development is responsible for the reduced cardiac contractility, arterial elasticity and arterial reactivity. Furthermore, both cardiac and vascular effects were more pronounced after prolonged $A C E$ inhibition than during $t-A C E$ deficiency. This might be explained by the remaining activity of circulating $A C E$ in $\mathrm{A}-\mathrm{ACE}-/$ mice, indicating that not the position of $\mathrm{ACE}$, but its general activity is related to cardiovascular maturation. A similar conclusion was drawn from a study in which the ACE expression was limited to the liver (ACE.3 $)^{225}$. Thus one may conclude that, although the endothelium is the major source of ACE activity, sulficient ACE expression by a different source is able to restore cardiovascular function in the absence of endothelial $\mathrm{ACE}^{225}$.

The balance between renin-angiotensin system (RAS) and kallikrein-kinin system (KKS) in t-ACE - /- mice

Due to its dual function, ACE has a pivotal role in the balance between the reninangiotensin system (RAS) and the kallikrein-kinin system (KKS).

\section{A}

HEART

$\mathbb{A}-\mathbf{A C E}+1+$

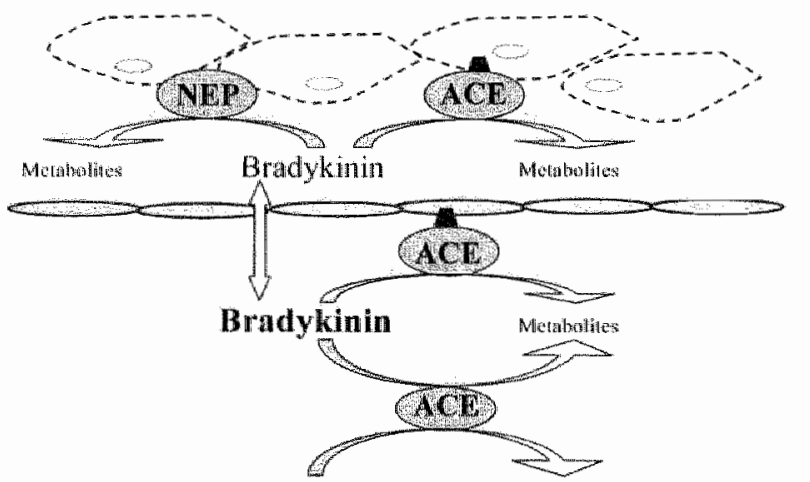

Muscle cells

Interstitiun

Endothelium

Blood

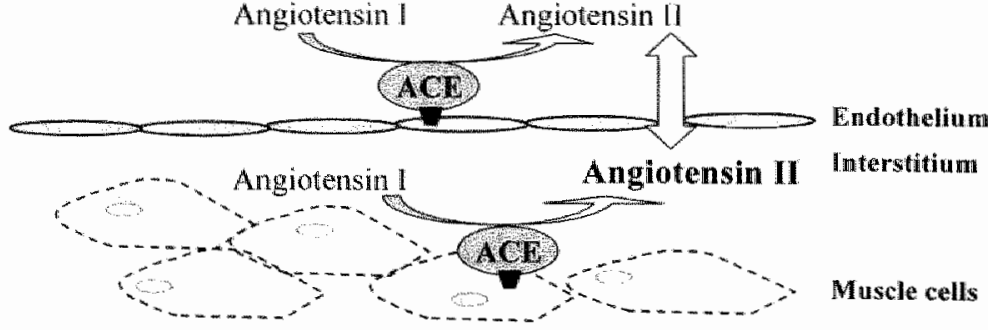


B

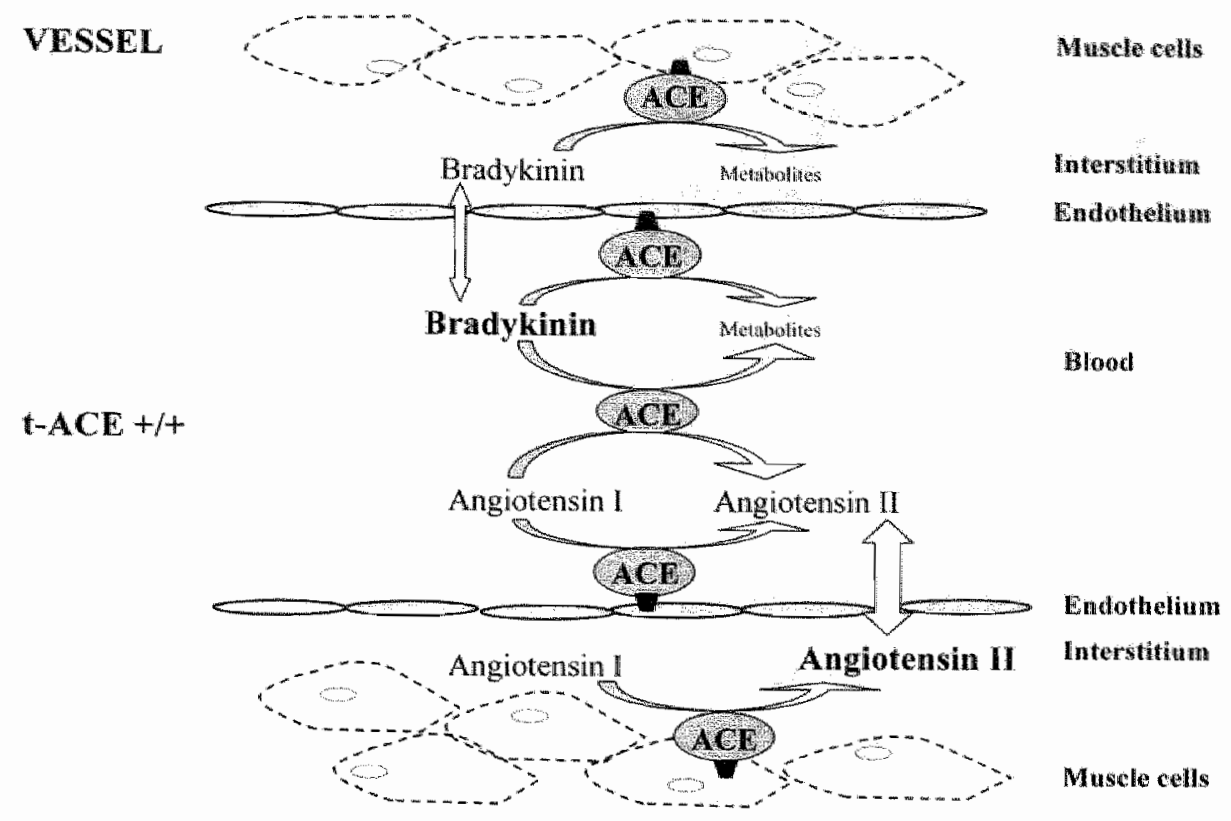

Figure 1. The balance between RAS and KKS depicted in heart (A) and vessels $(B)$ of $t-A C E+4$ mice

By converting circulating angiotensin I into angiotensin II, the endothelial-bound ACE provides the circulation and the interstitial fluid with angiotensin II. The strategic position of $\mathrm{ACE}$ leads to a high angiotensin II concentration near the endothelium and a high diffusion rate into the interstitium (figure 1). The second function of ACE is bradykinin degeneration. Bradykinin is present in the circulation and in cardiovaseular tissues ${ }^{257}$. In blood, bradykinin degeneration is mainly ACE dependent. As an endothelium-bound enzyme, $A C E$ is predominantly responsible for the breakdown of bradykinin in the vasculature $^{255}$. In the heart, however, $A C E$ is joined by neutral endopeptidase (NEP). This enzyme is present on the plasma membrane of myocytes and converts $90 \%$ of the cardiac bradykinin into $\mathrm{BK}-(\|-7)^{25.5}$. Thus, the role of ACE in regulating the balance between RAS and KKS is different in the heart role compared to the vasculature. As a consequence, the effects of $\mathrm{ACE}$ inhibition on the heart are distinct from its effects on the vasculature. In the Langendorff rat heart, ACE inhibition by captopril treatment resulted in undetectable interstitial angiotensin II levels ${ }^{20}$. When endothelial bound ACE is mechanically removed, the interstitial angiotensin II levels are reduced but not abolished, suggesting that interstitial angiotensin II is partly generated by non endothelial-bound $\mathrm{ACE}$, which is either circulating ACE or ACE bound to the cell membrane of myocytes, fibroblasts and other interstitial cells ${ }^{2}$. 
A

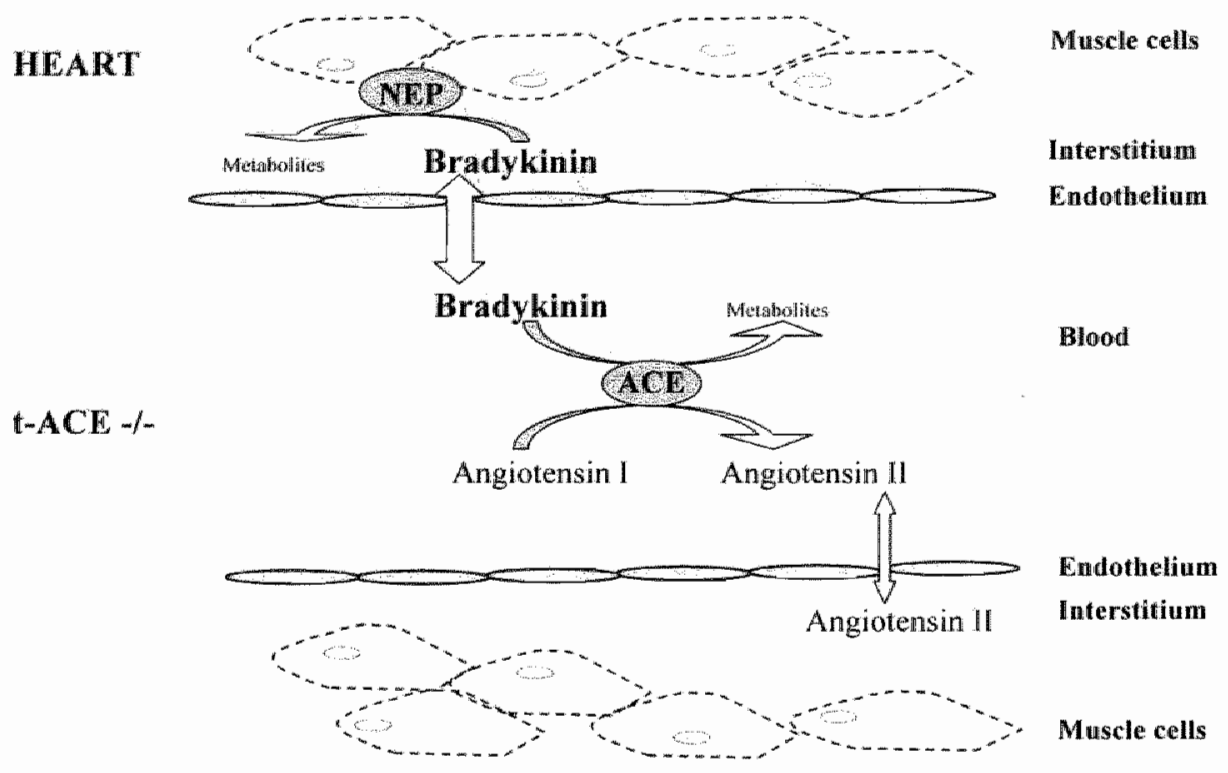

B

VESSEL

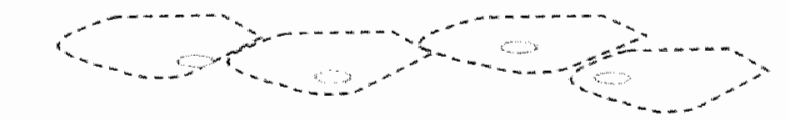

Musclle cells

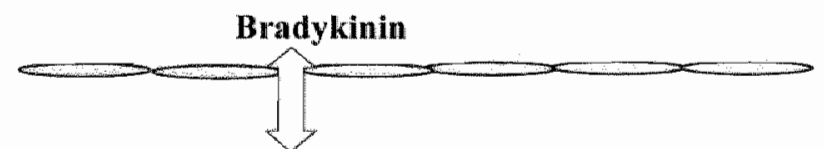

Interstitium

Endothelium

$\mathrm{t}-\mathrm{ACE}-\%$

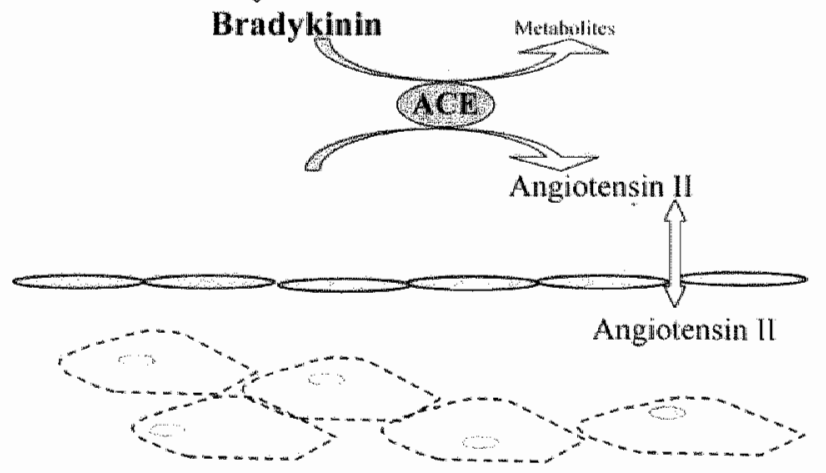

Blood

Endothelium

Interstitium

Muscle cells

Figure 2. The balance between RAS and KKS depicted in heart (A) and vessels (B) of t-ACE -.mice 
In the absence of membrane-bound $\mathrm{ACE}(\mathrm{t}-\mathrm{ACE} 4-)^{107}$ (figure 2), the interstital angiotensin II concentration becomes dependent upon diffusion of circulating angiotensin II produced by only circulating $\mathrm{ACE}$. The activity of circulating $\mathrm{ACE}$ in $\mathrm{t} A \mathrm{ACE}-1-$ mice is decreased (to $20 \%$ of the normal ACE activity), which results in low plasma and interstital angiotensin II concentrations. Due to the reduced circulating $A C E$ activity in $1-A C E-/-$ mice, plasma bradykinin levels are elevated ${ }^{250,421}$. Since endothelium-bound ACE is absent, bradykinin is no longer degenerated at the site of the endothelium, resulting in increased vascular bradykinin levels and an increased diffusion into the interstitium. In contrast, the cardiac interstitial bradykinin levels might be unaffected in the absence of membranebound $A C E$, since the degeneration of bradykinin in the cardiac interstitium is mainly regulated by the neutral endopeptidase (NEP) ${ }^{255421}$. An early report on cardiac bradykinin during $\mathrm{ACE}$ inhibition demonstrated an increase in tissue bradykinin levels ${ }^{222}$. However, more recent data suggest that bradykinin levels in cardiac tissue are, indeed, not affected by $\mathrm{ACE}$ inbibition ${ }^{423,424}$.

In $\mathrm{t}-\mathrm{ACE}-/$ mice, plasma and vascular angiotensin II levels are supposed to be decreased and at the same time bradykinin levels are supposed to be elevated. Cardibe interstitial angiotensin II levels are supposed to be low, while the cardiac interstitial bradykinin levels might be unaffected. The fact that the regulatory function of $\mathrm{ACE}$ in the heart is distinct from the regulatory function in the vasculature, suggests that the mechanisms underlying the cardiovascular alterations observed during $\mathrm{t}-\mathrm{ACE}$ deficiency are different. Thus, the reduction in angiotensin II supply might be the major cause for the impaired cardiac contractility observed in t-ACE -/- mice (chapters $1,2,4 \& 5$ ), while the increased bradykinin levels seem to have a major effect on the vascular elasticity (chapter 7).

\section{The role of $\mathrm{t}-\mathrm{ACE}$ after myocardial infarction}

ACE imhibitors have become established therapeutic agents in the treatment of hypertension and congestive heart failure ${ }^{206,205}$. Positive influences of $\mathrm{ACE}$ inlhibition on the survival rate and ventricular remodelling after myocardial infarction (MI) have been extensively documented in humans ${ }^{210-212}$ and animals ${ }^{205,213,214}$. Beneficial effects of $\mathrm{ACE}$ inhibition on coronary flow and cardiac contractility have even been found with low-dose ACE inhibition, without reduction of blood pressure ${ }^{223}$ and systemic vascular resistance or elevation of plasma renin activity ${ }^{22}$. These data point in the direction of cardiac RAS and its involvement in cardiac remodelling after $\mathrm{MI}$.

Membrane-bound ACE is a component of the cardiac RAS and the consequences of its absence for cardiac remodelling after MI were investigated in this thesis. Membrane-bound ACE deficiency impairs the functional remodelling after MI (chapter 4). Despite the reduced cardiac loading observed in $\mathrm{t}-\mathrm{ACE}$ - / mice, cardiac contractility after $\mathrm{MI}$ is significantly reduced. Since antagonism of the $\mathrm{AT}_{1}$ receptor immediately after $\mathrm{MI}$ (chapter 
5) also results in an impaired cardiac contractility, the involvement of the $A T$, receptor in the regulation of the cardiac contractility is likely. Previous studies on early treatment after MI with $\mathrm{ACE}$ inhibitors or $\mathrm{AT}$, antagonists have also reported a reduced cardiac pertormance ${ }^{148,354,37371}$. Because stimulation of the $\mathrm{AT}$, receptor might be a necessary part of the early compensatory response after $M I$ and related to the cardiac contractility, early and targeted ACE inhibition is, at least in the mouse, not in favour of the cardiac function.

Both early and late structural remodelling of the heart after $M I$ were not affected by the absence of membrane-bound $A C E$, indicating that structural remodelling of the heart after MI in mice is $t-A C E$ independent. Firm conchusions concerning the involvement of $1-A C E$ in structural remodelling after $M I$ in general should be drawn with care. A discrepancy is observed in structural remodelling of the mouse heart when compared to the structural remodelling of the rat or human heart ${ }^{425}$. Progressive collagen deposition is observed in both rat and human heart. However in mice, after $\mathrm{MI}_{\text {, }}$ myocyte components are released into the plasma (chapter 3), a scar is formed, the ventricle becomes dilated (chapters $4 \& 5$ ) and cardiac contractility is impaired ${ }^{313}$ but, increased collagen deposition in the surviving septum or right ventricle is absent ${ }^{425}$ or minor ${ }^{313}$. Although no conclusion can be drawn about the role of $1-A C E$ in progressive collagen deposition in septum and right ventricle after MI, $1-A C E$ is not crucial for scar formation and ventricular dilatation.

\section{Combined therapy with IGF-I and an $A T_{1}$ antagonist after MI}

Since high IGF-I levels are associated with physiological hypertrophy ${ }^{297}$ and high angiotensin II levels with pathological hypertrophy ${ }^{357}$, we hypothesised that combined therapy with IGF-I and an $A T_{1}$ antagonist would be more beneficial for cardiac performance after MI than AT, antagonism alone. Addition of IGF-I to losartan treatment altered the cardiac contractility, response to $\beta$-receptor stimulation and the plasma glucose level (chapter 5), which is comparable with single growth hormone (GH) treatment ${ }^{365}$. Although several animal studies demonstrated positive effects of GH and IGF administration on cardiac contractility after myocardial infarction and during heart failure ${ }^{21.4284,235.364 .362 .365 .426}$, growth hormone or IGF-I administration in patients with chronic heart failure demonstrated no major beneficial effect on cardiac performance ${ }^{\$ 26-42 \%}$. In our experiments, the combined treatment with IGF-I and losartan was started immediately after MI and did not result in a better cardiac contractility compared to untreated mice. Whether beneficial effects of the combined therapy with IGF-l and losartan are to be expected when treatment is started at a later time-point after $\mathrm{MI}$ is doubtful. Positive results of the combined treatment with $\mathrm{GH}$ and $\mathrm{ACE}$ inhibition have been described in rats with chronic heart failure ${ }^{43 t}$, while no improvement of the cardiac performance was observed in hamsters with chronic heart failure ${ }^{214}$. Furthermore, the severity of heart failure seems to determine the outcome of GH treatment. GH treatment combined with ACE inhibition leads to 
improvement of the cardiac function after ischaemia without heart failure, while simillar treatment in a situation of moderate to severe heart failure leads to adverse effects like rapid: worsening of heart failure, ventricular tachycardia and sudden death ${ }^{428,434}$. In view of these studies, the therapeutic window of the combined therapy with an $\mathrm{AT}$, blocker and IGF-I becomes rather small.

\section{Clinical implications}

In a normal situation there is a balance between the renin-angiotensin system (RAS) and the kallikrein-kinin system (KKS). In many cardiovascular diseases, components of the reninangiotensin system (RAS), such as renin, $A C E$, and the angiotensin receptors are upregulated, resulting in a disballance between $\mathrm{RAS}$ and $\mathrm{KKS}$, in favour of $\mathrm{RAS}^{253.42 .43}$ (figure 3). When ACE inhibitors are administered in this situation of disbalance many beneficial effects are observed such as reduction of the blood pressure, increased coronary blood flow, increased vascular compliance and increased cardiac performance ${ }^{205,210-216}$. In the $\mathrm{t}-\mathrm{ACE}-/$-mice, that lack the membrane-bound $\mathrm{ACE}$, the balance between RAS and KKS is shifted. The disbalance between RAS and KKS in $\mathrm{t}-\mathrm{ACE}-/-$ mice is in favour of the KKS and leads to adverse effects on the cardiovascular system, such as reduced cardiac contractility, arterial reactivity and arterial elasticity. The involvement of the $\mathrm{KKS}$, in the regulation of cardiovascular function and structure is proven in the last chapter. The alterations caused by the absence of $t-A C E$ or during prolonged ACE inhibition are very useful to unravel the exact mechanisms involved in the maturation of the cardiovascular system. Adverse effects on cardiac function, vascular reactivity and elasticity are observed during ACE inhibition and these results are in contrast to those obtained with ACE inhibition during cardiovascular disease. However, this should not lead to general conclusions, since the balance between RAS and KKS is completely different in a situation of cardiovascular disease compared to the situation of $t-\mathrm{ACE}$ deficiency. By treating cardiovascular diseases with $\mathrm{ACE}$ inhibitors the disbalance between $\mathrm{RAS}$ and $\mathrm{KKS}$ is abrogated and it is unlikely that the balance between RAS and KKS will be shifted to the situation of disbalance as observed in the $t-A C E-/$ mice. Thus, it seems that the balance between RAS and KKS has to be disturbed in favour of RAS before ACE inhibitors become beneficial. The necessity of an upregulated RAS might also explain why early treatment with $A C E$ inhibitors or $A T_{1}$ antagonists after $M I$ in mice results in adverse effects, whereas the same treatment started at a later time point (e.g. heart failure) shows obvious beneficial effects ${ }^{\text {d. }}$. The observation that the function of membrane-bound $\mathrm{ACE}$ can partly be compensated by the circulating $A C E$ activity (chapters 2,3 \& 7 ) suggests that systemic $A C E$ inhibition in general is expected to be more effective than targeted inhibition of the membrane-bound ACE. In other words, if the goal is to shift the disbalance between 
RAS and KKS to a more balanced situation, the conventional inhibition of both circulating and membrane-bound ACE is very effective.

t-ACE - /-

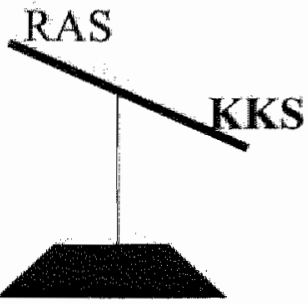

Normal

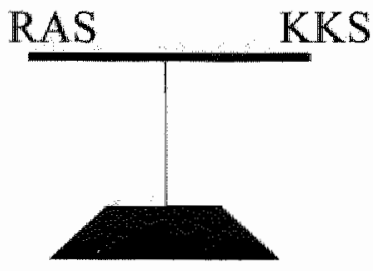

Cardiovascular

disease

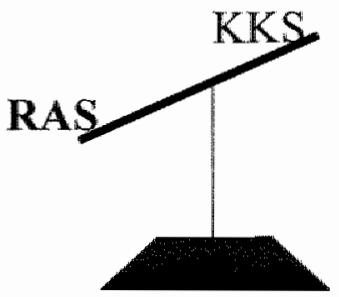

Figure 3. The differences in the balance of RAS and KKS in t-ACE - t- mice, normal and during cardiovascular diseases

\section{Future research}

The increased arterial stiffness is induced by stimulation of the $\mathrm{BK}$. receptor during $\mathrm{ACE}$ inhibition and this increase in stiffness is related to changes in the arterial wall-composition. Basic research on the mechanism and components (e.g. fibronectin and integrins) that are involved in this response should contribute to a better insight in the regulation of arterial elasticity. Alterations in the cell-cell and cell-matrix interactions are not only affecting the elasticity of the vasculature; part of the cardiac contractile function also depends on the cellarrangement. Research on cardiac elasticity and the involvement of the $\mathrm{BK}_{2}$ receptor could provide new possibilities to improve the cardiac contractility after MI (e.g. reduction of ventricular dilatation).

Genetic diversity, as demonstrated in the comparison between t-ACE $/$ mice and 1 -ACE $+/+$ mice (chapters $2,5 \& 7$ ) is an important determinant in the eventual cardiovascular risk. As described in the former paragraph a disbalance between RAS and KKS in favour of either one of them has adverse effects on the cardiovascular system. So far, genetic predisposition has mainly been investigated in relation to polymorphisms in the RAS system $^{25}$. For example, polymorphism of the ACE gene is related to increased arterial stiffiness ${ }^{39}$. Arterial elasticily is related to the pulse pressure, which is an independent risk factor for cardiovascular disease ${ }^{436}$. However, the balance contains two components. Genetic predisposition for an increased RAS activity can lead to a higher cardiovascular risk, but can be counterbalanced when combined with a genetic predisposition for an 
increased KKS activity. In contrast, cardiovascular risk can be enhanced if the genetic predisposition for an increased RAS activity is combined with a genetic predisposition of a decreased $\mathrm{KKS}$ activity. Since, inhibition of the $\mathrm{BK}_{2}$ receptor proved the involvement of the KKS in vascular elasticity (chapter 8), one could hypothesise that alterations in the KKS may contribute to an increased pulse pressure and increased cardiovascular risk. A polymorphism of the $\mathrm{BK}_{2}$ receptor has been described and related to increased receptor mRNA levels ${ }^{437.438}$. Research on the pulse pressure and arterial compliance in relation with single polymorphism of the $\mathrm{BK}_{2}$ receptor or combined with, for instance, the $\mathrm{ACE}$ polymorphism or $\mathrm{AT}_{\mathbb{1}}$ polymorphism could help to predict the cardiovascular risk of the patient and optimise the therapy. 


\section{References}

1. Kaz AM: The cardiomyopathy of overload: an unnatural growth response. Eur Heart J 1995;16:1110-114.

2. Bonneux L, Looman CWN, Barendregt JJ, Van der Maas PJ: Regression analysis of recent changes in cardiovascular morbidity and mortality in the Netherlands. Br Med J 1997;314:789-792.

3. Gheorghiade M, Bonow R.O: Chronic heart failure in the united states. A manifestation of coronary artery disease. Circulation 1998;97:282-289.

4. Grossman W: Diastolic dysfunction in congestive heart fallure. $N$ Engl $J$ Med $1991 ; 325: 1557-1564$.

5. Gaasch WH: Diagnosis and treatment of theart failure based on left ventricular systolic or diastolic dysfunction. JAMA 1994;271:1276-1280.

6. Eichhorn EJ, Bristow MR: Medical therapy can improve the biological properties of the chronically failing heart. A new era in the treatment of heart failure. Circulation 1996:94:2285-2296.

7. Sigurdsson $\mathcal{A}_{\text {, Held }} \mathrm{P}$, Swedberg $\mathrm{K}$ : Short- and long-term neurohomonal activation following acute myocardial infarction. Am Heart $J$ 1993; 126:10681076.

8. Hirsch AT, Pinto $\mathrm{YM}_{*}$, Schunkert $\mathrm{H}_{\text {, }}$ Dzau VJ: Potential role of the tissue reninaniotensin system in the pathophysiology of congestive heart failure. $A m$. Cardiol $1990 ; 66: 22-30$.

9. Stroth U, Unger $T$ : The renin-angiotensin system and its receptors, $J$ Cardiovasc Phamacol 1999;33(suppl 1):S21-S28.

10. Tigerstedt R, Bergman PG: Niere und Kreislauf. Scand Arch Physlol 1898;7$8: 223-271$.

11. Goldblatt $H$, Lynch J, Hanzal RF, Summerville WW: The production and persistent elevation of systolic blood pressure by means of renal ischemia. $J$ Exp Med 1934;59:347-380. 
12. Skeggs LT, Lentz KE, Gould AB, Hochstrasser H, Kahn JR: Biochemistry and kinetics of the renin angiotensin system. Fed Proc 1967;26:42-47.

13. Skeggs LT: Discovery of the two angiotensin peptides and the angiotensin converting enzyme. Hypertension 1993;21:259-260.

14. Hodge RL, $\mathrm{Ng}$ KKF, Vane JR: Disappearance of angiotensin from the circulation of the dog. Nature 1967:215:138-141.

15. Santos RAS, Campagnole-Santos MJ, Andrade SP: Angiotensin-(1-7): an update. Regul Pept 2000;91:45-62.

16. Kohara $\mathrm{K}$, Brosnihan $\mathrm{KB}$, Chapell $\mathrm{MC}$, Khosla MC, Ferrario CM: Angiotensin-(1-7), a member of circulating angiotensin peptides. Hypertension $1991 ; 17: 131-138$.

17. Goodfriend TL: Angiotensins, A family that grows from within. Hypertension 1991;17:139-140.

18. Biron P, Meyer P, Panisset JC: Removal of angiotensins from the systemic circulation. Can J Physiol Pharmacol 1968;46:175-178.

19. Hilgers KF, Bingener E, Stumpf C, Muller DN, Schmieder RE, Veelken R: Angiotensinases restrict locally generated angiotensin II to the blood vessel wall. Hypertension 1998;31:368-372.

20. Philips MI, Speakman EA, Kimura B: Levels of angiotensin and molecular biology of the tissue renin angiotensin in systems. Regul Pept 1993;43:1-20.

21. Sernia C: Location and secretion of brain angiotensinogen. Regul Pept $1995 ; 57:[1-18$.

22. Bader M, Peters J, Baltatu $O$, Müler DN, Luft FC, Ganten D: Tissue reninangiotensin systems: new insight from experimental animal models in hypertension research. $J \mathrm{Mol}$ Med $2001 ; 79: 76-102$.

23. Harding JW, Felix D: The effects of the aminopeptidase inhibitors amastatin and bestatin on angiotensin-evoked neuronal activity in rat brain. Brain Res 1987:424:299-304.

24. Madeddu P, Parpaglia P, Demontis MP, Varoni MV, Fattaccio MC, Glorioso $\mathrm{N}$ : Chronic inhibition of bradykinin B2-receptors enluances the slow vasopressor response to angiotensin II. Hypertension 1994;23:646-652.

25. Reaux A, Fournie-Zaluski MC, Llorens-Cortes C: Angiotensin III: a central regulator of vasopressin release and blood pressure. Trends Endocrinol Merab $2001 ; 12: 157-162$.

26. Lippoldt A, Paul M, Fuxe $K$, Ganten $D$ : The brain renin-angiotensin system: molecular mechanisms of cell to cell interactions. Clin Exp Hypertension $1995 ; 17: 251-266$.

27. Campbell DI: Circulating and tissue angiotensin systems. I Clin Imvest $1987 ; 79: 1-6$

28. Dzau VJ: Circulating versus local renin-angiotensin system in cardiovascular homeostasis. Circulation 1988;77(suppl 1):I4-I13. 
29. Dzau VJ: Tissue renin-angiotensin system: physiologio and pharmacologic implications. Circulation 1988;77:11-13.

30. Paul M, Wagner J, Dzau VJ: Gene expression of renin-angiotensin system in human tissues. I Chin Imest 1993;91:2058-2064.

31. Nicholls MG, Robertson JIS, Inagami T: The renin-angiotensin system in the twenty-first century. Blood Press 2001;10:327-343.

32. Gomez $R A$, Norling $L L$, Wilfong $N$, Isakson $P$, Lynol $K R$, Hock $R$, Quesenbery P: Leukocytes synthesis angiotensinogen. Hypertension $1993 ; 21: 470-475$.

33. Lynch KR, Peach MJ: Molecular biology of angiotensinogen. Hypertersion 1991;17:263-269.

34. Dostal DE, Rothblum KN, Chernin MI, Cooper GR, Baker KM: Intracardiac detection of angiotensinogen and renin: a localized renin-angiotensin system in neonatal rat heart. Am J Physiol 1992;263:C838-C850.

35. Dostal DE, Booz GW, Baker KM: Regulation of angiotensinogen gene expression and protein in neonatal rat cardiac fibroblasts by ghcococorticoid and B-adrenergic stimulation. Basic Res Cordiol 1999;95:485-490.

36. Danser AHJ, Kats van IP, Admiraal PJJ, Derkx FHM, Lamers JMJ, Verdouw PD, Saxena PR, Schalekamp MADH: Cardiac renin and angiotensins uptake from plasma versus in situ synthesis. Hypertension 1994;24:37-48.

37. Danser AHJ, van Kesteren CAM, Bax WA, Tavenier M, Derkx FHM, Saxena PR, Schalekamp MADH: Prorenin, renin, angiotensinogen, and angiotensinconverting enzyme in normal and failing human hearts. Evidence for renin binding. Cinculation 1997;96:220-226.

38. Danser AHJ, Saris JJ, Schujit MP, Kats van IP: Is there a local reninangiotensin system in the heart? Cardiovasc Res 1999;44:252-265.

39. Passier RCJJ, Smits JFM, Verluyten MJA, Daemen MJAP: Expression and localization of renin and angiotensinogen in trat heart after myocardial infarction. Am J Physiol 1996;271:H1040-H1048.

40. Skeggs LT, Dorer FE, Lentz KE, Kahn JR, Emancipator SN: A new mechanism in one-kidney, one-clip hypertension. Hypertension 1985;7:72-80.

41. Campbell DJ: Extrarenal renin and blood pressure regulation An alternative viewpoint. Am J Hypertens 1989;2:266-275.

42. Dzau VJ, Brut DW, Prat RE: Molecular biology of the renin-angiotensin system. Am J Physiol 1988;255:F563-F573.

43. Eijnden MMED v d, Saris JJ, Bruin RJA d, Wit E d, Sluiter W, Reudelhuber TL, Schalekamp MADH, Derkx FHM, Danser AHJ: Prorenin accumulation and activation in human endothelial cells. Importance of mannose 6-phosphate receptors. Arteriosct Thromb Vasc Biol 2001;21:911-916. 
44. Saris JJ, Derkx FHM, Bruin de RJA, Dekkers DHW, Lamers JMI, Saxena PR, Schalekamp MADH, Danser AHJ: High-affinity prorenin binding to cardiac man-6-p/IGF II receptors precedes proteolytic activation to renin. Am J Physiol $2001 ; 280: H 1706-H 1715$.

45. Ganten D, Schelling P, Vecsei $P$, Ganten $U$ : Iso-renin of extrarenal origin. Am $J$ Med 1976;60:760-772.

46. Hilgers KF, Veelken R, Müller DN, Kohler H, Hartner A, Botkin SR, Stumpf C, Schmeider RE, Gomez RA: Renin uptake by the endothelium mediates vascular angiotensin formation. Hypertension $2001 ; 38: 243-248$.

47. Loudon M, Bing RF, Thurston H, Swales JD: Arterial wall uptake of renal renin and blood pressure. Hypertension 1983;5:629-634.

48. Nielsen AH, Poulsen $\mathrm{K}$ : Evidence for a predominant renal secretion and clearance of inactive plasma renin, studied by in vivo inhibition of protein synthesis. J Hypertens 1988;6:129-137.

49. Lutterotti von $\mathrm{N}$, Catanzaro DF, Sealey JE, Laragh JH: Renin is not synthesized by cardiac and extrarenal vascular tissues. A review of experimental evidence. Circulation 1994;89:458-470.

50. Danser AHJ: Local renin-angiotensin systems. Mol Cell Biochem $1996 ; 157: 2 \llbracket 1-216$.

51. Katz SA, Opsahl JA, Forbis LM: Myocardial enzymatic activity of renin and cathepsin $\mathrm{D}$ before and after bilateral nepherectomy. Basic Res Cardiol $2001 ; 96: 659-668$.

52. Katwa LC, Tyagi SC, Campbell SE, Lee SJ, Cicila GT, Weber KT: Valvular interstitial cells express angiotensinogen and cathepsin $D$ and generate angiotensin peptides. Int J Biochem Cell Biol 1996;28:807-821.

53. Paul M, Stoll M, Kreutz R, Fernandez-Alfonso MS: The cellular basis of angiotensin converting enzyme mRNA expression in rat heart. Basic Res Cardiol 1996,91 (suppl2):57-63.

54. Lindpainter $\mathbb{K}$, Jin M, Wilhelm MJ, Suzuki F, Linz W, Schoelkens BA, Ganten D: Intracardiac generation of angiotensin and its physiologic role. Circulation $1988 ; 77: 118-123$.

55. Linz W, Scholkens BA, Han YF: Beneficial effects of the converting enzyme inhibitor, Ramipril, in ischemic rat hearts. I Cardiovasc Pharmacol 1986;8(suppl10):\$91-\$99.

56. Falkenhahn $\mathrm{M}$, Franke $\mathrm{K}$, Bohle RM, Zhu $\mathrm{YC}$, Stauss HM. Bachmann $\mathrm{S}$, Danilov $\mathrm{S}$, Unger $\mathrm{T}$ : Cellular distribution of angiotensin converting enzyme after myocardial infarction. Hypertension 1995;25:219-226.

57. Mulller DN, Luft FC: The renin-angiotensin system in the vessel wall. Basic Res Cardiol 1998;93 (Suppl 2):7-14. 
58. Rosenthal $\mathrm{JH}$, Pfeifle B, Michailov M, Pschorr Ji, Jacob $\| \mathrm{CM}$, Dahlheim H: Investigations of components of the renin-angiotensin system in rat vascular tissue. Hypertension 1984;6:383-390.

59. Gross $\mathrm{V}$, Schunk $\mathrm{W}-\mathrm{H}$, Honeck $\mathrm{H}_{\text {, Milia }} \mathrm{AF}$, Kärgel $\mathbb{E}_{\text {, Walther }} \mathrm{T}$, Bader $\mathrm{M}_{\text {* }}$ Inagami $\mathrm{T}$, Schneider $\mathrm{W}$, Luft $\mathrm{FC}$ : Inhibition of pressure natriuresis in mice lacking the AT2 receptor. Kidney Imt 2000;57:191-202.

60. Urata H, Kinoshita A, Misono KS, Bumpus FM, Husain A: Identification of a bighly specific chymase as the major angiotensin II-forning enzyme in the human heart. J Biol Chem 1990;265:22348-22357.

61. Urata H, Boehm KD, Philip A, Kinoshita A, Gabrovsek J, Bumpus FM, Husain A: Cellular localization and regional distribution of an angiotensinll-forming chymase in the heart. J Clin Invest 1993;91:1269-1281.

62. Barlucchi L, Leri A, Dostal DE, Fiordaliso F, Hintze TH, Kajstura J, NadalGinard B, Anversa P: Canine ventricular myocytes posses a renin-angiotensin system that is upregulated with heart failure. Circ Res 2001;88:298-304.

63. Inagami $T$, Iwai $N$, Sasaki $K$, Yamano $Y$, Bardhan $S$, Chaki $S$, Guo DF, Furuta

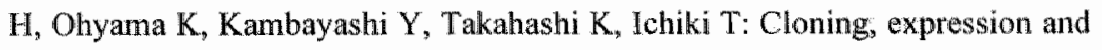
regulatoin of angiotensin II receptors. Eur Heart J 1994;15 (suppl D): 104-107.

64. Helin K, Stoll M, Meffert S, Stroth U, Unger T: The role of angiotensin receptors in cardiovasvular diseases. Ann Med 1997;29:23-29.

65. Saavedra JM, Viswanathan M, Shigematsu $\mathbb{K}$ : Localization of angiotensin ATI receptors in the rat heart conduction system. Eur I Pharmacol 1993;235:301303.

66. Burson JM, Aguilera G, Gross KW, Sigmund CD: Differential expression of angiotensin receptor $1 \mathrm{~A}$ and $1 \mathrm{~B}$ in mouse. Am J Physiol 1994;267:E260-E267.

67. Nio Y, Matsubara H, Murasawa S, Kanasaki M, Inada M: Regulation of gene transcription of angiotensin II receptor subtypes in myocardial infarction. I Clin Invest 1995;95:46-54.

68. Dinh DT, Frauman AG, Johnston Cl, Fabiani ME: Angiotensin receptors: distribution, signalling and function. Clin Sci 2001;100:481-492.

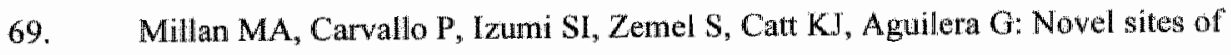
expression of functional angiotensin II receptors in the last gestation fetus. Science $1989 ; 244: 1340-1342$.

70. Grady EF, Sechi LA, Griffin CA, Schambelan M, Kalinyak JE: Expression of AT2 receptors in the developing rat fetus. J Clin lnvest 1991;88:921-933.

71. Shanmugam S, Snadberg K: Ontogeny of angiotensin II receptors. Cell Biol Intern $1996 ; 30: 169-176$.

72. Wang ZQ, Moore AF, Ozono R, Siragy HM, Carey RM: Immunolocalization of subtype 2 angiotensin (AT2) receptor protein in rat heart. Hypertension $1998 ; 32: 78-83$. 
73. Viswanatham $M$, Saavedra JM: Expression of angiotensin II AT2 receptors in the rat skin during experimental wound healing. Peptides 1992;13:783-786.

74. Dostal DE, Hunt RA, Kule CE, Bhat GJ, Karoor V, McWhinney CD, Baker KM: Molecular mechanisms of angiotensin II in modulating cardiac function: intracardiac effects and signal transduction pathways. I Mol Cell Cardiol $1997: 29: 2893-2902$.

75. Bilsen van $\mathrm{M}$ : Signal transduction revisited: recent developments in angiotensin II signaling in the cardiovascular system. Cardiovasc Res $1.997 ; 36: 310-322$.

76. Hontuchi $M$, Hayashida $W$, Kambe $T$, Yamada $T$, Dzau VJ: Angiotensin type 2 receptor dephosphorylates bol-2 by activating mitogen-activated protein kinase phosphotase-1 and induces apoptosis. J Biol Chem 1997;272:19022-19026.

77. Tsutsumi $\mathrm{Y}$, Matsubara $\mathrm{H}$, Masaki $\mathrm{H}$, Kurihara $\mathrm{H}$, Murasawa S, Takai S, Miyazaki M, Nozawa $Y$, Ozono $\mathbb{R}$, Nakagawa K, Miwa $Y$, Kawada N, Mori $Y$, Shibasaki Y, Tanaka Y, Fujiyama S, Koyama Y, Fujiyama A, Takahashi H, Iwasaka T: Angiotensin II type 2 receptor overexpression activates the vascular kinin system and causes vasodilation. J Clin Imest 1999; 104:925-935.

78. Smits JFM, Passier RCJ, Nelissen-Vrancken HJMG, Cleutjens JPM, Kuizinga MC, Daemen MJAP: Does ACE inhibition limit structural changes in the heart following myocardial infarction? Eur Heart J 1995; 16: N46-51.

79. Kuizinga MC, Smits JFM, Arends JW, Daemen MJAP: AT2 receptor blockade reduces cardiac interstital cell function after rat myocardial infaretion. $J \mathrm{Mol}$ Cell Cardiol 1998;30:425-434.

80. Hunyady L, Catt KJ, Clark AJL, Gáborik Z: Mechanisms and functions of ATI angiotensin receptor internalization. Regul Pept 2000;91:29-44.

81. Anderson KM, Murahashi T, Dostal DE, Peach MJ: Morphological and biochemical analysis of angiotensin II internalization in cultured rat aortic smooth muscle cells. Am J Physiol 1993;264"C179-C188.

82. Kats van JP, Lannoy de LM, Danser AHJ, Meegen van JR, Schalekamp MADH: Angiotensin II type 1 (ATI) receptor-mediated accumulation of angiotensin $\mathbb{I l}$ in tissues and its intracellular half-life in wivo. Hypertension $1997 ; 30: 42-49$

83. Booz GW, Conrad KM, Hess AL, Singer HA, Bakerr KM: Angiotensin-IIbinding sites on hepatocyte nuclei. Endocrinology 1992;130:3641-3649.

84. Sadoshima $\mathrm{X}, \mathrm{Xu} \mathrm{Y}$, Slayter HS, lzumo S: Autocrine release of angiotensin II mediates stretch-induced hypertrophy of cardiac myocytes in vitro. Cell $1993 ; 75: 977-984$.

85. Kats van IP, Lannoy de LM, Danser AHJ, Meegen $v$ JR, Verdouw PD, Schalekamp MADH: Angiotensin II type 1 (AT1) receptor-mediated accumulation of angiotensin II in tissues and its intracellular half-life in vivo. Hypertension $1997 ; 30: 42-49$. 
86. Robertson AL, Khairallah PA: Angiotensin II: rapid healization in nuclei of smooth and cardiac muscle. Science 1971;172:1138-1139.

87. Re RN, MacPhee AA, Fallon JT: Specific nuclear binding of angiotensin II by rat liver and spleen muclei. Clin Sci $1981 ; 61: 245 \mathrm{~s}-247 \mathrm{~s}$.

88. Tang SS, Rogg H, Schumacher $\mathbb{R}$, Dzau VJ: Characterization of nuclear angiotensin-II-binding sites in rat liver and comparison with plasma membrane receptors. Endocrinology 1992;131:374-380.

89. Sadoshima J, Izumo S: Molecular characterization of angiotensin II induced hypertrophy in cardiac myocytes and hyperplasia of cardiac fibroblasts. Critical role of the AT1 receptor sybtype. Circ Res $1993 ; 73: 413-423$.

90. Huckle WR, Earp HS: Regulation of cell proliferation and growth by angiotensin II. Prog Growth Factor Res 1994;5:177-194.

91. Cook JL, Zhang $Z$, Re RN: In vitro evidence for an intracellular site of angiotensin action. Circ Res 2001;89:1138-1146.

92. Schütz S, Le Moullec JM, Corvol P, Gasc JM: Early expression of all components of the renin-angiotensin system in human development. $\mathrm{Am} J$ Pathol 1996;149:2067-2079.

93. Gomez: Molecular biology of components of the renin-angiotensin system during development. Pediatr Nephrol 1990:4:421-423.

94. Kim HS, Hee BH, Han KH, Oh SI, Youn TJ, Kim CH, Lee MM, Park YB, Choi YS, Lee YW: Reciprocal change in angiotensinogen mRNA expression in rat myocardiun and liver after myocardiall infarction. Heart Vessels $1998 ; 13: 1-8$.

95. Jones CA, Hurley MI, Black TA, Kane CM, Pan L, Pruitt SC, Gross KW: Expression of a renin/GFP transgene in mouse embryomic, extra embryonic and adult tissues. Physiol Genomics 2000;4:75-81.

96. Fogo A, Ichikawa I: Renin angiotensin system in development of mice and men. Am J Pathol 1996;149:1797-1801.

97. Urata H, Hoffmann $\mathrm{S}$, Ganten D: Tissue angiotensin II system in human heart. Eur Heart J 1994;15 (suppl D):68-78.

98. Lumbers ER: Functions of the renin-angiotensin system during development. Clin Exp Pharmacol Physiol 1995;22:499-505.

99. Shotan A, Widerhom J, Hurst $A$, Elkayam U: Risks of angiotensin-converting enzyme inhibition during pregnancy: Experimental and dinical evidence, potential mechanisms and recommendations for use. Am J Med 1994;96:451456.

100. Yosipiv IV, Dipp S, El-Dahr SS: Ontogeny of somatic angiotensin-converting. enzyme. Hypertension 1994;23:369-374.

101. Guron $G$, Adams MA, Sundelin B, Friberg P: Neonatal angiotensin-converting enzyne intibition in the rat induces persistent abnormalities in renal function on histology. Hypertension 1997;29:91-97. 
102. Spence SG, Allen HL, Cukierski MA, Manson JM, Robertson.RT, Eydelloth RS: Defining the susceptible period of developmental toxicity for the ATIgelective angiotensin II receptor antagonist losartan in rats. Terafology $1995 ; 51.367-382$

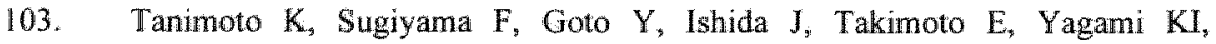
Fukamizu A, Murakani K: Angiotensinogen-deficient mice with hypotension. I Biol Chem 1994;269:31334-31337.

104. Nagata $M$, Taninoto $K$, Fukamizu A, Kon $Y$, Sugiyama $F$, Yagami $K$, Murakami K, Watanabe T: Nephrogenesis and renovascular development in angiotensinogen-deficient mice. Lab Imvest 1996;75:745-753.

105. Esther Jr. CR, Howard TE, Marino EM, Goddard JM, Capecchi MR, Bernstein. $\mathrm{KE}$ : Mice lacking angiotensin-converting enzyme have low blood pressure, renal pathology, and reduced male fertility. Lab Invest 1996;74:953-965.

106. Krege JH, John SWM, Langenbach LL, Hodgin JB, Hagaman JR, Bachman ES, Jennette JC, O'Brien DA, Smithies O: Male-female differences in fertility and blood pressure in ACE-deficient mice. Nature 1995;375:146-148.

107. Esther Jr. CR, Marino EM, Howard TE, Machaud A, Corvol P, Capecchi MR, Bernstein $\mathrm{KE}$ : The critical role of tissue angiotensin-converting enzyme as revealed by gene targeting in mice. J Clin Invest 1997;99:2375-2385.

108. Oliverio MI, Kim H-S, Ito M, Le T, Audoly L, Best CF, Hiller S, Kluckman K, Maeda N, Smithies $O$, Coffman TM: Reduced growth, abnormal kidney structure, and type 2. (AT2) angiotensin receptor-mediated blood pressure regulation in mice lacking both ATIA and ATIB receptors for angiotensin II. Proc Natl Acad Sci USA 1998;95:15496-15501.

109. Tsuchida S, Matsusaka T, Chen X, Okubo S, Niimura F, Nishimuar H, Fogo A, Utsunomiya $H$, Inagami $T$, Ichikawa $I$ : Murine double nullizygotes of the angiotsin type $1 \mathrm{~A}$ and $1 \mathrm{~B}$ receptor genes duplicate severe abnormal phenotypes of angiotensinogen nullizygotes. J Clin Inves: 1998;101:755-760.

110. Nagata $M$, Murakami $K$, Watanabe $T$ : Renal manifestations in angiotensindeficient mice: unexpected phenotypes emerge. Exp Nephrol 1997;5:445-448.

111. Moore RL, Korzick DH: Cellular adaptations of the myocardiun to chronic exercise. Prog Cardiowasc Dis 1995;37;371-396.

112. lemitsu M, Miyauchi T, Maeda S, Sakai S, Kobayashi T, Fujii N, Miyazaki H, Matsuda M, Yanaguchi I: Physiological and pathological cardiac hypertrophy induce different molecular phenotypes in the rat. Am $J$ Physiol 2001;281:R2029-R2036.

113. Hespel P, Lijnen P, Hoof van R, Fagard R, Goossens W, Lissens W, Moerman $E$, Amery $A$ : Effects of physical endurance training on the plasma reninangiotensin-aldosterone system. J Endocrin 1988;11 16:443-449. 
114. Mackenna D, Summerour SR, Vilarreal FJ: Role of mechanical factors in modulating cardiac fibroblast function and extracellular matrix synthesis. Cardiovasc Res 2000; $46: 257-263$.

115. Oparil S: Pathogenesis of ventricular hypertrophy. I Am Coll Cardiol $1985 ; 5: 57 \mathrm{~B}-65 \mathrm{~B}$.

116. Ausma J, Schart $G$, Thoné $F$, Shivalkar $B$, Flanneng $W$, Depré $C$, Vanoverschelde JL, Ramaekers $F$, Borgers $M$ : Chronic ischemic viable myocardium in man: aspects of dedifferentiation. Cardiowascular Pathology $1995 ; 4: 29-37$.

117. Swynghedauw B: Remodeling of the heart in chronic pressure overload. Basic Res Cardiol 1991;86:99-105.

118. Opie LH: The heart, physiology from cell to circulation, 3rd ed. Philadelphia, Lippincott-Raven publishers, 1997.

119. Kragten JA: New myocardial marker proteins in acute myocardial infarction. Quanitative aspects [Thesis]. Universiteit Maastricht; Maastricht, 1998.

120. Adams JE, Abendschein DR, Jaffe AS: Biochemical markers of myocardial injury, is MB creatine kinase the choice for the 1990's ? Circulation 1993;88:750-763.

121. Mair J: Progress in myocardial damage detection: new biochemical markers for clinicians. Crit Rev Clin Lab Sci 1997;34:1:1-66.

122. Katus HA, Remppis A, Looser $\mathrm{S}$, Hallermeier $\mathrm{K}$, Scheffold T, Kubler W: Enzyme linked immuno assay of cardiac troponin $\mathrm{T}$ for the detection of acute myocardial infarction in patients. J Mol Cell Cardiol 1989;21:1349-1353.

123. Müller-Bardorff $M$, Freitag $H$, Scheffold $T$, Remppis A, Kübler W, Katus HA: Development and characterization of a rapid assay for bedside determinations of cardiac troponin T. Circulation 1995;92:2869-2875.

124. Vork MM, Glatz JFC, Surtel DAM, Knubben HJM, Vusse van der GJ: A sandwich enzyme linked immuno-sorbent assay for the determination of rat heart fatty acid-binding protein using the streptavidin-biotin system. Application to tissue and effuent samples from normoxic rat heart perfusion. Biochim Biophys Acta 1991;1075:199-205.

125. Ohkaru $\mathrm{Y}$, Asayama $\mathbb{K}$, Ishii $H$, Nishimura $S$, Sunahara $N$, Tanaka $\mathrm{T}$, Kawamura K: Development of a sandwich enzyme-linked immunosorbent assay for the determination of human heart type fatty acid-binding protein in plasma and urine by using two different monoclonal antibodies specific for human heart faty acid-binding protein. J Immuno Meth 1995;178:99-111.

126. Müller-Bardorff M, Hallermayer $K$, Schröder A, Ebert C, Borgya A, Gerhardt W, Remppis A, Zehelein J, Katus HA: Improved troponin T ELISA specific for cardiac troponin $\mathrm{T}$ isoform: assay development and analytical validation. $C l i n$ Chem 1997;43:3:458-466. 
127. Kragten $J_{A}$, Hermens WT, Van Diejen-Visser MP: Quantification af cardiac troponin $\mathrm{T}$ release into plasma after acute myocardial infarction. Only fractional recovery compared with enzymes. Ann Clin Biochem 1996;33:1-10.

128. Cleutjens JPM, Blankesteijn WM, Daemen MJAP, Smits JFM: The infarcted myocardium: simply dead tissue, or lively target for therapeutic interventions. Cardiovasc Res 1999;44:232-241.

129. Sun Y, Weber KT: Infarct scar: a dynamic tissue. Cardiovasc Res $2000 ; 46: 250-256$.

130. Struijker-Boudier HAJ, Smits JFM, De Mey JGR: Pharmacology of cardiac and wascular remodeling. Ann Rev Pharmacol Toxicol 1995;35:509-539.

131. Anversa $P$, Olivetti $G$, Capasso $K \mathrm{~K}_{\text {: }}$ Cellular basis of ventricular remodeling after myocardial infarction. Am J Cardiol 1991;68:70-160.

132. Entl $\mathrm{G}$, Gaudron $\mathrm{P}$, Hu $\mathrm{K}$ : Ventricular remodeling after myocardial infarction. Experimental and clinical studies. Basic Res Cardiol 1993;88 (suppl 1):125137.

133. Pfeffer $\mathrm{MA}$, Braunwald $\mathrm{E}$ : Ventricular remodeling after myocardial infarction. Experimental observations and clinical implications. Circulation 1990;81:1161-1172.

134. Creemers E, Cleutjens J, Smits J, Heymans S, Moons $\mathbb{L}$, Collen D, Daemen M, Carmeliet P: Disruption of the plasminogen gene in mice abolishes wound healling after myocardial infarction. Am J Pathol 2000;156:1865-1873.

135. Blumenfeld ID, Sealey JE, Alderman MH, Cohen $H$, Lappin R, Catanzaro DF, Laragh JH: Pllasma renin activity in emergency department and its independent association with acute myocardial infarction. Am I Hypertens 2000;13:855863.

136. Cleland JGF, Cowburn PJ, Morgan K: Neuroendocrine activation after myocardial infarction: causes and consequences. Heart 1996;76 (suppl 3):5359.

137. McAlpine HM, Morton JJ, Leckie B, Rumley A, Gillen $G$, Dargie HJ: Neuroendocrine activation after myocardial infarction. $\mathrm{Br}$ Heart $J$ $1988 ; 60: 117-124$.

138. Dargie HJ, McAlpine HM, Morton IJ: Neuroendocrine activation in acute myocardial infarction. J Cardiovasc Pharmacol 1987:9 (suppl 2):S21-\$24.

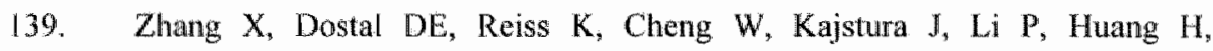
Sonnenblick EH, Meggs LG, Baker KM, Anversa P: Identification and activation of autocrine renin-angiotensin system in adult ventricular myocytes. Am J Physiol 1995;269:H1791-H1802.

140. Serneri GGN, Boddi M, Cecioni I, Vanni S, Coppo M, Pap ML, Bandinelli B, Bertolozzi I, Polidori G, Toscano T, Maccherinin M, Modesti PA: Cardiac angiotensin II formation in clinical course of heart failure and its relationship with left ventricular function. Circ Res $2001 ; 88: 961-968$. 
141. Pfeffer JM, Pfeffer MA, Braunwalid E: Hemodynamic benefits and prolonged survival witll long-term captopril therapy in rats with myocardial infarction and heart failure. Circulation 1987;75(Suppl 1):1149-1155.

142. Pfeffer JM, Pfeffer MA, Mirsky 1, Braunwald E: Regression of left ventricular hypertrophy and prevention of left ventricular dysfunction by captoprit in spontaneously hypertensive rat. Proc Natl Acad Sci USA 1982,79:3310-3314.

143. Sawa $H$, Kawaguchi $H$, Mochizuki $N$, Endo $Y$, Kudo $T$, Tokuchi F, Fjioka $Y$, Nagashima K, Kitabatake A: Distribution of angiotensinogen in diseased human hearts. Mol Cell Biochem 1994;132:15-23.

144. Lindpainter $\mathrm{K}$, Lu W, Niedermajer $\mathrm{N}$, Schieffer B, Just A, Ganten D, Drexler H: Selective activation of cardiac angiotensinogen gene expression in postinfarction ventricular remodeling in the rat. I Mol Cell Cardiol 1993;25:133143.

145. Hirsch AT, Opsahl JA, Lunzer MM, Katz SA: Active renin and angiotensinogen in cardiac interstitial fluid after myocardial infarction. $A m J$ Physiol 1999;276:H1818-H1826.

146. Sun Y, Zhang JQ, Weber KT: Renin expression at sites of repair in the infarcted rat heart. I Mol Cell Cardiol 2001;33:995-1003.

147. Passier RCJJ, Smits JFM, Verluyten MJA, Studer R, Drexler H, Daemen MJAP: Activation of angiotensin-converting enzyme expression in infaret zone following myocardial infarction. Am J Physiol 1995;269:H1268-H1276.

148. Hokimoto S, Yasue H, Fujimoto K, Yamanoto H, Nakao K, Kaikita K, Sakata $\mathrm{R}$, Miyamoto $\mathrm{E}$ : Expression of angiotensin-converting enzyme in remaining viable myocytes of human ventricles after myocardial infarction: Circulation 1996;94:1513-1518.

149. Sum $Y$, Weber KT: Angiotensin converting enzyme and myofibroblasts during tissue repair in the rat heart. J Mol Cell Cardiol 1996;28:851-858.

150. Hirsch AT, Talsness CE, Schunkert H, Paul M, Dzau VJ: Tissue-specific activation of cardiac angiotensin converting enzyme in experimental heart failure. Circ Res 1991;69:475-482.

151. Lefroy DC, Wharton J, Crake T, Knock GA, Rutherford RAD, Suzuki T, Morgan K, Polak JM, Poole-Wilson PA: Regional changes in angiotensin UI receptor density after experimental myocardial infarction. I Mol Cell Cardiol 1996;28:429-440.

152. Sun $\mathrm{Y}$, Weber KT: Cells expressing angiotensin II receptors in fibrous tissue of rat theart. Cardiovasc Res 1996;31:518-525.

153. Wharton $\mathrm{J}$, Morgan K, Rutherford RAD, Catravas ID, Chester A, Whitehead BF, Leval de MR, Yacoub MH, Polak JM: Differential distribution of angiotensin AT2 receptors in the normal and failing human heart. I Pharpacol Exp Ther 1998;284:323-336. 
154. Matsubara $H$, Kanasaki $M$, Murasawa $S$, Trukaguchi $\mathrm{Y}$, Nio $\mathrm{Y}$, Inada $\mathrm{M}$ : Differential gene expression and regulation of angiotensin II receptor subtypes in rat cardiac fibroblasts and cardiomyocytes in culture. $J$ Clin Imvert 1994;93:1592-1601.

155. Campbell SE, Katwa LC: Angiotemsin II stimulated expression of transforming growth factor- $\beta 1$ in cardiac fibroblasts and myofibroblasts. $J$ Mol Cell Cardiol $1997,29: 1947-1958$.

156. Ohkubo $\mathrm{N}$, Matsubara $\mathrm{H}$, Nozawa $\mathrm{Y}$, Mori $\mathrm{Y}$, Murasawa S, Kijima $\mathrm{K}$, Maruyama $\mathrm{K}$, Masaki $\mathrm{H}$, Tsutumi $\mathrm{Y}$, Shibazaki $\mathrm{Y}$, Iwasaka $\mathrm{T}$, Inada $\mathrm{M}$ : Angiotensin type 2 receptors are reexpressed by cardiac fibroblasts from failing myopathic hamster hearts and inhibit cell growth and fibrillar collagen metabolism. Cinculation 1997;96:3954-3962.

157. Tsutsumi Y, Matsubara H, Ohkubo N, Mori Y, Nozawa Y, Murasawa S, Kijima $\mathrm{K}$, Maruyama K, Masaki $H$, Moriguchi $Y$, Shibasaki $\mathrm{X}$, Kamihata $H$, Inada $M$, Iwasaka $T$ : Angiotensin II type 2 receptor is upregulated in human heart with interstitial fibrosis, and cardiac fibroblasts are major cell type for its expression. Circ Res 1998;83:1035-1046.

158. Schrob W, Booz GW, Dostal DE, Conrad KM, Chang KC, Baker KM: Angiotensin II is mitogen in neonatal rat cardiac fibroblasts. Circ Res $1993 ; 72: 1245-1254$.

159. Villarreal FJ, Kim NN, Ungab GD, Printz MP, Dilmann WH: Identification of functional angiotensin II receptors on rat cardiac fibroblasts. Circulation $1993 ; 88: 2849-2861$.

160. Regitz-Zagrosek $\mathrm{V}$, Fielitz J, Fleck E: Myocardial angiotensin receptors in human hearts. Basic Res Candiol 1998;93:37-42.

161. Kawano $H_{\text {, Do }}$ YS, Kawano Y, Starnes V, Barr M, Law RE, Hsueh WA: angiotensin II has multiple profibrotic effects in human cardiac fibroblasts. Circulation 2000;101:1130-1137.

162. Stauffenberger $S$, Jacobs $M$, Brandstärter $K$, Hafner $M$, Regitz-Zagrosek $V$, Ert $G$, Schrob W: Angiotensin II type 1 receptor regulation and differential trophic effects on rat cardiac myofibroblasts after acute myocardial infarction. I Cell Physiol 2001;187:326-335.

163. Reiss $K$, Capasso JM, Huang HE, Meggs LG, Li P, Anversa P: ANG II receptors, c-myc and c-jun in myocytes after myocardial infarction and ventricular failure. Am J Physiol 1993;264:H760-H769.

164. Suzuki J, Matsubara H, Urakami M, Inada M: Rat angiotensin II (type 1A) receptor mRNA regulation and subtype expression in myocardial growth and hypertrophy. Cinc Res 1993;73:439-447. 
165. Fijii M, Tanaka M, Ohnishi J, Yukawa K, Takimoto E, shimada S, Naruse M, Sugiyama F, Yagami K, Murakami K, Miyazaki H: Alterations of angiotensin II receptor contents in hypertrophied hearts. Biochem Biophys Res Comm $1995 ; 212: 326-333$.

166. Meggs LG, Coupet J, Huang $H_{\text {, }}$ Cheng W, Li P, Capasso JM, Homcy CJ, Anversa P: Regulation of angiotensin II receptors on ventricular myocytes after myocardial infarction in rats. Circ Res 1993;72:1149-1162.

167. Busche S, Gallinat S, Bohle RM, Reinecke A, Seebeck J, Franke F, Fink L, Zhu M, Sumners $C$, Unger $T$ : Expression of angiotensin AT1 and AT2 receptors in adult rat cardiomyocytes after myocardial infarction. $A m J$ Pathol 2000; $157: 605-611$.

168. Kijima $K$, Matsubara $\mathrm{H}$, Murasawa $\mathrm{S}$, Maruyama $\mathrm{K}$, Mori $\mathrm{Y}$, Ohkubo $\mathrm{N}$, Komuro $\mathrm{Y}$, Iwasaka $\mathrm{T}$, Inada $\mathrm{M}$ : Mechanical stretch induces enhanced expression of angiotensin II receptor subtypes in neonatal rat cardial myocytes. Circ Res 1996;79:887-897.

169. Kim NN, Villarreal FJ, Printz MP, Lee AA, Dillmann WH: Trophic effects of angiotensin II on neonatal rat cardiac myocytes are mediated by cardiac fibroblasts. Am J Physiol 1995;269:E426-E437.

170. Morgan JP: Abnormal intracellular modulation of calcium as a major cause of cardiac dysfunction. $N$ Engl $J$ Med 1991;325:625-632.

171. Ito K, Yan X, Tajima M, Su Z, Barry WH, Lorell BH: Contractile reserve and intracellular calcium regulation in mouse myocytes from normal and hypertrophied failing hearts. Circ Res 2000;87:588-595.

172. Spinale FG, Holzgrefe HH, Mukherjee R, Webb ML, Hird RB, Cavallo MJ, Powell JR, Koster WH: Angiotensin-converting enzyme inhibition and angiotensin II subtype-1 receptor blockade during the progression of left ventricular dysfunction: differential effects on myocyte contractile processes. $J$ Pharmacol Exp Ther 1997,283:1082-1094.

173. Fernandez-Alfonso MS, Ganten D, Paul M: Mechanisms of cardiac growth. The role of renin-angiotensin system. Basic Res Cardiol 1992;87 (suppl 2): $173-181$.

174. Watanabe $\mathrm{A}$, Endoh $\mathrm{M}$ : Relationship between the increase in Ca2+transcient and contractile force induced by angiotensin II in aequorin-loaded rabbit ventricular myocardium. Cardiovasc Res 1997;37:524-531.

175. Ahmed $\mathrm{SS}$, Levinson $\mathrm{GE}$, Weisse $\mathrm{AB}$, Regan $\mathrm{T}$ : The effect of angiotensin on myocardial contractility. J Clin Phamacol 1975;15:276-285.

176. Meissmer A, Min JY, Simon R: Effects of angiotensin II on inotropy and intracelhular $\mathrm{Ca} 2+$ handling in normal and hypertrophied rat myocardium. $J$ Mol Cell Cardiol 1998;30:2507-2518. 
177. Gallaglier AM, Bahnson TD, Yu H, Kim NN, Printz MP: Species variability in angiotensin receptor expression by cultures cardiac fibroblasts and the infarcted heart. Am I Physiol 1998;274:H801-H809.

178. Heugten van HAA. Jonge De HW, Bezstarosti $K$, Sharma HS, Verdouw $\mathrm{PD}_{\text {, }}$ Lamers $\mathrm{JMJ}$ : Intracellular signaling and genetic reprogramming during agonistinduced hypertrophy of cardiomyocyles. Anin N Y Acad Sci 1995;752:343-352.

179. Wollert $\mathrm{KC}$, Drexler $\mathrm{H}$ : The renin-angiotensin system and experimental heart failure. Cardiowasc Res 1999;43:838-849.

180. Bartucchi L, Leri A, Dostal DE, Fiordaliso F, Tada H, Hintze TH, Kajstura J, Nadal-Ginard B, Anversa P: Canin ventricular myocytes posses a reninangiotensin system that is upregulated with heart failure. Circ Res $2001 ; 88: 298-304$.

181. Booz GW, Dostal DE, Baker KM: Paracrine actions of cardiac fibroblasts on cardioamyocytes: implications for the cardiac renin-angiotensin system. $A m J$ Cardiol 1999;83:44H-47H.

182. Sil P, Sen S: Angiotensin II and myocyte growth. Hypertension 1997;30,209216.

183. Hollenberg NK: Implications of species difference for clinical investigation studies of the renin-angiotensin system. Hypertension 2000;35:150-154.

184. Corvol P, Chauveau D, Jeunemaitre $\mathrm{X}$, Ménard J: Human renin inhibitor peptides. Hypertension 1990;16:1-14.

185. Kim SH, Maeda N, Oh GT, Fernandez LG, Gomez RA, Smithies O: Homeostasis in mice with genetically decreased angiotensinogen is primarily by an increased number of renin-producing cells. $J$ Biol Chem $1999: 274: 14210-14217$.

186. Verburg KM, Kleinert HD, Kadam IRC, Chekal MA, Mento PF, Wilkes BM: Effects of chronic infusion of renin inhibitor A-64662 in sodium-depleted monkeys. Hypertension 1989;13:262-272.

187. Rongen GA, Lenders. WM, Smits P, Thien T: Clinical pharmacokinetics and efficacy of renin inhibitors. Clin Pharmacokinet 1995;29:6-14.

188. Nussberger J, Wuerzner G, Jensen C, Brunner HR: Angiotensin II suppression in humans by the orally active renin inhibitor Aliskiren (SPP100). Comparison with enalapril. Hypertension 2002;39 (suppl):e 1-e8.

189. Bader $\mathrm{M}$, Ganten $\mathrm{D}$ : Regulation of renim: new evidence from cultured cells and genetically modified mice. $J$ Mol Med 2000;78:130-139.

190. Yanai K, Saito T, Kakinuma $Y$, Kon $Y$, Hirota $K$, Taniguchi-Yanai K, Nishijo N, Shigematsu $Y$, Horiguchi $H$, Kasuya $Y$, Sugiyama F, Yagami K, Murakami K. Fukamizu A: Renin-dependent cardiovascular functions and reninindependent blood-brain barrier functions revealed by renin-deficient mice. I Biol Chem 1999;275:5-8. 
191. Ishida J, Sugiyama $F$, Tanimoto $\mathrm{K}$, Taniguchi $\mathrm{K}$, Syouji $\mathrm{M}$, Takimoto $\mathrm{E}$, Horiguchi $\mathbb{H}$, Murakami $K$, Yagami $K$, Fukamizu $A$ : Rescue of angiotensinogen-knockout mice. Biochem Broplys Res Comm 1998;252:610616.

192. Smithies $\mathrm{O}$. Kim HS: Targeted gene duplication and distuption for analyzing quantitative genetic traits in mice. Proc Natl Acad Sci USA 1994;1:36123615 .

193. Davisson RL, Kim HS, Krege JH, Lager DJ, Smithies O, Sigmund CD: Complementation of reduced survival, hypotension and renal abnornalities in angiotensinogen-deficient mice by human renin and human angiotensinogen genes. J Clin Invest 1997;99:1258-1264.

194. Kim HS, Krege JH, Kluckman KD, Hagaman JR, Hodgin JB, Best CF, Jenete $J C$, Coffnan TM, Maeda N, Smithies O: Genetic control of blood pressure and the angiotensinogen locus. Proc Nat Acad Sci USA 1995;92:2735-2739.

195. Nimura F, Labosky PA, Kakuchi J, Okubo S, Yoshida H, Oikawa T, Ickiki $T$, Naftilan AJ, Fogo A, Inagami T, Hogan BLM, Ichikawa L: Gene trageting in mice reveals a requirement for angiotensin in the development and maintanance of kidney morphology and growth factor regulation. I Clin Iwvest $1995 ; 96: 2947-2954$.

196. Müller DN, Hilgers KF, Bohlender J, Lippoldt A, Wagner J, Fischli W, Ganten D, Mann JFE, Luft FC: Effects of human renin in the vasculature of rats transgenic for human angiotensinogen. Hypertension 1995;26:272-278.

197. Davisson RL, Ding Y, Stec DE, Catterall JF, Sigmund CD: Novel mechanism of hypertension revealed by cell-specific targetting of human angiotensinogen in transgenic mice. Physiol Genomics 1999;1:3-9.

198. Bakhle Y'S: Conversion of angiotensin-I to angiotensin II by cell-free extracts of dog llung. Nature 1968;20:919-921.

199. Esther Jr. CR, Marino $\mathbb{E M}$, Bernstein $\mathrm{KE}$ : The role of angiotensin-converting enzyme in blood pressure control, renal function, and thale fertility. Trends Endocrinol Metab 1997;8:181-186.

200. Unger $T$, Gohlke P: Converting enzyme inhibitors in cardiovascular therapy: current status and future potential. Cardiovasc Res 1994;28:146-158.

201. Brown NJ, Vaughan DE: Angiotensin-converting enzyme inhibitors. Circulation 1998;97:1411-1420.

202. Michaud A, Williams TA, Chauvet MT, Corvol P: Substrate dependence of angiotensin I-converting enzyme inhibition: Captopril displays a partial selectivity for inhibition of $\mathrm{N}$-acetyl-seryl-aspartyl-lysyl-proline hydrolysis compared with that of angitensin I. Mol Pharmacol 1997;5:1070-1076.

203. Wei L, Clauser E, Alhenc-Gelas F, Corvol P: The two homologous domains of human angiotensin I- converting enzyme interact differently with competitive inhibitors. J Biol Chem 1992;267:13398-13405. 
204. Nash DT: Comparative properties of angiotensin-comvering enzyme inhibitors: relations with inhibition of tissue angitensin-converting enzyme and potential clinical implications. Am J Cardiol 1992;69 (suppl):26C-32C.

205. Vaughan DE, Pfeffer MA: Angiotensin converting enzyme inhibitors and cardiovascular remodelling. Cardiovasc Res 1994;28:159-165.

206. Scalbert E; Levy B, Desche P, Devissaguet M, Safar ME: Vascular effects of perindopril: from experimental to clinical investigation. $J$ Cardiovasc Pharmacol 1991;18(suppl 7):S25-\$32.

207. McVeigh GE: Effects of perindopril on cardiovascular remodeling. Am $J$ Cardiol 2001;88 (suppl):28i-35i.

208. Lee RMKW, Berecek KH, Tsoporis J, McKenzie R, Triggle CR: Prevention of hypertension and vascular changes by captopril treatment. Hypertension $1991 ; 17: 141-150$.

209. Rizzoni D, Porteri E, Piccoli A, Castellano M, Bettoni $G$, Muiescan ML, Pasini G, Guelfi D, Mulvany MJ, Rosei EA: Effects of losartan and enalapril on small artery structure in hypertensive rats. Hypertension 1998;32:305-310.

210. Pfeffer MA, Braunwald E, Moyé LA, Batsa L, Brown EJ, Cuddy TE, Davis BR, Geltman EM, Goldman S, Flaker GC, Klein M, Lamas GA, Packer M, Rouleau J, Rouleau JL, Rutherford $\mathrm{J}$, Wertheimer JH, Hawkins CM: Effect of captopril on mortality and morbidity in patients with left ventricular dysfunction after myocardial infarction. $N$ Engl J Med 1992;327:669-677.

211. The acute infarction ramipril (AIRE) study investigators: Effect of ramapril on mortality and morbidity of survivors of acute myacardial infaretion with clinical evidence of heart failure. Lancet 1993;342:821-828.

212. Swedberg K, Held P, Kjekshus J, Rasmussen K, Rydén L, Wedel H: Effects of the early administration of enalapril on mortality in patients with acute myocardial infarction. N Engl J Med 1992;327:678-684.

213. Mulder P, Devaux B, Richard V, Henry JP, Wimart MC, Thibout Ex Macé B, Thuillez $\mathrm{C}$ : Early versus delayed angiotensin-converting enzyme inhibition in experimental chronic heart failure. Circulation 1997;95:1314-1319.

214. Ryoke T, Gu Y, Mao L, Hongo M, Clark RG, Peterson KL, Ross J: Progressive cardiac dysfunction and fibrosis in the cardiomyopathic hamster and effects of growth hormone and angiotensin converting enzyme inhibition. Circulation 1999;100:1734-1743.

215. Huckell VF, Bernstein V, Cairns JA, Crowell R, Dagenais GR, Higginson LA. Isserow S, Laramee P, Liu P, McCans JL, Orchard RC, Prewitt R, Quinn BP, Samson M, Turazza F, Warnica JW, Wielgosz A: Angiotensin-converting enzyme inhibition in myocardial infarction - Part 1: Clinical data. Can $J$ Cardiol 1997;13:161-169. 


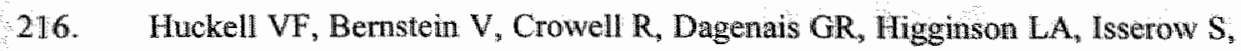
Laramee P, Liu P, McCans JL, Orehard RC, Prewitt R, Quim BP, Samson M, Turazza F, Wamica JW, Wielgosz A: Amgiotensin-converting enzyme inhibition in myocardial infarction - Part 2: Climical issues and controversies. Cam J Cardiol 1997;13:173-182.

217. Childs TJ, Adams MA, Mak AS: Regression of cardiac hypertroplyy in spontaneously hypertensive rats by enalapril and the expression of contractile proteins. Hypertension 1990;16:662-668.

218. Kromer EP, Riegger GAJ: Effects of long-term angiotensin converting enzyme inhibition on myocardial hypertrophy in experimental aortic stenosis in the rat. Am J Cardiol 1988;62:161-163.

219. Smits JFM, Cleutjens JPM, Krimpen van C, Schoemaker RG, Daenen MJAP: Cardiac remodeling in hypertension and following myocardial infarction: effects of arteriolar vasodilators. Basic Res Cardiol 1991;86:133-139.

220. Raya TE, Gay RG, Aguirre M, Goldman S: Importance of venodilatation in prevention of left ventricular dilatation after chronic large myocardial infarction in rats: A comparison of captopril and hydralazine. Cürc Res $1989 ; 64: 330-337$.

221. Gilst van WH, Scholtens E, Graeff de PA, Langen de CDJ, Wesseling H: Differential influences of angiotensin converting-enzyme inhibitors on the coronary circulation. Circulation 1988;77 (suppI I):I24-I29.

222. Grinstead WC, Young JB: The myocardial renin-angiotensin system: existance, importance and clinical implications. Am Heart J 1991;123:1039-1045.

223. Zhu $\mathrm{YC}, \mathrm{Zhu} \mathrm{YZ}$, Gohlke $\mathrm{P}$, Strauss HM, Unger T: Effects of angiotensinconverting enzyme inhibition and angiotensin II ATI receptor antagonism on cardiac parameters in left ventricular hypertrophy. Am $J$ Cardiol $1997 ; 80: 110 \mathrm{~A}-117 \mathrm{~A}$.

224. Liu $Y$, Leri A, Li B, Wang $X$, Cheng W, Kajstura $J_{*}$ Anversa P: Angiotensin II stimulation in vitro induces hypertrophy of normal and postinfarcted ventricular myocytes. Circ Res 1998:82:1145-1159.

225. Cole J, Le Quach D, Sundaram K, Corvol P, Capecchi MR, Bernstein KE: Mice lacking endothelial angiotensin-converting enxyme have a normal blood pressure. Circ Res 2002;90:87-92.

226. Cole J, Ertoy D, Lin H, Sutliff RL, Ezan E, Guyene TT, Capechi M, Corvol P, Bernstein KE: Lack of angiotensin II-facilitated erythropoiesis causes anemia in angiotensin-converting enzyme-deficient mice. $J$ Clin Invest 2000;106:13911398.

227. Doan TN, Gletsu N, Cole J, Bernstein KE: Genetic manipulation of the renirangiotensin system. Curr Opin Nephrol Hypertens $2001 ; 10: 483-491$.

228. Speth RC, Daubert DL, Grove KL: Angiotensin III: a reproductive hormone too? Regul Pept 1999; 79:25-40. 
229. Ramaraj P, Kessler SP, Colmenares, Sen GC: Selective restoration of male fertility in mice lacking angiotensin-converting enzymes by sperm-specific expression of the testicular isozyme. J Clm Invest 1998;102:371-378.

230. Hagaman JR, Moyer JS, Bachman ES, Sibony M, MAgyar PL, Welch JE, Smithies O, Krege JH, OBrein D: Angiotensin-converting enzyme and male fertility. Proc Natl Acad Sci USA 1998;95;2552-2557.

231. Monsees TK, Miska W, Blöcher S, Schill WB, Winkler A, Siems WE: Elements of the kallikrein-kinin system are present in rat seminiferous epithelium. Immunoph 1999;45:107-114.

232. Atanassova $\mathbb{N}$, Kancheva L, Somlev B: Bradykinin stimulates prepubertal rat germ cell proliferation in vitro. Immunoph 1998;40:173-178.

233. Timmermans PBMWM, Wong PC, Chiu AT, Herblin WF, Benfield P, Carini DJ, Lee RJ, Wexler RR, Saye JAM, Smith RD: Angiotensin II receptors and angiotensin II receptor antagonists. Phamacol Rev 1993;45:206-242.

234. Kang PM, Landrau AJ, Eberhardt RT, Frishman WH: Angiotensin III receptor antagonists: a new approach to blockade of the renin-angiotensin system. $\mathrm{Am}$ Heart $J 1994 ; 127: 1388-1401$.

235. Schiffin EL, Park JB, Intengan HD, Touyz RM: Correction of arterial structure and endotheliall dysfunction in human essential hypertension by angiotensin receptor antagonist losartan. Circulation 2000;101:1653-1659.

236. Pitt B, Poole-Wilson PA, Segal R, Martinez FA, Dickstein K, Camm A.J, Konstam MA, Reigger $G$, Klinger $G H$, Neaton $J$, Sharma D, Thiyagarajan $B$ : Effect of losartan compared with captopril on mortality in patients with symptomatic heart failure: randomised trail-losartan heart failure survival study ELITE II. Lancet 2000;355:1582-1587.

237. Jamali AH, Tang WH, Khot UN, Fowler MB: The role of angiotensin receptor blockers in the management of chronic heart failure. Arch Int Med $2001: 161: 667-672$.

238. Kats van JP, Duncker DJ, Haitsma DB, Schuijt MP, Niebuur R, Stubenitsky R, Boomsma F, Schalekamp MADH, Verdouw PD, Danser AHJ: Angiotensin converting enzyme inhibition and angiotensin II type 1 receptor blockade prevent cardiac remodeling in pigs after myocardial infarction. Role of tissue angiotensin II. Circulation 2000;102:1556-1563.

239. Capasso JM, Li P, Meggs LG, Herman HV, Anversa P: Efficacy of angiotensin-converting enzyme inhibition and AT1 receptor blockade on cardiac pump performance after myocardial infarction in rats. $J$ Cardiovasc Pharmacol 1994;23:584-593.

240. Holtz J: Role of ACE inhibition or ATI blockade in the remodeling following myocardial infarction. Basic Res Cardiol 1998;93 (suppl 2):92-100. 
241. Thai HM, Van HT, Gaballa MA, Goldman S, Raya TE: Effects of ATI receptor blockade after myocardial infaret on myocardial fibrosils, stiffness and contractility. Am J Physiol 1999;276:H873-H880.

242. Smits JFM, Krimpen van $C$, Schoemaker $R G_{;}$Cleutjens IPM, Damen MJAP. Angiotensin II receptor blockade after myocardial infarction in rats: effects on hemodynamics, myocardial DNA synthesis, and interstitial collagen content. $J$ Cardiovasc Pharmacal 1992;20:772-778.

243. Martorana PA, Kettenbach B, Breipohl G, Linz W, Schölkens BA: Reduction of infarct size by local angiotensin-converting enzyme inhibition is abolished by a bradykinin antagonist. Eur J Pharmacol $1990 ; 182: 395-396$.

244. Liu Y-H, Yang X-P, Sharov VG, Nass O, Sabbah NH, Peterson E, Carretero $\mathrm{OA}$ : Effects of angiotensin-converting enzyme inhibitors and angiotensin II type 1 receptor antagonists in rats with heart failure, $J$ Clin Irvest 1997;99:1926-1935.

245. Yu CM, Tipoe GL, Lai WHK, Lau CP: Effects of combination of angiotensinconverting enzyme inhibitor and angiotensin receptor antagonist on inflammatory cellular infiltration and myocardial interstitial fibrosis after acute myocardial infarction. J Am Coll Cardiol 2001;38:1207-1215.

246. Lee S, Kramer CM, Mankad S, Yoo SE, Sandberg MK: Combined angiotensin converting enzyme inhibition and angiotensin AT1 receptor blockade upregulates myocardial AT2 receptors in remodeled myocardium post-infarction. Cardiovasc Res 2001;51:131-139.

247. Ito M, Oliverio MI, Mannon PJ, Best CF, Maeda N, Smithies O, Coffinan TM: Regulation of blood pressure by type $1 \mathrm{~A}$ angiotensin II receptor gene. $P r o c$ Notl Acad Sci USA 1995;92:3521-3525.

248. Harada K, Sugaya T, Murakami K, Yazaki Y, Komuro I: Angiotensin II type $1 \mathrm{~A}$ receptor knockout mice display less left ventricular remodeling and improved survival after myocardial infarction. Circulation 1999;100:20932099.

249. Hein L, Barsh GS, Pratt RE, Drau V., Kobilka BK: Behavioural and cardiovascular effects of disrupting the angiotensin. II type-2 receptor gene in mice. Nature 1995;377:744-747.

250. Hunley TE, Tamuara $M$, Stoneking B.J, Nishimura H, Ichiki T, Inagami $T$, Kon $\mathrm{V}$ : The angiotensin type II receptor tonically inhibits angiotensin-converting enzyme in AT2 null mutant mice. Kidmey Int 2000;57:570-577.

251. Ma J, Nishimura $H$, Fogo A, Kon V, Inagami $T$, Ichikawa I: Accelerated fibrosis and collagen deposition developing the renal interstitium of angiotensin type 2 receptor null mutant mice during ureteral obstruction. Kidney Int 1998;53:937-944.

252. Schmaier AH: The plasma kallikrein-kinin system counterbalans the reninangiotensin system. . C Clin Invest 2002;109:1007-1009. 


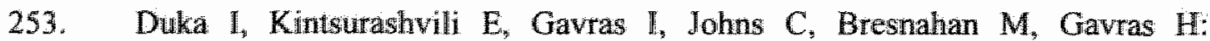
Vasoactive potential of the B1 bradykinin receptor in nomotension and hypertension. Circ Res 2001;88:275-281.

254. Ishigai $Y$, Mori $T$, Ikeda T, Fukuzawa A, Shibano $T$ : Role of bradykinin-NO pathway in prevention of cardiac hypertrophy by $A C E$ inhibitor in rat myocytes. Am J Physiol 1997;273:H2659-H2663.

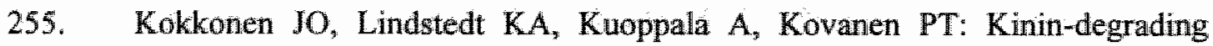
pattways in the human heart. Trends Cardiovasc Med 2000;10:42-45.

256. Tsuchida $\$$, Miyazaki $\mathrm{Y}$, Matsusaka $T$, Hunley TE, Inagami $T$, Fogo $A$, lchikawa I: Potent antihypertrophic effect of bradykinin B2 receptor system on renal vasculature. Kidney Int 1999;56:509-516.

257. Emanueli C, Madeddu P: Role of the kallikrein-kinin system in the maturation of cardiovascular phenotype. Am J Hyertens 1999;12:988-999.

258. McLean $P G$, Perretti $M$, Ahluwalia A: Kinin B1 receptors and the cardiovascular system: regulation of expression and function. Cardiovasc Res 2000;48:194-210.

259. Nolly H, Carbini LA, Scicli G, Carretero OA, Scicli AG: A local kallikreinkinitn system is present in rat hearts. Hypertension 1994;23:919-923.

260. Baumgarten CR, Linz W, Kunkel G, Schőlkens BA, Wiemer G: Ramiprilat increases bradykinin outflow from isolated heart of rat. $B r J$ Pharmacol 1993; 108:293-295.

261. Lamontagne D, Nadeau R, Adam A: Effect of enalaprilat on bradykinin and des-arg9-bradykinin release following reperfusion of the ischaemic rat heart. Br J Pharmacol 1995;115:476-478.

262. Duncan AM, Burrell LM, Kladis A, Campbell DJ: Amgiotensin and bradykinin peptides in rats with myocardial infarction. $J$ Card Fail 1997;3:41-52.

263. Tschöpe C, Heringer-Walther S, Koch M, Spillmann F, Wendorf M, Hauke D, Bader M, Schultheiss HP, Walther T: Myocardial bradykinin B2-receptor expression at different time points after induction of myocardial infarction. $J$ Hypertens 2000; 18:223-228.

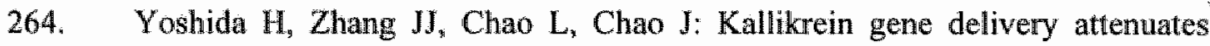
myocradial infarction and apoptosis after myocardial ischemia and reperfusion. Hypertension $2000 ; 35: 25-31$.

265. Wollert KC, Studer R, Doerfer K, Schieffer E, Holubarsch C, Just H, Drexler H: Differential effects of kinins an cardiomyocyte hypertrophy and interstitial collagen matrix in the surviving myocardium after myocardial infarction in the rat. Circulation 1997;95:1910-1917.

266. Gallagher AM, Yu H, Printz MP: Bradykinin-induced reductions of collagen gene expression involve prostacyclin. Hypertension 1998;32:84-88. 
267. Kintsurashvili E, Duka I, Gavras I, Johns C, Farmakiotis D, Gavras H: Elfects of ang II on bradykinin receptor gene expression in cardionyocytes and vascular smooth muscle cells. Am J Physiol 2001;281:H1778-11783.

268. Emanueli C, Maestri R, Corradi D, Marchione $R$, Minasi A, Tozzi MG, Salis MB, Straino S, Capogrossi $M C$, Olivetti $G$, Madeddu $P$. Dilated and failing cardiomyopathy in bradykinin B2 receptor knockout mice. Circulation 1999;100:2359-2365.

269. Yosipiv IV, Dipp S, El-Dahr SS: Targeted disruption of the bradykinin B2 recptor gene in mice alters the ontogeny of the renin-angiotensin system. Am $J$ Physiol Renal Physiol 2001;281:F795-F801.

270. Madeddu P, Emanueli C, Maestri R, Salis MB, Minasi A, Capogrossi M, Olivetti G: Angiotensin II type 1 recptor blockade prevents cardiac remodelling in bradykinin B2 receptor knockout mice. Hypertension 2000;35:391-396.

271. Argente J, Pozo J, Chowen JA: The growth hormone axis: control and effects. Horm Res 1996;45(suppl1):9-11.

272. Delafontaine $P$ : Insulin-like growth factor $I$ and its binding proteins in the cardiovascular system. Cardiovasc Res 1995;30:825-834.

273. D'Ercole AJ, Ye P, Gutierrez-Ospina $G$ : Use of transgenic mice for understandig the physiology of insulin-like growth factors. Horm Res $1996 ; 45$ (suppl 1):5-7.

274. Baker J, Liu JP, Robertson EJ, Efstratiadis A: Role of insulin-like growth factors in embryonic and postnatal growth. Cell 1993;75:73-82.

275. Schuller AGP, Groffen C, van Neck JW, Zwarthoff EC, Drop SLS: cDNA cloning and mRNA expression of the six mouse insuln-like growh factor binding proteins. Mol Cell Endo 1994;104:57-66.

276. Ooi GT, Orlowski CC, Brown AL, Becker RE, Unterman TG, Rechler MM: Different tissue distribution and hormonal regulation of messenger RNAs encoding rat insulin-like growth factor binding proteins-1 and -2 . Mol Endocrin 1990;4:321-328.

277. Bar RS, Clemmons DR, Boes M, Busby WH, Booth BA, Dake BL, Sandra A: Transcapillary permeability and subendothelial distribution of endothelial and amniotic fluid insulin-like growth factor binding proteins in the rat heart. Endocrinology 1990;127:1078-1086.

278. Standley PR, Obards tj, Martina CL: Cyclic stretch regulates autocrine IOF-1 in vascular smooth muscle cells: implications in vascular hyperplasia. $A m J$ Physiol 1999;276:E697-E705.

279. Dean R, Edmondson SR, Burel\| LM, Bach LA: Localization of the insulin-like growth factor system in a rat model of heart failure induced by myocardial infarction. J Histochem Cytochem 1999;47:649-659. 
280. Reiss $K$, Kajstura J, Zhang $X_{\text {, Li }}$, Szoke E, Olvetti $\mathrm{G}$, Anversa P. Acute myocardial infarction leads to upregulation of the IGF-1 autocrine system. DNA replication, and nuclear mitotic division in the remaining viable cardiac myocytes. Exp Cell Res 1994:213:463-472.

281. Reiss K, Meggs L G, Li P, Olivetti G, Capasso JM, Anversa P: Upregulation of IOF 1 , IGF 1 receptor, and late growth related genes in ventricular myocytes acutely after infarction in rats. J Cell Physiol 1994;158:160-168.

282. Ito $\mathrm{H}$, Hiroe $\mathrm{M}$, Hirata $\mathrm{Y}$, Tsujino $\mathrm{M}$, Adachi S, Shichiri M, Koike A, Nogam A, Maruomo F: Insulinlike growth factor-I induces hypertrophy with enhanced expression of muscle specific genes in cultured rat cardiomyocytes. Circulation $1993 ; 87: 1715-1721$.

283. Fuller SJ, Mynett JR, Sugden PH: Stimullation of cardiac protein synthesis by insulin-like growth factors. Biochem $J$ 1992;282:85-90.

284. Duerr RL, Hwang $\mathbf{S}$, Miraliakbar hr, Clark R, Chien KR, Ross J: Insulin-like growth factor-1 enilances ventricular hypertrophy and function during the onset of experimental cardiac faillure. J Clin Invest 1995;95:619-627.

285. Duerr RL, Mckiman MD, Gim RD, Clark RG, Chien KR, Ross J: Cardiovascular effects of insulin-like growth factor- 1 and growth hormone in chronic left ventricular failure in the rat. Circulation 1996;93:2188-2196.

286. Li Q, Li B, Wang X, Leri A, Jana KP, Liu K, Kajstura J, Baserga R, Anversa p: Overexpression of insulin-like growth factor-1 in mice protects from myocyte death after infarction, attenuating ventricular dilation, wall stress and cardiac hypertrophy. J Clin Invest 1997;100:1991-1999.

287. Battler A, Hasdai D, Goldberg I, Ohad D, Di Segni E, Bor A, Varda-Bloom N, Vered Z, Kornowski R, Lake M, Nass D, Savion N: Exogenous insulin-like growth factor II enhances post-infarction regional myocardial function in swine. Eur Heart J 1995;16:1851-1859.

288. Vogt AM, Htun P, Kluge A, Zimmermann R, Schaper W: Insulin-like growth factor-II delays myocardial infarction in expirimental coronary artery occlusion. Cardiovasc Res 1997;33:469-477.

289. Brink M, Wellen J, Delafontaine P: Angiotensin II causes weight loss and decreases circulating insulin-like growth factor I in rats through a pressorindependent mechanism. J Clin Invest 1996:97:2509-2516.

290. Delafontaine P, Lou $\mathrm{H}$ : Angiotensin II regulates insulin-like growth factor I gene expression in vascular smooth muscle cells. $I$ Biol Chem $1993 ; 268: 16866-16870$.

29 . Delafontaine P, Brink M, Du J: Angiotensin II modulation of insulin-like growth factor I expression in the cardiovascular system. Trends Cardiovasc Med 1996;6:187-193. 
292. Anwar A, Zahid AA, Philips L, Delafontaine P: Insulin-like growth factor binding protein-4 expression is decreased by angiotensin II and trombin in rat aortic vascular smooth musclle cells. Arterioscl Thromb Wasc Biol 2000;20:370376.

293. Cuneo RC, Salomon F, Wilmshurst P, Byme C, Wiles CM, HEsp R, Sönksen PH: Cardiovascular effects of growth hormone treatment in growth-hormonedeficient adults: stimulation of the renin- aldosterone system. Clin Sci $1991 ; 81: 587-592$.

294. Du I, Peng T, Scheidegger $\mathrm{KJ}$, Delafontaine P: Angiotensin II activation of insulin-like growth factor 1 receptor transcription is mediated by a tyrosine kinase-dependent redox-sensitive mechanism. Arteriosel Thromb Vase Biol $1999 ; 19: 2119-2126$.

295. Eickels van $M$, Vetter $H$, Grohé $C$ : Angiotensin-converting enzyme (ACE) inhibition attenuates insulin-like growth factor-I (IGF-I) induced cardiac fibroblast proliferation. Br J Pharmacol 2000;131: $1592-1596$.

296. Leri A, Liu Y, Claudio PP, Kajstura J, Wang X, Wang S, Kang P, Malhotra A, Anversa $P$ : Insulin-like growth factor-1 induces $m d m 2$ and down-regulates p53, attenuating the myocyte renin-angiotensin system and stretch-mediated apoptosis. Am J Pathol 1999;154:567-580.

297. Neri Serneri GG, Boddi M, Modesti PA, Cecioni I, Coppo M, Padeletti A, Colella $A$, Galanti $G$ : Increased cardiac sympathetic activity and insulin-like growth factor formation are associated with physiological hypertrophy in athletes. Circ Res 2001;89:977-982.

298. Mattiazzi A: Positive inotropic effect of angiotensin II. Increases in intracellular $\mathrm{Ca} 2+$ or changes in myofilament $\mathrm{Ca} 2+$ responsiveness? J Pharmacol Toxicol Methods 1997;37:205-214.

299. Janssen B, Debets J, Leenders P, Smits J: Chronic measurement of cardiac output in conscious mice. Am J Physiol 2002;282:R928-R935.

300. Majewski H, Hedler L, Schutr C, Strake K: Modulation of noradrenaline release in the pithed rabbit: a role for angiotensin II. J Cardiovasc Pharmacol $1984 ; 6: 888-896$.

301. Henegar JR, Brower GL, Kabour A, Janicki JS: Catecholamine response to chronic ANGII infusion and its role in myocyte and coronary vascular damage. Am J Physiol 1995;269:H1564-H1569.

302. Kawai H, Fan THM, Dong E, Siddiqui RA, Yatani A, Stevens SY, Liang CS: ACE inhibtion improves cardiac NE uptake and attenuates sympathetic nerve terminal abnormalities in heart failure. Am J Physiol 1999;277:H1609-H1617.

303. Raasch W, Bartels $t$, Gieselberg A, Dendorfer A, Dominiak P: Angiotensin Iconverting enzyme inhibition increases cardiac catecholamine content and reduces monoamine oxidase activity via an angiotensin type 1 receptormediated mechanism. I Pharmacol Exp Ther 2002;300:428-434. 
304. Janssen BJA, Leenders PJA, Smits JFM: Short-term and long-term blood pressure and heart rate variabillty in the mouse. Am I P/psiol 2000;278:R215.

305. Spiegel TV, Wietasch $G$, Hoeft $A$ : Basics of myocardial pump function. Thorac Cardiovasc Surg 1998;46:237-241.

306. Pfeffer JM, Pfeffer MA, Braumwald E: Influence of chronic captopril therapy on the infarcted left ventricle of the rat. Circ Res $1985 ; 57: 84-95$.

307. Brasch $H$, Sieroslawski L, Dominiak $P$ : Angiotensin II increases norepinephrine release from atria by acting on angiotensin subtype 1 receptors. Hypertension 1993:22:699-704.

308. Hu K., Gaudron P, Anders HJ, Weidemann F, Turschner O, Nahrendorf M, Ert G: Chronic effects of early started angiotensin converting enzyme inhibition and angiotensin ATl receptor subtype blockade in rats with myocardial infarction: role of bardykinin. Cardiovasc Res 1998;39:401-412.

309. Dostal DE, Baker KM: Angiotensin II stimulation of left ventricular hypertrophy in adult rat heart. Am Heart $J$ 1992;5:276-280.

310. De Young MB, Scarpa A: Extracellular ATP induces Ca2+ transients in cardiac myocytes which are potentiated by norepinephrine. FEBS 1987;223:5358.

311. Cittadini A, Ishiguro Y, Stromer H, Spindler M, Moses AC, Clark R, Douglas PS, Ingwall JS, Morgan JP: Insulin-like growth factor-1 but not growth hormone augments mammalian myocardial contractility by sensitizing the myofilament to $\mathrm{Ca} 2+$ through a wortmannin-sensitive pathway. Studies in rat and ferret isolated muscles. Circ Res 1998;83:50-59.

312. Wittstein IS, Kass DA, Pak PH, Maughan WL, Fetics B, Hare JM: Cardiac nitric oxide production due to angiotensin converting enzyme inhibition decreases beta-adrenergic myocardial contractility in patients with dilate cardiomyopathy. $J$ Am Coll Cardiol 2001;38:429-435.

313. Lutgens $E$, Daemen MJAP, de Muinck ED, Debets J, Leenders P, Smits JFM: Chronic myocardial infarction in the mouse: cardiac structural and functional changes. Candtovasc Res 1999;41:586-593.

314. Patten RD, Aronowitz MJ, Deras-Mejia L, Pandian NG, Hanak CG, Smith Jj: Ventricular remodeling in mouse model of myocardial infarction. Am J P $/ w$ siol $1998 ; 274: H 1812-1820$.

315. Wodzig KWH, Pelsers MMAL, Vusse van der GJ, Roos W, Glatz JFC: Onestep enzyme-linked immunosorbent assay (ELISA) for plasma fatty acidbinding protein. Awn Clin Blochem 1997;34:263-268.

316. Glatz JFC, Kleine AH, Nieuwenhoven van FA, Hermens WT, Dieijen-Visser van MP, Vusse van der G.J: Fatty-acid-binding protein as a plasma marker for the estimation of myocardial infarct size in humans. Br Heart $J$ 1994;1:135140. 
317. Tanaka $T$, Hirota $Y$, Sohmiya K-I, Nishimura $S$, Kawamura $K$ : Serum and urinary human heart fatty acid-binding protein in acute myocardial infarction. Clin Biochem 1991:24:195-201.

318. Volders PA, Vork MM, Glatz JFC, Smits JFM: Fatty acid-binding protemuria diagnoses myocardial infarction in the rat. Mol Cell Biochem 1993;123:185191.

319. Mair J: Cardiac troponin I and troponin $\mathrm{T}$ : are enzymes still relevant as cardiac markes? Clinica Chimica Acta 1996;257:99-115.

320. Smith SC, Ladenson JH, Mason JW, Jaffe AS: Elevations of cardiac troponin I associated with myocarditis, experimental and clinical correlates. Circulation $1997 ; 95: 163-168$.

321. Asayama $J$, Yamahara $X$, Ohta $B$, Miyazaki $H$, Tatsumi $T$, Matsumoto $T$, Inoue $D$, Nakagawa $M$ : Release kinetics of cardiac troponin $T$ in coronary effluent from isolated rat hearts during hypoxia and reoxygenation. Basic Res Cardiol $1992 ; 87: 428-436$.

322. Feng YJ, Chen C, Fallon JT, Lai T, Chen L, Knibbs DR, Waters DD, Wu AHB: Comparison of cardiac troponin $\mathrm{I}$, creatine kinase-MB, and myoglobin for detection of acute ischemic myocardial injury in a swine model. Am J Clin Pathol 1998;110:70-77.

323. Mair J, Morandell D, Genser $N$, Lechleitner P, Dienstl F, Puschendorf $B$ : Equivalent early sensitivities of myoglobin, creatine kinase $\mathrm{MB}$ mass, creatine kinase isoform ratios, and cardiac troponins $\mathrm{I}$ and $\mathrm{T}$ for acute myocardial infarction. Clin Chem 1995;41:1266-1272.

324. Jaffe AS, Landt $Y$, Parvin CA, Abendscheim DR, Geltman EM, Ladenson JH: Comparative sensitivity of cardiac troponin $\mathrm{I}$ and lactate dehydrogenase isoenzymes for diagnosing acute myocardial infarction. $\mathrm{Clin} \mathrm{Chem}$ $1996 ; 42: 1770-1776$.

325. Katus HA, Remppis $A_{*}$ Neumann $F$, Scheffold $T$, Diederich $K W$, Vinar $G$, Matern $G$, Kubler W: Diagnostic efficiency of troponin $T$ measurements in acute nyocardial infarction. Circulation 1991;83:902-912.

326. O'Brien PJ, Dameron GW, Beck ML, Kang YJ, Erickson BK, Battista THD, Miller $\mathrm{KF}$, Jackson $\mathrm{KN}$, Mittelstadt S: Cardiac troponin $\mathrm{T}$ is a sensitive, specific biomarker of cardiac injury in laboratory animals. Lab Anim Sci $1997 ; 47: 486-495$.

327. Glatz JFC, Paulussen RJA, Veerkamp JH: Fatty acid binding proteins from heart. Chem Phys Lipids 1985;38:115-129.

328. Offner GD, Brecher P, Sawlivich WB, Costello CE, Troxler RF: Characterization and amino acid sequence of a fatty acid-binding protein from human heart. Biochem J 1988;252:191-198.

329. Bass NM: The cellular fatty acid binding proteins: aspects of structure, regulation, and function. Int Rev Cytol 1988;111:143-184. 
330. Knowiton AA, Apstein CS, Saouf R, Brecher P: Leakage of heart fatty acid binding protein with ischemia and reperfusion in the rat. $J \mathrm{Mol}$ Cell Cardiol $1989 ; 21: 577-583$.

31. Nieuwenhoven van $\mathrm{FA}$, Kleine AH, Wodzig WH, Hermens WT, Kragten HA, Maessen $\mathrm{JC}_{2}$, Punt $\mathrm{CD}$, Dieijen van MP, Vusse van der GI, Glatz JFC: Discrimination between myocardial and skelletal muscle injury by assessment of the plasma ratio of myoglobin over fatty acid-binding protein. Cipculation $1995: 92: 2848-2854$.

332. Pearlstone JR, Carpenter MR, Smillie LB: Amino acid sequence of rabbit cardiac troponin T. J Biol Chem 1986;261:16795-16810.

333. Wilkinson IM, Grand RJA: Comparison of the amino acid sequence of troponin I from different striated muscles. Nature 1978;271:31-34.

334. Davies E, Gawad $Y$, Takahashi M, Shi Q, Lam P, Styba G, Lau A, Heeschen C, Usategui M, Jackowski G: Analytical performance and clinical utility of a sensitive immunoassay for determination of human cardiac troponin I. Cin Biochem 1997;30:479-490.

335. Katus HA, Remppis $A$, Scheffold $T$, Diederich $K W$, Kübler $W$ : Intracellular compartmentation of cardiac troponin $T$ and its release kinetics in patients with reperfused and nonreperfused myocardial infarction. Am $J$ Cardiol $1991 ; 67: 1360$-1367.

336. Bodor GS, Porter S, Landt Y, Ladenson IH: Development of monoclonal antibodies for an assay of cardiac troponin-I and preliminary results in suspected cases of myocardial infarction. Clin Chem 1992;38:1 1:2203-2214.

337. Zimmerman $\mathbb{R}$, Baki $S$, Dengler $T J$, Ring GH, Remppis A, Lange $\mathbb{R}$, Hagl $S$, Kubler W, Katus HA: Troponin $T$ measurements in acute myocardial infarction. Br Heart J 1993;69:395-398.

338. Waring WS: Early initiation of ACE inhibitor treatment after acute myocardial infaretion - a missed therapeutic oppurtunity? JRAAS 2000;1:245-251.

339. Schunkert H., Dzau VJ, Tang SS, Hirsch AT, Apstein CS, Lorell BH: Increased rat cardiac angiotensin converting enzyme activity and mRNA expression in pressure overload left ventricular hypertrophy. I Clin Invest 1990;86:19131920.

340. Sun Y, Weber KT: Angiotensin-converting enzyme and wound healing in diverse tissues of the rat. J Lab Clin Med 1996;127:94-101.

341. Wan Kesteren CAM, van Heugten HAA, Lamers JMJ, Saxena PR, Schalekamp MADH, Danser AHJ: Angiotensin II-mediated growth and antigrowth effects in cultured neonatal rat cardiac myocytes and fibroblasts. I Mol Cell Cardiol $1997 ; 29: 2147-2157$

342. Ehlers MRW, Riordan JF: Angiotensin-converting enzyme; new concepts conceming its biological role. Biochem 1989;28:5311-5318. 
343. Carvalho Frimm de C, Sun Y, Weber KT: Angiotensin II receptor blockade and myocardial fibrosis of the infarcted rat heart $J \mathrm{Lab}$ Clin $M$ $1997 ; 129: 439-446$.

344. Carvalho Frimm de C, Sum Y, Weber KT: Wound healing following myocardial infarction in the rat: role for bradykinin and prostaglandins. $J$ Mol Cell Cardiol 1996;28:1279-1285.

345. Suylen $\mathrm{RJ}_{3}$ Aartsen WM, Smits JFM, Daemen MJAP: Dissociation of pulmonary vascular remodeling and right ventricular pressure in tissue angiotensin-converting enzyme-deficient mice under conditions of chronic alveolar hypoxia. Am J Respir Crit Care Med 2001;163:1241-1245.

346. Beldent V, Michaud A, Bonnefoy C, Chauvet MT, Corvol P: Cell surface localization of proteolysis of human endothelial angiotensin l-converting enzyme. Effect of the amino-terminal domain in the solubilization process. I Biol Chem 1995;270:28962-28969.

347. Schoemaker RG, Debets JJM, Struyker-Boudier HAJ, Smits IFM: Delayed but not immediate captopril therapy improves cardiac function in conscious rats, following myocardial infarction. $J$ Mol Cell Cardiol 1991;23:187-197.

348. Dolber PC, Spach MS: Picrosirius red staining of cardiac muscle following phosphomolybdic acid treatment. Stain Tech 1987;62:23-26.

349. Kats van JP, Danser AHJ, Meegen van JR, Sassen LMA, Verdouw PD, Schalekamp MADH: Angiotensin production by the heart: A quantitative study in pigs with the use of radiolabeled angiotensin infusions. Circulation 1998:98:73-81.

350. Gray MO, Long CS, Kalinyak JE, Li HT, Karliner IS: Angiotensin II stimulates cardiac myocyte hypertrophy via paracrine release of TGF- $\mathrm{Bl}$ and endothelin-1 from fibroblasts. Cardiovasc Res 1998;40:352-363.

351. Klickstein LB, Kaempfer CE, Wintroub $\mathrm{BU}$ : The granulocyte-angiotensin system. Angiotensin I-converting activity of cathepsin $\mathbf{G}$, J Biol Chem $1982 ; 257: 15042-15046$.

352. Perry GI, Mori T, Wei CC, Xu XY, Chen YF, Oparil S, Lucchesi P, Dell'ltalia LJ: Genetic variation in angiotensin-converting enzyme does not prevent development of cardiac hypertrophy or upregulation of angiotenisi II in response to aortocaval fistula. Circulation 2001;103:1012-1016.

353. Hara M, Ono K, Hwang MW, lwasaki A, Okada M, Nakatani K, Sasayama S, Matsumori A: Evidence for a role of mast cells in the evolution to congestive heart failure. I Exp Med 2002;195:375-381.

354. Litwin SE, Morgan JP: Effects of stimulation frequency on calcium transients in noninfarcted myocardium: modulation by chronic captopril treatment. $J$ Card Fail 1999;5:224-235.

355. Linz W, Wiemer G, Schölkens BA: Role of kinins in the pathophysiology of myocardial ischemia. Diabetes $1996 ; 45:$ S51-S58. 
356. Weber KT: Extracellular matrix remodeling in heart failure, A role for de novo anglotensin II generation. Circularion 1997;96:4065-4082.

357. Yamazaki $T$, Komuro I, Yazaki $Y$ : Role of the renin-angiotensin system in cardiac hypertrophy. Am J Cardiol 1999;83:53H-57H.

358. Sato M, Engelman RM, Otani H, Maulik N, Rousou JA, Flack JE, Deaton DW, Das DK: Myocardial protection by preconditioning of heart with losartan, an angiotensin II type 1-receptor blocker. Implication of bradykinin-dependent and bradykinin-independent mechanisms. Circulation 2000; 102:II3 46-III351 .

359. Daniells MCG, Keller RS, De Tombe PP: Losartan prevents contractile dysfunction in rat myocardium after left ventricular myocardial infarction. $A m$ J Physiol $2001 ; 281: \mathrm{H} 2150-\mathrm{H} 2158$.

360. Spalding M, Ala-Kokko T, Kiviluoma $K$, Ruskoaho H, Alahuhta $S$ : The haemodynamic effects of losartan after right ventricle infarct in young pigs. Pharmacol Toxicol $2001 ; 88: 325-330$.

361. Cittadini A, Grossman JD, Napoli R, Katz SE, Strömer H, Smith RJ, Clark R, Morgan JP, Douglas PS: Growth hormone attenuates early left ventricular remodeling and improves cardiac function in rats with large myocardial infarction. I Am Coll Cardiol 1997;29:1109-16.

362. Isgaard $d$, Kujacic $V$, Jennische $E$, Holmämg $A$, Sun $X Y$, Hedner $T$, Hjalmarson A, Bengtsson BA: Growth hormone improves cardiac function in rats with experimental myocardial infarction. Eur $J$ Chin Imest 1997,27:517525 .

363. Wahlander $\mathrm{H}$, Wickman A, Isgaard J, Friberg P: Interaction between the reninangiotensin system and insulin-like growth factor $I$ in aorto-caval fistulainduced cardiac hypertrophy in rats. Acta Physiol Scand 1999;165:143-154.

364. Tanaka N, Ryoke T, Hongo M, Mao L, Rockman HA, Clark RG, Ross J: Effects of growth hormone and IGF-I on cardiac hypertrophy and gene expression in mice. Am J Physiol 1998;275:H393-H399.

365. Omerovic E, Bollano $\mathbb{E}$, Mobini $R$, Kujacic $V$, Madhu B, Soussi B, Fu M, Hjalmarson A, Waagstein F, lsgaard $J$ : Growth hormone improves bioenergetics and decreases catecholamines in postinfarct rat hearts. Endacinology 2000;141:4592-4599.

366. Corbalan R, Acevedo M, Godoy I, Jalil J, Campusano C, Klassen J: Enalapril restores depressed circulating insulin-like growth factor 1 in patients with chronic heart failure. $/$ Card Fail 1998;4:115-119.

367. Kovacs GT, Worgall S, Schwalbach P, Steichele T, Mehls O, Rosivall L: Hypoglycemic effects of insulin-like growth factor- 1 in experimental Uremia: can concomitant growth hormone administration prevent this effect? How $\mathrm{Res}$ $1998 ; 51: 193-200$. 
368. Kotlyar AA, Vered S, Goldberg I, Chouraqui P, Nas D, Firman E, Chen-Levy Z, Fytlovich S, Sangiorgi G, Spagnoli LG, Orlandi A, Savion N, Eldar M, Scheinowitz $\mathrm{M}$ : Insulin-like growth factor I and II preserve myocardial structure in postinfarct swine. Heart 2001;86:693-700.

369. Palmen M, Daemen MJAP, Bronsaer R, Dassen WRM, Zandbergen HR, Kockx M, Smits JFM, Zee van der R, Doevendans PA: Cardiac remodeling after myocardial infaretion is impaired in IGF-I deficient mice. Cardionasc Res 2001;50:516-524.

370. Jin H, Yang R, Gillet N, Clark RG, Ko A, Paoni NF: Beneficial effects of growth hormone and insulin-like growth factor-1 in experimental heart failure in rats treated with chronic ACE inhibition. I Cardiovasc Pharmacol 1995;26:420-425.

371. Litwin SE, Morgan JP: Captopril enhances intracellular calcium handling and $\beta$-adrenergic responsiveness of myocardium from rats with postinfaretion failure. Circ Res 1992;71:797-807.

372. Maisel AS, Phillips C, Michel MC, Ziegler MG, Carter SM: Regulation of cardiac $\beta$-adrenergic receptors by captopril. Implications for congestive heart failure. Circulation 1989;80:669-675.

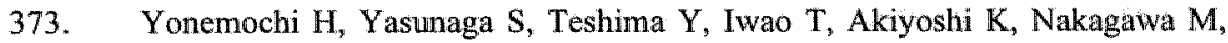
Saikawa T, Ito M: Mechanism of $\beta$-adrenergicreceptor upregulation induced by ACE inhibition in cultured neonatal rat cardiac myocytes. Roles of bradykinin and protein kinase C. Circulation 1998;97:2268-2273.

374. Lembo G, Rockman HA, Hunter JJ, Steinmetz H, Koch WJ, Ma L, Prinz MP, Ross J, Chien KR, Powell-Braxton $\mathbb{L}$ : Elevated blood pressure and enhanced myocardial contractility in mice with severe IGF-1 deficiency. $J$ Clin Invest 1996;98:2648-2655.

375. Park JB, Intengan HD, Schiffrin EL: Reduction of resistance artery stiffness by treatment with ATl-receptor antagonist losartan in essential hypertension. JRAAS 2000;1:40-45.

376. Morishita R, Gibbons GH, Tomita N, Zhang L, Kaneda Y, Ogihara T, Dzau VJ: Antisense oligodeoxynucleotide inhibition of vascular angiotensinconverting enzyme expression attenuates neointimal formation. Evidence for tissue angiotensin-converting enzyme function. Arterioscl Thromb Vasc Biol $2000 ; 20: 915-922$.

377. Hosomi N, Mizushige K, Ohyama H, Takahashi T, Kitadai M, Hatanaka $Y$, Matsuo H, Kohno M, Koziol JA: Angiotensin-converting enzyme inhibition with enalapril slows progressive intima-media thickening of the common carotid artery in patients with non-insulin-dependent diabetes mellitus. Stroke 2001;32:1539-1545. 
378. Goto $K$, Fujii $K$, Onaka $U$, Abe I, Fujishima $M$ : Renin-angiotensin system blockade improves endothelial dysfunction in hypertension. Hypertension $2000 ; 36: 575-580$.

379. Mancini GBJ, Henry GC, Macaya C, ONeill BJ, Pucillo AL, Carere RG, Wargowich TJ, Mudra H, Luscher TF, Klibaner MI, Haber HR, Uprichard $\mathrm{ACG}_{3}$ Pepine $\mathrm{CJ}$; Piti $\mathrm{B}$ : Angiotensin-converting enzyme inhibition with Quinapril improwes endothellial vasomotor dysfunction artery disease. The TREND (Trial on reversing endothelial dysfunction) study. Circulation $1996,94: 258-265$.

380. Hilgers KF, Hilgenfeldt $U$, Veelken $R$, Muley $T$, Ganten D, Luft FC, Mann FE: Angiotensinogen is cleaved to angiotensin in the isolated rat blood vessels. Hypertension 1993;21:1030-1034.

381. Berk BC, Vekshtein V, Gordon HM, Tsuda T: Angiotensin II stimulated protein synthesis in cutured vascular smooth muscle cells. Hypertension $1989 ; 13 ; 305-314$.

382. Griffin SA, Brown WCB, MacPerson F, McGrath JC, Wilson VG, Korsgaard N, Mulvany MJ, Lever AF: Angiotensin II causes vascular hypertrophy in part by a non-pressor mechanism. Hypertension 1991;17:626-635.

383. Schiffers PMH, Henrion D, Boulanger CM, Colucci-Guyon E, Langa-Vuves F, Essen van H, Fazzi GE, Lévy BI, De Mey JGR: Altered flow-induced arterial remodeling on vimentin-deficient mice. Arterioscl Thromb Vasc Biol $2000 ; 20: 611-616$.

384. Ceiler DL, Nelissen-Vrancken HJMG, Smits JFM, De Mey JGR: Pressure but not angiotensin III-induced increases in wall mass or tone influences static and dynamic aorta mechanics. J Hypertens 1999;17:1109-1116.

385. Pourageaud $\mathbb{F}$, Freslon $\mathrm{L}$ : Effects of nitric oxide and sodium nitroprusside on the intrinsic elastic properties of pressurized rat coronary artery. Fundam Clin Pharmacol 1996:10:136-143.

386. Bergel DH: The static elastic properties of the arterial wall. I Physiol $1961 ; 156: 445-457$.

387. Wolinsky $\mathrm{H}$, Glagov $\mathrm{S}$ : Structural basis for the static mechanical properties of the aorta media. Circ Res 1964;14:400-413.

388. Safar E: Carotid artery stiffness with applications to cardiovascular pharmacology. Gen Pharmacol 1996;27:1293-1302.

389. Albaladejo P, Bouaziz H., Duriez M, Gohlke P, Levy BL, Safar ME, Benetos A: Angiotensin converting enzyme inhibition prevents the increase in aortic collagen in rats. Hypertension 1994;23:74-82..

390. Tamura $K$, Chen YE, Lopez-llasaca $M$, Daviet $L$, Tamura $N$, Ishigami $T$, Akishita M, Takasaki I, Tokia Y, Pratt RE, Horiuchi M, Dzau VJ, Unemura S: Molecular mechanism of fibronectin gene activation by cyclic stretch in vascular smooth muscle cells. J Biol Chem 2000;275:34619-34627. 
391. Tatchum-Talum $\mathrm{R}$, Martel $\mathrm{C}$, Marette $A$ : Influence of estrogen on aortic stiffiness and endothelial function in female rats. Am I Physiol 2002,282:H491H498.

392. Stassen FRM, Raat NJH, Brouwers-Ceiler DL, Fazzi GE, Smits JFM, De Mey JGR: Angiotensin II induces media hypertrophy and hyperreactivity in mesenteric but not epigastric small arteries of the rat. If Vasc Res $1997 ; 1997: 289-297$.

393. Gumkowski F, Kaminska G, Kaminski M, Morrissey LW, Auerbach R: Heterogeneity of mouse vascular endotheliam. In vitro studies of lymphatic, large blood vessel and microvascular endothelial cells. Blood Vessels $1987 ; 24: 11-23$.

394. Cohen RA, Vanhoutte PM: Endothellium-dependent hyperpolization. Beyond nitric oxide and cyclic CMP. Circulation 1995;92:3337-3349.

395. Russell A, Watts S: Vascular reactivity of isolated thoracic aorta of the C57BL/6J mouse. I Pharmacol Exp Ther 2000;294:598-604.

396. Goetz RM, Holtz J: Enhanced angiotensin-converting enzyme activity and impaired endothelium-dependent vasodilation in aortae from hypertensive rats: evidence for a causal link. Clin Sci 1999;97:165-174.

397. Holtz J, Goetz RM: The endothelium and the renin-angiotensin system. Drug Res 1994;44:397-402.

398. Figueroa CD, Marchant A, Novoa U, Förstermann U, Jarnagin K, Schölkens B, Müller-Esterl W: Differential distribution of bradykinin $B 2$ receptors in the rat and human cardiovascular system. Hypertension 2001;37:110-120.

399. Zanchi A, Aubert JF, Brunner HR, Waeber B: Vascular acethylcholine response during chronic NO synthase inhibition: in vivo versus in vitro. Cardiovasc Res 1995;30:122-129.

400. Safar ME, Bortel van LMAB, Struijker-Boudier HAJ: Resistance and conduit arteries following converting enzyme inhibition in hypertiension. $J$ Vaso Res $1996 ; 34: 67-81$.

401. Ben Driss A, Himbert C, Poiltevin P, Duriez M, Michel JB, Levy BI: Enalapril improves arterial elastic properties in rats with myocardial infarction. $J$ Cardiovasc Pharmacol 1999;34:102-107.

402. Mulder $P$, Elfertak L, Richard V, Compagnon P, Devaux B, Henry JP, Scalbert E, Desché $\mathrm{P}$, Macé B, Thuillez $\mathrm{C}$ : Peripheral artery structure and endotheliall function in heart failure effect of ACE inluibition. Am $J$ Physiol 1996;271:H469-H477.

403. Vaughan DE: Angiotensin and vascular fibrinolytic balance. Am J Hypertens $2002 ; 15: 3 \mathrm{~S}-8 \mathrm{~S}$. 
404. Charpior P. Holland PH, Figgi A, Piquet P, Scalbent E, Bodard H, Barlatier A, Latrille $V$, Traniniet $P$, Mercier $C$, Luccioni $R$, Calaf $R$, Garçon $D$ : ACE inhibition with perindopril and atherogenesis-induced structural and functional changes in minipig arteries. Art Trom 1993;13:1125-1138.

405. Homing B, Drexler H: Endothelial function and bradykinin in humans. Drugs $1997 ; 54$ (suppl 5):42-47.

406. Bao $G$, Qadri F, Stauss B, Stauss $H$, Gohlke $P$, Unger T: HOE 140, a new highly potent and long-acting bradykinin antagonist in conscious rats. Eur $J$ Pharmacol 1991;200:179-182.

407. Aartsen WM, Schuijt MP, Danser AHJ, Daemen MJAP, Sunits JFM: The role of locally expressed angiotensin converting enzyme in cardiac remodeling after myocardial infarction. Cardiowasc Res 2002;56:205-213.

408. Levy BI, Michel JB, Salzmann JL, Poitevin P, Devissaguet M, Scalbert ME, Safar ME: Long-term effects of angiotensin-converting enzyme inhibition on the arterial wall of adult spontaneously hypertensive rats. $A m J$ Cardiol $1993 ; 71: 8 \mathrm{e}-16 \mathrm{e}$.

409. Bezie Y, Lamaziẻre JMD, Laurent $S$, Challande $P$, Sa Cunha R, Bonnet J, Lacolley P: Fibronectin expression and aortic wall elastic modulus in spontaneously hypertensive rats. Arterioscl Thromb Vasc Biol 1998;18:10271034.

410. Henriksen EJ, Jacob S, Fogt DL, Dietze GJ: Effect of chronic bradykinin administration on insulin action in an animal model of insulin resistance. $A m J$ Physiol 1998;275:R40-R45.

411. Henriksen EJ, Jacob S, Kinnick TR, Youngblood EB, Schnit MB, Dietze GJ: ACE inhibition and glucose transport in insulin-resistant muscle: roles of bradykinin and nitric oxide. Am J Physiol 1999;277:R332-R336.

412. Brown NJ, Gainer IV, Stein CM, Vaughan DE: Bradykinin stimulates tissue plasminogen activator release in human vasculature. Hypertension $1999 ; 33: 1431-1435$.

413. Brown NJ, Gainer NV, Murphey LJ, Vaugan DE: Bradykinin stimulates plasminogen activator release from human forearm vasculature through $\mathrm{B} 2$ receptor-dependent, NO synthase-independent, and cyclooxygenasseindependent pathway. Circulation 2000;102:2190-2196.

414. Madeddu P, Parpaglia PP, Demontis MP, Varoni MV, Fattaccio MC, Anania V, Glorioso N: Early blockade of bradykinin B2-receptors alters the adult cardiovascular phenotype in rats. Hypertension 1995;25:453-459.

415. Regoli D, Dioin S, Rhaleb NE, Drapeau G, D'Orléans-Juste P: Vasoactive peptides and their receptors. Blood Vessels 1990;27:137-145.

416. Safar $M$, Chamiot-Clerc $P$, Renaud JF: Pulse pressure, endothelium function and arterial stiffness in spontaneously hypertensive rats. Hypertension $2001 ; 38: 1416-1421$. 
417. Kinlay S, Creager MA, Fukumoto M, Hikita H, Fing JC, Selwyn AP, Ganz P: Endothellum-derived nitric oxide regulates arterial elasticity in human arteries in vivo. Hypertension 2001;38:1049-1053.

418. Benetos A, Elfertak L, Sfara M, Levy BI: Effects of bradykinin on carotid artery compliance: the role of the endothelium. I Hypertens 1991;9 (suppl 6): $: 5204-\$ 205$.

419. Campbell DB, Barckmann F: Cariovascular protective properties of indapamide. Am I Cardiol 1990;65:11H-27H.

420. Lannoy de LM, Schuijt MP, Schalekamp MADH, Danser AHJ: Angiotensin converting enzyme is the main contributor to angiotensin I-II conversion in the interstitium of the isolated perfused rat heart. J Hypentens 2001;19:959-965.

421. Campbell DJ: The kallikrein-kinin system in humans. Clin Exp Pharmacol Physiol 2001;28:1060-1065.

422. Campbell D., Kladis A, Duncan AM: Effects of converting enzyme inhibitors on angiotensin and bradykinin peptides. Hypertension 1.994;23:439-449.

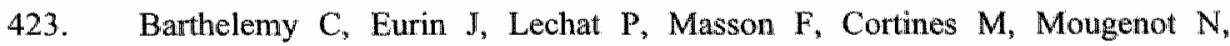
Soualmia $H$, Carayon $A$ : The mechanism of the agiotensin-converting enzyme inhibitor quinapril is not related to bradykinin level in heart tissue. Peprides $2002 ; 23: 1161-1169$.

424. Campbell DJ, Dancan AM, Kladis A: Angiotensin-converting enzyme inhibition modifies angiotensün but not kinin peptide levels in human atrial tissue. Hypertension 1999;34:171-175.

425. Gould KE, Taffet GE, Micheal LH, Christie RM, Konkol DL, Pocius IS, Zachariah JP, Chaupin DF, Daniel SL, Sandusky GE, Hartley CJ, Entman ML: Heart failure and greater infarct expansion in middle-aged mice: a relevant model for postinfarction failure. Am J Physiol 2002;282:H615-H621.

426. Houck WV, Pan LC, Kribbs SB, Clair MJ, McDaniel GM, Krombach S, Merritt WM, Piroe C, Iannini JP, Mukherjee $\mathrm{R}_{4}$ Spinale FG: Effects of growth hormone supplementation on left ventricular morphology and myocyle function with the development of congestive heart failure. Circulation $1999 ; 100: 2003-2009$.

427. Osterziel $\mathrm{KJ}$, Strohm $\mathrm{O}$, Schuler J, Friedrich.M, Hanlein $\mathrm{D}$, Willenbrock $\mathrm{R}$, Anker SD, Poole-Wilson PA, Ranke MB, Dietz R: Randomised, double-blind, placebo-controlled trial of human recombinant growth hormone in patients with chronic heart failure due to dilated cardiomyopathy. Lancet $1998 ; 351: 1233-1237$.

428. Spallarossa $P$, Rossettin $P$, Minuto $F$, Canuso $D$, Cordera $R$, Battistini $M$, Barreca A, Masperone MA, Brunelli $C$ : Evaluation of growth hormone administration in patients with chronic heart failure secondary to coronary artery disease. Am J Cardiol 1999;84:430-433. 
429. Isgaard $J$, Bergh $C H$, Caidah $K$, Lomsky M, Hjalmarson $A$, Bengtsson $B A$ : $A$ placebo-controlled study of growth homone in patients with congestive heart failute. Eur Heart J 1998;19:1704-1711.

430. Jin H, Yang R, Gillett N, Clark RG, Ko A, Paoni NF: Beneficial effects of growth hormone and insulin-like growth factor-1 in experimental heart falure in rats treated with chronic ACE inhibition. $J$ Cardiovasc Pharmacol $1995 ; 26: 420-425$.

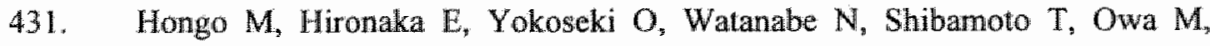
Ryoke $T$ : Effects of growth hormone following chronic angiotensin-converting enzyme inhibition in chronic heart failure: their relation to infarct size. Cardiovasc Drugs Ther 2001;15:241-249.

432. Dzau VJ: Local expression and pathophysiological role of renin-angiotensin in the blood vessels and heart. Basic Res Cardiol 1993;88 (suppl 1):1-14.

433. Allikmets $K$, Parik $T$, Viiginaa $M$ : The renin-angiotensin system in essential hypertension: associations with cardiovascular risk. Blood Press 1999;8:70-78.

434. Cavasin MA, Yang XP, Liu YH, Metha D, Karumanchi R, Bulagannawar M, Carretero OA: Effects of ACE inhibitor, ATI antagonist and combined treatment in mice with heart failure. I Cardiovasc Pharmacol 2000;36:472480 .

435. Balkestein EJ, Staessen JA, Wang IG, Heijden-Spek van der JJ, Van Bortel LM, Bianchi G, Brand E, Hermann SM, Struijker-Boudier HA: carotid and femoral artery stiffiness in rellation to three candidate genes in a white population. Hypertension 2001;38:1190-1197.

436. Bortel van LMAB, Struijker-Boudier HAJ, Safar ME: Pulse pressure, arterial stiffness and drug treatment of hypertension. Hypertevsion 2001;38:914-921.

437. Brull D, Dhamrait S, Myerson S, Erdmann d, Regitz-Zagrosek V, World M, Pennell D, Humphries SE: Bradykinin B2BKR receptor polymorphism and left-ventricular growth response. Lancet 2001;358:1155-1156.

438. Lung CC, Chan EKL, Zuraw BL: Analysis of an exon 1 polymorphism of the 82 bradykinin receptor gene and its transcript in normal subjects and patients with Cl inhibitor deficiency. J Alengy Clin Immunol 1997;99:134-146. 


\section{Summary}

The angiotensin-I-converting enzyme (ACE) is an essential component of the reninangiotensin system (RAS) and the target of therapy during cardiovascular diseases such as hypertension, myocardial infarction and heart failure. ACE is present in two forms, bound to the cell membrane as a component of the local RAS or circulating in plasma as a component of the circulating RAS. In cardiovascular diseases, beneficial effects of ACEinhibition on cardiovascular structure and function are often assigned to inhibition of the local RAS. However, before targeting ACE inhibition to the locally expressed ACE, more insight in the exact function of cell membrane-bound ACE (t-ACE) is necessary. Enhanced expression of the local RAS is often observed during cellular growth and angiotensin II is known to exhibit growth factor characteristics. Thus, the role of t-ACE might be related to cardiovascular growth, observed during maturation and after myocardial infarction (MI). Apart from refining the conventional therapy by unravelling the exact role of $t-A C E$, the therapy after MI could also be improved by combining the conventional RAS inhibition with factors able to increase the cardiac contractility. In this thesis, we investigated the involvement of $\mathrm{A}-\mathrm{ACE}$ in maturation of the cardiovascular system and its involvement in functional and structural remodelling of the heart after Mr. Moreover, the effects of combined administration with the $\mathrm{AT}_{1}$ antagonist, losartan and the insulin-like growth factor (IGF-I) on cardiac contractility and structural remodelling were investigated.

\section{Chapters 2, 3 and 7}

The function of local $\mathrm{ACE}$ in cardiovascular maturation was investigated by comparing cardiac performance and structure of adult $\mathrm{t}-\mathrm{ACE}-/-$ and $\mathrm{t}-\mathrm{ACE}+/+$ mice on the one hand and vascular reactivity and structure of adult $t-A C E-/-$ and $t-A C E+/-$ mice, on the other. $A$ transit-time flow probe was placed around the aorta to determine the cardiac output in conscious mice at rest and after maximal stimulation. The maximal cardiac output was not 
increased in $\mathrm{t}-\mathrm{ACE}-/-$ mice despite their reduced afterload, which suggests an impaired cardiac contractility. The impaired cardiac contractility in $\mathrm{t}-\mathrm{ACE}-/$ - mice was confirmed in wild-type mice treated with captopril for nine weeks. Structural analysis of large and smali vessels in $\mathrm{t}-\mathrm{ACE}-/$ - mice in an arteriograph revealed that the vascular elasticity is reduced in both vessel types compared to vessels from wild-type mice. Moreover, vascular reactivity, tested in a wire-myograph, was blunted by the lack of $\mathrm{t}-\mathrm{ACE}$. After prolonged treatment with captopril similar vascular alterations were observed. Since captopril treatment was started at 3 weeks after birth, it is evident that the reduced cardiac contractility, arterial elasticity and reactivity do not originate from an altered foetal development in the absence of $t$-ACE. Since the cardiovascular alterations observed in tACE - $t$ - mice are similar or even more pronounced after prolonged captopril treatment in wild-type mice, it can be concluded that the loss of $\mathrm{t}-\mathrm{ACE}$ activity can be replaced by ACE activity from a distinct source, such as the circulation. Thus, normal maturation of the cardiovascular system is influenced by the total ACE activity, independent of its source.

\section{Chapters 4,5 and 6}

After myocardial infarction (MI), stratification of the experimental groups would be very useful and economic. In chapter 3, a method to estimate cardiac damage after experimental MI via blood sampling was tested. Both heart fatty acid binding protein (H-FABP) and cardiac troponin T (cTnT) were proven to be successful plasma markers for the presence of MI and can even provide information about infarct size.

The question whether targeted ACE inhibition is a therapeutic goal after MI was investigated by comparing cardiac performance and cardiac structural remodelling in $\mathrm{t}-\mathrm{ACE}$ $-\%$ and $\mathrm{t}-\mathrm{ACE}+/+$ mice at 14 days and 3 months after experimentally induced MI. An electromagnetic flow probe was placed around the aorta to determine cardiac output at rest and after volume loading. Cardiac geometry and cardiac collagen content were used as parameters for structural remodelling. Early and targeted inhibition of ACE after MI does not improve the cardiac function or the structural remodelling in mice. On the contrary, functional recovery of the heart after $M I$ is impaired in the absence of $\mathrm{ACE}$ despite the reduced afterload. Moreover, targeted inhibition of ACE does not cause alterations in the structural remodelling after $\mathrm{MI}$.

The second therapeutic option investigated was the combined therapy with the $\mathrm{AT}$, receptor antagonist, losartan and IGF-I. At 14 days after MI, no beneficial effects of the combined treatment on cardiac contractility or structural remodelling were observed. Early after MI, both $\mathrm{ACE}$ inlibition and $\mathrm{AT}_{1}$ receptor antagonism led to adverse effects on the cardiac function, these data strongly suggest that increased angiotensin II levels in the early phase after MI are important for the functional compensatory response after MI. 


\section{Chapters 7 and 8}

T-ACE deficiency resulted in a reduced arterial reactiwity and elasticity. The latter originates from stimulation of the bradykinin type 2 receptor ( $B K_{2}$ receptor), since inhibition of this receptor by administration of the antagonist Hoe 140 for 14 days, restored the vascular elasticity in t-ACE deficient mice. These data demonstrate the close relationship between the renin-angiotensin system (RAS) and the kallikrein-kinin system (KKS), and the contribution of both systems to the maturation of the cardiovascular system. Especially maturation is a critical phase, in which environmental factors, interacting with a (predisposed) genetic background, can determine the adult cardiovascular phenotype. Research on the genetic predisposition of the balance between RAS and KKS, and the related eventual cardiovascular risk, could help to estimate the individual risk of the patient and optimise the patient's therapy. 


\section{Nederlandse Samenvatting}

Hoge bloeddruk, aderverkalking, een hartinfaret en hartfalen, zijn aandoeningen van het hart-en vaatstelsel, die in onze westerse samenleving veel voorkomen en een grote bedreiging vormen voor ons welzijn. In ons lichaam wordt de bloeddruk en de waterhuishouding gereguleerd door onder andere het renine-angiotensine systeem (RAS). Dit systeem bestaat uit een aantal eiwitten en enzymen die verantwoordelijk zijjn voor de productie van het zeer potente hormoon angiotensine II. De laatste stap in het vormingsproces van angiotensine II, wordt gereguleerd door het angiotensineconverterende enzym (ACE), dat centraal staat in dit proefschrift. ACE knipt de laatste twee aminozuren af van het inactieve angiotensine I, waardoor het angiotensine II ontstaat. Angiotensine II heeft een hele reeks effecten, die beginnen met het activeren van de angiotensine receptoren, angiotensine receptor type 1 en $2\left(\mathrm{AT}_{1}\right.$ en $\left.\mathrm{AT} \mathrm{T}_{2}\right)$. De meest bekende effecten van angiotensine II, zoals bloedvatwernauwing, afgifte van het watervasthoudend hormoon aldosteron en celgroei, beginnen met het binden van angiotensine II aan de AT, receptor.

Het ACE bezit, naast twee enzymatische plaatsen om angiotensin II te vormen, ook een membraan-anker, waarmee het in staat is te hechten aan de buitenmembraan van cellen. De meest gebruikelijke plaats voot het hechten wan ACE is het endotheel, de binnenste laag cellen van hart en vaten waarlangs het bloed stroomt. Het membraan-anker dat het ACE verbindt aan de cellen kan ook losgeknipt worden, waardoor het $\mathrm{ACE}$ de nogelijkheid om te hechten verliest en in het bloed terechtkomt. Gebonden aan de celmembraan behoort het ACE tot het locaal RAS en in de bloedbaan maakt het $\mathrm{ACE}$ deel wit van het circulerend RAS. Het circulerend RAS is betrokken bij de regulatie wan de bloeddruk en de waterhuishouding. De functie van het locaal RAS is onderdeel van de vraagstelling in dit proefschrift. 


\section{De functie van $-\mathrm{ACE}$ in de volgroeing wan het hart- en vatstelsel}

Het local RAS is aanwezig in veel verschillende organen, waaronder het hart en de vaatwand. Opmerkelijk is dat een extra hoge expressie van de meeste RAS eiwitten, waaronder het $A C E$, is waargenomen tijdens de embryonale ontwikkeling. Tijdens de embryonale ontwikkeling wordt de groei van hart en vaten gelijktijdig waargenomen met een verhoogde expressie van locale RAS eiwitten. Hogere expressie van RAS eiwitten leidt tot meer angiotensine II, dat voor veel verschillende celtypes een groei stimulerende factor is. De functie van het locaal RAS zou dus betrekking kumnen hebben op de regulatie van de celgroei. Om deze vraagstelling te kunnen onderzoeken hebben we gebruik gemaakt van een diemodel. Met behulp van genetische modificatie is er een muis ontwikkeld die het $A C E$ bezit zonder membraan-anker (t-ACE - - ) . Hierdoor kan het ACE alleen circuleren en is de locale vorming van angiotensine II verminderd. De vraag of de functie en de structuur van een wolgroeid hart- en vaatstelsel verandert wanneer het ACE niet kan hechten aan de celmembraan is onderzocht in dit proefschrift.

Om te kunnen bepalen hoe belangrijk het membraan-gebonden $\mathrm{ACE}$ ( $\mathrm{t}-\mathrm{ACE}$ ) is voor de volgroeiing van het hart- en vaatstelsel, is de functie en structuur van het hart in een volwassen $\mathrm{t}-\mathrm{ACE}$ \% muis vergeleken met de functie en structuur van het hart in een volwassen muis met beide vormen van $\mathrm{ACE}$ ( $\mathrm{t}-\mathrm{ACE}+1+$; hoofdstukken 2 en 5). Deze vergelijking is ook gemaakt woor de reactivitent en structuur van grote en kleine slagaders (hoofdstuk 7). Uit de resultaten blijkt dat de afwezigheid van het $t-A C E$ leidt tot een verminderde contractiliteit (de kracht tijdens samentrekken) van het hart, een verminderde reactiviteit (het kunnen vernauwen of verwijden) van de grote slagaders en een verhoogde stjjtheid van alle slagaders. Hieruit blijkt dat de aanwezigheid van het t-ACE van belang is voor de volgroeiing van het hart- en vaatstelsel. De vraag bliff of deze veranderingen ontstaan tijdens de aanleg van het hart- en vaatstelsel in de foetus, of daarna. Uit de hoofstukken 3 en 7 blijkt dat farmacologische remming van het ACE in de periode na aanleg van het hart- en vaatstelsel (3 tot 12 weken oud) leidt tot dezelfde veranderingen in het hart- en vatstelsel. De effecten van farmacologische $\mathrm{ACE}$ remming zijn zelfs groter dan het weghalen van alleen het $t$-ACE. Hieruit kan men concluderen dat de totale ACEactiviteit van invloed is op de volgroeiing van het hart en vaatstelsel. Daamaast is het ontbreken wan $t-A C E$ tijdens de foetale ontwikkeling niet de oorzaak van de veranderdingen wargenomen in het hart- en vaatstelsel van $t-A C E-/$ - muizen.

In het laatste hoofdstuk van dit proefschrift is het mogelijk mechanisme verantwoordelijk voor de verhoogde stijtheid van de slagaders, die ontstaat in afwezigheid van het $\mathrm{t}-\mathrm{ACE}$, onderzocht. Het produceren van angiotensine II is niet de enige functie van het ACE. Het ACE is ook verantwoordelijk voor de afbraak van het hormoon bradykinine. Bradykinine is een component van het kallikreine-kinine systeem en de tegenspeler van angiotensine II. Het zorgt voor vaatverwijding en remt de celgroei. Op het moment dat de ACE-activiteit 
wordt geremd, wordt er dus niet alleen minder angiotensine II aängemaakt, matar ook minder bradykinine afgebroken. Een tekort aan angiotensine II of een teveel aw bradykinine zou kumnen leiden tot de veranderingen in het hart-en vaatstelsel. Door in t$\mathrm{ACE}-/ \%$ en $\mathrm{t}-\mathrm{ACE}+/+$ muizen de bradykinine receptor type 2 (BK, reeptor) gedurende 14 dagen te blokkeren, was het verschil in arteriële stijfheid tussen $1-A C E-1$-vaten en $-\mathrm{ACE}$ $+1+$ vaten verdwenen. Dit doet vemoeden dat de $B K_{2}$ receptor een rol speeit in het ontstaan van arterièle stijfheid tijdens $\mathrm{ACE}$ remming.

\section{De rol van t-ACE tijdens de functionele en structurele veranderingen van het hart na een hartinfarct}

Verhoogde expressie van de locale RAS eiwitten, inclusief het $t-A C E$, wordt ook gezien in het hart na een hartinfarct. Het is bekend dat patienten met een hartinfarct beter functioneren en een grotere overlevingskans hebben als de ACE-activiteit wordt geremd. De vraag of het $\mathrm{ACE}$ betrokken is bij de functionele en structurele veranderingen van het hart na een hartinfarct, is ook onderzocht in $\mathrm{t}-\mathrm{ACE}+1+$ en $\mathrm{t}-\mathrm{ACE}-/$-muizen. Door operatief én van de kransslagaders van het muizenhart af te binden ontstaat er een hartinfarct. Dit is gedaan in $t-A C E-/$ en $t-A C E+/+$ muizen (hoofdstuk 5). Op 14 dagen en 3 matanden na het hartinfarct is de hartfunctie en hartstructuur bepaald, om te kumen zien hoe het lart zich herstelt. Zonder de aanwezigheid van $t-A C E$ is het functioneel herstel van het hart slechter dan in aanwezigheid van het $t-A C E$. De structurele veranderingen na het hartinfarct zijn echter gelijk in aan- of afwezigheid van t-ACE. Het $t$-ACE is dus van bellang voor een goed functioneel herstel van het hart na een hartinfarct, terwijl het geen grote rol speelt bij het ontstaan van bijvoorbeeld littekenweefsel. Uit deze resultaten blijkt dat therapie na een hartinfarct, die alleen gericht is op het verminderen van de locale ACE activiteit in plaats van remming van de totale ACE activiteit, hoogstwaarschijnlijk niet effectiever is.

\section{Therapie met AT, blokker en IGF-I na een hartinfaret}

De derde vraagstelling die we ons stelden tenaanzien van het RAS heeft een iets andere strekking. Na een hartinfarct is gebleken dat ook het blokkeren van de $\mathrm{AT}_{\sharp}$ receptor, de gezondheid en overlevingskansen van de patiênt verbetert. Om de hartfunctie nog verder to verbeteren kan de bestaande therapie met $A T_{\|}$blokkers uitgebreid worden met een hormoon dat de contractiliteit van het hart verder vergroot. Een potentiele kandidaat hiervoor is de "insulin-like" groeifactor-I (IGF-I). Tijdens intensief en langdurig sporten zijn hoge IGF-I spiegels waargenomen bij de groei van het hart. Het zogenaande sporthart is groter en kan een hogere capaciteit leveren zonder direct schadelijk te zijn voor de gezondheid. In dit proefschrift is ook onderzocht of de combinatie-therapie, bestaande uit een $\mathrm{AT}_{1}$ blokker en IGF-I van positieve invloed is op de hartfunctie na een hartinfarct. 
Muizen met een hartinfarct werden verdeeld in drie groepen. De eerste groep is niet behandeld gedurende de eerste 14 dagen na het hartinfarct. De tweede groep is gedurende de eerste 14 dagen behandeld met de AT, blokker, losartan en in de derde groep is losartan behandeling gecombineerd met IGF-I toediening. Ondanks dat IGF-I toediening inderdaad de contractiliteit van het hart vergroot is de gecombineerde toediening van losartan en IGFI gedurende de eerste 14 dagen na een thartinfarct niet beter voor de hartfunctie.

\section{Klinische relewantie}

In dit proefschrift is aangetoond dat de totale ACE-activiteit belangrijk is voor een goede ontwikkeling van het hart- en vaatstelsel. Daarnaast is gebleken dat het ontstaan van arteriele stijfheid, een vaatwand eigenschap die bijdraagt aan een verhoogd risico op harten vaatziekten, niet alleen gerelateerd is aan veranderingen in het renine-angiotensine systeem, maar ook aan veranderingen in het kallikreine-kinüne systeem.

Gezien de verslechterde hartfunctie na een hartinfarct, waargenomen bij $\mathrm{t}$-ACE $-/$ - muizen ten opzichte wan $\mathrm{t}-\mathrm{ACE}+\mathrm{H}$ muizen en het gegeven dat een deel van de $\mathrm{t}-\mathrm{ACE}$ functie overgenomen kan worden door actief $\mathrm{ACE}$ afkomstig uit de bloedbaan, maakt de gedachte om met name het locaal $\mathrm{ACE}$ te remmen na een hartinfarct geen aantrekkelijke optie ter verbetering van de huidige therapie na een hartinfarct. Dat laatste geldt ook voor de combinatie-therapie met een $A T_{1}$ blokker en IGF-I. De data beschreven in dit proefschrift tesamen met in de literatuur beschreven experimenten laten zien dat de toepassingsmogellikheden van een dergelijke therapie, ter verbetering van de hartfunctie na een hartinfarct, zeer gering zijn. 


\section{Bedankt}

\section{Professoren}

Jos en Mat, voor het scheppen van de mogelijkheid om te promoveren. Zonder het nauwkeurig en zinvol commentaar van dit team was mijn proefschrift nooit afgerond. Daarnaast dank ik jullie voor de vrijheid en het vertrouwen, watardoor ik op mijn eigen(gereide) manier invulling heb kunnen geven aan mijn AlO-tijd.

Jo, woor de snelle en adequate introductie in de vaatwereld. Je gevoel voor humor en jouw enthousiasme zijn een bron van energie.

\section{U(H)D, Post-doc en Aio's}

Ben, Paul, Rob, Jos, Matthijs, Jacques, Kitty, voor het beantwoonden van de meest uiteenlopende vragen, het meedenken en de goede samenwerking.

Karin, Marijke, Xander, Karin, Maaike, Esther, Geraldine, Kristel, Liesje, Marielle, Esther, voor de gesprekken en discussies, waarin ik mijn hart mocht luchten, mijn mening kon staven en mocht delen in jullie kennis en inzichten. Bovenal, dank ik jullie voor de enorme gezelligheid. Deze gezelligheid deelden we met vele anderen op de afdeling, tijdens etentjes, cursussen en congressen, bedankt allemaal. Ik wens Marijke, Geraldine, Cherida Chantal, Rachelle, Mariken, Gertian, Agnes, Ewald, Susame, Veerle, Tujl, Rob, Monica, Els en de rest van de AIO-clan nog veel succes met het onderzoek en de promoties.

\section{Studenten}

Anke, Rinse, Rogier, Roeland, Paola, Justin, woor het werk dat jullie hebben verzet. Het routinewerk, de eerste schreden op een nieuw pad en de definitieve vaststelling van doodspoor lagen vaak in jullic handen. Paola, good things come by surprise. Ik bedank jullie allemaal, maar in het bijzonder Justin, woor het geduld waarmee jullie mijn goed bedoelde, maar soms onhandige en strenge begeleiding hebben ontvangen. Justin was het langst getuigen van de pieken en de dalen. Ik neem mijn petje af voor het werk dat je geleverd heb in de tijd dat ik er niet was. Naast serieus werken zijn lol, pesten en gekkigheid voor mij onmisbaar en daarin heb ik mijn maatjes wel gevonden (doen we nog 
cen wedstrijdje wie het langst zijn hand in het ijs kan houden?). Ik wens jullie alle zes veel succes.

\section{Technische ondersteuning}

Jacques, Peter, Nicolle, Agnieszka, voor het leeuwendeel van mijn proefschrift. Opereren heb ik van Jacques geleerd, een goede leemeester, want als ik de kans krijg opereer ik nog altijd met veel plezier. Peter, voor alle metingen en operaties, maar ook zeker voor de discussies, ongezoutten warheden en efficiënte samenwerking. Nicole, mijn maatje, als ik alle dingen die jij woor mij gedaan hebt hier moet vermelden, is het blad te klein. Was ik zoekende dan wist jij waarnaar en op dit moment zoek ik naar woorden om jou te bedanken. Paull, voor al het bijspringen bij experimenten met zowel de myograaf als de arteriograaf. Jouw goedwillendheid maakt het anderen wel erg makkelijk. Marijke en Karin, voor het monteren van de vaten in de myograt, alle handige tips en wetenswarardigheden. Rob, voor de druk-diametercurves van de mesenteriale arteriem. De morfometrie van alle vaten was in handen van Gregorio en ook bedankt voor alle assistentie bij computerproblemen. Ger, was verantwoordelijk voor de catecholamine-bepalingen. Jet en Loes hebben meegeholpen atan de genotypering. Monique, Anique, Petra en Wendy, waren mij altijd van dienst bij pathologie om zo alle coupes gesneden en gekleurd te krijgen. De H-FABP en cTnT bepalingen zijn gedaan onder de begeleiding van Maurice en Marie-José. Mijn dank is groot. Pauline, Richard en alle andere CPVers, bedank ik voor het verzorgen van de (soms wat uit de hand gelopen) fok. Bedankt Mia en Els, voor alle secretariele ondersteuning en voor het creëren van een thuisgevoel op de afdeling. Techmische ondersteuning kwam ook van thuis, Sanne heeft een groot deel van de referenties ingevoerd, Marijke heeft het ontwerp van de kaft geleverd en Arie het programma en de uitleg om de kaft te maken, een mooi staaltje werk.

\section{Paranimfen}

Karin en Jorg, een betere steun kan ik mij niet bedenken.

\section{Mentale ondersteuning}

Mia, Els, Nicole, Karin \& Ewoud, Jos \& Marisca, Marijke, Géraldine, Rob, Lilian, Fazzi \& Gwen, Maaike, Marianne, Yvette, Amold, Mariska en alle anderen.

Familie en natuurlijk mijn thuisfront, Jorg, Sanne, Arie \& Marijke. Dit zijn de mensen die ik het liefst persoonlijk bedank en als ik dat nog niet gedaan heb, hoop ik dat er nog genoeg gelegenheid kont dat alsnog te doen, weet wel, jullie vormen voor mij

die kleur van gisteren, de glans van vandaag en de fonkeling van morgen. 


\section{Curriculum vitae \& Publications}

\section{Curriculum vitae}

Wendy Mirjam Aartsen

Geboren 25 september 1974

Gymnasium, September 1986 - Juni 1992

Christelijke Scholengemeenschap Overvoorde, Den Haag

Medische Biologie, September 1992 - Augustus 1997

Vrije Universiteit, Amsterdam

Assistent in opleiding (AIO), September 1997 - Maart 2003

Afdeling Farmacologie \& Toxicologie

Cardiovascular Research Institute Maastricht (CARIM)

Universiteit Maastricht, Maastricht 


\section{Publications}

K.J. Laing, L. J. Hardie, W.M. A.artsen, P.S. Grabowski and C.J. Secombes

Expression of an inducible nitric oxide synthase gene in rainbow trout Oncorhynchus Mykiss. Dev. Comp. Immunol. 1999, 23: 71-85

W.M. Aartsen, M.M.A.L. Pelsers, W.T. Hermens, J.F.C. Glatz, M.J.A.P. Daemen and J.F.M. Snits

Heart fatty acid binding protein and cardiac troponin $T$ plasma concentrations as markers for myocardial infarction after coronary artery ligation in mice. Pflügers Arch. / Eur". J. Physiol. 2000, 439: 416-422

R.J. van Suylen, W.M. Aartsen, J.F.M. Smits and M.J.A.P. Daemem.

Dissociation of pumonary vascular remodeling and right ventricular pressure in tissue angiotensin-converting enzyme-deficient mice under conditions of chronic alveolar hypoxia. Am. J. Respir. Crit. Care med. 2001, 163: 1241-1245

W.M. Aartsen, M.P. Schuijt, A.H.J. Danser, M.J.A.P. Daemen and J.F.M. Smits

The role of locally expressed angiotensin converting enzyme in cardiac remodeling after myocardial infarction in mice. Cardiovasc. Res. 2002, 56: 205-213

W.M. Aartsen, M.J.A.P. Daemen and J.F.M. Smits

Activation of the Renin-Angiotensin system after Myocardial Infarction.

Chapter 36 in the Handbook of Experimental Pharmacology (in press)

Wendy M. Aartsen, R.H. Hilgers, P.M.H. Schiffers, M.J.A.P. Daemen, J.G.R. De Mey and J.F.M. Smits

Absence of membrane-bound angiotensin-I-converting enzyme enhances stiffiness and blunts reactivity of peripheral arteries. (submitted)

Wendy M. Aartsen, M.J.A.P. Daemen, J.G.R. De Mey and J.F.M. Smits

The bradykinin type 2 receptor regulates arterial stiffness during membrane-bound angiotensin-1-converting enzyme deficiency. (submitted) 
(3) . . 
Nun der Tag mich müd gemacht, soll mein sehnliches Verlangen, freundlich die gestirnte Nacht, wie ein müdes Kind emfangen.

Hande, laßt von allem Tun, Stirn, vergiß du alles Denken; alle meine Sinne nun, wollen sich in Schlummer senken.

Und die Seele, unbewacht, will in freien flugeln schweben, um im Zauberkreis der Nacht, tief und tausendfach zu leben.

\section{Hermann Hesse}

Richard Strauss

CD $430-5 \| 1-2$ 